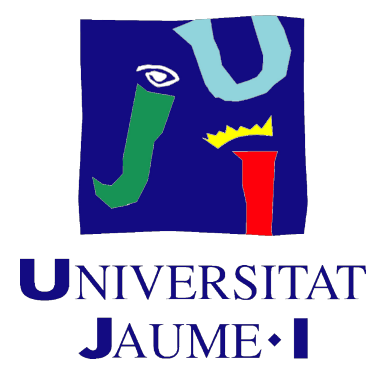

Doctoral Programme in Economics And Business

Universitat Jaume I Doctoral School

\title{
Analysis of environmental policy and emission control instruments
}

Report submitted by Lidia Vidal Meliá in order to be eligible for a doctoral degree awarded by the Universitat Jaume I

Author:

Supervisors:

Lidia VIDAL MELiá

Dr. Eva Camacho Cuena

Dr. Miguel Ginés VilaR

Castelló de la Plana, October 2019 

A mis abuelos 



\section{Agradecimientos}

Hay muchas personas sin las cuales esta tesis no habría sido posible. Me gustaría aprovechar la oportunidad para agradecer a todos los que han contribuido a esta tesis y que me han apoyado durante todo el proceso.

En primer lugar, quiero agradecer a mis supervisores, Eva Camacho y Miguel Ginés. Su guía, apoyo y dedicación han sido cruciales para mí y para mi investigación. Gracias por ayudarme a crecer como investigadora.

I would also like to thank Till Requate for his kindness, dedication, and advice during my stay at the University of Kiel. It has been a pleasure to have been working with you. I would like to thank also the staff at the Department of Economics at the University of Kiel, especially those who helped me during the design and implementation of the experiments.

I am truly in debt to Carmen Arguedas, José Luis Zofío, and Israel Waichman for accepting being my coauthors and for their valuable comments during this process. I hope this is just the beginning of future collaborations.

No me olvido de Simone por estar siempre dispuesto a ayudar, así como de Silvia por su infinita amabilidad. Al resto de compañeros de los departamentos de Economía y Finanzas de la Universitat Jaume I, quiero agradecerles por el buen ambiente y las facilidades prestadas durante estos años: Alba, Diego, David, Alex, Annarita, Jordi, Isabel, Marko, Mariya y Gabriele.

Me gustaría dedicar algunas palabras a aquellas personas que me hicieron sentir como en casa cuando estuve de estancia en Kiel. Mis queridas amigas Laura B., Melissa y Laura G., siempre estaré agradecida por ser tan amables, generosas y comprensivas, y por estar a mi lado como una família cuando más lo necesitaba.

Por último, quiero expresar mi agradecimiento a mi familia. Su sacrificio y esfuerzo me han llevado aquí hoy, y su apoyo y amor me han dado fuerzas para seguir adelante. Les dedico este trabajo. 



\section{Funding}

I am grateful for funding the Deutscher Akademischer Austauschdienst (DAAD) for a short-term grant to do a research stay at the Department of Economics at Christian Albrecht University from Kiel. I am also thankful for being hired under the European projects FinMaP and Symphony. 



\section{Contents}

List of Figures

$\begin{array}{ll}\text { List of Tables } & \text { xv }\end{array}$

$\begin{array}{lll}\text { Abstract } & \text { xvii }\end{array}$

$\begin{array}{lr}\text { Introduction } & 1\end{array}$

1 Market size asymmetry and industrial policy 5

1.1 The model . . . . . . . . . . . . . . . . 8

1.2 Subgame perfect Nash equilibrium . . . . . . . . . . . . . . 10

1.3 A numerical example . . . . . . . . . . . . . . . . . 13

1.3.1 A numerical example in scenarios with a unique equilibrium . . 13

1.3.2 A numerical example for the scenario with multiple equilibria . 16

1.4 Conclusions . . . . . . . . . . . . . . . . . . . . 17

$\begin{array}{lr}\text { Appendix } & 19\end{array}$

1.A Subgame perfect Nash equilibrium _. . . . . . . . . . . . . 19

1.B The symmetric case. Why large markets do not regulate? . . . . . . . 28

1.B.1 The model . . . . . . . . . . . . . . . . . . . . . 29

1.B.2 Sub-game perfect Nash equilibrium . . . . . . . . . . . . 31

1.B.3 Results . . . . . . . . . . . . . . . . 32

1.B.4 Conclusions . . . . . . . . . . . . . . . 33

2 Timing and commitment in environmental policy 35

2.1 Related experimental literature . . . . . . . . . . . . . . . 36

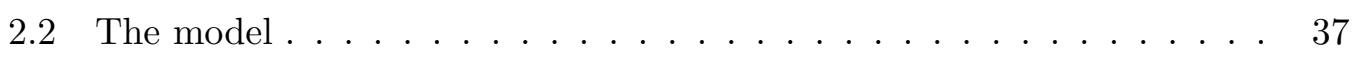

2.3 Experimental design and procedure . . . . . . . . . . . . 38

2.3.1 Parameters . . . . . . . . . . . . . . . . . . . 39

2.3.2 Experimental procedure . . . . . . . . . . . . . . 41

2.4 Results. . . . . . . . . . . . . . . . . . . 42

2.4 .1 Technology adoption . . . . . . . . . . . . . . 42

2.4 .2 Emission taxes . . . . . . . . . . . . . . . . . 44

2.4 .3 Emission permits . . . . . . . . . . . . . 46

2.4.4 Efficiency comparisons . . . . . . . . . . . . . . . 49

2.4 .5 Social cost . . . . . . . . . . . . . . . 51

2.5 Conclusions . . . . . . . . . . . . . . . . . . 51 
$\begin{array}{ll}\text { Appendix } & \mathbf{5 3}\end{array}$

2.A Extra figures .................... . . 53

2.B Experimental instructions . . . . . . . . . . . . . 60

2.B.1 AT treatment ................. 60

2.B.2 PT treatment .................. 63

2.B.3 AP treatment ................... 66

2.B.4 PP treatment ................. . . 70

2.C Screenshots .................... . . 75

3 An experimental analysis of the effects of imperfect compliance 77

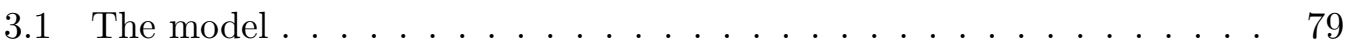

3.2 Experimental design . . . . . . . . . . . . . . . . . . 82

3.2.1 Parameters and treatments .............. 82

3.3 Emission taxes ..................... . 84

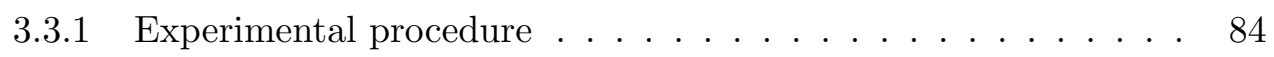

3.3.2 Results ...................... 85

Technology adoption . . . . . . . . . . . . . . . 85

Real emissions . . . . . . . . . . . . . . . 88

Violation level and tax evasion . . . . . . . . . . . . 89

Efficiency comparisons . . . . . . . . . . . . . . . . 91

3.4 Emission permits . . . . . . . . . . . . . . . . . 92

3.4.1 Experimental procedure ................ 92

Risk attitude ................... . . 93

New ecological paradigm scale . . . . . . . . . . . . 94

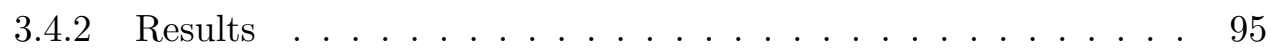

Technology adoption . . . . . . . . . . . . . 95

Real emissions . . . . . . . . . . . . . . . . . 98

The permit auction . . . . . . . . . . . . . . . . . 99

Violation behavior ................. . . 101

Efficiency comparisons . . . . . . . . . . . . . 103

Social cost . . . . . . . . . . . . . . . . . . 105

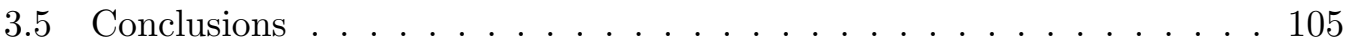

$\begin{array}{ll}\text { Appendix } & 107\end{array}$

3.A Holt and Laury's (2002) menu of paired lottery . . . . . . . . . . . 107

3.B New ecological paradigm . . . . . . . . . . . . . . 108

3.C Additional results . . . . . . . . . . . . . . . . . 109

3.D Experimental instructions . . . . . . . . . . . . . 113

3.D.1 Fines in the V2 treatments . . . . . . . . . . . . . . 125

3.E Screenshots ...................... 126

$\begin{array}{lr}\text { General conclusions and future perspectives } & 129\end{array}$ 


\section{List of Figures}

1.1 Game tree showing the four stages . . . . . . . . . . 10

1.2 Area in which quantities, taxes and subsidies are interior and positive, where $i=H, F$ and $j=h, f \ldots \ldots \ldots \ldots \ldots \ldots$

1.3 Definition of the four subareas in area A . . . . . . . . 12

1.4 Area in which quantities, taxes and subsidies are interior and positive, where $i=H, F$ and $j=h, f \ldots \ldots \ldots \ldots \ldots \ldots$

1.5 $\quad F_{1}(\alpha)$ and $F_{4}(\alpha)$ (left) and the area in which subgame TT has an

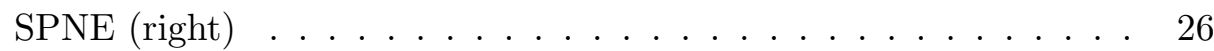

1.6 $\quad F_{1}(\alpha)$ and $F_{2}(\alpha)$ (left) and the area in which subgame TS is a SPNE

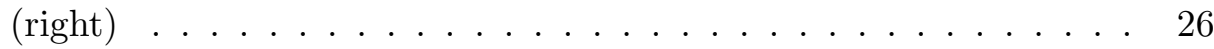

1.7 $\quad F_{3}(\alpha)$ and $F_{2}(\alpha)$ (left) and the area in which subgame SS has an

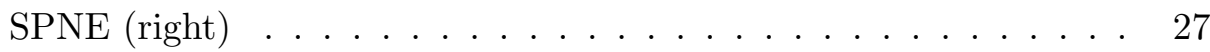

1.8 $F_{3}(\alpha)$ and $F_{4}(\alpha)$ (left) and the area in which subgame ST has an

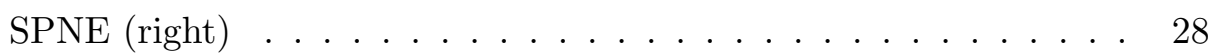

$2.1 \quad$ Socially optimal instrument level, tax and emission permits . . . 39

2.2 Percentage of firms investing in technology $a$ per initial Technology $k=T_{1}, \ldots, T_{5} \ldots \ldots \ldots \ldots \ldots \ldots \ldots$

2.3 Average observed and expected tax rate under the two different treatments pooling all sessions together . . . . . . . . . .

2.4 Average observed and expected emissions under the two different treatments pooling all sessions together . . . . . . . . . . .

2.5 Average observed and expected price under the two different treatments i.e., median observed and expected auction price pooling all

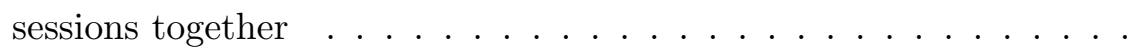

2.6 Average observed and expected permit holding under the two different treatments i.e., median observed and expected permit holding pooling all sessions together $\ldots \ldots \ldots \ldots \ldots$

2.7 Average observed and expected price under ex-ante treatment i.e., median observed and expected auction price pooling all sessions together per group . . . . . . . . . . . . . . .

2.8 Average observed and expected price under ex-post treatment i.e., median observed and expected auction price pooling all sessions together per group ..................... 
2.9 Screenshot of Stage 1. The left-hand side of the screen displays the current technology, while the right-hand side indicates the cost of investment. On the right-hand side, the subject indicates whether he/she wishes to invest in the new technology or not . . . . . . 75

2.10 Screenshot of Stage 2. The left-hand side of the screen displays the current technology. The right-hand side shows the number of permits being issued and the subject decides on how many permits he/she wants to buy at that price . . . . . . . . . 75

$3.1 \quad$ Socially optimal instrument level and tax . . . . . . . . . . . . 82

3.2 Percentage of firms investing in technology a per initial Technology

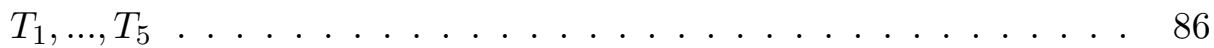

3.3 Average difference between individual real and optimal emissions $\left(e_{i}-e^{*}\right)$ per initial technology and treatment $\ldots \ldots \ldots 88$

3.4 Average individual violation level deviations from optimal violation $\left(v_{i}-v^{*}\right)$ per initial technology and treatment $\ldots \ldots \ldots . \ldots 8$

3.5 Average individual tax evasion per technology and treatment . . . 90

$3.6 \quad$ Average individual fine per technology and treatment . . . . . . . 9 90

3.7 The distribution of the risk-attitude measures (average: 7.01 ; standard deviation: 1.85). Measure in the range 1-4 indicates risk-loving, a measure of 5 indicates risk neutrality, and measure in the range $6-10$ indicates risk aversion . . . . . . . . . . . . . . 94

3.8 The distribution of the ecological-attitude measures (average: 48.75; standard deviation: 5.24). Measure in the range 15-45 indicates anti-ecological, a measure of 46-60 indicates mid-ecological, and measure in the range 61-75 indicates pro-ecological . . . . . . . 95

3.9 Percentage of firms investing in technology a per initial Technology $k=T_{1}, \ldots, T_{5}$ and monitoring strategy . . . . . . . . . 96

3.10 Difference between average real and optimal emissions $\left(e_{i}-e^{*}\right)$ per technology and treatment . . . . . . . . . . . 99

3.11 Average observed and expected price under the four different treatments i.e., median observed and expected auction price pooling all periods together . . . . . . . . . . . . . . 100

3.12 Average individual permits held $s$ per initial technology and treatment101

3.13 Average deviations from optimal violation level $\left(v_{i}-v^{*}\right)$ per technology and treatment . . . . . . . . . . . . . . . 102

3.14 Average individual fine per technology and treatment . . . . . . . 103

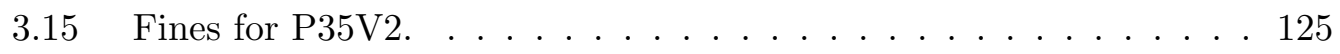

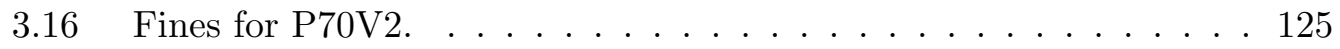


3.17 Screenshot of Stage 1. The left-hand side of the screen displays the current technology, while the right-hand side indicates the tax rate, the inspection probability, and the cost of investment. On the right-hand side, the subject indicates whether he/she wishes to invest in the new technology or no . . . . . . . . . . . . 126

3.18 Screenshot of Stage 2. The left-hand side of the screen displays the current technology. On the right-hand side, the subject indicates how many units he/she wants to emit, and from those how many he/she wants to report . . . . . . . . . . . . . . . 126

3.19 Screenshot of Stage 1. The left-hand side of the screen displays the current technology, while the right-hand side indicates the number of permits being issued, the inspection probability and the cost of investment. On the right-hand side, the subject indicates whether he/she wishes to invest in the new technology or not . . . . . . . .

3.20 Screenshot of Stage 2. The left-hand side of the screen displays the current technology. On the right-hand side, the subject indicates how many permits he/she wants to buy at that price . . . . . . . . 127

3.21 Screenshot of Stage 3. The left-hand side of the screen displays the current technology. On the right-hand side, the subject indicates how many permits he/she purchased at the final price, and how many units he/she is willing to release including those covered by permits . . . . . . . . . . . . . . . . . . 128 



\section{List of Tables}

1.1 Comparative Statics for the three different scenarios at an aggregate level ............................. . . 14

1.2 Comparative Statics for three different scenarios comparing the components of social welfare . . . . . . . . . . . 15

1.3 Comparative Statics for the two possible SPNE at an aggregate level 16

1.4 Comparative Statics for the two possible SPNE . . . . . . . . . 17

1.5 Normal form of the game at stage $1 \ldots \ldots 23$

$1.6 \quad$ Comparative statics for small and large markets . . . . . . . . . . . 33

2.1 Marginal Abatement Cost (MAC) per technology type. $T_{1}, \ldots, T_{5}$ denote the initial technologies, while $a$ denotes the advanced abatement technology . . . . . . . . . . . . . . . . . 4 40

$2.2 \quad$ Experimental treatments and parameters . . . . . . . . . . . . 40

2.3 Probit estimation (with clustered standard errors across sessions) of investment per treatment using Technology $T_{1}$ as baseline (std. err. are given in parentheses). The dependent variable: new technology adoption in period $t$ by firm $i$. ***, **, and ${ }^{*}$ denote significance at the $1 \%, 5 \%$, and $10 \%$, respectively . . . . . . . .

2.4 Mean observed and expected tax rates and aggregate emissions across sessions and periods within a given treatment (SD are given within parenthesis $\ldots \ldots \ldots \ldots \ldots \ldots$

2.5 Mean observed and expected prices and holding of permits across sessions and periods within a given treatment (SD are given within parenthesis $\ldots \ldots \ldots \ldots \ldots \ldots \ldots \ldots$

2.6 Permit holding per technology after investment decision (SD are given within parenthesis $\ldots \ldots \ldots \ldots \ldots$. . . . . . . . 48

2.7 Mean (Std. Dev.) of the different efficiency ratios . . . . . . . . . . 49

2.8 Mean (Std. Dev.) of the social cost . . . . . . . . . . . . 51

2.9 Efficiency ratios per group and period for the four treatments. . . . 59

3.1 Distribution of technologies among firms: firm type (according to the initial technologies), number of firms per type . . . . . . 83

$3.2 \quad$ Experimental treatments and parameters . . . . . . . . . . . 83

3.3 Marginal Abatement Cost (MAC) per technology type. $T_{1}, \ldots, T_{5}$ denote the initial technologies, while $a$ denotes the advanced abatement technology ....................... 84 
3.4 Pooled Probit estimation (with clustered standard errors across sessions) of investment per treatment using Technology $T_{1}$ as a baseline (std. err. are given in parentheses). The dependent variable: probability to adopt the new technology in period $t$ by firm $i$. ***, **, and $*$ denote significance at the $1 \%, 5 \%$, and $10 \%$, respectively 87

3.5 Mean (Std. Dev.) of the different efficiency ratios . . . . . . . . . . 91

3.6 Pooled Probit estimation (with clustered standard errors across sessions) of investment per treatment using Technology $T_{1}$ as baseline (std. err. are given in parentheses). The dependent variable: new technology adoption in period $t$ by firm $i$. ***, **, and ${ }^{*}$ denote significance at the $1 \%, 5 \%$, and $10 \%$, respectively $\ldots \ldots . \ldots 97$

3.7 Mean observed and expected prices and volume of permits across sessions and periods within a given treatment $(\mathrm{SD}$ are given within

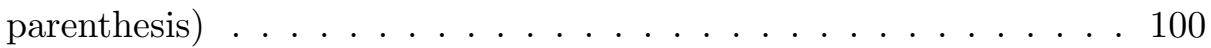

3.8 Mean (Std. Dev.) of the different efficiency ratios . . . . . . . . 103

3.9 Mean (Std. Dev.) of the social cost . . . . . . . . . . . . 105

3.10 Holt and Laury's (2002) menu of paired lottery . . . . . . . . . 107

3.11 The 15 Item Revised NEP Scale . . . . . . . . . . . . . . . 108

3.12 Average real $\left(e_{i}\right)$ and reported $\left(r_{i}\right)$ individual and industry emissions per technology and treatment across periods and groups. $e_{\max }$ denotes the firm's default emissions if no abatement effort is made (See Table 3.3) . . . . . . . . . . . . . . . . . 109

3.13 Average individual and industry tax evasion per treatment and technology . . . . . . . . . . . . . . . . . . 109

3.14 Average individual and industry fine per treatment and technology 109

3.15 Efficiency ratios per group and period for the four treatments in the case of permits. . . . . . . . . . . . . . . . . . . 112 


\section{Abstract}

The debate on the emissions control instruments for improving environmental policy is the inspiration of the present thesis. In a first attempt, we use a theoretical model to study how international trade affects the governments' decision on their industrial policy. We show that the countries' market size might drive the regulator's decision on the optimal industry policy. Our results illustrate why regulators might be reluctant to introduce environmental regulations as part of their policies if they believe that such policies can undermine the competitiveness of the industry.

We also use laboratory methods to evaluate the impact of different combinations of instruments, compliances, and timings on firms' investment incentives. The asymmetric model of Requate and Unold, 2001 is the base of our experimental design by allocating different initial technologies to the firms, where firms can adopt an advanced abatement technology, which is the same for all firms. In particular, this thesis attempts to demonstrate whether this procedure induces an optimal allocation of investment decisions. We find that the firms' overall performance concerning investment is remarkably good; however, we observe some under-investment by firms with dirtier technologies and some over-investment by firms with cleaner technologies. However, this inefficiency in the investment decisions and the further results are affected by the different combinations we have previously mentioned. 



\section{Resumen}

La inspiración de la presente tesis gira entorno al debate sobre los instrumentos de control de emisiones para mejorar la política ambiental. En un primer intento, utilizamos un modelo teórico para estudiar cómo el comercio internacional afecta la decisión de los gobiernos sobre su política industrial. Mostramos que el tamaño del mercado de los países podría impulsar la decisión del regulador sobre la política óptima de la industria. Nuestros resultados ilustran por qué los reguladores podrían ser reacios a introducir regulaciones ambientales como parte de sus políticas si creen que tales políticas pueden socavar la competitividad de la industria.

También empleamos métodos de laboratorio para evaluar el impacto de diferentes combinaciones de instrumentos, cumplimientos y tiempos en los incentivos de inversión de las empresas. El diseño experimental se basa en el modelo asimétrico de Requate and Unold, 2001 al asignar diferentes tecnologías iniciales a las empresas, donde las empresas pueden adoptar una tecnología de reducción avanzada, que es la misma para todas las empresas. En particular, esta tesis intenta demostrar si este procedimiento induce una asignación óptima de las decisiones de inversión. Encontramos que el desempeño general de las empresas con respecto a la inversión es notablemente bueno; sin embargo, observamos cierta subinversión por parte de las empresas con tecnologías más sucias y cierta sobreinversión por parte de las empresas con tecnologas más limpias. Sin embargo, esta ineficiencia en las decisiones de inversión y los resultados adicionales se ven afectados por las diferentes combinaciones que hemos mencionado anteriormente. 



\section{Introduction}

Economic research has generally relied on observational field data and the use of econometrics to examine relationships between economic variables of interest. Mainly through the work of Vernon Smith and Daniel Kahnemann, experimental economics is now a growing field within (environmental) economics, permitting to infer nonobservable data through experiments.

Environmental economics is a branch of economics with available empirical data on a wide range of topics such as resource consumption, waste generation, air emissions, energy or taxes; however, some questions are still hard to answer due to the lack of data, for instance, agents' behavior. Experiments provide randomization in key variables allowing a deeper understanding of major economic events. Hence, experimental economics can provide relevant insights into economic problems, including those associated with environmental issues. These insights complement those provided by more traditional nonexperimental research, to give researchers a much more detailed comprehension of the problems they are trying to solve.

In recent decades, environmental policy has aroused great interest on the part of the academic community, both in the theoretical field and in its different applications. In this field, market-based pollution control instruments are powerful and efficient tools for curbing pollution, using either a price mechanism, as in the case of taxes, or mechanisms based on quantities, such as the permits associated with emission rights. Kneese and Schultze, 1975 stated that one of the most determining criteria for ranking various pollution control policies is the degree to which these policies give incentives to firms to develop or adopt advanced abatement technologies. Since then, a great deal of both theoretical and empirical research has analyzed the effects of different policy instruments on both the adoption and development of new technologies. ${ }^{1}$

Plott, 1983 first laboratory experiment on emissions trading gave rise to numerous experiments on permit trading. Since then, the main results of the literature, summarized in Muller and Mestelman, 1998, show that the markets for emission permits are efficient. Therefore, the question now is how this permit systems should be applied. Nevertheless, only very few experiments contemplate investment in advanced abatement technology when firms take part in emission permit markets. Ben-David et al., 1999 find that firms' investment decisions create a heterogeneity of technologies that can lead to a reduction in the volume of emission permits exchanged and with

\footnotetext{
${ }^{1}$ See Requate, 2005a for a survey of incentives provided by environmental policy instruments to adopt and develop advanced abatement technology.
} 
this a lower efficiency of the market. Camacho-Cuena et al., 2012 and Gangadharan et al., 2013 observe some under-investment by inefficient (dirtier) firms and some over-investment by less inefficient (cleaner) firms.

Although there is a broad consensus in the academic field on the importance of cost heterogeneity to evaluate the possible gains derived from the application of a market mechanism, nobody has systematically studied the relationship between industry heterogeneity and the results derived from market mechanisms for emission control. Nichols, 1984 is the first to study the effect of heterogeneity among firms on the operation of different emission control mechanisms. More recently, Newell and Stavins, 2003 demonstrate the relationship between cost savings derived from different sources of heterogeneity in emission reduction costs: baseline emissions (default emissions as a result of the production processes) and marginal abatement cost. Besides, these authors estimate the cost savings of applying a market-based instrument against measures such as uniform standards (command-and-control). However, none of these works consider firms' investment in cleaner technologies. Thus, Camacho et al., 2009 is the first experimental analysis on the effect of technological heterogeneity derived from firms with different baseline emissions, on the operation of an emission control mechanism based on a similar system to the European Union Emissions Trading System (EU ETS), in which firms have the possibility to invest in cleaner technologies, thereby modifying the initial level of technological heterogeneity in the industry. In this study, the authors conclude that an increase in firms' heterogeneity increases both market efficiency and the firms' investment behavior efficiency.

Following this line of research, the results derived from this thesis can help the regulator in evaluating the results of a possible extension in the type of sectors included in the EU ETS, since the application of the best available technologies (BAT) to reduce emissions can lead to a more complex environment in which she must take into account not only those results that imply a higher reduction of emissions but also this must be sustainable by the firms.

The two main research questions of the present thesis are: is there an optimal allocation of investment decisions? Is there an efficient allocation of permits after the investment phase?

We organize this thesis as follows: in Chapter 1, we analyze how international trade affects the governments' decision on their industrial policy in the context of bilateral international trade and imperfect competition. We model an international duopoly with market size asymmetry and product heterogeneity. Each firm produces two different products, one for the domestic market and the other one for the foreign market, where the firms' production generates local emissions. The government in each country decides, as an industrial policy between two options: an emission tax or a production subsidy. The findings of our chapter show the crucial role of market asymmetry in 
determining the optimal industrial policy in a setting where both firms and regulators act strategically. We find the governments in small countries have incentives to set an environmental tax to the firms competing in international markets with similar size; even if the government in the large market decides to set a production subsidy, as long as market size asymmetry is low enough. Instead, if firms in a small country compete in large markets, that is, increasing the market size asymmetry between countries, it is then optimal for the government in the small country to forfeit emission taxes and pay production subsidies to keep the firms' competitiveness in the home and foreign markets if the government in the big country subsidizes production. In this case, an increase in the firms' profits offsets the effects of emission damages on the country social welfare.

The last two chapters of this thesis aim to study the incentives to adopt advanced abatement technologies by using laboratory experiments. Our experimental design mimics an industry with small asymmetric polluting firms operating in a competitive market and regulated by emission taxes or permits auctioned off (costly) through an ascending clock auction. More specifically, Chapter 2 focuses on the timing and commitment of environmental policy under perfect compliance. We consider two different timing regimes: to determine the optimal policy level before or after the adoption activity. Our results suggest that permit prices in the ex-ante treatment reduce compared to ex-post treatment. Despite this, timing does not affect the pattern of technology adoption.

In Chapter 3, we assume imperfect compliance, i.e., we allow violations. A regulator induces the firms to emit any desired level with different combinations of the inspection probability and the induced optimal violation level (perfect vs. imperfect compliance). As predicted by the theoretical model, inducing imperfect compliance reduces the adoption rate of advanced abatement technologies and, as a consequence, increases aggregate emissions. Our results regarding taxes suggest that imperfect compliance results in tax evasion. While in the case of permits, permit prices under imperfect compliance decrease compared when we induce perfect compliance.

Finally, I conclude summarizing the main findings and pointing out a research direction beyond this thesis. 



\section{Chapter 1}

\section{Market size asymmetry and industrial policy under an international duopoly: environmental tax vs. production subsidy}

It is widely accepted that national industrial policies can affect free trade. In particular, the industrial policy might have a direct effect on national welfare and firm competitiveness. This effect is particularly relevant when individual countries are allowed to establish unilateral industrial policies.

The analysis of trade with imperfect competition has deepened our understanding of the costs and benefits of different trade policies. Specifically, the works by Dixit, 1984, Brander and Spencer, 1985, and Eaton and Grossman, 1986 have shown the role of the profit-shifting effect in international markets. If a government policy can be employed to boost the share of industry profits that belong to domestic firms, this can be beneficial to national welfare, and there is a reason to intervene. This argument was put forward by Brander and Spencer, 1985 in a third-country model with Cournot competition where firms were given an export subsidy to gain a competitive advantage in the market. However, as shown by Dixit, 1984, export subsidies decrease as the number of domestic firms grows.

In this chapter, we consider two industrial policies: production subsidies and environmental (emission) taxes. Governments implement production subsidies for two different reasons. On the one hand, they increase the producer's income, e.g. agricultural and farm subsidies. On the other hand, they stimulate the output of products that are crucial for national security, such as coal or steel, among others. An example is the investment of governments in subsidies for hard coal production in Europe; without these subsidies, it would not be as competitive due to geological disadvantages. Although there has been a reduction in these subsidies in recent years, some governments continue subsidizing this industry. However, Frondel et al., 2007 claim that there are no plausible reasons for maintaining hard coal subsidies in Europe, especially in Germany. They encourage politicians to quickly remove them and to set a definite deadline for their elimination, as has also been suggested by the International Energy Agency. Jewell et al., 2018 show that in some countries, mostly major fossil fuel exporters, the fact of removing subsidies could lead to notable improvements 
in both the use of renewable energy and pollution reductions. However, on a global level, the impact would be minor. Hence, additional actions should be taken, such as carbon pricing, investments in innovation, and greater implementation of less polluting technologies.

Export and production subsidies have also been studied in the strategic trade literature by Spencer and Brander, 1983 and Brander and Spencer, 1985 who show that countries with imperfectly competitive industries that export to a third country can increase their joint profits if they commit to limited production by agreeing to withdraw subsidies. Dixit, 1984 extends their analysis to multiple firms showing that export subsidy weakens as the number of domestic firms increases. ${ }^{1}$ However, these studies focus on the strategic interest of the producer countries while ignoring global welfare questions or correcting market failures (see Fischer, 2016).

Concerning environmental taxes, national environmental policies, such as emission taxes, can serve as a rent-shifting device in international trade settings as part of a country's industrial policy (see Duval and Hamilton, 2002). This topic has received particular attention from the trade literature: countries develop their environmental policy strategies in settings where oligopolistic industries in each country compete to export final products to a third country (see, among others, Conrad, 1993, Barrett, 1994 or Kennedy, 1994). Simpson, 1995 shows that, under duopoly, there is no definite relationship between the optimal pollution tax rate and the marginal value of the environmental damage. International competition between two countries has also been analyzed specifically from the point of view of strategic trade policy (Krugman, 1984, Dixit, 1984, Brander and Spencer, 1985, Eaton and Grossman, 1986). Several studies have also analyzed the optimal pollution tax in the context of international competition between two trading countries in their own markets (Duval and Hamilton, 2002, Copeland and Taylor, 2004 and Requate, 2006).

Barrett, 1994 and Kennedy, 1994 studied the idea that environmental policy can be used as a rent-shifting device. In an initial concern about eco-dumping, Barrett, 1994 showed that the incentives for setting lax environmental policies may be small or even reversed for several reasons, e.g., if there is a welfare cost, in terms of a more polluted environment, to offset any strategic trade gains. In their search for efficient control of externalities, economists have traditionally supported taxes. However, optimal taxation is complicated. Kennedy, 1994 shows that strategic interaction between governments can lead to an inefficient distortion of pollution taxes. Moreover, he demonstrates that transboundary pollution intensifies the incentives for environmental dumping.

\footnotetext{
${ }^{1}$ Eaton and Grossman, 1986 compare Cournot with Bertrand competition.
} 
Although economists recognize the importance of environmental regulations, many national governments seem hesitant to implement such policies because these regulations can lower the production of domestic firms' (see Ekins, 1999) and undermine free trade. Contrary to this tendency, we find many papers that discuss the validity of the Porter hypothesis (Porter and Linde, 1995), which states that well-designed environmental regulations might lead to improved competitiveness, such as Asano and Matsushima, 2014, for example.

To analyze how (international) market asymmetry might be a determinant in the choice of a given industrial policy, we model an economy with two countries and two firms. We consider a domestic firm and a foreign firm. Each firm is a monopolist which produces in its own country, but sells in the home market and abroad. We also assume the foreign country to be larger than the home country in terms of market size. ${ }^{2}$ Each firm produces two different products, one to be sold in the domestic market and one to be sold in the foreign market. The government in each country acts strategically and chooses between two different policies: an emission tax (giving firms incentives to invest in cleaner technologies) or a production subsidy. ${ }^{3}$ In particular, we compare the strategic incentives of firms under four (international) policy regimes: (i) domestic and foreign governments set a tax on emissions, (ii) the government of the foreign country (large market size) provides a production subsidy, while the home-country government (small market size) sets an emission tax, (iii) domestic and foreign governments establish a subsidy for production, and (iv) the foreign country's government (large market size) sets an emission tax, while the home-country government (small market size) implements a production subsidy. Using a simple duopoly model, we show that when the two countries have small, similar market sizes, governments have an incentive to apply emission taxes. As the market size asymmetry increases, the government in the foreign country (large market size) will have incentives to shift to production subsidies. When the difference between the market size of the two countries is very large, the home country (small market size) will have incentives to provide a production subsidy in order to maintain firm competitiveness if the government in the competing country (large country) decides to subsidize firms in order to increase their competitiveness in the market.

This chapter is organized as follows. Section 2 describes the model, while Section 3 shows the normal form of the game at Stage 1 and offers some results. Section 4 presents the conclusions. Finally, the computation of the model (from Stage 2 to 4 ) and all proofs are available in the appendix.

\footnotetext{
${ }^{2}$ Find the symmetric case in the Appendix.

${ }^{3}$ Burguet and Sempere, 2003, Lai and Hu, 2008 and Baksi and Chaudhuri, 2009 examine pollution problems in an international competition setting. However, they do not consider firm incentives to invest in cleaner technologies.
} 


\subsection{The model}

We consider an economy with two countries, a home country and a foreign country, denoted as $H$ and $F$, respectively. We assume that country $F$ has a large market size and that country $H$ has a small market size. In each country there is one firm which produces two differentiated products; that is, the firm produces two varieties of the same good, one for the domestic market and one for the foreign market. Firm $f$ is the only firm producing in the foreign country, and firm $h$ is the only firm producing in the home country. Firms compete à la Cournot in the foreign and domestic markets.

The inverse demand function for the differentiated product in the home (foreign) country is:

$$
\begin{gathered}
p_{H}=\alpha_{H}-\left(q_{h H}+q_{f H}\right) \\
p_{F}=\alpha_{F}-\left(q_{f F}+q_{h F}\right)
\end{gathered}
$$

where $p_{H}\left(p_{F}\right)$ is the price of the final product in country $H(F)$ and $\alpha_{H}\left(\alpha_{F}\right)$ is country $H$ 's $(F)$ market size. As $F$ is the country with the large market size, $\alpha_{F}=\alpha_{H}+\Delta$, where $\Delta \geq 0$ denotes the market size asymmetry between the two countries, $q_{h H}\left(q_{h F}\right)$ is the quantity produced by firm $h$ for country $H(F)$, and $q_{f H}\left(q_{f F}\right)$ is the quantity produced by firm $f$ and sold in country $H(F)$. In order to simplify, from now on we denote $\alpha_{H}=\alpha$, and thus, $\alpha_{F}=\alpha+\Delta$.

During the production process firms generate local emissions. We assume that the damage function for pollution in the home (foreign) country, denoted as $D_{H}\left(D_{F}\right)$, is linear, and for simplicity, it is equal to the emissions level in the home (foreign) country, $E_{H}\left(E_{F}\right)$ :

$$
\begin{aligned}
& D_{H}=E_{H}=q_{h H}+q_{h F}-I_{h} \\
& D_{F}=E_{F}=q_{f F}+q_{f H}-I_{f}
\end{aligned}
$$

Note that the damage function depends on the total production in the home (foreign) country minus the reduction in emissions if firm $h(f)$ invests in a cleaner technology, denoted as $I_{h}\left(I_{f}\right)$, when appropriate ${ }^{4}$, and the marginal damage is constant, $D_{H}^{\prime}=0$ $\left(D_{F}^{\prime}=0\right) .^{5}$

The government in the home (foreign) country can impose an environmental tax, $\tau_{H}\left(\tau_{F}\right)$, to reduce pollutants that affect social welfare, or can grant a production subsidy, $\sigma_{H}\left(\sigma_{F}\right)$.

\footnotetext{
${ }^{4}$ When the government provides production subsidies firms do not have incentives to invest in cleaner technologies, thus, $I_{h}=0\left(I_{f}=0\right)$.

${ }^{5}$ Duval and Hamilton, 2002 also assume constant marginal damage, which allows for global damage to be expressed in terms of the amount of produced and consumed pollution in each country.
} 
Let us define the profit of firm $h$ :

$$
\pi_{h}= \begin{cases}p_{H} q_{h H}+\left(p_{F}-d\right) q_{h F}-\left(q_{h H}^{2}+q_{h F}^{2}\right)-\tau_{H} D_{H}-\frac{I_{h}^{2}}{2} & \text { for a tax } \\ p_{H} q_{h H}+\left(p_{F}-d\right) q_{h F}-\left(q_{h H}^{2}+q_{h F}^{2}\right)+\sigma_{H}\left(q_{h H}+q_{h F}\right) & \text { for a subsidy }\end{cases}
$$

Equivalently, the profit for firm $f$ located in the foreign country $F$ can be written as follows:

$$
\pi_{f}= \begin{cases}p_{F} q_{f F}+\left(p_{H}-d\right) q_{f H}-\left(q_{f F}^{2}+q_{f H}^{2}\right)-\tau_{F} D_{F}-\frac{I_{f}^{2}}{2} & \text { for a tax } \\ p_{F} q_{f F}+\left(p_{H}-d\right) q_{f H}-\left(q_{f F}^{2}+q_{f H}^{2}\right)+\sigma_{F}\left(q_{f F}+q_{f H}\right) & \text { for a subsidy }\end{cases}
$$

where $d$ is the transportation cost applied to exported output (for analytical simplicity, we assume that $d=2) ; \frac{I_{h}^{2}}{2}\left(\frac{I_{f}^{2}}{2}\right)$ is the amount that firm $h(f)$ needs to invest in the cleaner technology in order to reduce emissions in $I_{h}\left(I_{f}\right)$ units, that is, the abatement cost. Thus, if the respective government applies a tax, firm profits depend on the revenues of the quantities sold in the home and the foreign markets, minus the tax on emissions and minus the abatement cost. If the government provides a subsidy, firm profits depend on the sale revenues of the quantities sold in the home and the foreign markets, plus the subsidy on production. Therefore, from the profit function, we can see that it is only when the government has set an emission tax, that the firm will have an incentive to invest in new technologies and reduce emissions.

We define then social welfare in each country is the sum of consumer surplus, firm profits, and government revenue, minus the pollution damage:

$$
\begin{gathered}
S W_{H}=C S_{H}+\pi_{h}+G R_{H}-D_{H} \\
S W_{F}=C S_{F}+\pi_{f}+G R_{F}-D_{F}
\end{gathered}
$$

where:

- $C S_{H}=\frac{\left(q_{h H}+q_{f H}\right)^{2}}{2}\left(C S_{F}=\frac{\left(q_{f F}+q_{h F}\right)^{2}}{2}\right)$ is the consumer surplus in the home (foreign) country as a function of the total consumption of final goods in that country, i.e. $q_{h H}+q_{f H}\left(q_{f F}+q_{h F}\right)$,

- $G R_{H}=\tau_{H}\left(q_{h H}+q_{h F}-I_{h}\right)>0\left(G R_{F}=\tau_{F}\left(q_{f F}+q_{f H}-I_{f}\right)>0\right)$ is the government revenue in the home (foreign) country if the country applies an emission tax,

- $G R_{H}=-\sigma_{H}\left(q_{h H}+q_{h F}\right)<0\left(G R_{F}=-\sigma_{F}\left(q_{f F}+q_{f H}\right)<0\right)$ is the government revenue if the home (foreign) country establishes a production subsidy.

We propose a four-stage game, ${ }^{6}$ which is depicted in Figure 1.1. In stage 1, each government decides which policy instruments to use, either a production subsidy

\footnotetext{
${ }^{6}$ We assume that the two firms and the two governments decide simultaneously and independently in each stage.
} 
or a tax on emissions. In stage 2, each government sets the policy level concerning the tax or subsidies which maximizes the country's social welfare. In stage 3 , if the corresponding government decides to introduce an emission tax, the firm will decide whether to invest in a cleaner technology or not and on the investment level. Finally, in stage 4, each firm chooses its amount of production for each country. We obtain the Subgame Perfect Nash Equilibrium (SPNE from now on) of the game by backward induction.

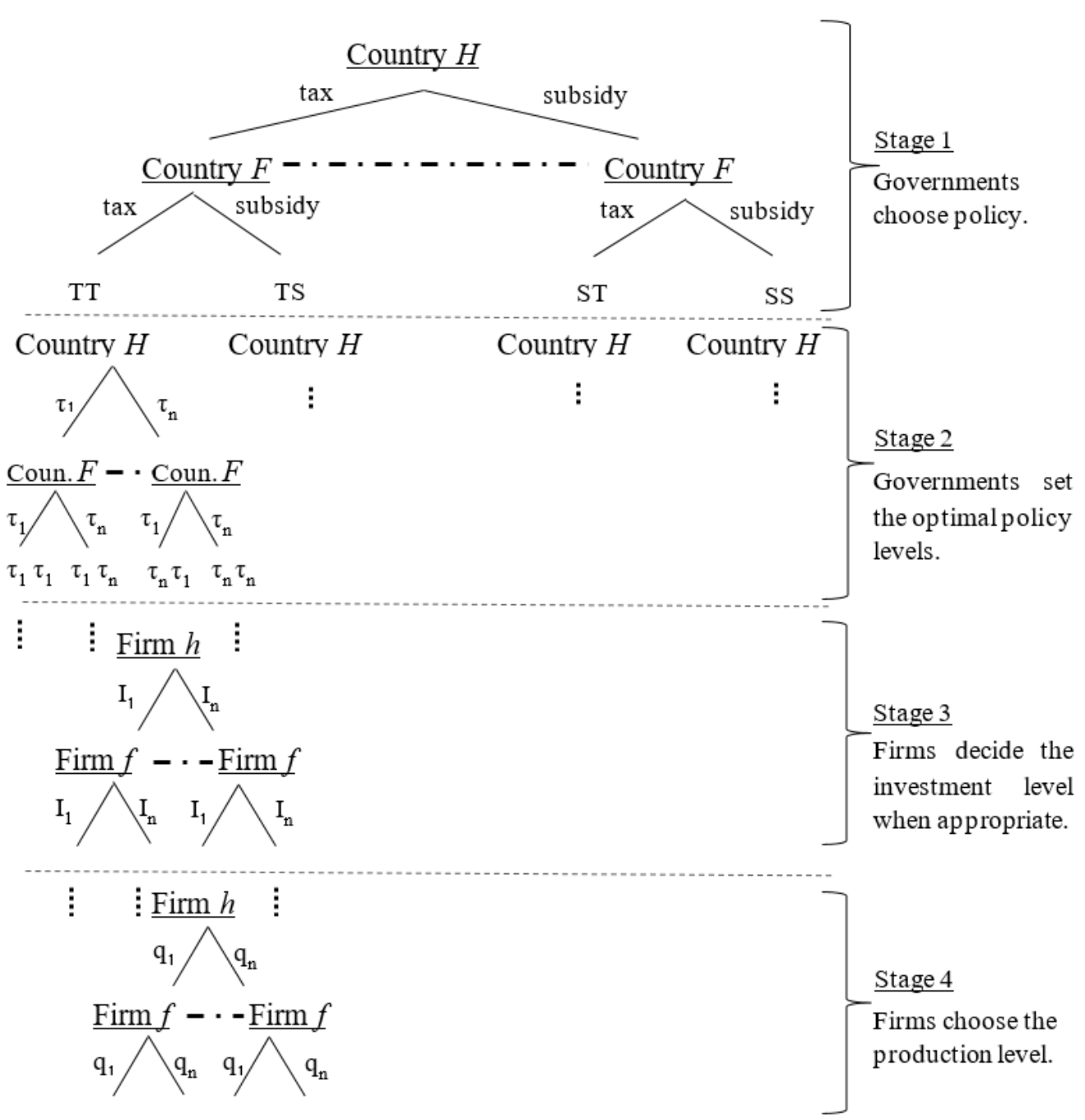

Figure 1.1 Game tree showing the four stages

\subsection{Subgame perfect Nash equilibrium}

After solving the game using backward induction (see the computation of the game equilibria in the Appendix), we define area A, which represents the characteristics of the markets $(\alpha, \Delta)$ in the two countries whose governments act strategically. That is, governments have two options in stage 1: to establish an emission tax or to provide a production subsidy. Mathematically speaking, it is the area which represents the values for $\alpha$ and $\Delta$ that ensures a positive and interior solution for quantities, taxes, and 
subsidies. Properly defined, $A \equiv\left\{(\alpha, \Delta) \in \Re_{+}^{2} / 24 \alpha+3 \Delta-148 \geq 0,8 \alpha+6 \Delta-116 \geq 0\right\}$, as can be seen in Figure 1.2.

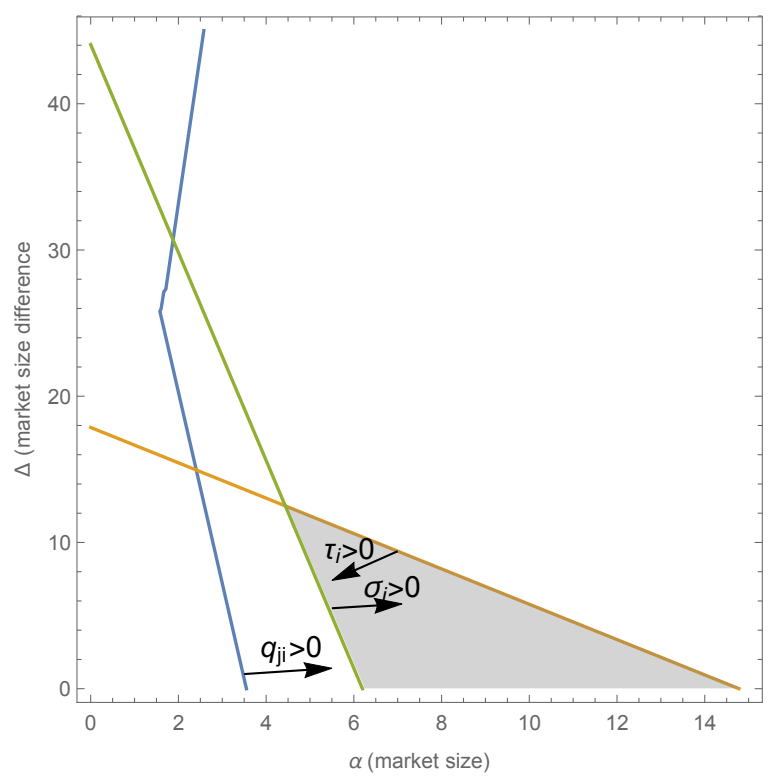

Figure 1.2 Area in which quantities, taxes and subsidies are interior and positive, where $i=H, F$ and $j=h, f$

From the solution of the game in stage 1 , we obtain two relevant functions, $F_{1}(\alpha)$ and $F_{2}(\alpha)$ :

$$
\begin{aligned}
& F_{1}(\alpha)=0.01 \sqrt{(\alpha-4) \alpha+550644}-1.15 \alpha+2.3 \\
& F_{2}(\alpha)=1.02 \sqrt{(\alpha-4) \alpha+2233}-6.78 \alpha+13.56
\end{aligned}
$$

These two functions divide area $\mathrm{A}$ into four subareas (see the shaded area in Figure 1.3), which differ in the obtained equilibrium, i.e., there are areas such as A(I), $\mathrm{A}(\mathrm{II})$ and $\mathrm{A}(\mathrm{III})$ with only one SPNE, whereas in area $\mathrm{A}(\mathrm{IV})$ we find a multiplicity of equilibria. Areas are defined as follows:

$$
\begin{aligned}
& \mathrm{A}(\mathrm{I}) \equiv\left\{(\alpha, \Delta) \in A / \Delta \leq \min \left\{F_{1}(\alpha), F_{2}(\alpha)\right\}\right\} \\
& \mathrm{A}(\mathrm{II}) \equiv\left\{(\alpha, \Delta) \in A / F_{1}(\alpha) \leq \Delta \leq F_{2}(\alpha)\right\} \\
& \mathrm{A}(\mathrm{III}) \equiv\left\{(\alpha, \Delta) \in A / \Delta \geq \max \left\{F_{1}(\alpha), F_{2}(\alpha)\right\}\right\} \\
& \mathrm{A}(\mathrm{IV}) \equiv\left\{(\alpha, \Delta) \in A / F_{1}(\alpha) \geq \Delta \geq F_{2}(\alpha)\right\}
\end{aligned}
$$




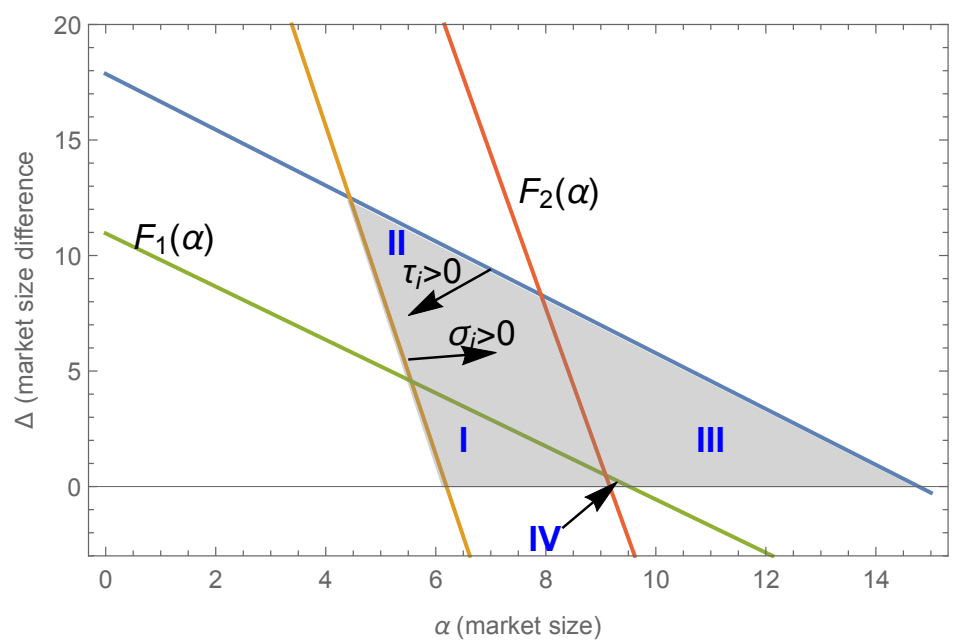

Figure 1.3 Definition of the four subareas in area A

Theorem 1. If $(\alpha, \Delta) \in A(I) \equiv\left\{(\alpha, \Delta) \in A / \Delta \leq \min \left\{F_{1}(\alpha), F_{2}(\alpha)\right\}\right\}$ then $\left[\left(\boldsymbol{t a x}, \tau_{H}^{*}\right),\left(\boldsymbol{t a x}, \tau_{F}^{*}\right),\left(I_{h}^{*}, q_{h H}^{*}, q_{h F}^{*}\right),\left(I_{f}^{*}, q_{f F}^{*}, q_{f H}^{*}\right)\right]$ is the unique SPNE of the game.

Proof. From Proposition 5, at least we know that the strategy used by both governments to apply an emission tax is part of the SPNE. From propositions 6 to 8 in the appendix, we know that it is the unique SPNE for countries in this area.

Theorem 1 shows that if the two markets are small enough and there is low asymmetry, then there is a unique SPNE and thus the governments of both countries are advised to set a tax on emissions.

Theorem 2. If $(\alpha, \Delta) \in A(I I) \equiv\left\{(\alpha, \Delta) \in A / F_{1}(\alpha) \leq \Delta \leq F_{2}(\alpha)\right\}$ then $\left[\left(\boldsymbol{t a x}, \tau_{H}^{*}\right),\left(\right.\right.$ subsidy, $\left.\left.\sigma_{F}^{*}\right),\left(I_{h}^{*}, q_{h H}^{*}, q_{h F}^{*}\right),\left(I_{f}^{*}, q_{f F}^{*}, q_{f H}^{*}\right)\right]$ is the unique SPNE of the game.

Proof. From Proposition 6, we at least know that the strategy with which the homecountry government applies an emission tax and the foreign country's government establishes a production subsidy is part of the SPNE. From propositions 5, 7 and 8 in the appendix, we know that it is the unique SPNE for countries in this area.

Theorem 2 shows that if the market size asymmetry between the two countries increases but the market in the home country is small enough, there is a unique SPNE; thus the government in the home country is advised to set an emission tax while the government in the foreign country is advised to provide a production subsidy.

Theorem 3. If $(\alpha, \Delta) \in A(I I I) \equiv\left\{(\alpha, \Delta) \in A / \Delta \geq \max \left\{F_{1}(\alpha), F_{2}(\alpha)\right\}\right\}$ then $\left[\left(\right.\right.$ subsidy,$\left.\sigma_{H}^{*}\right),\left(\right.$ subsidy,$\left.\left.\sigma_{F}^{*}\right),\left(I_{h}^{*}, q_{h H}^{*}, q_{h F}^{*}\right),\left(I_{f}^{*}, q_{f F}^{*}, q_{f H}^{*}\right)\right]$ is the unique SPNE of the game.

Proof. From Proposition 7, we at least know that the strategy used by both governments to provide a production subsidy is part of the SPNE. From propositions 
5, 6 and 8 in the appendix, we know that it is the unique SPNE for countries in this area.

Theorem 3 shows that (i) if the market in the home country is not very large but markets are very asymmetric, or (ii) if the two markets are large enough, then there is a unique SPNE and, consequently, the governments of both countries are advised to establish production subsidies.

Theorem 4. If $(\alpha, \Delta) \in A(I V) \equiv\left\{(\alpha, \Delta) \in A / F_{1}(\alpha) \geq \Delta \geq F_{2}(\alpha)\right\}$ there are two SPNE: $\left[\left(\boldsymbol{t a x}, \tau_{H}^{*}\right),\left(\boldsymbol{t a x}, \tau_{F}^{*}\right),\left(I_{h}^{*}, q_{h H}^{*}, q_{h F}^{*}\right),\left(I_{f}^{*}, q_{f F}^{*}, q_{f H}^{*}\right)\right]$ and $\left[\left(\right.\right.$ subsidy, $\left.\sigma_{H}^{*}\right),\left(\right.$ subsidy,$\left.\left.\sigma_{F}^{*}\right),\left(I_{h}^{*} q_{h H}^{*}, q_{h F}^{*}\right),\left(I_{f}^{*}, q_{f F}^{*}, q_{f H}^{*}\right)\right]$.

Proof. From propositions 5 and 7, we at least know that the strategies used by both governments to apply an emission tax or to establish a production subsidy are part of the SPNE. From propositions 6 and 8, we know that those are the two SPNEs for the two countries in this area.

Theorem 4 shows that, in area IV, markets are almost symmetric, i.e., both countries have a medium and identical market size. As we describe in the next section, this area has multiple equilibria, i.e., there are two SPNE, one that advises governments in both countries to set emission taxes, while the other advises governments in both countries to establish production subsidies.

\subsection{A numerical example}

\subsubsection{A numerical example in scenarios with a unique equilibrium}

In this section, we provide a numerical example of comparative statics for three different scenarios in which the SPNE is unique. More specifically, in Table 1.1, we present a numerical example in which the home country faces three possible scenarios. Given a value for the home market $(\alpha=8.5)$, we introduce different degrees of asymmetry between the markets $(\Delta)$ and compute the equilibrium magnitudes for taxes, subsidies, global damage and social welfare for the two countries. 


\begin{tabular}{lccc} 
& $\begin{array}{c}\text { Scenario i } \\
(\text { Area I })\end{array}$ & $\begin{array}{c}\text { Scenario ii } \\
(\text { Area II })\end{array}$ & $\begin{array}{c}\text { Scenario iii } \\
\text { (Area III })\end{array}$ \\
\hline Country H market size $(\alpha)$ & 8.5 & 8.5 & 8.5 \\
\hline Market size asymmetry $(\Delta)$ & 1 & 2.5 & 7.5 \\
\hline Policy instrument & Tax & Tax & Subsidy \\
Country H & Tax & Subsidy & Subsidy \\
Country F & & & \\
\hline Policy level & $\tau_{H}=0.5$ & $\tau_{H}=0.46$ & $\sigma_{H}=0.95$ \\
Country H & $\tau_{F}=0.45$ & $\sigma_{F}=1.06$ & $\sigma_{F}=2.18$ \\
Country F & & & \\
\hline Damage & 2.49 & 2.66 & 4.72 \\
$D_{H}$ & 2.58 & 4.13 & 5.53 \\
$D_{F}$ & & & \\
\hline Social Welfare & 12 & 13.26 & 20.31 \\
$S W_{H}$ & 13.75 & 18.38 & 39.69 \\
$S W_{F}$ & \multicolumn{3}{c}{} \\
\hline
\end{tabular}

Table 1.1 Comparative Statics for the three different scenarios at an aggregate level

Following Theorem 1, in scenario $i$ the two countries have a small, similar market size $\left(\alpha=8.5, \alpha_{F}=9.5\right)$. Consequently, it is optimal for the governments of both countries to apply an emission tax (see Area I in Figure 1.3). Following Theorem 2 , in scenario $i i$ the difference in market size increases $\left(\alpha=8.5, \alpha_{F}=11\right)$. Thus, the home-country government applies an emission tax, and the foreign country's government establishes a production subsidy (see in Area II in Figure 1.3). Finally, following Theorem 3, in scenario iii the market size of the foreign country almost doubles that of the home country $\left(\alpha=8.5, \alpha_{F}=16\right)$. Hence, it is optimal for the governments of both countries to establish a production subsidy (see area III in Figure 1.3).

If we compare scenarios $i$ and $i i$, we infer that the home country goes from competing with a country that has set an emission tax to competing with a country which provides a production subsidy. This makes the home country's social welfare increase by $10.5 \%$, while both countries face greater damage, at almost $34 \%$.

Comparing scenarios $i$ and iii, the difference in market size between the two countries is so great that the home country is forced to establish a production subsidy to be able to compete with the foreign country. As a consequence social welfare in the home country increases by more than $69 \%$. However, the home country is worse off in environmental terms due to a significant increase in global damage. We can conclude, therefore, that countries are better off but at the expense of increased pollution and environmental damage. 


\begin{tabular}{lccc} 
& $\begin{array}{c}\text { Scenario i } \\
\text { (Area I) }\end{array}$ & $\begin{array}{c}\text { Scenario ii } \\
\text { (Area II) }\end{array}$ & $\begin{array}{c}\text { Scenario iii } \\
\text { (Area III) }\end{array}$ \\
\hline Country H market size $(\alpha)$ & 8.5 & 8.5 & 8.5 \\
\hline Market size asymmetry $(\Delta)$ & 1 & 2.5 & 7.5 \\
\hline Policy instrument & Tax & Tax & Subsidy \\
Country H & Tax & Subsidy & Subsidy \\
Country F & & & \\
\hline Policy level & $\tau_{H}=0.5$ & $\tau_{H}=0.46$ & $\sigma_{H}=0.95$ \\
Country H & $\tau_{F}=0.45$ & $\sigma_{F}=1.06$ & $\sigma_{F}=2.18$ \\
Country F & & & \\
\hline Firm profits & 9.29 & 9.83 & 22.93 \\
$\Pi_{h}$ & 10.02 & 18.39 & 35.32 \\
$\Pi_{f}$ & & & \\
\hline Consumer surplus & 3.95 & 4.87 & 6.57 \\
$C S_{H}$ & 5.15 & 8.49 & 21.94 \\
$C S_{F}$ & & & \\
\hline Government revenue & 1.25 & 1.22 & -4.47 \\
$G R_{H}$ & 1.16 & -4.38 & -12.04 \\
$G R_{F}$ & & & \\
\hline Damage & 2.49 & 2.66 & 4.72 \\
$D_{H}$ & 2.58 & 4.13 & 5.53 \\
$D_{F}$ & & & \\
\hline
\end{tabular}

Table 1.2 Comparative Statics for three different scenarios comparing the components of social welfare

Table 1.2 shows the breakdown of social welfare, i.e., the results for firm profits, consumer surplus, government revenue, and damage. If we compare scenarios $i$ with $i i$ where market size asymmetry increases so that the government in the foreign country is better off switching from an emission tax (in scenario $i$ ) to a production subsidy (in scenario $i$ ), we observe that the increase in social welfare in the home country is mainly due to an increase in firm profits. The home country's consumer surplus increases by $23 \%$, while government revenue decreases. Finally, damage in the home country is greater.

If we compare scenario $i$ with $i i i$, we can see that the increase in social welfare in the home country occurs because firm profits are almost three times higher. The home country's consumer surplus is $66 \%$ higher, while government revenue is lower because in scenario iii governments subsidize firms. Finally, the amount of damage in the home country almost doubles.

The conclusion is that when a country with a small market size competes with a country with a large market size and the two governments provide production 
subsidies, although firms are indeed better off, this is not the case for consumers, since the increase in consumer surplus does not compensate the taxes they have to pay in order to subsidize firms. Moreover, consumers also have to deal with environmental damage that is almost five times greater.

\subsubsection{A numerical example for the scenario with multiple equilibria}

In this section, we provide a numerical example where there are multiple equilibria. More specifically, we offer a numerical example for area IV (i.e., where areas I and III intersect, see Figure 1.3), in which markets are medium-sized, and asymmetry is almost null $(\Delta \simeq 0)$. Following Theorem 4 from the previous section, governments can choose between two different SPNEs, i.e., both governments set an emission tax, or they establish a production subsidy.

\begin{tabular}{lcc} 
& TT & SS \\
\hline Country H market size $(\alpha)$ & 9.3 & 9.3 \\
\hline Market size asymmetry $(\Delta)$ & 0.3 & 0.3 \\
\hline Policy instrument & & \\
Country H & Tax & Subsidy \\
Country F & Tax & Subsidy \\
\hline Policy level & & \\
Country H & $\tau_{H}=0.45$ & $\sigma_{H}=0.84$ \\
Country F & $\tau_{F}=0.43$ & $\sigma_{F}=0.89$ \\
\hline Damage & & \\
$D_{H}$ & 2.75 & 3.71 \\
$D_{F}$ & 2.77 & 3.74 \\
\hline Social Welfare & & \\
$S W_{H}$ & 14.12 & 14.02 \\
$S W_{F}$ & 14.67 & 14.63 \\
\hline
\end{tabular}

Table 1.3 Comparative Statics for the two possible SPNE at an aggregate level

Table 1.3 shows that, at the aggregate level, social welfare in both countries is greater (and global damage is lower) with an emission tax rather than with a production subsidy. Nevertheless, as shown in Table 1.4 where we decompose social welfare, when governments establish a production subsidy in both countries, firms' profits and consumers surplus are greater; therefore, the worsening in social welfare is only due to the negative government revenue. 


\begin{tabular}{lcc} 
& TT & SS \\
\hline Country H market size $(\alpha)$ & 9.3 & 9.3 \\
\hline Market size asymmetry $(\Delta)$ & 0.3 & 0.3 \\
\hline Policy instrument & & \\
Country H & Tax & Subsidy \\
Country F & Tax & Subsidy \\
\hline Policy level & & \\
Country H & $\tau_{H}=0.45$ & $\sigma_{H}=0.84$ \\
Country F & $\tau_{F}=0.43$ & $\sigma_{F}=0.89$ \\
\hline Firms profits & & \\
$\pi_{h}$ & 10.69 & 14.12 \\
$\pi_{f}$ & 10.91 & 14.53 \\
\hline Consumer surplus & & \\
$C S_{H}$ & 4.94 & 6.72 \\
$C S_{F}$ & 5.32 & 7.16 \\
\hline Government revenue & & \\
$G R_{H}$ & 1.24 & -3.11 \\
$G R_{F}$ & 1.21 & -3.32 \\
\hline Damage & & \\
$D_{H}$ & 2.75 & 3.71 \\
$D_{F}$ & 2.77 & 3.74 \\
\hline
\end{tabular}

Table 1.4 Comparative Statics for the two possible SPNE

\subsection{Conclusions}

Using a simple duopoly model, we study how the industrial policy implemented by governments might be affected by international oligopolistic trade. We consider the local impact of emissions generated by the production activity of both a domestic and a foreign industry, taking into account one firm in the home country and one in the foreign country. We analyze a scenario in which both firms and governments, act strategically when deciding on their production and industrial policy, respectively. Additionally, we introduce different degrees of asymmetry between countries and use a setting where governments compete in the level of emission taxes (production subsidies), which they apply to the firms that produce goods and generate emissions in their territory, while firms compete directly, both in the domestic and foreign market. We demonstrate that governments in small countries have an incentive to impose emission taxes on the industry to encourage firms to (invest in and) use cleaner technologies. This industrial policy will contribute positively to the country's social welfare, thanks to a significant reduction in environmental damage. 
Our results show that when home and foreign countries are small (small market size), the governments in both countries have incentives to impose an emission tax on their industries. This result explains why in small countries whose industries compete in international and local markets, environmental policy can be sustained in equilibrium. If international trade takes place between asymmetric countries, it might be still optimal for the government in the small (home) country to maintain an industrial policy based on emission taxes, even if the government in the large (foreign) country has incentives to switch to an industrial policy based on production subsidies in order to improve firm competitiveness in the home and foreign market. Furthermore, if the industrial (environmental) policy implemented in the home (small) country gave home-country firms a competitive advantage in the domestic market but a competitive disadvantage abroad, a reduction in environmental damages would compensate the firms' loss of competitiveness in the home country with overall social welfare.

We also observe a special case in which both home and foreign countries have medium-sized markets that are almost symmetric. In this case, it is part of the equilibrium that both governments decide on the same industrial policy, either an environmental tax or a production subsidy. We show that social welfare in the two countries is slightly higher under an environmental tax, mainly due to a significant reduction in damage and higher government revenue that offsets the reduction in firm profits and consumer surplus, compared to a scenario where governments of the two countries subsidize the production of firms.

Finally, we demonstrate that it might be optimal for the home-country government to remove the emission tax and subsidize firm production if the home-country firms are competing with firms of a large country which also receive production subsidies. Our model shows, therefore, how market size asymmetry might be a determinant in the optimal government industrial policies in economies with international trade.

Our results illustrate why regulators might be reluctant to introduce environmental regulations as part of their industrial policies if they believe that such policies could undermine the competitiveness of the industry. The results of this study can be used to illustrate the effects of international trading on the countries' industrial policy. Taken together, the findings support the evidence that in oligopolistic international markets the regulators' decision on the optimal industrial policy might be driven by the market conditions, in particular by the size of the country it is trading with. We have shown that when international trade takes place between highly asymmetric countries, larger countries have no incentives to establish environmental policies. In other words, trading competitiveness is not an argument to move from subsidies to taxes. As a consequence, the small country is better off adopting the same policy. 


\section{Appendix}

\section{A Subgame perfect Nash equilibrium}

In this appendix, we show the computation of the subgame perfect Nash equilibrium (SPNE) of the game using backward induction:

\section{Firms' output decision (Stage 4)}

In stage 4, each firm decides on the output level for the two varieties of products to maximize profits.

The first-order conditions imply that output always increases with market size:

- Scenario 1: country $H$ and $F$ apply an emission tax:

$$
\begin{gathered}
q_{h H}^{T T}=\frac{1}{15}\left(3 \alpha-4 \tau_{H}+\tau_{F}+2\right) \\
q_{h F}^{T T}=\frac{1}{15}\left(3 \alpha+3 \Delta-4 \tau_{H}+\tau_{F}-8\right) \\
q_{f F}^{T T}=\frac{1}{15}\left(3 \alpha+3 \Delta+\tau_{H}-4 \tau_{F}+2\right) \\
q_{f H}^{T T}=\frac{1}{15}\left(3 \alpha+\tau_{H}-4 \tau_{F}-8\right)
\end{gathered}
$$

- Scenario 2: the government in country $H$ sets an emission tax and the government in country $F$ establishes a production subsidy:

$$
\begin{gathered}
q_{h H}^{T S}=\frac{1}{15}\left(3 \alpha-4 \tau_{H}-\sigma_{F}+2\right) \\
q_{h F}^{T S}=\frac{1}{15}\left(3 \alpha+3 \Delta-4 \tau_{H}-\sigma_{F}-8\right) \\
q_{f F}^{T S}=\frac{1}{15}\left(3 \alpha+3 \Delta+\tau_{H}+4 \sigma_{F}+2\right) \\
q_{f H}^{T S}=\frac{1}{15}\left(3 \alpha+\tau_{H}+4 \sigma_{F}-8\right)
\end{gathered}
$$

- Scenario 3: country $H$ and $F$ provide production subsidies:

$$
\begin{gathered}
q_{h H}^{S S}=\frac{1}{15}\left(3 \alpha+4 \sigma_{H}-\sigma_{F}+2\right) \\
q_{h F}^{S S}=\frac{1}{15}\left(3 \alpha+3 \Delta+4 \sigma_{H}-\sigma_{F}-8\right)
\end{gathered}
$$




$$
\begin{gathered}
q_{f F}^{S S}=\frac{1}{15}\left(3 \alpha+3 \Delta-\sigma_{H}+4 \sigma_{F}+2\right) \\
q_{f H}^{S S}=\frac{1}{15}\left(3 \alpha-\sigma_{H}+4 \sigma_{F}-8\right)
\end{gathered}
$$

- Scenario 4: the government in country $H$ establishes a production subsidy and the government in country $F$ sets an emission tax:

$$
\begin{gathered}
q_{h H}^{S T}=\frac{1}{15}\left(3 \alpha+4 \sigma_{H}+\tau_{F}+2\right) \\
q_{h F}^{S T}=\frac{1}{15}\left(3 \alpha+3 \Delta+4 \sigma_{H}+\tau_{F}-8\right) \\
q_{f F}^{S T}=\frac{1}{15}\left(3 \alpha+3 \Delta-\sigma_{H}-4 \tau_{F}+2\right) \\
q_{f H}^{S T}=\frac{1}{15}\left(3 \alpha-\sigma_{H}-4 \tau_{F}-8\right)
\end{gathered}
$$

When both countries apply a tax on emissions, the home country's total output decreases if the corresponding government chooses to apply an emission tax, whereas it increases if an emission tax is applied in the foreign country. The opposite holds when both countries establish a production subsidy: the home country's total output increases with the home-country production subsidy and it decreases when a production subsidy is provided in the foreign country. On the other hand, when a country's government sets an emission tax and the other one provides a production subsidy, the production of the country that applies emission taxes decreases due to both the domestic tax and the foreign subsidy, while the opposite happens to the production of the country that provides a production subsidy.

\section{Firms' investment decisions (Stage 3)}

If governments set a tax on emissions in stage 1, firms will have incentives to invest in cleaner technologies.

- Scenario 1: governments in the two countries set an emission tax:

$$
\begin{aligned}
& I_{h}^{T T}=\tau_{H} \\
& I_{f}^{T T}=\tau_{F}
\end{aligned}
$$

- Scenario 2: the home-country government sets an emission tax and the foreign country's government establishes a production subsidy:

$$
\begin{gathered}
I_{h}^{T S}=\tau_{H} \\
I_{f}^{T S}=0
\end{gathered}
$$


- Scenario 3: governments in both countries establish a production subsidy:

$$
\begin{aligned}
& I_{h}^{S S}=0 \\
& I_{f}^{S S}=0
\end{aligned}
$$

- Scenario 4: the home-country government establishes a production subsidy and the foreign country's government sets an emission tax:

$$
\begin{gathered}
I_{h}^{S T}=0 \\
I_{f}^{S T}=\tau_{F}
\end{gathered}
$$

From these first-order conditions, we know that the level of investment is equal to the tax level when governments apply a pollution tax, and null if governments establish a production subsidy.

\section{Government decisions on policy level (Stage 2)}

In the second stage of the game, according to the policy decided in Stage 1, the government of each country chooses the level of policy that maximizes social welfare, considering as given the decision of the other country.

From the maximization of social welfare we obtain the best response function for each of the governments regarding the other country's decision, ${ }^{7}$ and if the first-order conditions are met, we obtain the optimal policy rates.

- Scenario 1: governments in both countries set an emission tax:

$$
\begin{gathered}
\tau_{H}^{T T}=\frac{1}{328}\left(-24 \alpha-3 \Delta+7 \tau_{F}+369\right) \\
\tau_{F}^{T T}=\frac{1}{328}\left(-24 \alpha-21 \Delta+7 \tau_{H}+369\right)
\end{gathered}
$$

If we solve the system for equations (1.5) and (1.6), we obtain:

$$
\begin{aligned}
& \tau_{H}^{T T}=-0.07 \alpha-0.01 \Delta+1.15 \\
& \tau_{F}^{T T}=-0.07 \alpha-0.06 \Delta+1.15
\end{aligned}
$$

- Scenario 2: the home-country government sets an emission tax and the foreign country's government establishes a production subsidy:

$$
\tau_{H}^{T S}=\frac{1}{328}\left(-24 \alpha-3 \Delta-7 \sigma_{F}+369\right)
$$

\footnotetext{
${ }^{7}$ The second-order condition for welfare maximization is verified since $\frac{\partial^{2} S W_{H}}{\partial \tau_{H} \partial \tau_{H}}<0$.
} 


$$
\sigma_{F}^{T S}=\frac{1}{103}\left(24 \alpha+21 \Delta-7 \tau_{H}-144\right)
$$

If we solve the system for equations (1.7) and (1.8) we obtain:

$$
\begin{gathered}
\tau_{H}^{T S}=-0.08 \alpha-0.01 \Delta+1.16 \\
\sigma_{F}^{T S}=0.24 \alpha+0.2 \Delta-1.48
\end{gathered}
$$

- Scenario 3: governments in both countries establish a production subsidy:

$$
\begin{gathered}
\sigma_{H}^{S S}=\frac{1}{103}\left(24 \alpha+3 \Delta+7 \sigma_{F}-144\right) \\
\sigma_{F}^{S S}=\frac{1}{103}\left(24 \alpha+21 \Delta+7 \sigma_{H}-144\right)
\end{gathered}
$$

If we solve the system for equations (1.9) and (1.10), we obtain:

$$
\begin{aligned}
& \sigma_{H}^{S S}=0.25 \alpha+0.04 \Delta-1.5 \\
& \sigma_{F}^{S S}=0.25 \alpha+0.21 \Delta-1.5
\end{aligned}
$$

- Scenario 4: the home-country government establishes a production subsidy and the foreign country's government sets an emission tax:

$$
\begin{gathered}
\sigma_{H}^{S T}=\frac{1}{103}\left(24 \alpha+3 \Delta-7 \tau_{F}-144\right) \\
\tau_{F}^{S T}=\frac{1}{328}\left(-24 \alpha-21 \Delta-7 \sigma_{H}+369\right)
\end{gathered}
$$

If we solve the system for equations (1.11) and (1.12), we obtain:

$$
\begin{gathered}
\sigma_{H}^{S T}=0.24 \alpha+0.03 \Delta-1.48 \\
\tau_{F}^{S T}=-0.08 \alpha-0.06 \Delta+1.16
\end{gathered}
$$

From these first-order conditions, we can see that taxes (subsidies) decrease (increase) with market size; in other words, the larger the market size, the lower (higher) the level of taxes (subsidies). When both countries apply the same (different) policy instrument, the higher the tax or subsidy level of the foreign country, the greater the incentive of governments to increase (decrease) the tax on emissions or the subsidy for production.

Figure 1.4 below, shows the area with an interior and positive solution for quantities, taxes, and subsidies, i.e., the area in which governments can behave strategically: $A \equiv\left\{(\alpha, \Delta) \in \Re_{+}^{2} / q_{j i}^{P O} \geq 0, \tau_{i}^{P O} \geq 0, \sigma_{i}^{P O} \geq 0\right\} \equiv\left\{(\alpha, \Delta) \in \Re_{+}^{2} / \tau_{F}^{S T} \geq 0, \sigma_{H}^{S T} \geq 0\right\}$ where $i \in\{H, F\}$, where $j \in\{h, f\}$ and $P, O \in\{T, S\}$ 


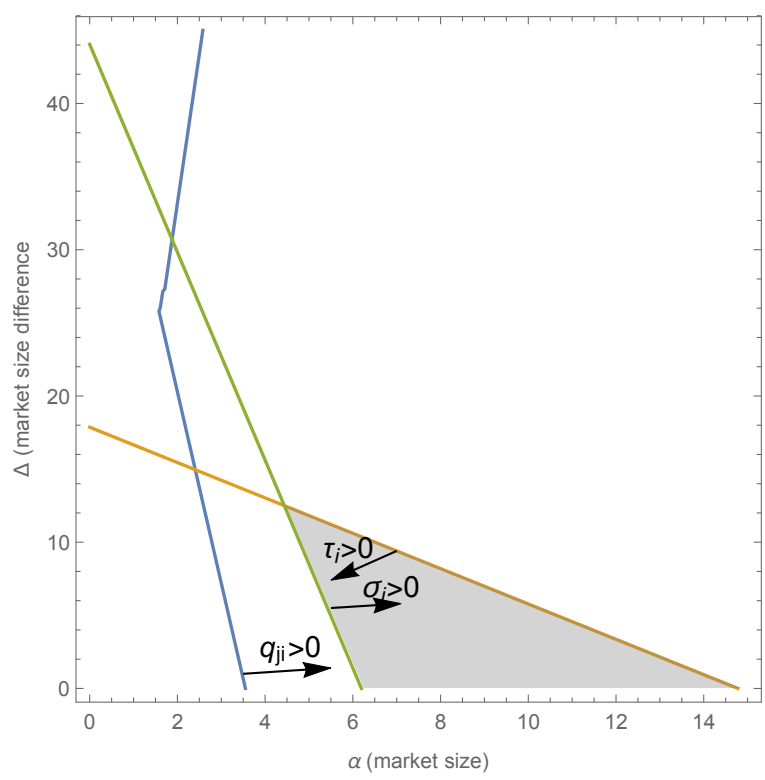

Figure 1.4 Area in which quantities, taxes and subsidies are interior and positive, where $i=H, F$ and $j=h, f$

This area shows the kind of markets our analysis is valid for, i.e., there is no guarantee out of this area that all governments can choose between two policies.

\section{Government decisions on policy instruments (Stage 1)}

To obtain the SPNE in stage 1, we compare the social welfare levels of each country considering as given the policy decision of the government in the other country. After solving the game using backward induction, the normal form of the game at Stage 1, in which governments decide on the policy instruments, is as follows:

$$
\begin{array}{ll|c|c|}
\multicolumn{2}{c}{\text { Tax }} & \multicolumn{2}{c}{\text { Country } F} \\
\cline { 3 - 4 } \text { Country } H & \text { Tax } & \left(S W_{H}^{T T}, S W_{F}^{T T}\right) & \left(S W_{H}^{T S}, S W_{F}^{T S}\right) \\
\cline { 3 - 4 } & \text { Subsidy } & \left(S W_{H}^{S T}, S W_{F}^{S T}\right) & \left(S W_{H}^{S S}, S W_{F}^{S S}\right) \\
\cline { 3 - 5 } & &
\end{array}
$$

Table 1.5 Normal form of the game at stage 1

In which $S W_{H}^{T T}\left(S W_{F}^{T T}\right)$ denotes social welfare in country $\mathrm{H}(\mathrm{F})$ if the two governments set an emission tax; $S W_{H}^{S S}\left(S W_{F}^{S S}\right)$ denotes social welfare in country $\mathrm{H}(\mathrm{F})$ if the two governments establish a production subsidy; $S W_{H}^{T S}\left(S W_{F}^{T S}\right)$ denotes social welfare in country $\mathrm{H}(\mathrm{F})$ if the home-country government sets an emission tax and the foreign country's government establishes a production subsidy; finally, $S W_{H}^{S T}\left(S W_{F}^{S T}\right.$ ) denotes social welfare in country $\mathrm{H}(\mathrm{F})$ if the home-country government establishes a production subsidy and the foreign country's government sets an emission tax.

We examine four different subgames: (i) subgame in which both countries apply a tax on emissions (subgame TT); (ii) subgame in which the home country applies an emission tax, and the foreign country provides a production subsidy (subgame $T S$ ); 
(iii) subgame in which both countries provide a subsidy for production (subgame $S S$ ); and (iv) subgame in which the home country provides a production subsidy and the foreign country applies an emission tax (subgame $S T$ ).

We first consider the best response of the foreign country when the home country applies a tax on emissions. If we compare the social welfare of two countries whose governments apply a tax on emissions with that of a home-country government which applies a tax on emissions together with that of a foreign country's government which provides a production subsidy, the government in country $\mathrm{F}$ will be indifferent between setting an emission tax or providing a production subsidy if:

$$
S W_{F}^{T S}-S W_{F}^{T T}=15.37 \Delta(\alpha-2)+8.85 \alpha(\alpha-4)-464.59+6.67 \Delta^{2}=0
$$

If we solve $\Delta$, we obtain the positive root:

$$
\begin{gathered}
F_{1}(\alpha)=0.01 \sqrt{(\alpha-4) \alpha+550644}-1.15 \alpha+2.3 \\
0 \leq \Delta \leq F_{1}(\alpha) \Rightarrow S W_{F}^{T S}-S W_{F}^{T T} \leq 0 \\
\Delta \geq F_{1}(\alpha) \Rightarrow S W_{F}^{T S}-S W_{F}^{T T} \geq 0
\end{gathered}
$$

Secondly, we consider the best response of the home country when the foreign country provides a subsidy for production. If we compare the social welfare of two countries when the home-country government applies a tax on emissions and the foreign country's government provides a production subsidy with that of two countries whose governments grant production subsidies, the government in country $\mathrm{H}$ will be indifferent between setting an emission tax or providing a production subsidy if:

$$
S W_{H}^{S S}-S W_{H}^{T S}=2.94 \Delta(\alpha-2)+9.75 \alpha(\alpha-4)-464.02+0.22 \Delta^{2}=0
$$

If we solve $\Delta$, we obtain the positive root:

$$
\begin{gathered}
F_{2}(\alpha)=1.02 \sqrt{(\alpha-4) \alpha+2233}-6.78 \alpha+13.56 \\
0 \leq \Delta \leq F_{2}(\alpha) \Rightarrow S W_{H}^{S S}-S W_{H}^{T S} \leq 0 \\
\Delta \geq F_{2}(\alpha) \Rightarrow S W_{H}^{S S}-S W_{H}^{T S} \geq 0
\end{gathered}
$$

Next, we consider the best response for the foreign country when the home country provides a subsidy for production. If we compare the social welfare of two countries when the home-country government provides a production subsidy and the foreign country's government applies an emission tax with that of two countries whose governments provide a production subsidy, the government in country $F$ will 
be indifferent between setting an emission tax or providing a production subsidy if:

$$
S W_{F}^{S S}-S W_{F}^{S T}=16.55 \Delta(\alpha-2)+9.75 \alpha(\alpha-4)-461.02+7.02 \Delta^{2}=0
$$

If we solve $\Delta$, we get the positive root:

$$
\begin{gathered}
F_{3}(\alpha)=0.03 \sqrt{86290+\alpha(\alpha-4)}-1.18 \alpha+2.4 \\
0 \leq \Delta \leq F_{3}(\alpha) \Rightarrow S W_{F}^{S S}-S W_{F}^{S T} \leq 0 \\
\Delta \geq F_{3}(\alpha) \Rightarrow S W_{F}^{S S}-S W_{F}^{S T} \geq 0
\end{gathered}
$$

Finally, we consider the best response of the home country when the foreign country applies a tax. If we compare the social welfare in two countries where governments apply a tax with that of two countries where the foreign country applies government applies a tax on emissions and the home-country government provides a production subsidy, the government in country $\mathrm{H}$ will be indifferent between setting an emission tax or providing a production subsidy if:

$$
S W_{H}^{T T}-S W_{H}^{S T}=-2.23 \Delta(\alpha-2)-8.85 \alpha(\alpha-4)+464.59-0.15 \Delta^{2}=0
$$

If we solve $\Delta$, we obtain the positive root:

$$
\begin{gathered}
F_{4}(\alpha)=2.14 \sqrt{703-\alpha(\alpha-4)}-7.29 \alpha+14.59 \\
0 \leq \Delta \leq F_{4}(\alpha) \Rightarrow S W_{H}^{T T}-S W_{H}^{S T} \geq 0 \\
\Delta \geq F_{4}(\alpha) \Rightarrow S W_{H}^{T T}-S W_{H}^{S T} \leq 0
\end{gathered}
$$

Comparing $\Delta$ with $F_{1}(\alpha), F_{2}(\alpha), F_{3}(\alpha)$ and $F_{4}(\alpha)$, our results are as follows:

Proposition 5. If $(\alpha, \Delta) \in A$ and $\Delta \leq \min \left\{F_{1}(\alpha), F_{4}(\alpha)\right\}$, then the governments of both countries can set environmental taxes as part of an SPNE.

Proof. From eq. (1.14), we see that if $\Delta \leq F_{1}(\alpha)$, then $S W_{F}^{T S}-S W_{F}^{T T} \leq 0$, and from eq. (1.23), we see that if $\Delta \leq F_{4}(\alpha)$ then $S W_{H}^{T T}-S W_{H}^{S T} \geq 0$.

If $(\alpha, \Delta) \in A \cap\left\{(\alpha, \Delta) \in \Re_{+}^{2} / \Delta \leq \min \left\{F_{1}(\alpha), F_{4}(\alpha)\right\}\right\}$ then $S W_{F}^{T T}-S W_{F}^{T S} \geq 0$ and $S W_{H}^{T T}-S W_{H}^{S T} \geq 0$, therefore, the governments of both countries can set environmental taxes as part of an SPNE. 

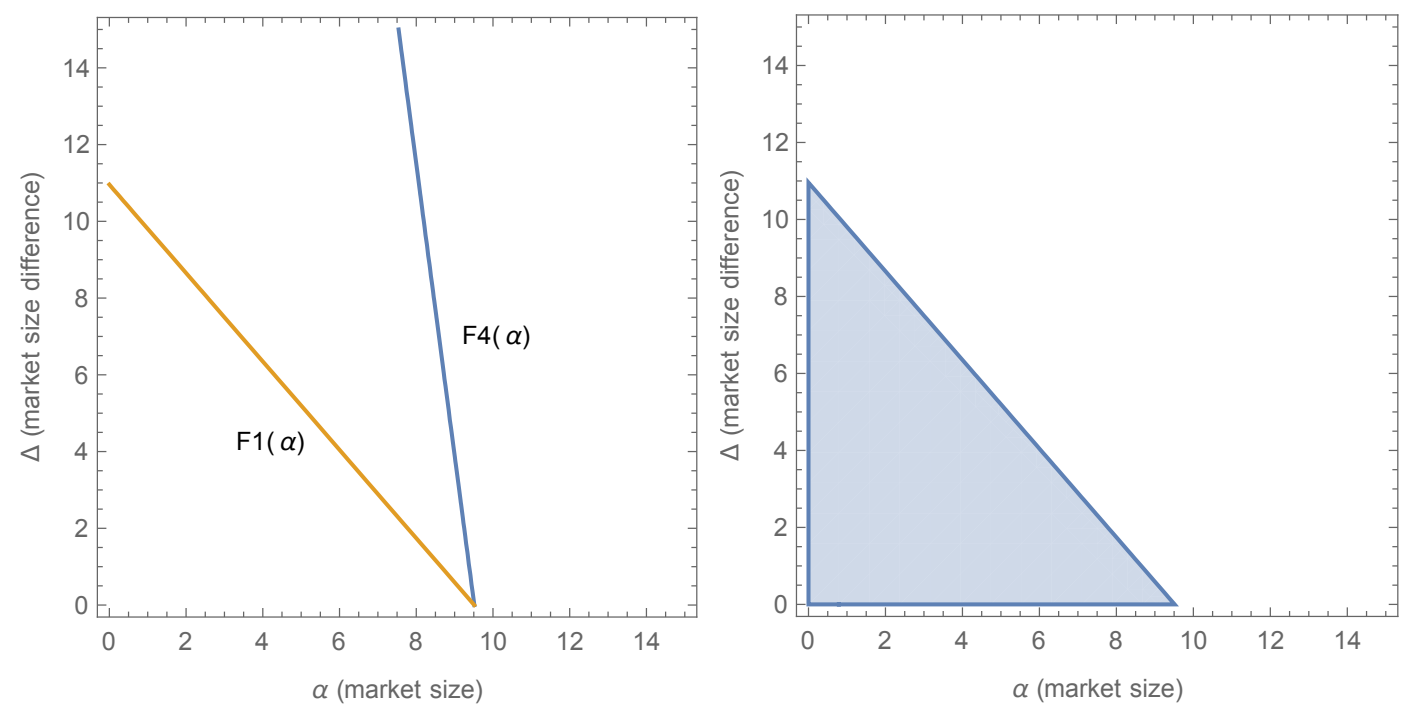

Figure 1.5 $F_{1}(\alpha)$ and $F_{4}(\alpha)$ (left) and the area in which subgame TT has an SPNE (right)

Proposition 6. If $(\alpha, \Delta) \in A$ and $F_{1}(\alpha) \leq \Delta \leq F_{2}(\alpha)$, then the home-country government can apply an emission tax, while the foreign country's government can establish a production subsidy as part of an SPNE.

Proof. From eq. (1.15), we see that if $\Delta \geq F_{1}(\alpha)$ then $S W_{F}^{T S}-S W_{F}^{T T} \geq 0$ and from eq. (1.17), we see that if $\Delta \leq F_{2}(\alpha)$, then $S W_{H}^{S S}-S W_{H}^{T S} \leq 0$.

If $(\alpha, \Delta) \in A \cap\left\{(\alpha, \Delta) \in \Re_{+}^{2} / F_{1}(\alpha) \leq \Delta \leq F_{2}(\alpha)\right\}$ then $S W_{F}^{T S}-S W_{F}^{T T} \geq 0$ and $S W_{H}^{T S}-S W_{H}^{S S} \geq 0$, therefore, the governments of both countries can set environmental taxes as part of an SPNE.
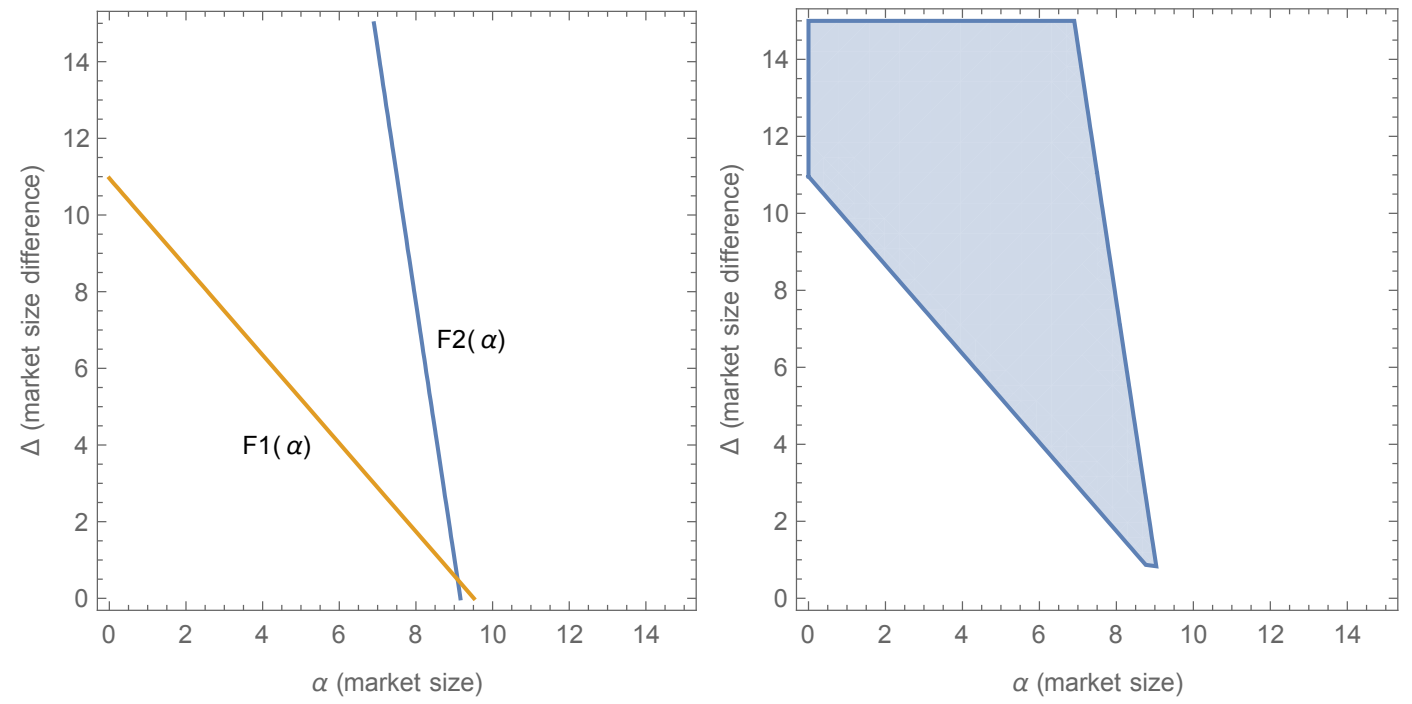

Figure 1.6 $F_{1}(\alpha)$ and $F_{2}(\alpha)$ (left) and the area in which subgame TS is a SPNE (right)

Proposition 7. If $(\alpha, \Delta) \in A$ and $\Delta \geq \max \left\{F_{2}(\alpha), F_{3}(\alpha)\right\}$, then the governments of both countries can provide production subsidies as part of an SPNE. 
Proof. From eq. (1.18) we see that if $\Delta \geq F_{2}(\alpha)$, then $S W_{H}^{S S}-S W_{H}^{T S} \geq 0$, and from eq. (1.21) we see that if $\Delta \geq F_{3}(\alpha)$, then $S W_{F}^{S S}-S W_{F}^{S T} \geq 0$.

If $(\alpha, \Delta) \in A \cap\left\{(\alpha, \Delta) \in \Re_{+}^{2} / \Delta \geq \max \left\{F_{2}(\alpha), F_{3}(\alpha)\right\}\right\}$ then $S W_{H}^{S S}-S W_{H}^{T S} \geq 0$ and $S W_{F}^{S S}-S W_{F}^{S T} \geq 0$, therefore, the governments of both countries can establish production subsidies as part of an SPNE.
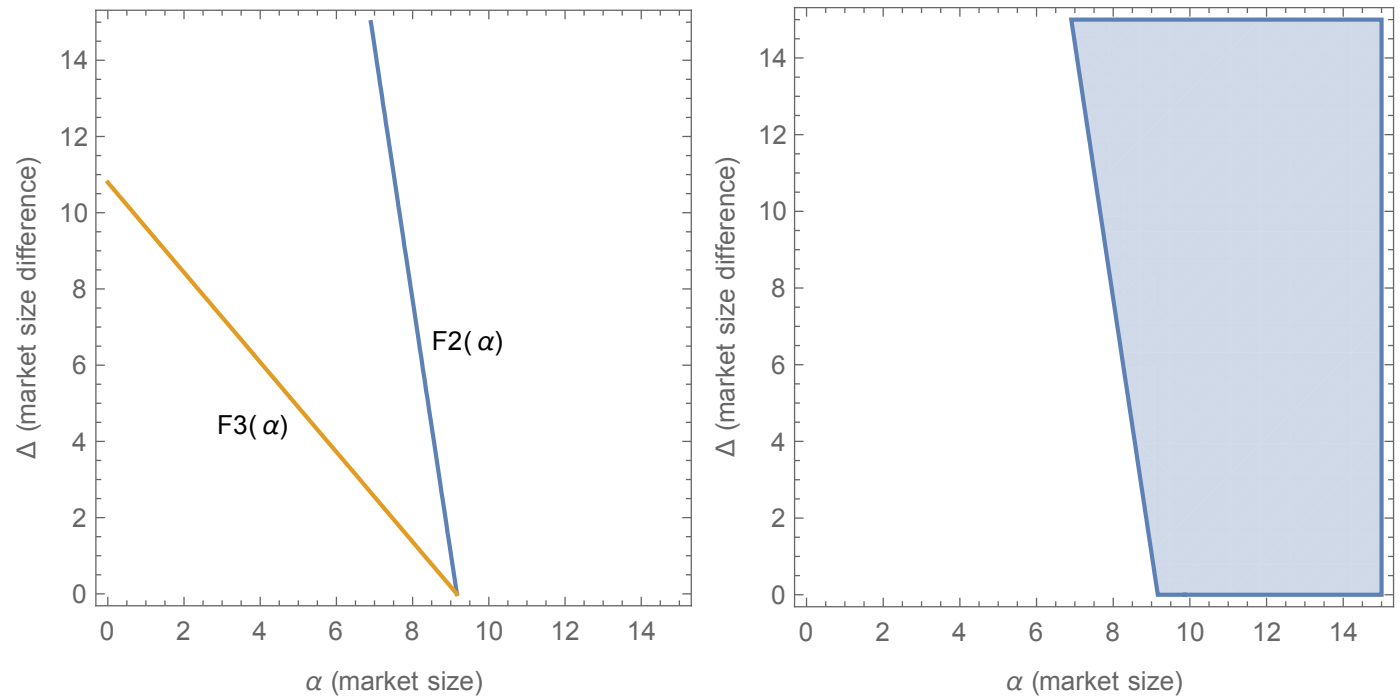

Figure 1.7 $F_{3}(\alpha)$ and $F_{2}(\alpha)$ (left) and the area in which subgame SS has an SPNE (right)

Proposition 8. There is no value for $\Delta$ such that $F_{3}(\alpha) \geq \Delta \geq F_{4}(\alpha)$, therefore the subgame in which the home country can establish a production subsidy, while the foreign country can set an emission tax, is never part of an SPNE.

Proof. From eq. (1.20) we see that if $\Delta \leq F_{3}(\alpha)$, then $S W_{F}^{S S}-S W_{F}^{S T} \leq 0$ and from eq. (1.24) we see that $S W_{H}^{T T}-S W_{H}^{S T} \leq 0$, therefore, $A \cap\left\{(\alpha, \Delta) / F_{3}(\alpha) \geq \Delta \geq\right.$ $\left.F_{4}(\alpha)\right\}=\varnothing$.

If $(\alpha, \Delta) \in A \cap\left\{(\alpha, \Delta) \in \Re_{+}^{2} / F_{3}(\alpha) \geq \Delta \geq F_{4}(\alpha)\right\}$, then $S W_{F}^{S T}-S W_{F}^{S S} \geq 0$ and $S W_{H}^{S T}-S W_{H}^{T T} \geq 0$, therefore the subgame in which the home country can establish a production subsidy, while the foreign country can set an emission tax, is never part of an SPNE.

Indeed, subsidies are not good policies for countries with small market sizes, and governments of countries with large market sizes are not likely to impose emission taxes on their firms. 

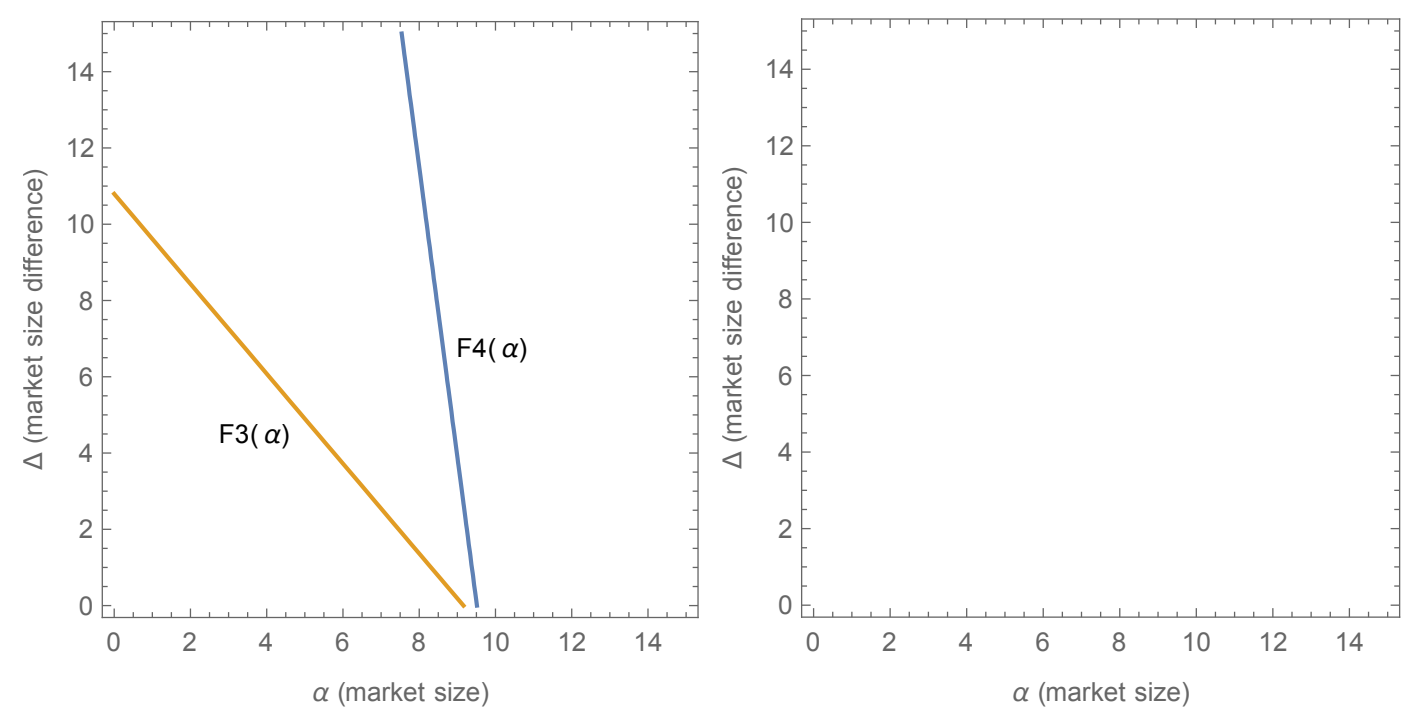

Figure 1.8 $F_{3}(\alpha)$ and $F_{4}(\alpha)$ (left) and the area in which subgame ST has an SPNE (right)

\section{B The symmetric case. Why large markets do not reg- ulate?}

Even if the efficiency of emissions taxes has been widely recognized, we must not forget the potential effect that the decisions of governments regarding their environmental policy have on the competitiveness of their industries, both in national and international markets. For this reason, in recent years an interest has been growing in the analysis of how environmental policy can be a tool to improve the competitiveness of firms. In this line, several studies have addressed the issue of global pollution in an international oligopolistic environment. The works of Barrett, 1994 and Ulph, 1996, like ours, assume in their analysis local emissions and identical countries. Both studies conclude that unilaterally implemented pollution taxes are generally not socially optimal. On the one hand, Barrett, 1994 shows that if firms compete in quantities $(\grave{a}$ la Cournot) and the domestic industry is a monopoly, governments have incentives to implement weak environmental standards. However, if the domestic industry is an oligopoly the incentive to weaken environmental regulation is reduced, inverted even in some cases. If firms compete in prices (à la Bertrand), governments have incentives to tighten their emissions control policy. On the other hand, Ulph, 1996, with a similar model, shows that if producers act strategically, the incentive of governments to relax their environmental policies is reduced. However, if governments act strategically when deciding on their environmental policy, the incentive of producers to act strategically increases, causing a decrease in social welfare. Finally, they demonstrate that the incentives of regulators and firms to act strategically are greater when the environmental policy is based on the use of taxes on emissions, concerning emission standards. 
In a more recent work, Poyago-Theotoky, 2007; Poyago-Theotoky, 2010 studies an oligopolistic industry in which firms invest in $R \& D$ activities to reduce emissions, generating a positive externality over other firms in the industry. In a country where the government uses emissions taxes as an instrument of environmental policy, it compares two regimes concerning firms' investment in environmental R\&D: independent and cooperative. In case of an investment in efficient R\&D (with positive externalities in other firms) and reduced levels of damage, the cooperation of firms in their investment in environmental R\&D generates a greater investment than in the case of doing so independently. While the cooperation generates less investment in R\&D in case of non-efficient R\&D and higher levels of damage.

The objective of this appendix is to analyze how the decisions made by governments on pollution taxes affect the competitiveness of their firms, thus modifying their incentives concerning the optimal environmental policy. For this, we consider an economy formed by two countries where the instrument of emission control used by both governments are taxes. In each country, there is a firm that produces both for the domestic market and for the international market, where each firm has the option of investing in R\&D activities that reduce emissions resulting from its production processes. As a result, we obtain that a larger market size makes it optimal for the regulators to relax their environmental policy, reducing the emissions taxes of the firms with the objective of improving their competitiveness in the markets. When the size of the markets is reduced, these incentives disappear and governments have incentives to raise firms' emissions taxes, thereby increasing incentives for investment in cleaner technologies.

The problem described above will be modeled as a multi-stage game: (1) governments unilaterally establish the levels of taxes that maximize the social welfare of each country; (2) firms decide whether to invest in R\&D and how much to invest in a non-cooperative way; and (3) each firm decides how much to produce for the domestic market and how much for the foreigner. Emissions are reduced by the firm's own $R \& D$ effort, that is, we do not consider externalities of other firms.

\section{B.1 The model}

We consider an economy composed of two countries $(H$ and $F)$. In each country, there is a single firm that produces two varieties of a good: one for the domestic market and another for the foreign market. In each of the markets the firms compete in quantities, with the inverse demand functions in each of the countries:

$$
\begin{aligned}
& p_{H}=\alpha_{H}-\left(q_{h H}+q_{f H}\right) \\
& p_{F}=\alpha_{F}-\left(q_{f F}+q_{h F}\right)
\end{aligned}
$$


where $p_{H}\left(p_{F}\right)$ denotes the final product price in country $H(F), \alpha_{H}\left(\alpha_{F}\right)$ is the market size of country $H(F), q_{h H}\left(q_{f F}\right)$ is the quantity produced by the firm located in country $H(F)$ for the domestic market and $q_{h F}\left(q_{f H}\right)$ the quantity that it sends to the foreign market. From equations (1) and (2) we see that the products of both firms are perfect substitutes within their respective market. The production of the firms generates polluting emissions to the atmosphere. For simplicity, we assume that the emissions are local and coincide with the total production of the firms in the country in which they are located. Besides, we assume that the damage caused by the emissions in each country coincides with the level of emissions of the firm that operates in it ${ }^{8}$ :

$$
\begin{gathered}
D_{H}=E_{H} \\
D_{F}=E_{F}
\end{gathered}
$$

where $D_{H}\left(D_{F}\right)$ denotes the negative externality generated by the productive activity of the firms in country $H(F)$ in which it produces. However, firms can invest in the development of cleaner production processes. Thus, we define the emissions in each of the countries as:

$$
\begin{aligned}
& E_{H}=q_{h H}+q_{h F}-I_{h} \\
& E_{F}=q_{f F}+q_{f H}-I_{f}
\end{aligned}
$$

where $I_{h}\left(I_{f}\right)$ is the investment of firms in the development of less polluting production processes. For simplicity, we assume that the investment of the firms directly translates into a proportional reduction of emissions.

Regarding the environmental policy applied by governments to control emissions, we assume that the governments of both countries use taxes as the main mechanism in their environmental policy. Thus, governments tax firms operating in their territory with a tax, $\tau$, on firms' emissions.

Decision-making by firms and governments is carried out sequentially in three stages ${ }^{9}$ :

- Stage i: Governments decide the tax rate on firms' emissions.

- Stage ii: Once the tax rate applied by governments is announced to the firms, they decide on their investment in the development of productive processes that allow reducing the pollutant emissions as a result of their productive activity in the country in which they operate.

\footnotetext{
${ }^{8}$ Thus we assume a linear damage function and therefore constant marginal damage. Duval and Hamilton, 2002 also assume constant marginal damage, allowing global damage to be expressed in terms of produced and consumed pollution actions in each country.

${ }^{9}$ In each of the stages we assume that both firms and governments decide simultaneously and independently.
} 
- Stage iii: Each firm chooses its production levels both for the domestic market and for the foreign market.

Next, we will solve each of the stages of the game following the method of backward induction to find the subgame perfect Nash equilibrium.

\section{B.2 Sub-game perfect Nash equilibrium}

In the last stage (Stage iii), firms are aware of both the tax rate applied by each government on the emissions of firms located in its territory and also the investment in emission reduction of each one of them. Thus, we can express the benefit of firms as:

$$
\begin{aligned}
& \Pi_{h}=p_{H} q_{h H}+\left(p_{F}-d\right) q_{h F}-\left(q_{h H}^{2}+q_{h F}^{2}\right)-\tau_{H} D_{H}-\frac{I_{h}^{2}}{2} \\
& \Pi_{f}=p_{F} q_{f F}+\left(p_{H}-d\right) q_{f H}-\left(q_{f F}^{2}+q_{f H}^{2}\right)-\tau_{F} D_{F}-\frac{I_{b}^{2}}{2}
\end{aligned}
$$

where $d$ is the transport cost that is applied to products intended for export (for simplicity we assume $\mathrm{d}=2), \tau_{H}\left(\tau_{F}\right)$ is the pollution tax applied by the government to the firm located in the country $H(F)$. From equations (3) and (4) we can see that firms' profits depend on revenues from sales in both markets (domestic and foreign) net of production costs, investment cost in emissions' reduction and taxes on emissions.

If we solve by finding the quantities produced for the domestic and foreign market that maximizes the benefit of the firms, the resulting first-order conditions are:

$$
\begin{aligned}
& q_{h H}=\frac{1}{15}\left(3 \alpha-4 \tau_{H}+\tau_{F}+2\right) \\
& q_{h F}=\frac{1}{15}\left(3 \alpha-4 \tau_{H}+\tau_{F}-8\right) \\
& q_{f F}=\frac{1}{15}\left(3 \alpha+\tau_{H}-4 \tau_{F}+2\right) \\
& q_{f H}=\frac{1}{15}\left(3 \alpha+\tau_{H}-4 \tau_{F}-8\right)
\end{aligned}
$$

From equations (5) - (8) we see that the total production in each of the countries increases with the size of the market. However, the output of each of the firms depends negatively on the tax rate of the country in which they are located, while benefiting from an increase in the tax rate of the foreign country. With this, we can conclude that the competitiveness of firms is negatively affected by the harsh environmental policy of the country in which they are located and positively by a tightening of the tax rate in the foreign country.

Substituting the firms' optimal production values into profit equations (3) and (4), in Stage ii firms decide on the level of investment in emissions' reduction that maximizes their benefit:

$$
I_{h}=\tau_{H}
$$




$$
I_{f}=\tau_{F}
$$

From equations (9) and (10) it follows that firms will invest in the reduction of emissions an amount equal to the tax rate applied in the country in which they produce. Thus, we see that an increase in the tax rate is an incentive for firms to invest in a reduction of emissions.

Finally, in Stage i, the government of each country decides the tax rate on emissions that will maximize the country's social welfare. The social welfare of each country is expressed as the sum of consumer surplus, firms' profits, government revenue through taxes, minus pollution damages:

$$
\begin{gathered}
S W_{H}=C S_{H}+\Pi_{h}+G R_{H}-D_{H} \\
S W_{F}=C S_{F}+\Pi_{f}+G R_{F}-D_{F}
\end{gathered}
$$

where $C S_{H}=\frac{\left(q_{h H}+q_{f H}\right)^{2}}{2}\left(C S_{H}=\frac{\left(q_{f F}+q_{h F}\right)^{2}}{2}\right)$ is the consumer surplus in country $H$ $(F)$ and $G R_{H}=\tau_{H}\left(q_{h H}+q_{h F}-I_{h}\right)>0\left(G R_{F}=\tau_{F}\left(q_{f F}+q_{f H}-I_{f}\right)>0\right)$ are the revenues of the government in country $H(F)$ from the emissions taxes of the firm located in the country.

\section{B.3 Results}

From the social welfare's maximization, we obtain that the best response function of each one of the governments to the decision of the other country on the tax rate that taxes the polluting emissions is:

$$
\begin{gathered}
\tau_{H}=\frac{1}{328}\left(-24 \alpha+7 \tau_{F}+369\right) \\
\tau_{F}=\frac{1}{328}\left(-24 \alpha+7 \tau_{H}+369\right)
\end{gathered}
$$

The best response function of each of the governments described by equations (11) and (12) shows that the level of taxes on emissions in each country are strategic complements. Therefore, the greater the tax rate of the foreign country, the greater the incentive of the government to increase the tax on the pollutant emissions imposed on the firms that operate in them.

However, the incentives to raise the tax rate on emissions decrease with the size of the market. We can even think that for sufficiently large market sizes, governments have incentives to eliminate the taxes on emissions imposed on the productive activity of their firms.

Substituting in equations (11) or (12) $\tau_{H}=\tau_{F}=0$ we find the maximum market size for which countries have incentives to apply an emission control policy through a tax: 
Result 1a If the market size is small enough $(\alpha<15,375)$, governments have incentives to set a tax on the emissions of firms located in their territory, thus encouraging the investment of firms in REDD activities that reduce the emissions of the industry.

Result $\mathbf{1 b}$ If the market size is large enough $(\alpha>15,375)$, governments have incentives to encourage the competitiveness of their firms by eliminating the tax on emissions generated by the productive activity of the industry.

By way of illustration, we next compare two markets: one of them small enough for emissions control to optimize social welfare $(\alpha=8)$ and another large enough to make it socially optimal to eliminate regulation of firms' emissions $(\alpha=24)$. Table 1 shows the main magnitudes in each of the markets ${ }^{10}$ :

\begin{tabular}{lcc} 
& Small market size & Large market size \\
\hline Market size $\left(\alpha_{H}\right)$ & 8 & 24 \\
Tax on emissions $\left(\tau_{H}\right)$ & 0.55 & 0 \\
Investment on R\&D $\left(I_{h}\right)$ & 0.55 & 0 \\
Domestic production $\left(q_{h H}\right)$ & 1.62 & 4.93 \\
Exports $\left(q_{h F}\right)$ & 0.96 & 4.26 \\
Emissions $\left(E_{H}\right)=$ Damage $\left(D_{H}\right)$ & 2.03 & 9.20 \\
Firm's profit $\left(\Pi_{h}\right)$ & 7.25 & 85.03 \\
Consumer surplus $\left(C S_{H}\right)$ & 3.33 & 42.23 \\
Government revenue $\left(G R_{H}\right)$ & 1.12 & 0 \\
Social welfare $\left(S W_{H}\right)$ & 9.67 & 118.06 \\
\hline
\end{tabular}

Table 1.6 Comparative statics for small and large markets

Comparing both markets, we see that an increase in the market size gives incentives to the government to relax the environmental policy, eliminating the emission tax of the home firm. This causes an increase in emissions and the environmental damage associated with them, thereby reducing social welfare. However, this reduction in social welfare caused by an increase in emissions (whose externality is not internalized by the production firm in a large market), is compensated by a considerable increase in the production of the firm, both for the domestic and for the foreign market, as well as an increase in the prices. All of this implies that both the firms' profits and the consumers' surplus of the country are multiplied by ten, offsetting the decrease in government income from the elimination of the emissions tax, as well as the value of the environmental damage caused.

\section{B.4 Conclusions}

In this appendix, we have discussed the interaction between the environmental policy of emission control of productive activity and the competitiveness of firms located in

\footnotetext{
${ }^{10}$ Since the countries are symmetrical in the example we will refer only to one of them, country $H$.
} 
a country. In a model where we consider a local impact of the emissions generated by the production of the firms, we analyze a scenario in which both the firms and the government act strategically when they make decisions about production and investment in environmental R\&D, and environmental policy, respectively. For simplicity, we assume the existence of only two countries where the regulators compete in the level of taxes on the emissions that they apply to the firms that produce (and emit) in their territory, whereas the firms compete directly, in the domestic market as in abroad.

Despite using a simple model, the conclusions we get help us understand the environmental policy and its interaction with the industrial policy of the countries. In markets small enough, governments have incentives to reduce the negative externality generated by the productive activity of their firms through a tax levied on the emissions of firms located therein. In turn, this encourages the investment of firms in environmental $\mathrm{R} \& \mathrm{D}$, with a consequent decrease in emissions in the country.

However, in countries with relatively large markets, the situation is completely different. In this case, governments (social welfare maximizers) may have incentives to sacrifice environmental policy to reduce emissions to make their firms more competitive in markets. We must take into account that we are in a situation in which the environmental policy of two countries, in whose markets compete the same firms, become strategic complements. That is, if a foreign country relaxes its environmental policy, to maintain the competitiveness of its firms (both domestically and abroad), the government has incentives to relax the pressure of its environmental policy in response. The direct consequence is a considerable increase in emissions and the elimination of incentives for firms to invest in environmental R\&D. However, social welfare is overcompensated by an increase in the profits of firms.

The results of this study can be used as a reflection of the consequences of the globalization of the markets on the environmental policy of the countries. 


\section{Chapter 2}

\section{Timing and commitment in environmental policy to trigger technology adoption}

Emission permit trading schemes are increasingly being employed as a powerful market-based environmental policy instrument to curb emissions in a cost-effective way. The ex-ante dynamic efficiency that tradable permit markets create for the adoption of advanced abatement technologies has been extensively studied. Our study aims to fill this gap by providing experimental evidence on such investment behavior, providing some empirical insights into the ex-post dynamic efficiency of a system of both emission taxes and tradable emission permits.

Technological innovation is important for pursuing sustainability in many pollution control problems. Since Kneese and Schultze, 1975, a great deal of both theoretical and empirical literature has tried to rank different policy instruments on both technological change and the adoption of new technologies (see, e.g., Requate, 2005a). Coria, 2009 explores how the choice between taxes and permits affects the pattern of adoption of a cleaner technology.

The allocation mechanism is also a fundamental issue for the design, implementation, and (dynamic) efficiency of markets. The European Union Emissions Trading System (EU ETS) is transitioning from mostly grandfathered to mostly auctioned permits. Montero, 2002 finds that grandfathering and auctioning generate the same $\mathrm{R} \& \mathrm{D}$ incentives when both permit and output markets are competitive. Botelho et al., 2011 provide experimental evidence that abatement costs are similar under a full auctioning and full grandfathering allocation mechanisms; moreover, auctioning allocates permits more accurately.

In this chapter, we have conducted a series of economic experiments to study investment in low-pollution technology when firms are regulated by emission taxes and permits, and compare the results with the theoretical predictions in Requate, 2005b. In particular, we investigate the impact of timing of the regulator's commitment on the firms' behavior concerning the adoption of advanced abatement technologies, i.e., we want to study the effects of setting the optimal policy level before or after the firms' investment decision. In the ex-ante treatments, the regulator sets the number of permits being issued (tax rate) before the investment decision. On the contrary, in the 
ex-post treatments, after observing the number of firms that have adopted the new technology, the regulator responds optimally by adjusting its quantity of permits (tax rate).

Our results suggest that timing has (no) significant effect on the pattern of technology adoption when firms are initially endowed with a dirtier (cleaner) technology. Firms' overall performance concerning investment is remarkably good; however, like in Gangadharan et al., 2013, we observe that some firms with dirtier technologies under-invest and some firms with cleaner technologies over-invest. Moreover, we find similar results for taxes and permits, i.e., observed tax rate (permit prices) are significantly higher than the expected ones in the ex-ante treatment. Likewise, observed emissions (permit holding) are lower than the expected ones in the four treatments, and they are significantly higher in the ex-ante treatments.

Our experiment is close to that of Camacho-Cuena et al., 2012, in which the regulator makes the first move by committing herself to a number of permits, and firms move second by deciding whether or not to adopt the new technology. In our case, timing is just reversed, therefore firms move first by choosing whether or not to adopt the new technology, and, after observing that, the regulator responds optimally by adjusting its quantity of permits.

The chapter is organized as follows. The next section reviews the related literature. Section 3 presents the main hypotheses we want to evaluate with our laboratory experiments. Section 4 contains a description of the experimental design and procedure. Section 5 presents the results. Finally, Section 6 concludes.

\subsection{Related experimental literature}

Regarding the experimental literature, Ben-David et al., 1999 consider an emission permit market in which the firms' investment decision is irreversible. Their study finds that trade volume is not affected by an increase in cost heterogeneity, although higher price variability leads to lower efficiency from trade.

Cochard et al., 2005 consider technology adoption incentives using emission taxes, and assume that emissions affect only the polluters themselves, but not other nonpolluting agents. They show that an ambient tax does not generate any social dilemma, since the group optimum is a Nash equilibrium, resulting as a very efficient and reliable mechanism that improves welfare concerning the status quo.

More recently, Camacho-Cuena et al., 2012 also study the incentives to adopt advanced abatement technologies under emissions trading. They find that the observed investment patterns are relatively close to the theoretical first-best allocation, and the initial technology mainly determines the individual investment decision. Moreover, 
they conclude that auctioning and grandfathering are equivalent to dynamic efficiency. Gangadharan et al., 2013 also focus on an industry with asymmetric firms that differ concerning maximum emissions. As in our work, the effect of investment in cleaner technology is asymmetric (dirty firms gain more by investing). Taschini et al., 2014 in a laboratory setting, explore the timing of irreversible adoption decisions of abatement technology under a grandfathering allocation rule. Their findings show that firms tend to invest in abatement technology faster when a strict enforcement mechanism is applied. Cason and Vries, 2018 study the performance of permit markets on dynamic efficiency, with permits being auctioned or grandfathered. Their results show that auctioning permits usually provides stronger R\&D incentives, leading to greater dynamic efficiency.

\subsection{The model}

This section presents the theoretical model that serves as a basis for our experimental design. As mentioned above, our study draws on the model of Requate, 2005b, who establishes the dynamic (ex-ante and ex-post) optimality of emission permits.

Consider an industry with $n$ polluting firms and $T$ different initial technologies, each firm $i=1, \ldots, n$ is endowed with one of these initial technologies. In the absence of regulation firm $i$ pollutes $e_{i}^{\max }>0$. However, firm $i$ can abate emissions by using its conventional technology, or by adopting a new technology $a$ at a fixed cost $I>0$, the same for all firms. ${ }^{1}$ The firms' technologies are represented by their abatement cost functions $c_{i}^{k}\left(e_{i}\right)$ with $k=1, \ldots, T, a$. For any targeted emission level $e$ we assume $c_{i}^{k}(e)>0$ for $e<e_{i}^{\max }$. Adopting the new technology leads to lower marginal abatement costs, i.e. $-c_{i}^{T}\left(e_{i}\right)>-c_{i}^{a}\left(e_{i}\right)$ for all $e \leq e_{i}^{\max }$, where $-c_{i}^{k}\left(e_{i}\right) \equiv-\partial c_{i}^{k}\left(e_{i}\right) / \partial e$ is the marginal abatement cost.

A regulator is interested in reducing the industry's aggregate emissions at a level of $E^{*}$. When setting the optimal number of permits being issued $S>0$ (or the optimal emission $\operatorname{tax} \tau>0$ ), the regulator uses an increasing and convex social damage function, $D(E)$; where $E=\sum_{i=1}^{n} e_{i}$ indicates aggregate emissions. We assume that firms have to hold a permit in order to be legally able to emit a unit.

A social planner minimizes total social costs concerning emissions and the number of firms. When the fixed investment cost is independent of the initial technology, and if not all firms are supposed to adopt in equilibrium the advanced technology, it is always optimal for at least those firms with the highest abatement costs to invest, i.e. there will be some index $j$ such that the firms $i=1, \ldots, j$ will invest.

\footnotetext{
${ }^{1}$ We follow the asymmetric model of Requate and Unold, 2001 by allocating different initial technologies to the firms, whereas the new technology is the same for all firms.
} 
Using $A M A C^{*}(E, j)$ to denote the optimal aggregate marginal abatement cost when the first $j$ firms have adopted the advanced abatement technology, the regulator will choose the optimal aggregate emission level $E^{*}$, satisfying:

$$
D^{\prime}\left(E^{*}\right)=A M A C^{*}\left(E^{*}, j\right)
$$

A risk-neutral firm $i$ solves the following optimization problem when an emission tax is applied:

$$
\min _{c_{i}^{T}, c_{i}^{a}}\left\{\begin{array}{l}
\min _{e_{i}, r_{i}} c_{i}^{T}\left(e_{i}\right)+\tau e_{i} ; \\
\min _{e_{i}, r_{i}} c_{i}^{a}\left(e_{i}\right)+\tau e_{i}+I
\end{array}\right\},
$$

And the following when an emission permit is applied:

$$
\min _{c_{i}^{T}, c_{i}^{a}}\left\{\begin{array}{l}
\min _{e_{i}, r_{i}} c_{i}^{T}\left(e_{i}\right)+p\left[\bar{s}_{i}\right] ; \\
\min _{e_{i}, r_{i}} c_{i}^{a}\left(e_{i}\right)+p\left[\bar{s}_{i}\right]+I
\end{array}\right\},
$$

where $p$ is the uniform price resulting from the auction and $\overline{s_{i}}$ is the number of permits held (purchased in the auction).

After solving the Lagrangian problem, the optimal policy level is given by:

$$
\tau=p=D^{\prime}\left(E^{*}\right)
$$

In line with the underlying theoretical model, the hypothesis to be tested in this chapter is:

Hypothesis 1: The timing of the regulator's commitment to a given emission control policy (ex-ante vs. ex-post) does not affect the firms' behavior.

\subsection{Experimental design and procedure}

We conducted the experiments at the experimental laboratory of the University of Kiel using the oTree experimental software (Chen et al., 2016). Subjects were volunteer undergraduate students. Earnings during the experiments were designated in Experimental Currency Units (ECUs) and converted into Euro at the end of the session. 


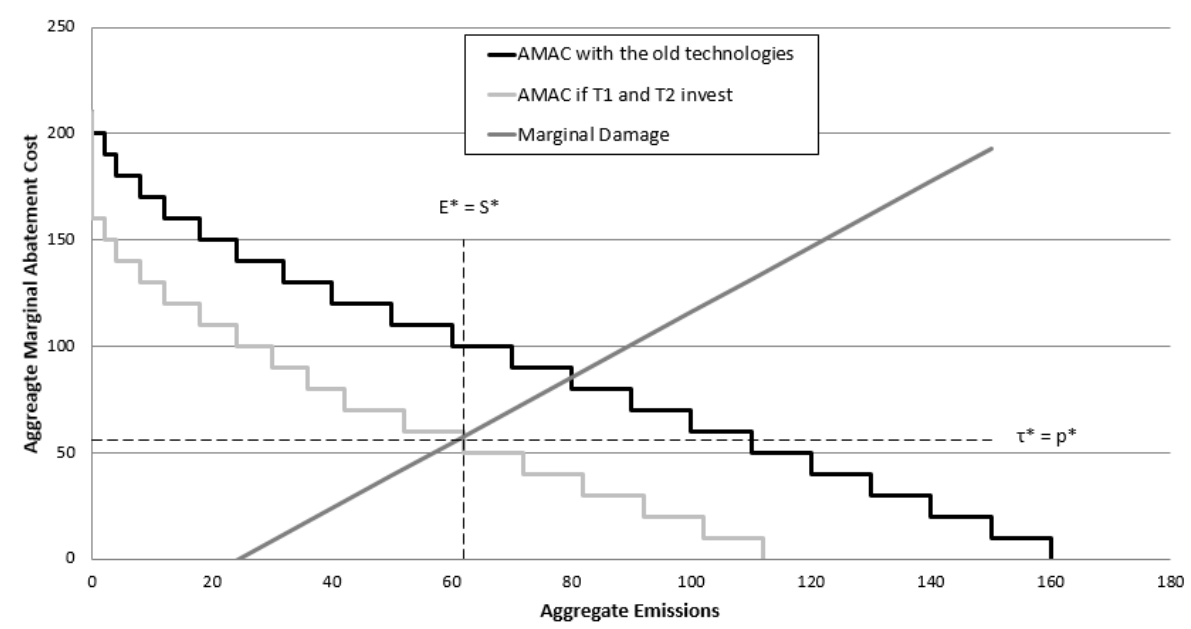

Figure 2.1 Socially optimal instrument level, tax and emission permits

In the following sections, we describe the treatments and the experimental procedure implemented.

\subsubsection{Parameters}

We consider an industry populated by 10 firms producing with one of the 5 conventional technologies available $T_{1}, \ldots, T_{5}$ (there are 2 firms endowed with each technology); being each technology characterized by the default emissions, thus technology $T_{1}$ (technology $T_{5}$ ) implies the highest (lowest) maximum default emissions chosen in the absence of regulation. The firms' technologies are represented by stepwise, downward sloping marginal abatement cost functions depicted in Table 2.1. Firms obtain a default profit of 1200 ECU from their production activity and can invest, by paying a fixed amount of $580 \mathrm{ECU}$, in adopting advanced technology $a$ that is the same for all firms. The adoption of advanced technology leads to lower default emissions and, therefore, lower marginal abatement cost. $^{2}$

With these parameters, only the firms with technologies $T_{1}$ and $T_{2}$ (4 firms) have incentives to invest in the new technology.

\footnotetext{
${ }^{2}$ The hypothetical damage function is $D(E)=0.77 E^{2}-38.1 E$ (as illustrated in Fig. 2.1).
} 


\begin{tabular}{ccccccc}
\hline \multicolumn{6}{c}{ Emissions per technology type } & MAC \\
\hline$T_{1}$ & $T_{2}$ & $T_{3}$ & $T_{4}$ & $T_{5}$ & $a$ & \\
\hline 20 & 18 & 16 & 14 & 12 & 7 & 0 \\
19 & 17 & 15 & 13 & 11 & 6 & 10 \\
18 & 16 & 14 & 12 & 10 & 5 & 20 \\
17 & 15 & 13 & 11 & 9 & 4 & 30 \\
16 & 14 & 12 & 10 & 8 & 3 & 40 \\
15 & 13 & 11 & 9 & 7 & 2 & 50 \\
14 & 12 & 10 & 8 & 6 & 1 & 60 \\
13 & 11 & 9 & 7 & 5 & 0 & 70 \\
12 & 10 & 8 & 6 & 4 & & 80 \\
11 & 9 & 7 & 5 & 3 & & 90 \\
10 & 8 & 6 & 4 & 2 & & 100 \\
9 & 7 & 5 & 3 & 1 & & 110 \\
8 & 6 & 4 & 2 & 0 & & 120 \\
7 & 5 & 3 & 1 & & & 130 \\
6 & 4 & 2 & 0 & & & 140 \\
5 & 3 & 1 & & & & 150 \\
4 & 2 & 0 & & & & 160 \\
3 & 1 & & & & & 170 \\
2 & 0 & & & & & 190 \\
1 & & & & & & 200 \\
0 & & & & &
\end{tabular}

Table 2.1 Marginal Abatement Cost (MAC) per technology type. $T_{1}, \ldots, T_{5}$ denote the initial technologies, while $a$ denotes the advanced abatement technology

Table 2.2 shows the experimental treatments and parameters implemented. We conducted 4 sessions of the 4 different treatments varying the policy instrument (taxes vs. permits) and the timing of the regulator's commitment concerning the type and level of emissions control instrument (ex-ante vs. ex-post): AT, PT, AP, PP.

\begin{tabular}{ccccc}
\hline Treatment & Timing & Policy & $\tau$ & $N$ \\
\hline AT & ex-ante & tax & 56 & - \\
PT & ex-post & tax & $f(I)$ & - \\
AP & ex-ante & permit & - & 62 \\
PP & ex-post & permit & - & $f(I)$ \\
\hline
\end{tabular}

Table 2.2 Experimental treatments and parameters

Regarding policy instrument, in treatments $\mathrm{AT}$ and $\mathrm{PT}$, firms are regulated by an emission tax; while in treatments $\mathrm{AP}$ and $\mathrm{PP}$ firms are regulated by an emission permits mechanism.

Regarding timing, in treatments $\mathrm{AT}$ and $\mathrm{AP}$, the regulator sets the number of permits (the tax rate) ex-ante, that is, before firms make any decision; while in treatments $\mathrm{PT}$ and PP, the regulator commits to a given policy instrument but responds optimally by adjusting its quantity of permits (tax rate) ex-post, that is, 
after observing the investment pattern, i.e., the number of firms that have adopted the new technology.

\subsubsection{Experimental procedure}

We conducted 4 sessions for each treatment. A group of 10 subjects participated in each session, mimicking firms operating in an industry subject to environmental regulation. ${ }^{3}$ Upon arrival at the laboratory, we randomly assigned subjects to one of the computer terminals. We distributed instructions and answered subjects questions before they participated in a trial period. ${ }^{4}$ In each session, subjects played 15 periods of a given treatment.

In the ex-ante treatments, each period consisted of the following stages:

Stage 1: Optimal policy level The regulator sets the optimal policy level. In the AT treatment, the optimal tax rate is $\tau=56$, while in the AP treatment, the total number of auctioned permits is fixed to $S=62$. This information is known to the subjects during the experiment.

Stage 2: Technology assignment and investment decision Each subject is randomly assigned an initial technology $k=T_{1}, \ldots, T_{5}$. Two subjects will operate with the same technology. This initial distribution of technologies is common knowledge to the subjects. In this stage subjects simultaneously decide whether to keep the initial technology or to adopt the new technology $a$, paying the corresponding cost of 580 ECU. ${ }^{5}$

When the policy instrument is emission permits, there is an additional stage:

Stage $2 *$ : Permit auctioning Permits are costly allocated among firms using an ascending clock auction. In this process, the opening price is 5 ECU. Subjects then have three minutes to submit their permit demand at the current price. If aggregate permit demand exceeds the permit supply set by the regulator (62 permits), the price is increased by $10 \mathrm{ECU}$ (so that the next price is $15 \mathrm{ECU}$, then $25 \mathrm{ECU}$, and so on). The auction then proceeds until the firms' aggregate demand is smaller or equal to the permit supply. If this is the case, the auction closes, and each subject is allocated the quantity demanded at this last price.

Stage 3: Abatement decision Subjects should decide how many units they want to reduce their emissions (paying the corresponding total abatement cost, see Table 2.1), knowing that for the emitted units they will pay the corresponding tax

\footnotetext{
${ }^{3}$ Each subject participated only in one session.

${ }^{4}$ This trial period was identical to the real periods (i.e., including both investment and abatement decisions) except that we did not consider it for the final payoff.

${ }^{5}$ In case of ex-post treatments, the regulator determines the optimal policy level (stage 1) after observing the investment pattern (stage 2).
} 
rate or should hold the corresponding number of emission permits.

According to the above settings, the profit of firm $i$ in period $t$ is as following if an emission tax is applied:

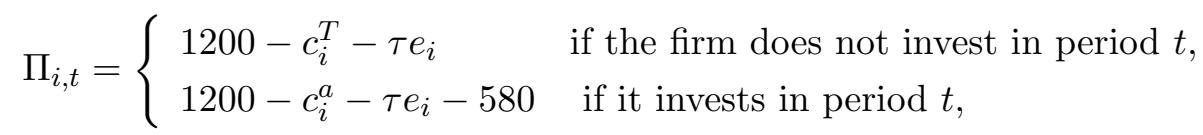

where $c_{i}^{T}\left(c_{i}^{a}\right)$ is the abatement cost function given the conventional (new) technology used by the firm.

Under an emission permit mechanism the profit function is:

$$
\Pi_{i, t}=\left\{\begin{array}{l}
1200-c_{i}^{T}-p s_{i} \quad \text { if the firm does not invest in period } t \\
1200-c_{i}^{a}-p s_{i}-580 \quad \text { if it invests in period } t
\end{array}\right.
$$

where $p$ is the uniform price resulting from the auction, while $\bar{s}_{i}$ is the number of permits allocated to firm $i$ in the auction.

The subjects' final payoff was obtained by computing the average of the profit obtained in two randomly chosen periods at the end of the session. Each session lasted approximately 90 minutes, and the average payoff was around $€ 14$.

\subsection{Results}

We are particularly interested in testing whether timing provides significant differences in the performance of the different policy instruments; therefore, in this section, we will compare the results on technology adoption, emissions, taxes, permit price and permit holding if the optimal policy level is set ex-ante or ex-post the firms' investment decision.

\subsubsection{Technology adoption}

Recall that, in equilibrium, we expect 4 out of the 10 firms in the industry to adopt the new technology $a$. In particular, given the parameters used in our experimental design, only those firms initially endowed with technologies $T_{1}$ and $T_{2}$ have incentives to adopt the new technology.

Figure 2.2 shows the distribution of firms' adopting the new technology as a function of the initial technology assigned. A general feature common to all implemented treatments is that most of the firms using initially technologies $T_{1}$ and $T_{2}$ adopt the new technology, and this proportion decreases as we move to technologies $T_{3}, T_{4}$ and $T_{5}$, i.e., those with initially lower maximum emissions. 


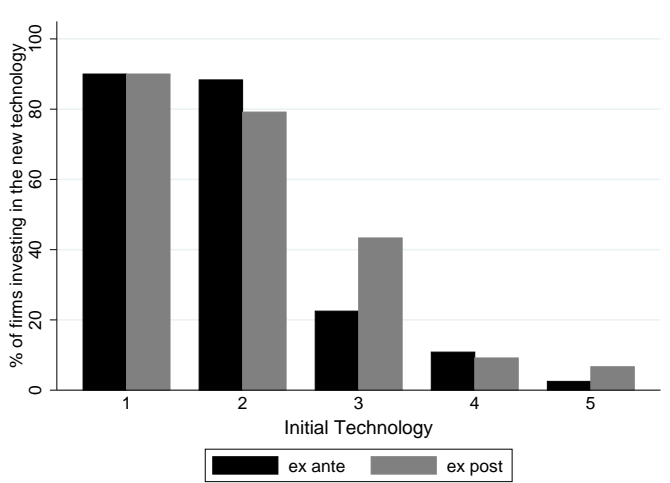

(a) Taxes

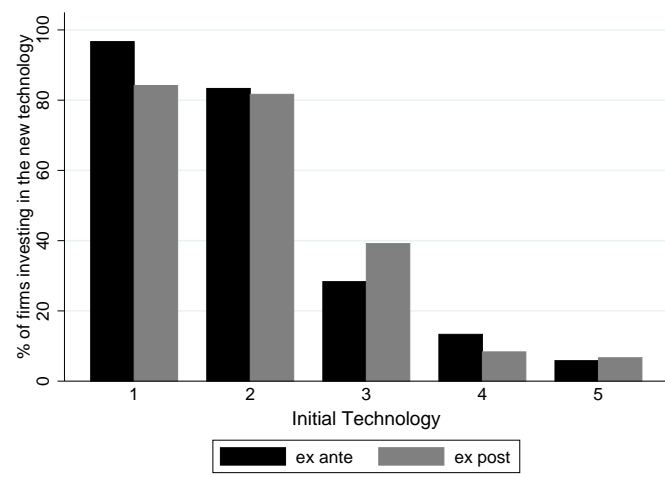

(b) Permits

Figure 2.2 Percentage of firms investing in technology $a$ per initial Technology $k=$ $T_{1}, \ldots, T_{5}$

Using a Wilcoxon signed-rank test, we check that the percentage of firms adopting the new technology when initially endowed with technologies $T_{1}$ and $T_{2}\left(T_{3}, T_{4}\right.$ and $\left.T_{5}\right)$ is statistically different from a $100 \%(0 \%)$ adoption rate expected in equilibrium.

We observe that the timing in the regulator's commitment has a significant effect on the firms' adoption of the new technology depending on the policy instrument and the initial technology. Relying on the $\chi^{2}$ test, the observed differences are significant for technologies $T_{2}$ and $T_{3}$ under the tax treatments (AT vs. PT), and for technologies $T_{1}$ and $T_{3}$ under the emission permit treatments (AP vs. PP).

Result 1. The timing in the regulator's commitment to the type and level of an emission control instrument has a significant effect on the investment decision of those firms endowed with technology $T_{3}$, that is, the first with no incentives to adopt the new technology in equilibrium.

Note that when the regulator decides the level of the instrument after observing firms' investment decisions, those firms operating with technology $T_{3}$ are more likely to invest in the new technology, independently on the emission control instrument applied.

To better understand the factors influencing investment behavior in the different treatments, we estimated a pooled Probit model with robust standard errors clustered across sessions. We study the impact of the initial technology on the probability to invest. Since firms endowed with dirtier technologies gain more from adopting the new technology, we expect the firms' investment probability to decrease when initially being endowed with cleaner technology. More precisely, we expect discrete jumps in adoption when moving across technologies (particularly between $T_{2}$ and $T_{3}$ denoting 
the borderline between adoption and non-adoption in social optimum). The results reported in Table 2.3 confirm our hypothesis for all implemented treatments. ${ }^{6}$

\begin{tabular}{lcccc}
\hline Treatment & $\mathrm{AT}$ & $\mathrm{PT}$ & $\mathrm{AP}$ & $\mathrm{PP}$ \\
\hline Technology $T_{2}$ & -0.083 & $-0.454^{* * *}$ & $-0.882^{* *}$ & -0.169 \\
& $(0.124)$ & $(0.114)$ & $(0.360)$ & $(0.159)$ \\
Technology $T_{3}$ & $-2.039^{* * *}$ & $-1.460^{* * *}$ & $-2.395^{* * *}$ & $-1.303^{* * *}$ \\
& $(0.279)$ & $(0.202)$ & $(0.240)$ & $(0.258)$ \\
Technology $T_{4}$ & $-2.535^{* * *}$ & $-2.573^{* * *}$ & $-2.953^{* * *}$ & $-2.388^{* * *}$ \\
& $(0.189)$ & $(0.542)$ & $(0.346)$ & $(0.229)$ \\
Technology $T_{5}$ & $-3.264^{* * *}$ & $-2.728^{* * *}$ & $-3.337^{* * *}$ & $-2.565^{* * *}$ \\
& $(0.271)$ & $(0.565)$ & $(0.480)$ & $(0.399)$ \\
Tax t-1 & - & 0.016 & - & - \\
Price t-1 & & $(0.011)$ & & \\
Period & & - & 0.000 & $0.013^{* * *}$ \\
& -0.025 & -0.029 & -0.001 & -0.006 \\
Cons & $(0.016)$ & $(0.025)$ & $(0.022)$ & $(0.024)$ \\
& $1.559^{* * *}$ & $0.726^{* * *}$ & $1.820^{* * *}$ & $0.408^{* * *}$ \\
Pseudo- $R^{2}$ & $(0.064)$ & $(0.167)$ & $(0.425)$ & $(0.129)$ \\
$\mathrm{N}$ & 0.511 & 0.392 & 0.470 & 0.383 \\
\hline
\end{tabular}

Table 2.3 Probit estimation (with clustered standard errors across sessions) of investment per treatment using Technology $T_{1}$ as baseline (std. err. are given in parentheses). The dependent variable: new technology adoption in period $t$ by firm $i .{ }^{* * *},{ }^{* *}$, and ${ }^{*}$ denote significance at the $1 \%, 5 \%$, and $10 \%$, respectively

\subsubsection{Emission taxes}

A relevant aspect is whether emission tax rates reflect the firms adoption pattern. Note that in order to evaluate the observed tax rates, we cannot use the theoretically optimal equilibrium tax rates as a benchmark, since that tax results from the theoretically optimal investment pattern (if only firms of type $T_{1}$ and $T_{2}$ invest in the new technology, we expect an equilibrium tax rate of 56 ECU - see Fig. 2.1) and we have already seen that firms do not behave optimally concerning technology adoption. Therefore, we should calculate the theoretical equilibrium tax rates given the observed investment pattern.

Table 2.4 shows the observed average tax rates and emissions in the first two columns and the efficient (expected) tax rates and emissions in the last two columns.

\footnotetext{
${ }^{6}$ Using a t-test to compare the coefficients for every technology, we find that they are statistically different from each other at any level between $T_{2}$ and $T_{3}$ for the tax treatments (AT vs. PT), and between $T_{3}$ and $T_{5}$ for the permit treatments (AP vs. PP).
} 


\begin{tabular}{ccccc}
\hline Treatment & \multicolumn{2}{c}{ Observed } & \multicolumn{2}{c}{ Expected } \\
\hline & Tax & Emitted units & Tax & Emitted units \\
\hline AT & 56 & 60.42 & 55.28 & 60.60 \\
& $(-)$ & $(9.66)$ & $(4.45)$ & $(3.09)$ \\
PT & 53.72 & 58.86 & 54.27 & 60.08 \\
& $(8.48)$ & $(6.72)$ & $(7.52)$ & $(4.91)$ \\
\hline
\end{tabular}

Table 2.4 Mean observed and expected tax rates and aggregate emissions across sessions and periods within a given treatment (SD are given within parenthesis)

Figure 2.3 displays the mean tax rates across all 15 periods and pooled across all 4 sessions.
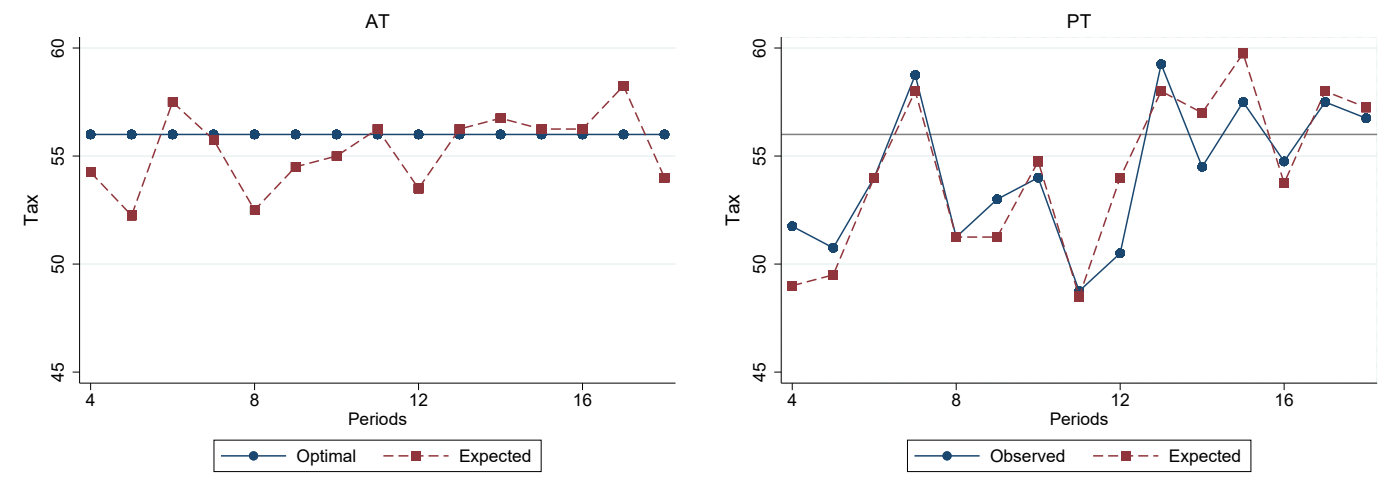

Figure 2.3 Average observed and expected tax rate under the two different treatments pooling all sessions together

Regarding tax rates, in the ex-ante treatment, the observed taxes are higher than the expected taxes given the observed investment patterns resulting from the first phase of each period.

Figure 2.4 displays the mean emitted units across all 15 periods and pooled across all 4 sessions.
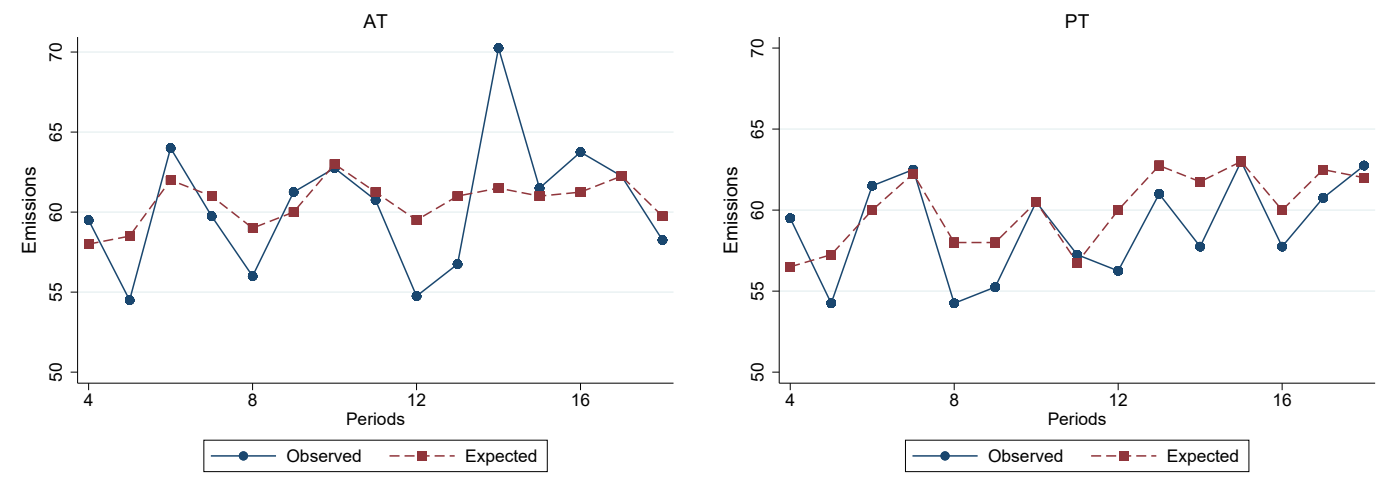

Figure 2.4 Average observed and expected emissions under the two different treatments pooling all sessions together 
Regarding emissions, observed ones are significantly lower than the expected ones for both treatments. Moreover, in AT treatment observed emissions are significantly higher than in PT treatment. Based on nonparametric Wilcoxon and Mann-Whitney tests we can state the following result:

\section{Result 2.}

(i) In the ex-ante treatment observed tax rates are significantly higher than expected tax rates, while observed emissions are (marginally) significantly lower than the expected ones.

(ii) In the ex-post treatment observed and expected tax rates are not significantly different from each other. While observed emissions are significantly lower than the expected ones.

(iii) Comparing ex-ante and ex-post, first, we observe that observed and expected tax rates in ex-ante treatment are significantly higher than in the ex-post treatment. Second, regarding observed and expected emissions, in the ex-ante treatment, they are (marginally) significantly higher than in the ex-post treatment.

\subsubsection{Emission permits}

In this section, we study the different treatments according to permit prices and holding. A relevant aspect is the performance of the emission permit market since the emission permit price is endogenously determined in the auction; the performance of the emission permit market could influence the firms' decisions concerning investment. As in the previous section, in order to evaluate the observed permit prices and volumes, we cannot use the theoretically optimal equilibrium price and volumes as a benchmark, since that price results from the theoretically optimal investment pattern (if only firms of type $T_{1}$ and $T_{2}$ invest in the new technology, we expect that 62 permits are auctioned off at an equilibrium permit price equal to 56 ECU - see Fig. 2.1) and we have already seen that firms do not behave optimally concerning technology adoption. Therefore, we should calculate the theoretical equilibrium prices, and permit holding given the observed investment pattern.

Table 2.5 shows the observed average prices and volumes in the first two columns and the efficient (expected) prices and volumes given the firms' investment decision that is, the technology used by the firms after the investment decision has been made - in the last two columns. 


\begin{tabular}{ccccc}
\hline Treatment & \multicolumn{2}{c}{ Observed } & \multicolumn{2}{c}{ Expected } \\
\hline & Price & Volume & Price & Volume \\
\hline AP & 51.67 & 58.03 & 48.97 & 62 \\
& $(10.76)$ & $(3.06)$ & $(8.17)$ & $(-)$ \\
PP & 53.67 & 55.35 & 55.63 & 61.05 \\
& $(10.14)$ & $(5.56)$ & $(5.87)$ & $(3.70)$ \\
\hline
\end{tabular}

Table 2.5 Mean observed and expected prices and holding of permits across sessions and periods within a given treatment (SD are given within parenthesis)

Figure 2.5 and 2.6 display the mean auction prices $^{7}$ and permit holding respectively across all 15 periods and pooled across all 4 sessions.
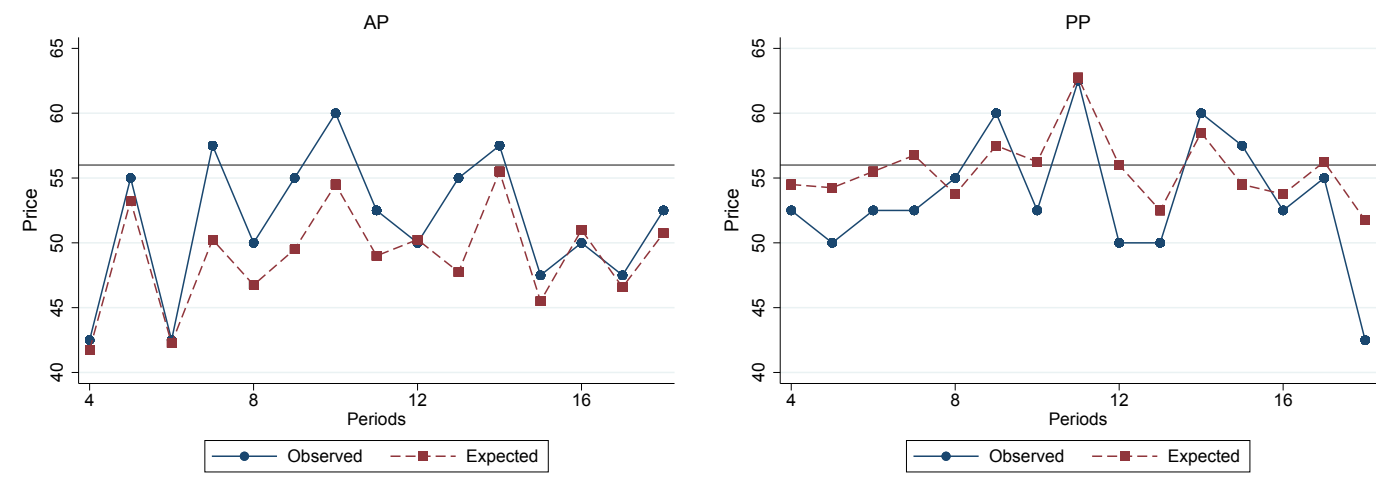

Figure 2.5 Average observed and expected price under the two different treatments i.e., median observed and expected auction price pooling all sessions together

Regarding prices, recall that in the ex-ante treatment, the regulator issues 62 emission permits that are distributed among firms using a uniform price ascending auction. We observe that in this treatment, the permit market suffers from over-pricing, that is, the observed prices are higher than the expected price given the observed investment patterns resulting from the first phase of each period. The permit price under ex-ante is smaller than that under ex-post.

\footnotetext{
${ }^{7}$ Find in Figures 2.7 and 2.8 in the Appendix the comparison between groups for ex-ante and ex-post treatments respectively.
} 

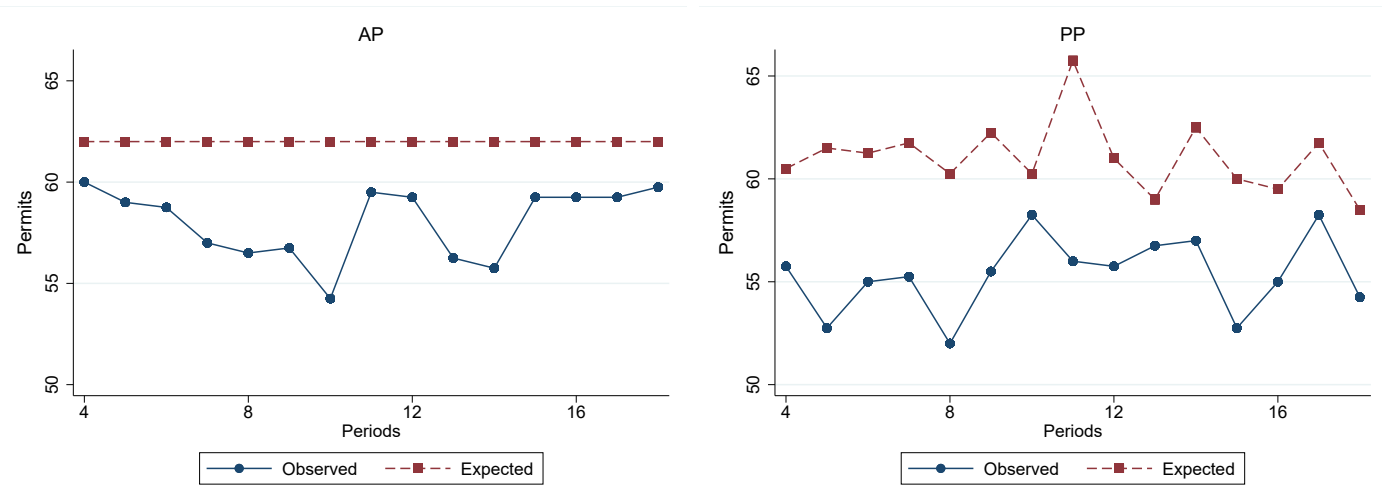

Figure 2.6 Average observed and expected permit holding under the two different treatments i.e., median observed and expected permit holding pooling all sessions together

Regarding the number of permits distributed, it is significantly lower than the permits issued by the regulator (on average) for all treatments (Wilcoxon signed-rank test p-value 0.000), i.e., there are spare permits in the auction. Moreover, in AP treatment observed permit holding is significantly higher than in PP treatment (Wilcoxon signed-rank test p-value 0.000).

Table 2.6 shows the mean permit holding per technology (after the investment decision).

\begin{tabular}{ccccccc}
\hline & $T_{1}$ & $T_{2}$ & $T_{3}$ & $T_{4}$ & $T_{5}$ & $a$ \\
\hline AP & 59.18 & 57.24 & 58.11 & 57.93 & 58.04 & 57.93 \\
& $(2.52)$ & $(3.33)$ & $(3.23)$ & $(3.15)$ & $(3.18)$ & $(3.19)$ \\
PP & 58.43 & 58.13 & 56.03 & 55.43 & 55.55 & 54.16 \\
& $(5.11)$ & $(6.36)$ & $(5.64)$ & $(5.84)$ & $(5.66)$ & $(5.51)$ \\
\hline
\end{tabular}

Table 2.6 Permit holding per technology after investment decision (SD are given within parenthesis)

We summarize our findings on the permit auction performance as follows:

\section{Result 3.}

(i) In the ex-ante treatment observed prices are significantly higher than expected prices, while observed permit holding is significantly lower than the expected one.

(ii) In the ex-post treatment observed prices seem lower than the expected ones; however, this difference is not significant. While observed permit holding is significantly lower than the expected one.

(iii) Comparing ex-ante and ex-post, first, we observe that observed and expected prices in ex-ante treatment are significantly lower than in the ex-post treatment. Second, regarding observed permit holding, in the ex-ante treatment, it is significantly higher than in the ex-post treatment. 
Given the firms' investment pattern, both treatments suffer from insufficient trading (spare permits in the auction) and over-pricing only under the ex-ante treatment.

\subsubsection{Efficiency comparisons}

In this section, we aim to compare the efficiency of the different policy instruments and commitment conditions. A well-known efficiency measure, used by Camacho-Cuena et al., 2012, to test the performance of mechanisms in experimental economics is the ratio between the theoretical minimal social cost and the social cost induced by the observed behavior. Note that in the emission permit instrument, we find two sources for possible inefficiencies: suboptimal investment decisions and suboptimal permit allocations through auction. It is therefore convenient to decompose these two sources for potential inefficiencies, i.e., the overall efficiency in the emission permit depends on the permit auction and the investment. ${ }^{8}$

\begin{tabular}{ccccc}
\hline & AT & PT & AP & PP \\
\hline$E R^{\text {Invest }}$ & & & 0.96 & 0.88 \\
& & & $(0.17)$ & $(0.08)$ \\
$E R^{\text {Permit }}$ & & & 0.93 & 0.94 \\
& & & $(0.44)$ & $(0.15)$ \\
$E R^{\text {Total }}$ & 0.94 & 0.89 & 0.87 & 0.85 \\
& $(0.12)$ & $(0.11)$ & $(0.07)$ & $(0.07)$ \\
\hline
\end{tabular}

Table 2.7 Mean (Std. Dev.) of the different efficiency ratios

\section{Efficiency of investment}

We also study investment efficiency by looking at the total abatement cost (including investment) that will result if an efficient allocation results from permit auctioning. We define: $A=\left(A_{1}, \ldots, A_{n}\right)$ with $A_{i} \in\{0,1\}$ as the investment pattern, where $A_{i}=1$ if subject $i$ invests and $A_{i}=0$, otherwise. We write $A^{*}=\left(A_{i}^{*}, \ldots, A_{n}^{*}\right)$ for the optimal investment pattern, and $A^{o b s}=\left(A_{i}^{o b s}, \ldots, A_{n}^{o b s}\right)$ for the observed one. $A^{*}$ and $A^{o b s}$ induce the corresponding technology profiles $\kappa^{*}$ and $\kappa^{o b s}$. Then we can define efficiency ratio of investment as the ratio between the lowest possible total abatement cost, including investment cost, and the observed total abatement cost, given that emissions are allocated efficiently.

$$
E R^{\text {Invest }}=\frac{T V A C\left(e^{*}\left(\kappa^{*}\right), \kappa^{*}\right)+I \sum_{i=1}^{n} A_{i}^{*}}{T V A C\left(e^{*}\left(\kappa^{o b s}\right), \kappa^{o b s}\right)+I \Sigma_{i=1}^{n} A_{i}^{o b s}}
$$

In the second row of Table 2.7, we see that the investment efficiency ratios are above $85 \%$ in all treatments. A pairwise application of a Mann Whitney test shows a significant difference in overall performance between ex-ante and ex-post.We summarize our findings as follows:

\footnotetext{
${ }^{8}$ Find in Table 2.9 in the Appendix the efficiency ratios per group and period.
} 
Result 4. Investment performs better in the ex-ante treatment, that is, when the regulator optimally adopts the number of permits to be issued before the firms' technology decisions.

\section{Efficiency in the permit auction}

We begin by looking at the efficiency of permit allocation. For this purpose, we denote the total variable abatement cost as TVAC, i.e. $T V A C=\sum_{i=1}^{n} C^{i}\left(e_{i}, \kappa(i)\right)$, where $\kappa(i) \in\{k(i), a\}$ is the actual technology used by firm $i$ after the investment decision. Let $\kappa=(\kappa(1), \ldots, \kappa(n))$ be the technology profile after the investment stage. Further $\kappa^{o b s}=\left(\kappa^{o b s}(1), \ldots, \kappa^{o b s}(n)\right)$ is the observed technology profile while $\kappa^{\star}=\left(\kappa^{\star}(1), \ldots, \kappa^{\star}(n)\right)$ is the efficient one. Additionally, we use $e^{o b s}=$ $\left(e_{1}^{o b s}, \ldots, e_{n}^{o b s}\right)$ to denote the observed emission-permit allocation, and $e^{\star}(\kappa)$ to denote the optimal emission-permit allocation contingent on a given technology profile $\kappa$. Then $T V A C\left(e^{o b s}, \kappa^{o b s}\right)=\sum_{i=1}^{n} C^{i}\left(e_{i}^{o b s}, \kappa^{o b s}(i)\right)$ is the observed TVAC, while $T V A C\left(e^{\star}\left(\kappa^{o b s}\right), \kappa^{o b s}\right)=\sum_{i=1}^{n} C^{i}\left(e_{i}^{\star}\left(\kappa^{o b s}\right), \kappa^{o b s}(i)\right)$ is the theoretically minimal TVAC contingent on the observed investment profile $\kappa$.

Permit-market efficiency is now defined as the ratio between the expected TVAC contingent on the observed investment profile to the observed TVAC, formally:

$$
E R^{\text {Permit }}=\frac{T V A C\left(e^{*}\left(\kappa^{o b s}\right), \kappa^{o b s}\right)}{T V A C\left(e^{o b s}, \kappa^{o b s}\right)}
$$

The permit-auction efficiency-ratios resulting from our four treatments are displayed in the first row of Table 2.7. A pairwise application of a Mann Whitney test (comparing average efficiency ratios at the session level for each pair of treatments, i.e., comparing between AP and PP treatments) shows a significant difference in overall performance between ex-ante and ex-post treatments. We summarize our results as follows:

Result 5. Emission permit markets perform better in the ex-post treatment, that is, when the regulator optimally adopts the number of permits to be issued after the firms' technology decisions.

\section{Overall efficiency}

Finally we look at the total efficiency, measured as the ratio of the lowest possible total abatement cost divided by the observed total abatement cost. ${ }^{9}$

$$
E R^{T o t a l}=\frac{T V A C\left(e^{*}\left(\kappa^{*}\right), \kappa^{*}\right)+I \sum_{i=1}^{n} A_{i}^{*}}{T V A C\left(e^{o b s}, \kappa^{o b s}\right)+I \sum_{i=1}^{n} A_{i}^{o b s}}
$$

\footnotetext{
${ }^{9}$ Note that the total efficiency cannot simply be written as the product of permit-market efficiency and investment efficiency, the reason being that $E-$ Ratio $^{\text {invest }}$ and $E-$ Ratio $^{\text {total }}$ contain the investment cost while $E-$ Ratio $^{\text {permit }}$ does not. To relate $E-$ Ratio $^{\text {permit }}$ and $E-$ Ratio $^{\text {invest }}$ by the factor $\frac{\sum_{i=1}^{n} A C_{i}\left(e_{i}^{o b s}, \kappa_{i}^{o b s}\right)}{\sum_{i=1}^{n} A C_{i}\left(e_{i}^{o b s}, \kappa_{i}^{o b s}\right)+\Sigma_{i=1}^{n} A_{i}^{o b s}+I} / \frac{\sum_{i=1}^{n} A C_{i}\left(e_{i}^{*}\left(\kappa^{o b s}\right), \kappa_{i}^{o b s}\right)}{\sum_{i=1}^{n} A C_{i}\left(e_{i}^{*}\left(\kappa^{o b s}\right), \kappa_{i}^{o b s}\right)+\Sigma_{i=1}^{n} A_{i}^{o b s}+I}$ the values of which, however, are of no further interest.
} 
The results are displayed in the third row of Table 2.7. A pairwise application of a Mann Whitney test shows a significant difference in overall performance between ex-ante and ex-post. We summarize our findings as follows:

Result 6. Overall efficiency is better in the ex-ante treatment, that is, when the regulator optimally adopts the number of permits to be issued before the firms' technology decisions.

\subsubsection{Social cost}

In this subsection we use social cost as an alternative to measure efficiency. More specifically, we define social cost as the sum of total abatement cost and environmental damage. For this purpose, we denote the total variable abatement cost as $T A C$, i.e. $T A C=\sum_{i=1}^{n} C^{i}\left(e_{i}, \kappa(i)\right)$, where $\kappa(i) \in\{k(i), a\}$ is the actual technology used by firm $i$ after the investment decision. Let $\kappa=(\kappa(1), \ldots, \kappa(n))$ be the technology profile after the investment stage. And we denote the environmental damage as $\mathrm{D}(\mathrm{E})$, where $E=\sum_{i=1}^{n} e_{i}$ indicates aggregate emissions.

\begin{tabular}{lcccc}
\hline & AT & PT & AP & PP \\
\hline TAC & 166.42 & 169.05 & 175.85 & 198.35 \\
Damage & 564.44 & 462.67 & 389.40 & 273.94 \\
\hline Social Cost & 730.86 & 631.72 & 565.25 & 472.29 \\
\hline
\end{tabular}

Table 2.8 Mean (Std. Dev.) of the social cost

Result 7. Social cost under ex-post treatments is statistically lower than under ex-ante treatments regardless of the instrument implemented by the regulator.

\subsection{Conclusions}

A principal concern for policy-makers in designing effective environmental instruments is the creation of incentives for firms to adopt advanced pollution technologies. This chapter investigates whether emission taxes and permits provide efficient incentives for polluting firms to adopt cleaner technologies, using laboratory experiments. Considering timing is one of the innovations of our experiment, which can bring in new comprehension into design characteristics of policy instruments that promote dynamic efficiency. To evaluate the dynamic efficiency of our permit market, the treatments follow a permit allocation rule based on an (ascending clock) auction, as is currently being implemented for carbon emissions in Europe under EU ETS.

Using as a theoretical benchmark Requate, 2005b, the key result of our study is that timing has (no) significant effect on the pattern of technology adoption when firms are initially endowed with a dirtier (cleaner) technology. In other words, timing has a significant effect on the investment decision of those firms endowed with technology 
$T_{3}$, that is, the first with no incentives to adopt the new technology in equilibrium.

Regarding taxes, we find that observed tax rates are significantly higher than the expected ones in the ex-ante treatment. As well as, observed emissions are lower than the expected ones in the two treatments, and they are significantly higher in the ex-ante treatment.

Regarding permits, we find that in ex-ante treatment (observed and expected) prices are significantly lower than in the ex-post treatment. In terms of market liquidity, our results show that permit holding depends on timing since in the ex-ante treatment firms hold more permits compared to the ex-post treatment; moreover, observed permit holding is significantly lower than the expected one in both treatments. This result is also as expected since the bidding for permits under auctioning is driven by the firms' marginal valuation of emissions (and abatement). 


\section{Appendix}

\section{A Extra figures}
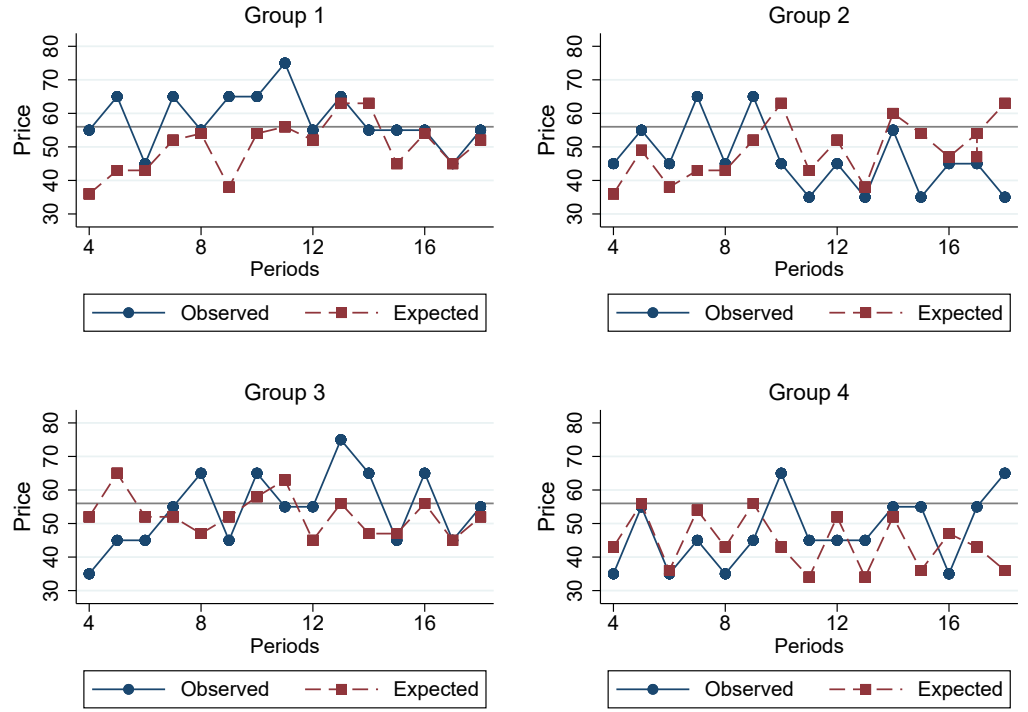

Figure 2.7 Average observed and expected price under ex-ante treatment i.e., median observed and expected auction price pooling all sessions together per group
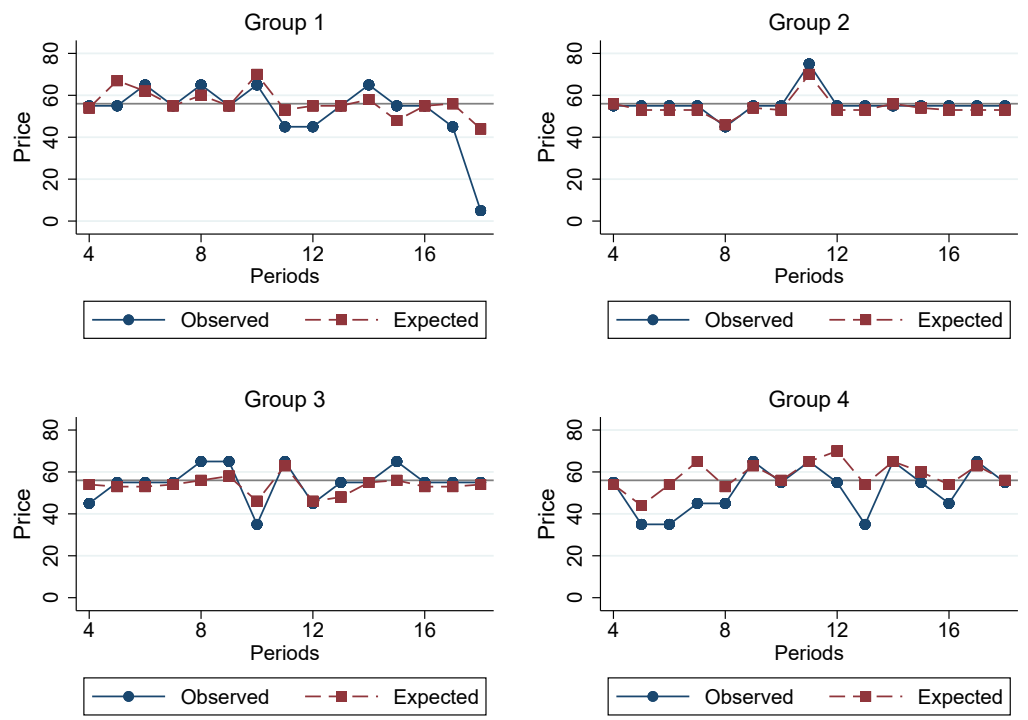

Figure 2.8 Average observed and expected price under ex-post treatment i.e., median observed and expected auction price pooling all sessions together per group 


\begin{tabular}{|c|c|c|c|c|c|}
\hline Treatment & Group & Period & $E R^{\text {Investment }}$ & $E R^{\text {Permit }}$ & $E R^{\text {Total }}$ \\
\hline $\mathrm{AT}$ & 1 & 4 & 1.646552 & 0 & 0.9820051 \\
\hline $\mathrm{AT}$ & 1 & 5 & 1.317241 & 0 & 0.832244 \\
\hline $\mathrm{AT}$ & 1 & 6 & 1.646552 & 0 & 0.9870801 \\
\hline $\mathrm{AT}$ & 1 & 7 & 1.646552 & 0 & 0.9573935 \\
\hline $\mathrm{AT}$ & 1 & 8 & 1.317241 & 0 & 0.8842593 \\
\hline $\mathrm{AT}$ & 1 & 9 & 2.195402 & 0 & 1.212698 \\
\hline AT & 1 & 10 & 1.646552 & 0 & 0.9227053 \\
\hline $\mathrm{AT}$ & 1 & 11 & 1.646552 & 0 & 0.9249395 \\
\hline $\mathrm{AT}$ & 1 & 12 & 1.646552 & 0 & 0.8801844 \\
\hline $\mathrm{AT}$ & 1 & 13 & 1.317241 & 0 & 0.8451328 \\
\hline $\mathrm{AT}$ & 1 & 14 & 1.646552 & 0 & 0.9845361 \\
\hline $\mathrm{AT}$ & 1 & 15 & 1.646552 & 0 & 1.013263 \\
\hline $\mathrm{AT}$ & 1 & 16 & 1.646552 & 0 & 1.013263 \\
\hline $\mathrm{AT}$ & 1 & 17 & 1.646552 & 0 & 1 \\
\hline $\mathrm{AT}$ & 1 & 18 & 1.646552 & 0 & 1.021390 \\
\hline $\mathrm{AT}$ & 2 & 4 & 1.317241 & 0 & 0.8681818 \\
\hline $\mathrm{AT}$ & 2 & 5 & 1.646552 & 0 & 0.8925233 \\
\hline $\mathrm{AT}$ & 2 & 6 & 1.317241 & 0 & 0.8761468 \\
\hline $\mathrm{AT}$ & 2 & 7 & 2.195402 & 0 & 1.133531 \\
\hline $\mathrm{AT}$ & 2 & 8 & 1.097701 & 0 & 0.7564356 \\
\hline $\mathrm{AT}$ & 2 & 9 & 1.097701 & 0 & 0.8093221 \\
\hline $\mathrm{AT}$ & 2 & 10 & 3.293103 & 0 & 0.7166979 \\
\hline $\mathrm{AT}$ & 2 & 11 & 1.646552 & 0 & 0.9845361 \\
\hline $\mathrm{AT}$ & 2 & 12 & 1.317241 & 0 & 0.8179871 \\
\hline $\mathrm{AT}$ & 2 & 13 & 1.317241 & 0 & 0.802521 \\
\hline $\mathrm{AT}$ & 2 & 14 & 1.646552 & 0 & 1.150602 \\
\hline AT & 2 & 15 & 1.317241 & 0 & 0.8761468 \\
\hline $\mathrm{AT}$ & 2 & 16 & 1.646552 & 0 & 0.9896373 \\
\hline $\mathrm{AT}$ & 2 & 17 & 1.317241 & 0 & 0.7431906 \\
\hline $\mathrm{AT}$ & 2 & 18 & 1.317241 & 0 & 0.8565022 \\
\hline $\mathrm{AT}$ & 3 & 4 & 1.646552 & 0 & 0.9820051 \\
\hline AT & 3 & 5 & 1.097701 & 0 & 0.7655311 \\
\hline $\mathrm{AT}$ & 3 & 6 & 2.195402 & 0 & 1.154079 \\
\hline $\mathrm{AT}$ & 3 & 7 & 1.097701 & 0 & 0.7564356 \\
\hline $\mathrm{AT}$ & 3 & 8 & 1.317241 & 0 & 0.8761468 \\
\hline $\mathrm{AT}$ & 3 & 9 & 1.317241 & 0 & 0.8662131 \\
\hline $\mathrm{AT}$ & 3 & 10 & 1.317241 & 0 & 0.8414097 \\
\hline $\mathrm{AT}$ & 3 & 11 & 2.195402 & 0 & 1.018667 \\
\hline $\mathrm{AT}$ & 3 & 12 & 1.317241 & 0 & 0.8761468 \\
\hline AT & 3 & 13 & 1.317241 & 0 & 0.8662131 \\
\hline
\end{tabular}




\begin{tabular}{|c|c|c|c|c|c|}
\hline AT & 3 & 14 & 2.195402 & 0 & 1.175385 \\
\hline $\mathrm{AT}$ & 3 & 15 & 1.317241 & 0 & 0.7780041 \\
\hline $\mathrm{AT}$ & 3 & 16 & 1.317241 & 0 & 0.8662131 \\
\hline $\mathrm{AT}$ & 3 & 17 & 2.195402 & 0 & 1.113703 \\
\hline $\mathrm{AT}$ & 3 & 18 & 1.317241 & 0 & 0.8662131 \\
\hline $\mathrm{AT}$ & 4 & 4 & 1.317241 & 0 & 0.8642534 \\
\hline $\mathrm{AT}$ & 4 & 5 & 1.317241 & 0 & 0.8781609 \\
\hline $\mathrm{AT}$ & 4 & 6 & 1.646552 & 0 & 0.955 \\
\hline $\mathrm{AT}$ & 4 & 7 & 1.317241 & 0 & 0.8451328 \\
\hline $\mathrm{AT}$ & 4 & 8 & 1.646552 & 0 & 0.8741419 \\
\hline $\mathrm{AT}$ & 4 & 9 & 1.646552 & 0 & 0.8681818 \\
\hline $\mathrm{AT}$ & 4 & 10 & 1.646552 & 0 & 0.997389 \\
\hline $\mathrm{AT}$ & 4 & 11 & 1.646552 & 0 & 0.858427 \\
\hline $\mathrm{AT}$ & 4 & 12 & 1.646552 & 0 & 0.9695432 \\
\hline $\mathrm{AT}$ & 4 & 13 & 2.195402 & 0 & 1.079096 \\
\hline $\mathrm{AT}$ & 4 & 14 & 1.646552 & 0 & 1 \\
\hline $\mathrm{AT}$ & 4 & 15 & 2.195402 & 0 & 1.236246 \\
\hline $\mathrm{AT}$ & 4 & 16 & 2.195402 & 0 & 1.107246 \\
\hline $\mathrm{AT}$ & 4 & 17 & 2.195402 & 0 & 1.164634 \\
\hline $\mathrm{AT}$ & 4 & 18 & 1.646552 & 0 & 0.9339854 \\
\hline $\mathrm{PT}$ & 1 & 4 & 1.646552 & 0 & 0.9073634 \\
\hline $\mathrm{PT}$ & 1 & 5 & 1.097701 & 0 & 0.7892562 \\
\hline $\mathrm{PT}$ & 1 & 6 & 1.317241 & 0 & 0.832244 \\
\hline $\mathrm{PT}$ & 1 & 7 & 3.293103 & 0 & 0.9845361 \\
\hline $\mathrm{PT}$ & 1 & 8 & 1.317241 & 0 & 0.7780041 \\
\hline $\mathrm{PT}$ & 1 & 9 & 1.646552 & 0 & 0.9744898 \\
\hline PT & 1 & 10 & 1.097701 & 0 & 0.832244 \\
\hline $\mathrm{PT}$ & 1 & 11 & 1.097701 & 0 & 0.8395604 \\
\hline $\mathrm{PT}$ & 1 & 12 & 1.317241 & 0 & 0.9182692 \\
\hline $\mathrm{PT}$ & 1 & 13 & 1.317241 & 0 & 0.9138756 \\
\hline $\mathrm{PT}$ & 1 & 14 & 1.317241 & 0 & 0.8526786 \\
\hline $\mathrm{PT}$ & 1 & 15 & 2.195402 & 0 & 1.026882 \\
\hline $\mathrm{PT}$ & 1 & 16 & 1.646552 & 0 & 1.032432 \\
\hline $\mathrm{PT}$ & 1 & 17 & 1.317241 & 0 & 0.8883721 \\
\hline $\mathrm{PT}$ & 1 & 18 & 2.195402 & 0 & 1.018667 \\
\hline $\mathrm{PT}$ & 2 & 4 & 1.097701 & 0 & 0.9052133 \\
\hline $\mathrm{PT}$ & 2 & 5 & 3.293103 & 0 & 0.8232759 \\
\hline $\mathrm{PT}$ & 2 & 6 & 1.646552 & 0 & 0.9720102 \\
\hline $\mathrm{PT}$ & 2 & 7 & 3.293103 & 0 & 0.9227053 \\
\hline $\mathrm{PT}$ & 2 & 8 & 1.317241 & 0 & 0.9009434 \\
\hline PT & 2 & 9 & 1.646552 & 0 & 0.6882883 \\
\hline PT & 2 & 10 & 1.097701 & 0 & 0.7941788 \\
\hline
\end{tabular}




\begin{tabular}{|c|c|c|c|c|c|}
\hline PT & 2 & 11 & 0.9408867 & 0 & 0.7193974 \\
\hline PT & 2 & 12 & 1.317241 & 0 & 0.6882883 \\
\hline PT & 2 & 13 & 1.646552 & 0 & 0.7941788 \\
\hline PT & 2 & 14 & 2.195402 & 0 & 0.8863109 \\
\hline PT & 2 & 15 & 1.097701 & 0 & 0.7958333 \\
\hline PT & 2 & 16 & 1.317241 & 0 & 0.7795919 \\
\hline PT & 2 & 17 & 3.293103 & 0 & 0.8988235 \\
\hline PT & 2 & 18 & 1.646552 & 0 & 0.8215054 \\
\hline $\mathrm{PT}$ & 3 & 4 & 1.646552 & 0 & 0.9408867 \\
\hline PT & 3 & 5 & 0.9408867 & 0 & 0.7843943 \\
\hline PT & 3 & 6 & 1.646552 & 0 & 1.024129 \\
\hline PT & 3 & 7 & 1.097701 & 0 & 0.7991632 \\
\hline PT & 3 & 8 & 1.097701 & 0 & 0.8197425 \\
\hline PT & 3 & 9 & 1.317241 & 0 & 0.8526786 \\
\hline PT & 3 & 10 & 1.646552 & 0 & 0.9204819 \\
\hline PT & 3 & 11 & 1.646552 & 0 & 0.9408867 \\
\hline PT & 3 & 12 & 1.317241 & 0 & 0.9138756 \\
\hline PT & 3 & 13 & 1.646552 & 0 & 1.038043 \\
\hline PT & 3 & 14 & 1.317241 & 0 & 0.8988235 \\
\hline PT & 3 & 15 & 2.195402 & 0 & 1.024129 \\
\hline PT & 3 & 16 & 1.317241 & 0 & 0.8526786 \\
\hline PT & 3 & 17 & 1.646552 & 0 & 0.9009434 \\
\hline PT & 3 & 18 & 1.097701 & 0 & 0.7892562 \\
\hline $\mathrm{PT}$ & 4 & 4 & 1.097701 & 0 & 0.8781609 \\
\hline PT & 4 & 5 & 1.097701 & 0 & 0.7860082 \\
\hline PT & 4 & 6 & 1.317241 & 0 & 0.9294404 \\
\hline PT & 4 & 7 & 1.097701 & 0 & 0.832244 \\
\hline PT & 4 & 8 & 1.646552 & 0 & 0.8801844 \\
\hline PT & 4 & 9 & 1.097701 & 0 & 0.8883721 \\
\hline PT & 4 & 10 & 2.195402 & 0 & 1.052342 \\
\hline PT & 4 & 11 & 1.317241 & 0 & 0.9646465 \\
\hline PT & 4 & 12 & 1.317241 & 0 & 0.8232759 \\
\hline PT & 4 & 13 & 3.293103 & 0 & 0.9870801 \\
\hline PT & 4 & 14 & 1.317241 & 0 & 0.9182692 \\
\hline PT & 4 & 15 & 2.195402 & 0 & 1.043716 \\
\hline PT & 4 & 16 & 1.646552 & 0 & 0.9317073 \\
\hline PT & 4 & 17 & 1.317241 & 0 & 0.9294404 \\
\hline PT & 4 & 18 & 1.646552 & 0 & 1.064067 \\
\hline $\mathrm{AP}$ & 1 & 4 & 1.150602 & 0.4854369 & 0.8721461 \\
\hline AP & 1 & 5 & 1.394161 & 0.3533569 & 0.8358862 \\
\hline $\mathrm{AP}$ & 1 & 6 & 1.150602 & 0.4524887 & 0.8432671 \\
\hline AP & 1 & 7 & 1 & 0.8287293 & 0.9249395 \\
\hline
\end{tabular}




\begin{tabular}{|c|c|c|c|c|c|}
\hline $\mathrm{AP}$ & 1 & 8 & 0.8681818 & 0.9493671 & 0.8526786 \\
\hline $\mathrm{AP}$ & 1 & 9 & 1.150602 & 0.462963 & 0.8526786 \\
\hline $\mathrm{AP}$ & 1 & 10 & 1 & 0.6465517 & 0.8232759 \\
\hline $\mathrm{AP}$ & 1 & 11 & 0.9947917 & 0.8366534 & 0.8988235 \\
\hline $\mathrm{AP}$ & 1 & 12 & 0.8681818 & 0.9202454 & 0.8432671 \\
\hline $\mathrm{AP}$ & 1 & 13 & 0.8642534 & 1.034483 & 0.8781609 \\
\hline $\mathrm{AP}$ & 1 & 14 & 0.764 & 1.206897 & 0.8232759 \\
\hline $\mathrm{AP}$ & 1 & 15 & 0.8681818 & 0.8333333 & 0.812766 \\
\hline $\mathrm{AP}$ & 1 & 16 & 1 & 0.802139 & 0.9116945 \\
\hline $\mathrm{AP}$ & 1 & 17 & 0.8681818 & 1.229508 & 0.9271845 \\
\hline $\mathrm{AP}$ & 1 & 18 & 1 & 0.9202454 & 0.9670886 \\
\hline $\mathrm{AP}$ & 2 & 4 & 0.9794872 & 0.7352941 & 0.8967136 \\
\hline $\mathrm{AP}$ & 2 & 5 & 1 & 0.7894737 & 0.9052133 \\
\hline $\mathrm{AP}$ & 2 & 6 & 0.8526786 & 0.9174312 & 0.8358862 \\
\hline $\mathrm{AP}$ & 2 & 7 & 1 & 0.4524887 & 0.8432671 \\
\hline $\mathrm{AP}$ & 2 & 8 & 0.9794872 & 0.591716 & 0.832244 \\
\hline $\mathrm{AP}$ & 2 & 9 & 1 & 0.7009346 & 0.8565022 \\
\hline $\mathrm{AP}$ & 2 & 10 & 0.764 & 1.265060 & 0.8377193 \\
\hline $\mathrm{AP}$ & 2 & 11 & 0.8526786 & 1.190476 & 0.8842593 \\
\hline $\mathrm{AP}$ & 2 & 12 & 1 & 0.8571429 & 0.9385749 \\
\hline $\mathrm{AP}$ & 2 & 13 & 0.8526786 & 1.204819 & 0.8863109 \\
\hline $\mathrm{AP}$ & 2 & 14 & 0.8642534 & 0.9375 & 0.8377193 \\
\hline $\mathrm{AP}$ & 2 & 15 & 0.7670683 & 1.785714 & 0.8842593 \\
\hline $\mathrm{AP}$ & 2 & 16 & 0.8681818 & 1.094890 & 0.8946136 \\
\hline $\mathrm{AP}$ & 2 & 17 & 0.8681818 & 1.094890 & 0.8946136 \\
\hline $\mathrm{AP}$ & 2 & 18 & 0.6845878 & 2.333333 & 0.8721461 \\
\hline $\mathrm{AP}$ & 3 & 4 & 0.7670683 & 1.898734 & 0.8946136 \\
\hline $\mathrm{AP}$ & 3 & 5 & 0.6701754 & 2.314049 & 0.9294404 \\
\hline $\mathrm{AP}$ & 3 & 6 & 0.8681818 & 1.013514 & 0.8721461 \\
\hline $\mathrm{AP}$ & 3 & 7 & 1 & 0.7425743 & 0.8801844 \\
\hline $\mathrm{AP}$ & 3 & 8 & 1 & 0.7352941 & 0.8761468 \\
\hline $\mathrm{AP}$ & 3 & 9 & 0.7670683 & 1.304348 & 0.825054 \\
\hline $\mathrm{AP}$ & 3 & 10 & 0.8642534 & 0.8235294 & 0.7843943 \\
\hline $\mathrm{AP}$ & 3 & 11 & 0.8642534 & 1.186441 & 0.9339854 \\
\hline $\mathrm{AP}$ & 3 & 12 & 1 & 0.9615384 & 0.9845361 \\
\hline $\mathrm{AP}$ & 3 & 13 & 0.9947917 & 0.7692308 & 0.8545861 \\
\hline $\mathrm{AP}$ & 3 & 14 & 1 & 0.6329114 & 0.9294404 \\
\hline $\mathrm{AP}$ & 3 & 15 & 0.8681818 & 1.181102 & 0.9160671 \\
\hline $\mathrm{AP}$ & 3 & 16 & 0.8642534 & 0.9375 & 0.8377193 \\
\hline $\mathrm{AP}$ & 3 & 17 & 0.8681818 & 1.181102 & 0.9160671 \\
\hline $\mathrm{AP}$ & 3 & 18 & 1 & 0.9259259 & 0.9695432 \\
\hline $\mathrm{AP}$ & 4 & 4 & 0.8526786 & 1.219512 & 0.8883721 \\
\hline
\end{tabular}




\begin{tabular}{|c|c|c|c|c|c|}
\hline AP & 4 & 5 & 0.764 & 1.363636 & 0.8603604 \\
\hline $\mathrm{AP}$ & 4 & 6 & 0.8526786 & 1.098901 & 0.8701594 \\
\hline AP & 4 & 7 & 0.8681818 & 1.315789 & 0.9455445 \\
\hline $\mathrm{AP}$ & 4 & 8 & 0.9794872 & 0.5617977 & 0.8162393 \\
\hline $\mathrm{AP}$ & 4 & 9 & 0.8642534 & 0.9459459 & 0.8414097 \\
\hline $\mathrm{AP}$ & 4 & 10 & 1.394161 & 0.3401361 & 0.8162393 \\
\hline AP & 4 & 11 & 1.091429 & 0.4878049 & 0.9249395 \\
\hline AP & 4 & 12 & 1 & 0.6607929 & 0.832244 \\
\hline AP & 4 & 13 & 0.9362745 & 0.4878049 & 0.8110403 \\
\hline AP & 4 & 14 & 1 & 0.433526 & 0.6608996 \\
\hline AP & 4 & 15 & 1.150602 & 0.613497 & 0.9670886 \\
\hline AP & 4 & 16 & 0.8681818 & 0.7537689 & 0.7811861 \\
\hline $\mathrm{AP}$ & 4 & 17 & 1.150602 & 0.4807692 & 0.8681818 \\
\hline AP & 4 & 18 & 1.394161 & 0.3831418 & 0.8781609 \\
\hline PP & 1 & 4 & 1 & 0.78125 & 0.9009434 \\
\hline $\mathrm{PP}$ & 1 & 5 & 0.8414097 & 0.9655172 & 0.8232759 \\
\hline $\mathrm{PP}$ & 1 & 6 & 0.8642534 & 0.7023411 & 0.7193974 \\
\hline $\mathrm{PP}$ & 1 & 7 & 0.764 & 1.004785 & 0.7655311 \\
\hline PP & 1 & 8 & 0.8642534 & 0.6930693 & 0.7140187 \\
\hline PP & 1 & 9 & 0.764 & 0.941704 & 0.7446394 \\
\hline $\mathrm{PP}$ & 1 & 10 & 0.9646465 & 1.040892 & 0.9922078 \\
\hline $\mathrm{PP}$ & 1 & 11 & 0.8681818 & 0.7537689 & 0.7811861 \\
\hline $\mathrm{PP}$ & 1 & 12 & 0.764 & 1.034483 & 0.7748479 \\
\hline $\mathrm{PP}$ & 1 & 13 & 0.764 & 1.179775 & 0.8162393 \\
\hline $\mathrm{PP}$ & 1 & 14 & 0.8642534 & 0.9012876 & 0.8215054 \\
\hline $\mathrm{PP}$ & 1 & 15 & 0.7670683 & 0.8333333 & 0.7234849 \\
\hline PP & 1 & 17 & 0.8642534 & 0.9090909 & 0.825054 \\
\hline $\mathrm{PP}$ & 1 & 16 & 0.764 & 1.304348 & 0.8470067 \\
\hline $\mathrm{PP}$ & 1 & 18 & 0.8526786 & 0.7462686 & 0.7925311 \\
\hline PP & 2 & 4 & 0.8642534 & 1 & 0.8741419 \\
\hline PP & 2 & 5 & 0.8681818 & 0.8928571 & 0.8340611 \\
\hline $\mathrm{PP}$ & 2 & 6 & 0.8681818 & 0.9933775 & 0.8662131 \\
\hline $\mathrm{PP}$ & 2 & 7 & 0.8681818 & 0.9615384 & 0.8565022 \\
\hline $\mathrm{PP}$ & 2 & 8 & 0.7670683 & 1.171875 & 0.802521 \\
\hline PP & 2 & 9 & 1 & 0.9615384 & 0.9845361 \\
\hline PP & 2 & 10 & 0.8681818 & 0.887574 & 0.832244 \\
\hline $\mathrm{PP}$ & 2 & 11 & 0.9646465 & 0.9964413 & 0.9622166 \\
\hline $\mathrm{PP}$ & 2 & 12 & 0.8681818 & 0.9615384 & 0.8565022 \\
\hline $\mathrm{PP}$ & 2 & 13 & 1 & 0.9615384 & 0.9845361 \\
\hline $\mathrm{PP}$ & 2 & 14 & 0.8642534 & 1 & 0.9095238 \\
\hline PP & 2 & 15 & 1 & 0.9615384 & 0.9845361 \\
\hline PP & 2 & 16 & 0.8681818 & 0.8571429 & 0.8215054 \\
\hline
\end{tabular}




\begin{tabular}{cccccc} 
PP & 2 & 17 & 1 & 0.9615384 & 0.9845361 \\
PP & 2 & 18 & 0.8681818 & 0.9615384 & 0.8565022 \\
\hline PP & 3 & 4 & 0.8681818 & 0.7653061 & 0.7860082 \\
PP & 3 & 5 & 0.8681818 & 0.7653061 & 0.7860082 \\
PP & 3 & 6 & 0.8681818 & 0.9259259 & 0.8451328 \\
PP & 3 & 7 & 0.8681818 & 0.9259259 & 0.8451328 \\
PP & 3 & 8 & 0.8642534 & 1 & 0.8642534 \\
PP & 3 & 9 & 0.8642534 & 1 & 0.8642534 \\
PP & 3 & 10 & 0.7670683 & 1 & 0.8093221 \\
PP & 3 & 11 & 0.9947917 & 0.8235294 & 0.8904429 \\
PP & 3 & 12 & 0.7670683 & 1.351351 & 0.832244 \\
PP & 3 & 13 & 0.7670683 & 1 & 0.7670683 \\
PP & 3 & 14 & 0.764 & 1.166667 & 0.812766 \\
PP & 3 & 15 & 0.764 & 1.029412 & 0.7732794 \\
PP & 3 & 16 & 0.8681818 & 0.9259259 & 0.8451328 \\
PP & 3 & 17 & 1 & 0.7653061 & 0.8925233 \\
PP & 3 & 18 & 1 & 0.78125 & 0.9009434 \\
\hline PP & 4 & 4 & 0.8681818 & 0.8241758 & 0.8093221 \\
PP & 4 & 5 & 0.8526786 & 0.7194245 & 0.7843943 \\
PP & 4 & 6 & 1 & 0.7936508 & 0.9073634 \\
PP & 4 & 7 & 0.8414097 & 1 & 0.9271845 \\
PP & 4 & 8 & 0.8681818 & 0.7894737 & 0.7958333 \\
PP & 4 & 9 & 0.9947917 & 0.8300395 & 0.8946136 \\
PP & 4 & 10 & 0.8642534 & 1 & 0.8761468 \\
PP & 4 & 11 & 0.8414097 & 0.9032258 & 0.7892562 \\
PP & 4 & 12 & 0.8414097 & 1 & 0.8946136 \\
PP & 4 & 13 & 1 & 0.8064516 & 0.9138756 \\
PP & 4 & 14 & 0.8414097 & 1 & 0.9160671 \\
PP & 4 & 15 & 0.8642534 & 0.8536586 & 0.7991632 \\
PP & 4 & 16 & 1 & 0.8928571 & 0.955 \\
PP & 4 & 17 & 0.9947917 & 0.7692308 & 0.8545861 \\
PP & 4 & 18 & 0.8642534 & 0.8203125 & 0.7827869 \\
\hline & & & & &
\end{tabular}

Table 2.9 Efficiency ratios per group and period for the four treatments. 


\section{B Experimental instructions}

\section{B.1 AT treatment}

Welcome to our economic experiment. In this experiment, you can earn a considerable amount of money depending on your decisions and on the decision of the other participants. During the experiment, your earnings will be calculated in Experimental Currency Units (ECU). At the end of the experiment, your earnings in ECUs will be converted to Euros at the following rate: 40 ECU: $€ 1$. In addition, you will receive a $€ 3$ show-up fee.

At the beginning of the experiment, you will be assigned a number. From now on, you and the other participants will be identified by that number. It is prohibited to communicate with the other participants during the experiment. Should you have any questions, please raise your hand to ask us, and we will answer you privately. If you violate this rule, we will have to exclude you from the experiment, and in which case, you will not receive any payment.

\section{Industry and decision rules}

Consider an industry consisting of 10 firms. In this experiment, you represent one of these firms. In this industry, firms use different conventional technologies. Production, however, generates emissions to the environment. Each technology is defined by the maximum emission level if no abatement measure is adopted. In Table 1, you can see the details about the different available technologies. At the beginning of each period each firm is randomly assigned a specific technology. All firms are given the opportunity to invest in a new technology with lower maximum emissions. This technology is the same for each firm, i.e., independently of the initial technology assigned. With both the conventional and the new technology, you can reduce your emissions at a certain cost. We will explain it in detail below.

As production generates emissions to the environment a regulator decides to use a system of taxes to control emissions. The tax system works as follows: you must pay a tax for each unit of emissions generated by your firm.

The experiment lasts for $\mathbf{1 5}$ rounds. At the beginning of each period you will be assigned randomly a technology. In each round you and the other participants will decide simultaneously and independently the following:

1. Technology decision: Each firm must decide whether to invest in the new technology or to continue producing with the assigned technology. For adopting the new technology, the firm must pay 580 ECU. 
2. Abatement decision: You must decide how many units you want to reduce your emissions (paying the corresponding total abatement cost- See Table 1), knowing that for the units emitted you will pay the corresponding tax. Note that, given the maximum emission level provided by your technology, you can either reduce emissions (and pay the corresponding abatement cost) or pay the corresponding tax for your emissions.

Once you have made all your decisions, your profit is computed at the end of each period. Your default profit from producing is 1200 ECU each period. Then, your earnings at the end of each period are determined by:

\section{Profit $=1200$ - investment (if applicable) - tax*emissions (if applicable) - total abatement cost (if applicable)}

After all 15 periods are over, a random lottery will determine 2 periods whose average will count for the payment. Therefore, it is in your interest that you correctly understand the experiment. If you have any question, please raise your hand, and we will answer you privately.

To better understand the auction procedure, take a look at the following examples:

\section{Example 1:}

Let's assume that you were randomly allocated to Technology 1 (TC1 in Table 1) and the regulator sets a tax rate of 60 ECU. You decided not to invest in the new technology (hence you do not need to pay ECU 580). Now, you decide to abate 6 units (i.e., to emit 14 units). That is, you will have to pay the abatement costs for 6 units (according to Technology 1). According to Table 1 abating 6 units incurs a total abatement cost of 210 ECU. You also have to pay tax for the remaining emissions of 14 units (14 times 60 ECU). Your profit in this period is then:

$$
120021014 * 60=150 \mathrm{ECU}
$$

\section{Example 2:}

Lets assume that the regulator sets a tax rate of $60 \mathrm{ECU}$ and you were randomly allocated to a certain technology, but you decided to invest in the new technology (hence you pay $580 \mathrm{ECU}$ ). Now, you decide to abate 6 units (i.e., to emit 1 unit). That is, you will have to pay the abatement costs of 6 units (according to Technology 1). According to Table 1 abating 6 units incurs a total abatement cost of 210 ECU. You also have to pay tax for the remaining emissions of 1 unit (1 times 60 ECU). Your profit in this period is then:

$$
1200580210-1^{*} 60=350 \mathrm{ECU}
$$

Before starting the experiment there will be one trial round that will help you understand how it works. If you have any doubts during the experiment, please, do not hesitate to ask any question.

Thanks for your participation. 
Table 1. Technologies

\begin{tabular}{|c|c|c|c|c|c|c|c|c|}
\hline \multicolumn{7}{|c|}{ TUS EMISIONES } & \multicolumn{2}{c|}{ REDUCIR EMISIONES } \\
\hline TC1 & TC2 & TC3 & TC4 & TC5 & $\begin{array}{c}\text { Nueva } \\
\text { Tecnología }\end{array}$ & $\begin{array}{c}\text { Coste } \\
\text { MARGINAL }\end{array}$ & $\begin{array}{c}\text { Coste } \\
\text { TOTAL }\end{array}$ & $\begin{array}{c}\text { Unidades } \\
\text { REDUCIDAS }\end{array}$ \\
\hline 20 & 18 & 16 & 14 & 12 & 7 & --- & 0 & 0 \\
\hline 19 & 17 & 15 & 13 & 11 & 6 & 10 & 10 & 1 \\
\hline 18 & 16 & 14 & 12 & 10 & 5 & 20 & 30 & 2 \\
\hline 17 & 15 & 13 & 11 & 9 & 4 & 30 & 60 & 3 \\
\hline 16 & 14 & 12 & 10 & 8 & 3 & 40 & 100 & 4 \\
\hline 15 & 13 & 11 & 9 & 7 & 2 & 50 & 150 & 5 \\
\hline 14 & 12 & 10 & 8 & 6 & 1 & 60 & 210 & 6 \\
\hline 13 & 11 & 9 & 7 & 5 & 0 & 70 & 280 & 7 \\
\hline 12 & 10 & 8 & 6 & 4 & & 80 & 360 & 8 \\
\hline 11 & 9 & 7 & 5 & 3 & & 90 & 450 & 9 \\
\hline 10 & 8 & 6 & 4 & 2 & & 100 & 550 & 10 \\
\hline 9 & 7 & 5 & 3 & 1 & & 110 & 660 & 11 \\
\hline 8 & 6 & 4 & 2 & 0 & & 120 & 780 & 12 \\
\hline 7 & 5 & 3 & 1 & & & 130 & 910 & 13 \\
\hline 6 & 4 & 2 & 0 & & & 140 & 1050 & 14 \\
\hline 5 & 3 & 1 & & & & 150 & 1200 & 15 \\
\hline 4 & 2 & 0 & & & & 160 & 1360 & 16 \\
\hline 3 & 1 & & & & & 170 & 1530 & 17 \\
\hline 2 & 0 & & & & & 180 & 1710 & 18 \\
\hline 1 & & & & & & 190 & 1900 & 19 \\
\hline 0 & & & & & & 200 & 2100 & 20 \\
\hline
\end{tabular}

EXPLANATION: Given any technology, TOTAL COST refers to the cost of reducing emissions in a certain number of units. For example, if you want to reduce your emissions by 4 units from your maximum emissions, this will cost you $10+20$ $+30+40=100$ ECU. Note, however, that the cost of reducing each of the units is not the same, the more units you want to reduce, the greater the cost of reducing each additional unit. This cost is called MARGINAL COST. For example, if you want to reduce your emissions from 4 to 5 units, this will cost you 50 additional ECU. Therefore, the total cost of reducing your emissions by 5 units is $10+20+30+40+$ $\mathbf{5 0}=150$ ECU. 


\section{B.2 PT treatment}

Welcome to our economic experiment. In this experiment, you can earn a considerable amount of money depending on your decisions and on the decision of the other participants. During the experiment, your earnings will be calculated in Experimental Currency Units (ECU). At the end of the experiment, your earnings in ECUs will be converted to Euros at the following rate: 40 ECU: $€ 1$. In addition, you will receive a $€ 3$ show-up fee.

At the beginning of the experiment, you will be assigned a number. From now on, you and the other participants will be identified by that number. It is prohibited to communicate with the other participants during the experiment. Should you have any questions, please raise your hand to ask us, and we will answer you privately. If you violate this rule, we will have to exclude you from the experiment, and in which case, you will not receive any payment.

\section{Industry and decision rules}

Consider an industry consisting of 10 firms. In this experiment, you represent one of these firms. In this industry, firms use different conventional technologies. Production, however, generates emissions to the environment. Each technology is defined by the maximum emission level if no abatement measure is adopted. In Table 1 , you can see the details about the different available technologies. At the beginning of each period each firm is randomly assigned a specific technology. All firms are given the opportunity to invest in a new technology with lower maximum emissions. This technology is the same for each firm, i.e., independently of the initial technology assigned. With both the conventional and the new technology, you can reduce your emissions at a certain cost. We will explain it in detail below.

As production generates emissions to the environment a regulator decides to use a system of taxes to control emissions. The tax system works as follows: you must pay a tax for each unit of emissions generated by your firm.

The tax rate set by the regulator depends on aggregate emissions (and thus depends on the technologies used by the firms). In each period, after all firms have made their investment decisions, the regulator determines the optimal tax rate.

Note that the more firms have invested in the new technology, the lower will be the tax rate. The idea behind this is that the higher the level of total emissions (emitted by all the firms) the higher is the additional harm to the environment. By contrast, the more firms invest in the new technology, the lower the is the cost of emission abatement which would lead to lower emissions. 
The experiment lasts for $\mathbf{1 5}$ rounds. At the beginning of each period you will be assigned randomly a technology. In each round you and the other participants will decide simultaneously and independently the following:

1. Technology decision: Each firm must decide whether to invest in the new technology or to continue producing with the assigned technology. For adopting the new technology, the firm must pay 580 ECU.

2. Abatement decision: Once the corresponding tax level set by the regulator in announced, you must decide how many units you want to reduce your emissions (paying the corresponding total abatement cost- See Table 1), knowing that for the units emitted you will pay the corresponding tax. Note that, given the maximum emission level provided by your technology, you can either reduce emissions (and pay the corresponding abatement cost) or pay the corresponding tax for your emissions.

Once you have made all your decisions, your profit is computed at the end of each period. Your default profit from producing is $\mathbf{1 2 0 0}$ ECU each period. Then, your earnings at the end of each period are determined by:

\section{Profit $=1200-$ investment (if applicable) - tax*emissions (if applicable) - total abatement cost (if applicable)}

After all 15 periods are over, a random lottery will determine 2 periods whose average will count for the payment. Therefore, it is in your interest that you correctly understand the experiment. If you have any question, please raise your hand, and we will answer you privately.

To better understand the auction procedure, take a look at the following examples:

\section{Example 1:}

Let's assume that you were randomly allocated to Technology 1 (TC1 in Table 1). You decided not to invest in the new technology (hence you do not need to pay ECU 580). After all firms made their investment decisions, the regulator observes the technologies used by the firms, and sets a tax rate of 60 ECU per emission unit. Now, you decide to abate 6 units (i.e., to emit 14 units). That is, you will have to pay the abatement costs for 6 units (according to Technology 1). According to Table 1 abating 6 units incurs a total abatement cost of 210 ECU. You also have to pay tax for the remaining emissions of 14 units (14 times $60 \mathrm{ECU}$ ). Your profit in this period is then:

$$
120021014 * 60=150 \mathrm{ECU}
$$

\section{Example 2:}

Let's assume that you were randomly allocated to a certain technology, but you decided to invest in the new technology (hence you pay 580 ECU). After all firms made their investment decisions, the regulator observes the technologies used by the 
firms, and sets a tax rate of 60 ECU. Now, you decide to abate 6 units (i.e., to emit 1 unit). That is, you will have to pay the abatement costs of 6 units (according to Technology 1). According to Table 1 abating 6 units incurs a total abatement cost of 210 ECU. You also have to pay tax for the remaining emissions of 1 unit (1 times 60 ECU). Your profit in this period is then:

$$
1200580210-1^{*} 60=350 \mathrm{ECU}
$$

Before starting the experiment there will be one trial round that will help you understand how it works. If you have any doubts during the experiment, please, do not hesitate to ask any question.

Thanks for your participation.

Table 1. Technologies

\begin{tabular}{|c|c|c|c|c|c|c|c|c|}
\hline \multicolumn{7}{|c|}{ TUS EMISIONES } & \multicolumn{2}{c|}{ REDUCIR EMISIONES } \\
\hline TC1 & TC2 & TC3 & TC4 & TC5 & $\begin{array}{c}\text { Nueva } \\
\text { Tecnología }\end{array}$ & $\begin{array}{c}\text { Coste } \\
\text { MARGINAL }\end{array}$ & $\begin{array}{c}\text { Coste } \\
\text { TOTAL }\end{array}$ & $\begin{array}{c}\text { Unidades } \\
\text { REDUCIDAS }\end{array}$ \\
\hline 20 & 18 & 16 & 14 & 12 & 7 & ---- & 0 & 0 \\
\hline 19 & 17 & 15 & 13 & 11 & 6 & 10 & 10 & 1 \\
\hline 18 & 16 & 14 & 12 & 10 & 5 & 20 & 30 & 2 \\
\hline 17 & 15 & 13 & 11 & 9 & 4 & 30 & 60 & 3 \\
\hline 16 & 14 & 12 & 10 & 8 & 3 & 40 & 100 & 4 \\
\hline 15 & 13 & 11 & 9 & 7 & 2 & 50 & 150 & 5 \\
\hline 14 & 12 & 10 & 8 & 6 & 1 & 60 & 210 & 6 \\
\hline 13 & 11 & 9 & 7 & 5 & 0 & 70 & 280 & 7 \\
\hline 12 & 10 & 8 & 6 & 4 & & 80 & 360 & 8 \\
\hline 11 & 9 & 7 & 5 & 3 & & 90 & 450 & 9 \\
\hline 10 & 8 & 6 & 4 & 2 & & 100 & 550 & 10 \\
\hline 9 & 7 & 5 & 3 & 1 & & 110 & 660 & 11 \\
\hline 8 & 6 & 4 & 2 & 0 & & 120 & 780 & 12 \\
\hline 7 & 5 & 3 & 1 & & & 130 & 910 & 13 \\
\hline 6 & 4 & 2 & 0 & & & 140 & 1050 & 14 \\
\hline 5 & 3 & 1 & & & & 150 & 1200 & 15 \\
\hline 4 & 2 & 0 & & & & 160 & 1360 & 16 \\
\hline 3 & 1 & & & & & 170 & 1530 & 17 \\
\hline 2 & 0 & & & & & 180 & 1710 & 18 \\
\hline 1 & & & & & & 190 & 1900 & 19 \\
\hline 0 & & & & & & 200 & 2100 & 20 \\
\hline
\end{tabular}

EXPLANATION: Given any technology, TOTAL COST refers to the cost of reducing emissions in a certain number of units. For example, if you want to reduce your emissions by 4 units from your maximum emissions, this will cost you $10+20$ $+30+40=100$ ECU. Note, however, that the cost of reducing each of the units is not the same, the more units you want to reduce, the greater the cost of reducing each additional unit. This cost is called MARGINAL COST. For example, if you want to reduce your emissions from 4 to 5 units, this will cost you 50 additional ECU. Therefore, the total cost of reducing your emissions by 5 units is $10+20+30+40+$ $\mathbf{5 0}=150 \mathrm{ECU}$. 


\section{B.3 AP treatment}

Welcome to our economic experiment. In this experiment, you can earn a considerable amount of money depending on your decisions and on the decision of the other participants. During the experiment, your earnings will be calculated in Experimental Currency Units (ECU). At the end of the experiment, your earnings in ECUs will be converted to Euros at the following rate: 40 ECU: $€ 1$. In addition, you will receive a $€ 3$ show-up fee.

At the beginning of the experiment, you will be assigned a number. From now on, you and the other participants will be identified by that number. It is prohibited to communicate with the other participants during the experiment. Should you have any questions, please raise your hand to ask us, and we will answer you privately. If you violate this rule, we will have to exclude you from the experiment, and in which case, you will not receive any payment.

\section{Industry and decision rules}

Consider an industry consisting of 10 firms. In this experiment, you represent one of these firms. In this industry, firms use different conventional technologies. Production, however, generates emissions to the environment. Each technology is defined by the maximum emission level if no abatement measure is adopted. In Table 1, you can see the details about the different available technologies. At the beginning of each period each firm is randomly assigned a specific technology. All firms are given the opportunity to invest in a new technology with lower maximum emissions. This technology is the same for each firm, i.e., independently of the initial technology assigned. With both the conventional and the new technology, you can reduce your emissions at a certain cost. We will explain it in detail below.

As production generates emissions to the environment, a regulator decides to use a system of emission permits to control emissions. The permit system works in the following way: you must have one permit for each unit of emissions issued by your firm. For example, if the maximum level of emissions of your technology is 18 units of emissions and you have 10 permits, you are only allowed to issue 10 units of emissions, so you will have to reduce emissions by 8 units and incur the corresponding abatement costs.

The government will issue a number of permits with a 1-period duration, which means that you can only use the permits for one period. The price of the permits will be determined by an auction where you can buy government permits.

The experiment lasts for $\mathbf{1 5}$ periods. At the beginning of each period, you will be randomly assigned a technology. In each period, you and the other participants will decide simultaneously and independently the following: 
1. Technology decision: Each firm must decide whether to invest in the new technology or to continue producing with the assigned technology. For adopting the new technology, the firm must pay 580 ECU.

2. Buy emission permits. Remember that for each pollution unit that you want to emit, you must buy an emission permit. An auction will determine the price of the permits; we will explain its functioning below. Keep in mind that the difference between your maximum emissions and the number of permits you bought will be your abatement decision (paying the corresponding total abatement cost- See Table 1). Note that, given the maximum emission level provided by your technology, you can either reduce emissions (and pay the corresponding abatement cost) or buy permits for your emissions.

Once you have made all your decisions, your profit is computed at the end of each period. Your default profit from producing is $1200 \mathrm{ECU}$ each period. Then, your earnings at the end of each period are determined by:

\section{Profit $=1200$ - investment (if applicable) - auction costs (if applicable) - total abatement cost (if applicable)}

After all 15 periods are over, a random lottery will determine 2 periods whose average will count for the payment. Therefore, it is in your interest that you correctly understand the experiment. If you have any question, please raise your hand, and we will answer you privately.

\section{Auction of emission permits}

The number of permits that will be issued to the firms $(\mathrm{S})$ will be the same in each period. In each period, you can buy those permits at the auction.

Each auction will have the following phases:

- The permit price starts at 5 ECU.

- You and the other participants make your demands for permits, that is, you notify the number of permits you are willing to buy at that price. Keep in mind that you will not be able to buy more permits than your maximum level of emissions.

- The total demand for permits (total number of permits that all firms demand) will be calculated.

- If the total demand for permits is equal to or less than $\mathrm{S}$ (number of permits issued by law), the auction ends, and you will get the number of permits you had demanded at that price.

- If the total demand for permits is greater than $\mathrm{S}$, the permit price will be increased by $10 \mathrm{ECU}$, and a new period of auction will start. 
You have 60 seconds to decide the number of permits you want to buy. If you do not demand anything after 60 seconds, the system will choose the former demand that you had selected with the previous price. If you have not placed a demand at the initial price (5 ECU), the system will consider your demand as equal to the maximum emission level!

To better understand the auction procedure, take a look at the following examples:

\section{Example 1:}

Let's assume that you were randomly assigned Technology 1 (TC1 in Table 1). You decided not to invest in the new technology (hence you do not pay ECU 580). The auction stops at 55 ECU per permit, and you have bought 14 permits at that price; therefore you will have to reduce your emissions by 6 units, incurring an abatement cost of 210 (see Table 1). Your profit in this period is:

$$
1200-55 * 14-210=220
$$

\section{Example 2:}

Let's assume that you were randomly assigned Technology 1 (TC1 in Table 1). You decided not to invest in the new technology (hence you do not pay ECU 580). The auction stops at 55 ECU per permit, and you have bought 15 permits at that price; therefore you will have to reduce your emissions by 5 units incurring an abatement cost of 150 (see Table 1). Your profit in this period is:

$$
1200-55 * 15-150=225
$$

\section{Example 3:}

Let's assume that you were randomly allocated to a certain technology, but you decided to invest in the new technology (hence you pay 580 ECU). The auction stops at 65 ECU per permit, and you have bought 1 permit at that price; therefore you will have to reduce your emissions by 6 units incurring an abatement cost of 210 (see Table 1). Your profit in this period is:

$$
1200-65-1 * 580-210=345
$$

Before starting the experiment, there will be one trial period that will help you understand how the permit auction works. If you have any doubts during the experiment, please, do not hesitate to ask any question.

Thanks for your participation. 
Table 1. Technologies

\begin{tabular}{|c|c|c|c|c|c|c|c|c|}
\hline \multicolumn{7}{|c|}{ TUS EMISIONES } & \multicolumn{2}{c|}{ REDUCIR EMISIONES } \\
\hline TC1 & TC2 & TC3 & TC4 & TC5 & $\begin{array}{c}\text { Nueva } \\
\text { Tecnología }\end{array}$ & $\begin{array}{c}\text { Coste } \\
\text { MARGINAL }\end{array}$ & $\begin{array}{c}\text { Coste } \\
\text { TOTAL }\end{array}$ & $\begin{array}{c}\text { Unidades } \\
\text { REDUCIDAS }\end{array}$ \\
\hline 20 & 18 & 16 & 14 & 12 & 7 & ---- & 0 & 0 \\
\hline 19 & 17 & 15 & 13 & 11 & 6 & 10 & 10 & 1 \\
\hline 18 & 16 & 14 & 12 & 10 & 5 & 20 & 30 & 2 \\
\hline 17 & 15 & 13 & 11 & 9 & 4 & 30 & 60 & 3 \\
\hline 16 & 14 & 12 & 10 & 8 & 3 & 40 & 100 & 4 \\
\hline 15 & 13 & 11 & 9 & 7 & 2 & 50 & 150 & 5 \\
\hline 14 & 12 & 10 & 8 & 6 & 1 & 60 & 210 & 6 \\
\hline 13 & 11 & 9 & 7 & 5 & 0 & 70 & 280 & 7 \\
\hline 12 & 10 & 8 & 6 & 4 & & 80 & 360 & 8 \\
\hline 11 & 9 & 7 & 5 & 3 & & 90 & 450 & 9 \\
\hline 10 & 8 & 6 & 4 & 2 & & 100 & 550 & 10 \\
\hline 9 & 7 & 5 & 3 & 1 & & 110 & 660 & 11 \\
\hline 8 & 6 & 4 & 2 & 0 & & 120 & 780 & 12 \\
\hline 7 & 5 & 3 & 1 & & & 130 & 910 & 13 \\
\hline 6 & 4 & 2 & 0 & & & 140 & 1050 & 14 \\
\hline 5 & 3 & 1 & & & & 150 & 1200 & 15 \\
\hline 4 & 2 & 0 & & & & 160 & 1360 & 16 \\
\hline 3 & 1 & & & & & 170 & 1530 & 17 \\
\hline 2 & 0 & & & & & 180 & 1710 & 18 \\
\hline 1 & & & & & & 190 & 1900 & 19 \\
\hline 0 & & & & & & 200 & 2100 & 20 \\
\hline
\end{tabular}

EXPLANATION: Given any technology, TOTAL COST refers to the cost of reducing emissions in a certain number of units. For example, if you want to reduce your emissions by 4 units from your maximum emissions, this will cost you $10+20$ $+30+40=100$ ECU. Note, however, that the cost of reducing each of the units is not the same, the more units you want to reduce, the greater the cost of reducing each additional unit. This cost is called MARGINAL COST. For example, if you want to reduce your emissions from 4 to 5 units, this will cost you 50 additional ECU. Therefore, the total cost of reducing your emissions by 5 units is $10+20+30+40+$ $\mathbf{5 0}=150$ ECU. 


\section{B.4 PP treatment}

Welcome to our economic experiment. In this experiment, you can earn a considerable amount of money depending on your decisions and on the decision of the other participants. During the experiment, your earnings will be calculated in Experimental Currency Units (ECU). At the end of the experiment, your earnings in ECUs will be converted to Euros at the following rate: 40 ECU: $€ 1$. In addition, you will receive a $€ 3$ show-up fee.

At the beginning of the experiment, you will be assigned a number. From now on, you and the other participants will be identified by that number. It is prohibited to communicate with the other participants during the experiment. Should you have any questions, please raise your hand to ask us, and we will answer you privately. If you violate this rule, we will have to exclude you from the experiment, and in which case, you will not receive any payment.

\section{Industry and decision rules}

Consider an industry consisting of 10 firms. In this experiment, you represent one of these firms. In this industry, firms use different conventional technologies. Production, however, generates emissions to the environment. Each technology is defined by the maximum emission level if no abatement measure is adopted. In Table 1, you can see the details about the different available technologies. At the beginning of each period each firm is randomly assigned a specific technology. All firms are given the opportunity to invest in a new technology with lower maximum emissions. This technology is the same for each firm, i.e., independently of the initial technology assigned. With both the conventional and the new technology, you can reduce your emissions at a certain cost. We will explain it in detail below.

As production generates emissions to the environment, a regulator decides to use a system of emission permits to control emissions. The permit system works in the following way: you must have one permit for each unit of emissions issued by your firm. For example, if the maximum level of emissions of your technology is 18 units of emissions and you have 10 permits, you are only allowed to issue 10 units of emissions, so you will have to reduce emissions by 8 units and incur the corresponding abatement costs.

The emissions target set by the government depends on the overall level of technology (and thus depends on the number of firms that have invested in the new technology). Therefore, after all firms have made their decision to invest or not, the government will issue a number of permits with a 1-round duration, which means that you can only use the permits for a round. The price of the permits will be determined by an auction where you can buy government permits. 
The experiment lasts for $\mathbf{1 5}$ periods. At the beginning of each period, you will be randomly assigned a technology. In each period, you and the other participants will decide simultaneously and independently the following:

1. Technology decision: Each firm must decide whether to invest in the new technology or to continue producing with the assigned technology. For adopting the new technology, the firm must pay 580 ECU.

2. Buy emission permits. Remember that for each pollution unit that you want to emit, you must buy an emission permit. An auction will determine the price of the permits; we will explain its functioning below. Keep in mind that the difference between your maximum emissions and the number of permits you bought will be your abatement decision (paying the corresponding total abatement cost- See Table 1). Note that, given the maximum emission level provided by your technology, you can either reduce emissions (and pay the corresponding abatement cost) or buy permits for your emissions.

Once you have made all your decisions, your profit is computed at the end of each period. Your default profit from producing is $\mathbf{1 2 0 0}$ ECU each period. Then, your earnings at the end of each period are determined by:

\section{Profit $=1200-$ investment (if applicable) - auction costs (if applicable) - total abatement cost (if applicable)}

After all 15 periods are over, a random lottery will determine 2 periods whose average will count for the payment. Therefore, it is in your interest that you correctly understand the experiment. If you have any question, please raise your hand, and we will answer you privately.

\section{Auction of emission permits}

After each round after the firms have made their investment decisions, the regulator observes how many and which firms have invested in the new technology. On the basis of this observation, the regulator determines the optimal number permits that will be issued to the firms $(\mathrm{N})$ according to the following rule. The lower the total number of maximal emissions, the lower the smaller the number of permits issued. In each round, you can buy those permits at the auction.

Each auction will have the following phases:

- The permit price starts at 5 ECU.

- You and the other participants make your demands for permits, that is, you notify the number of permits you are willing to buy at that price. Keep in mind that you will not be able to buy more permits than your maximum level of emissions.

- The total demand for permits (total number of permits that all firms demand) will be calculated. 
- If the total demand for permits is equal to or less than $\mathrm{S}$ (number of permits issued by law), the auction ends, and you will get the number of permits you had demanded at that price.

- If the total demand for permits is greater than $\mathrm{S}$, the permit price will be increased by 10 ECU, and a new period of auction will start.

You have 60 seconds to decide the number of permits you want to buy. If you do not demand anything after 60 seconds, the system will choose the former demand that you had selected with the previous price. If you have not placed a demand at the initial price ( 5 ECU), the system will consider your demand as equal to the maximum emission level!

Note that the more firms (participants) have invested in the new technology, the lower will be the amount of permits being issued (S). The idea behind this is that the higher the level of total emissions (emitted by all the firms) the higher is the additional harm to the environment. By contrast, the more firms invest, the lower the default emissions and the lower the net emissions after emission reduction, and eventually the lower the (marginal) harm to the environment by an additional emission unit.

Please think about the following consideration (or trade-off): If no other participants (firms) invest (or only few other participants invest), S will be high, and, depending on the technology assigned to you, it might be profitable for you to invest! If, on the contrary, many other participants decide to invest, the $\mathrm{S}$ set by the experimentalist will be low, and therefore it might not be profitable for you to also invest.

In other words, the $\mathrm{S}$ in each round depends on your investment decision and the investment decisions of the other participants (firms), and the more participants invest, the lower, the resulting $\mathrm{S}$.

To better understand the auction procedure, take a look at the following examples:

\section{Example 1:}

Let's assume that Technology 1 (TC1 in Table 1) was randomly assigned to you. You decided not to invest in the new technology (hence you do not need to pay ECU 580). After all firms made their investment decisions, the regulator observes the technologies used by the firms, and determines the optimal number of permits issued. The auction is stopped at the price of 55 ECU per permit and you have bought 14 permits at that price, therefore you will have to reduce your emissions by 6 units incurring an abatement cost of 210 (see Table 1). Your profit in this round is:

$$
1200-55 * 14-210=220
$$

\section{Example 2:}

Let's assume that Technology 1 (TC1 in Table 1) was randomly assigned to you. You decided not to invest in the new technology (hence you do not need to pay 
ECU 580). After all firms made their investment decisions, the regulator observes the technologies used by the firms, and determines the optimal number of permits issued. The auction is stopped at the price of 55 ECU per permit and you have bought 15 permits at that price, therefore you will have to reduce your emissions by 5 units incurring an abatement cost of 150 (see Table 1). Your profit in this round is:

$$
1200-55 * 15-150=225
$$

\section{Example 3:}

Let's assume that you were randomly allocated to a certain technology, but you decided to invest in the new technology (hence you pay 580 ECU). After all firms made their investment decisions, the regulator observes the technologies used by the firms, and determines the optimal number of permits issued. The auction is stopped at the price of $65 \mathrm{ECU}$ per permit and you have bought 1 permit at that price, therefore you will have to reduce your emissions by 6 units incurring an abatement cost of 210 (see Table 1). Your profit in this round is:

$$
1200-65-1 * 580-210=345
$$

Before starting the experiment, there will be one trial period that will help you understand how the permit auction works. If you have any doubts during the experiment, please, do not hesitate to ask any question.

\section{Thanks for your participation.}


Table 1. Technologies

\begin{tabular}{|c|c|c|c|c|c|c|c|c|}
\hline \multicolumn{7}{|c|}{ TUS EMISIONES } & \multicolumn{2}{c|}{ REDUCIR EMISIONES } \\
\hline TC1 & TC2 & TC3 & TC4 & TC5 & $\begin{array}{c}\text { Nueva } \\
\text { Tecnología }\end{array}$ & $\begin{array}{c}\text { Coste } \\
\text { MARGINAL }\end{array}$ & $\begin{array}{c}\text { Coste } \\
\text { TOTAL }\end{array}$ & $\begin{array}{c}\text { Unidades } \\
\text { REDUCIDAS }\end{array}$ \\
\hline 20 & 18 & 16 & 14 & 12 & 7 & --- & 0 & 0 \\
\hline 19 & 17 & 15 & 13 & 11 & 6 & 10 & 10 & 1 \\
\hline 18 & 16 & 14 & 12 & 10 & 5 & 20 & 30 & 2 \\
\hline 17 & 15 & 13 & 11 & 9 & 4 & 30 & 60 & 3 \\
\hline 16 & 14 & 12 & 10 & 8 & 3 & 40 & 100 & 4 \\
\hline 15 & 13 & 11 & 9 & 7 & 2 & 50 & 150 & 5 \\
\hline 14 & 12 & 10 & 8 & 6 & 1 & 60 & 210 & 6 \\
\hline 13 & 11 & 9 & 7 & 5 & 0 & 70 & 280 & 7 \\
\hline 12 & 10 & 8 & 6 & 4 & & 80 & 360 & 8 \\
\hline 11 & 9 & 7 & 5 & 3 & & 90 & 450 & 9 \\
\hline 10 & 8 & 6 & 4 & 2 & & 100 & 550 & 10 \\
\hline 9 & 7 & 5 & 3 & 1 & & 110 & 660 & 11 \\
\hline 8 & 6 & 4 & 2 & 0 & & 120 & 780 & 12 \\
\hline 7 & 5 & 3 & 1 & & & 130 & 910 & 13 \\
\hline 6 & 4 & 2 & 0 & & & 140 & 1050 & 14 \\
\hline 5 & 3 & 1 & & & & 150 & 1200 & 15 \\
\hline 4 & 2 & 0 & & & & 160 & 1360 & 16 \\
\hline 3 & 1 & & & & & 170 & 1530 & 17 \\
\hline 2 & 0 & & & & & 180 & 1710 & 18 \\
\hline 1 & & & & & & 190 & 1900 & 19 \\
\hline 0 & & & & & & 200 & 2100 & 20 \\
\hline
\end{tabular}

EXPLANATION: Given any technology, TOTAL COST refers to the cost of reducing emissions in a certain number of units. For example, if you want to reduce your emissions by 4 units from your maximum emissions, this will cost you $10+20$ $+30+40=100$ ECU. Note, however, that the cost of reducing each of the units is not the same, the more units you want to reduce, the greater the cost of reducing each additional unit. This cost is called MARGINAL COST. For example, if you want to reduce your emissions from 4 to 5 units, this will cost you 50 additional ECU. Therefore, the total cost of reducing your emissions by 5 units is $10+20+30+40+$ $\mathbf{5 0}=150$ ECU. 


\section{C Screenshots}

Auswahl der Technologie

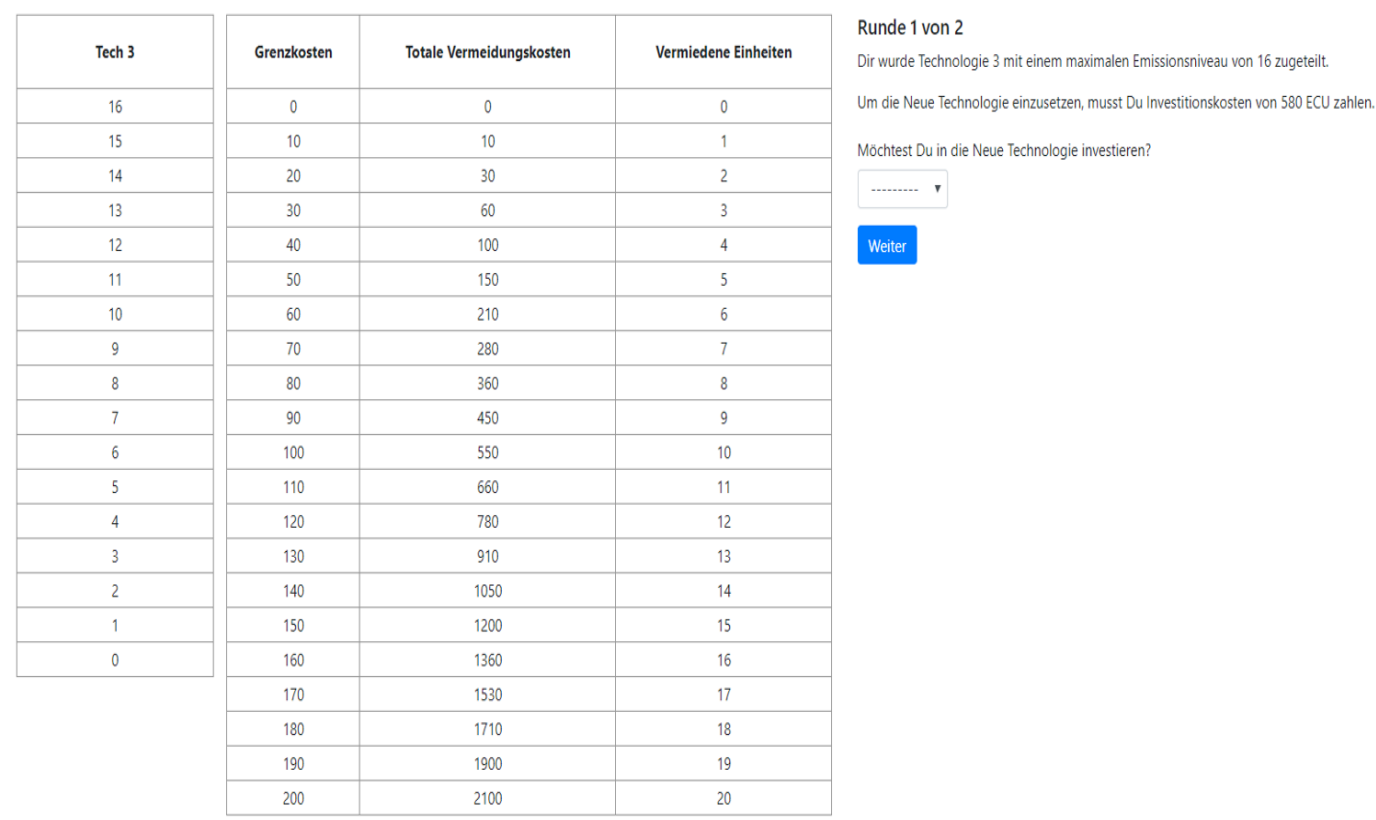

Figure 2.9 Screenshot of Stage 1. The left-hand side of the screen displays the current technology, while the right-hand side indicates the cost of investment. On the right-hand side, the subject indicates whether he/she wishes to invest in the new technology or not

Auktion

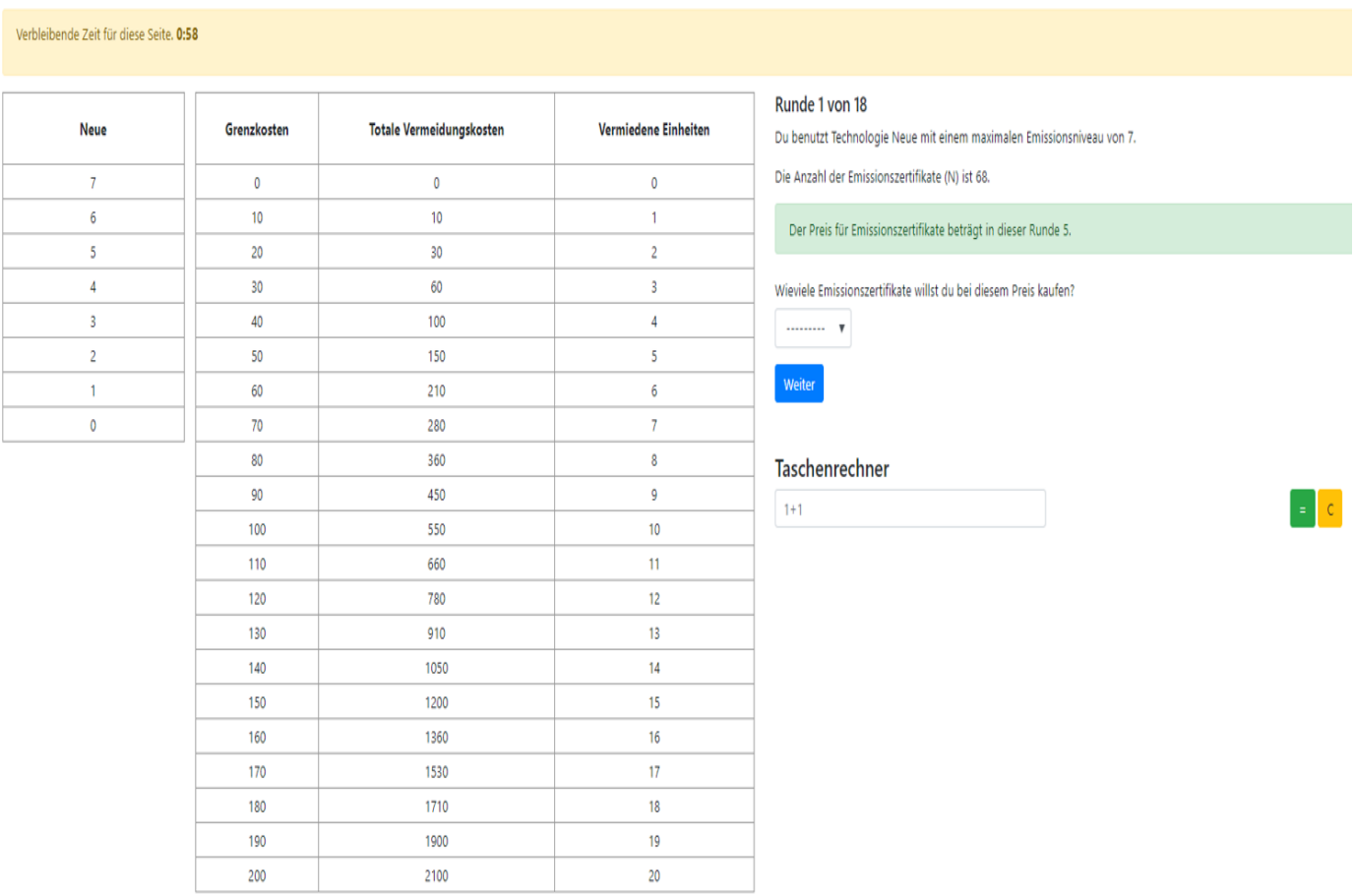

Figure 2.10 Screenshot of Stage 2. The left-hand side of the screen displays the current technology. The right-hand side shows the number of permits being issued and the subject decides on how many permits he/she wants to buy at that price 



\section{Chapter 3}

\section{An experimental analysis of the effects of imperfect compliance on technology adoption}

Researchers have been extensively studying the incentives that pollution taxes and tradable permit markets create for the adoption of advanced abatement technology in the case of perfect compliance. Our research tries to fill this gap by providing experimental evidence on such adoption behavior, providing some empirical insights into the dynamic efficiency of pollution taxes and tradable emission permits under imperfect compliance.

Coria, 2009 explores how the choice between taxes and permits affects the pattern of adoption of a cleaner technology. However, we are interested in analyzing the dynamic properties of emission taxes in the presence of imperfect compliance. Arguedas et al., 2010 find that under a system of exogenous pollution taxes in the presence of imperfect compliance, the pollution levels, and the incentives to adopt advanced abatement technologies are the same that under perfect compliance. Consequently, the presence of imperfect compliance only results in tax evasion. Villegas-Palacio and Coria, 2010 partly share these results, and conclude that the (endogenous) rate of technology adoption is not affected by the enforcement strategy.

A crucial criterion for policy design in environmental economics in the last years has been cost-effectiveness when policymakers include both abatement and enforcement costs. A relevant issue for the regulator is what would be more cost-effective: to set the legal cap at a certain level under perfect compliance or to set it at a lower level and allow for imperfect compliance. Stranlund, 2007, Arguedas, 2008, and Caffera and Chávez, 2011 found that (i) the differences in costs between the two alternatives depend on the fine structure, and (ii) inducing perfect compliance minimizes the total expected costs.

After a vast literature review, Stranlund, 2015, highlights the important insights into the nature of sources' compliance incentives and the effective and efficient design of enforcement strategies. However, he states that the enforcement challenges become more difficult as markets are developed to control greenhouse gas emissions. Coria and Zhang, 2015 analyze the consequences of an inspection framework where targeting is based on firms' past compliance record and the adoption of less polluting technologies 
as well. They conclude that targeted state-dependent enforcement has a deterrent effect and can help reduce total enforcement costs.

In this chapter, we study adoption incentives in the presence of imperfect compliance from an experimental perspective and compare the obtained results with the theoretical predictions in Arguedas et al., 2010. To this purpose, we have carried out a set of economic experiments to study the adoption of a cleaner technology when the regulator monitors firms emissions by emission taxes or permits and conducts imperfect compliance on the firms' emissions. In particular, we investigate the effect of different inspection probabilities and different induced optimal violation levels (perfect vs. imperfect compliance) on the firms' behavior concerning the adoption of advanced abatement technologies.

Regarding the experimental literature, only a minority of experiments on environmental policy instruments consider investment in low-pollution technology. Cochard et al., 2005 consider technology adoption incentives using emission taxes, and assume that emissions affect only the polluters themselves, but not other non-polluting agents. They show that an ambient tax does not generate any social dilemma, since the group optimum is a Nash equilibrium, resulting as a very efficient and reliable mechanism that improves welfare concerning the status quo. Ben-David et al., 1999 consider an emission permit market in which the firms' investment decision is irreversible. Their study finds that trade volume is not affected by an increase in cost heterogeneity, although higher price variability leads to lower efficiency from trade.

More recently, Camacho-Cuena et al., 2012 also study the incentives to adopt advanced abatement technologies under emissions trading, but unlike us, they consider perfect compliance. They find that the observed investment patterns are relatively close to the theoretical first-best, and the initial technology mainly determines the individual investment decision. Moreover, they conclude that auctioning and grandfathering are equivalent concerning their dynamic efficiency. Gangadharan et al., 2013 also focus on an industry with asymmetric firms that differ concerning maximum emissions. As in our model, the effect of investment in cleaner technology is asymmetric (dirty firms gain more by investing). Taschini et al., 2014 in a laboratory setting, explore the timing of irreversible adoption decisions of abatement technology under a grandfathering allocation rule. Their findings show that firms tend to invest in abatement technology faster when a strict enforcement mechanism is applied. Cason and Vries, 2018 study the performance of permit markets on dynamic efficiency, with permits being auctioned or grandfathered. Their results show that auctioning permits usually provides stronger R\&D incentives, leading to greater dynamic efficiency. 
Closer to our work, Caffera and Chávez, 2016 study the compliance behavior of firms for both transferable permits and standards. Unlike us, by allowing noncompliance, they find that the regulator could produce a reduction in emissions and a rise in the market price of tradable permits, which is at odds with theoretical predictions. Our experiment extends their study by introducing the possibility of investment in cleaner technology.

Our results suggest that firms' overall performance concerning investment is remarkably good; however, like Gangadharan et al., 2013, some firms with dirtier technologies under-invest and some firms with cleaner technologies over-invest.

In the case of taxes, and contrary to what Arguedas et al., 2010 theoretical model predicts, inducing imperfect compliance reduces the number of firms adopting the new technology only if the regulator implements a monitoring policy with a high inspection probability. However, in the case of permits, as predicted by Arguedas et al., 2010, permit prices under imperfect compliance are smaller than that under perfect compliance. As a consequence, adoption incentives under imperfect compliance are smaller, regardless of the inspection probability.

The chapter is organized as follows. We present two sections, one for taxes and other for permits. In each of them, we summarize the theoretical model and present the main hypotheses we want to evaluate with our laboratory experiments. We also describe the experimental design and procedure. Finally, we present the results and conclusions.

\subsection{The model}

As mentioned before, our investigation draws on the model of Arguedas et al., 2010, who establish the dynamic optimality of taxes and permits.

Consider an industry with $n$ polluting firms and $T$ different initial technologies, each firm $i=1, \ldots, n$ is endowed with one of these initial technologies. In the absence of regulation firm $i$ pollutes $e_{i}^{\max }>0$. However, firm $i$ can abate emissions by adopting a new technology $a$ at a fixed cost, $I>0$, the same for all firms. The firms technologies are represented by their abatement cost functions $c_{i}^{k}\left(e_{i}\right)$ with $k=1, \ldots, T, a$. For any targeted emission level $e$ we assume $c_{i}^{k}(e)>0$ for $e<e_{i}^{\max }$. Adopting the new technology leads to lower marginal abatement costs, i.e. $-c_{i}^{T}\left(e_{i}\right)>-c_{i}^{a}\left(e_{i}\right)$ for all $e \leq e_{i}^{\max }$, where $-c_{i}^{k}\left(e_{i}\right) \equiv-\partial c_{i}^{k}\left(e_{i}\right) / \partial e$ is the marginal abatement cost.

A regulator is interested in reducing the aggregate emissions of the firms in the industry at a level of $E^{*}$. When setting the optimal number of permits being issued $S>0$ (the optimal tax rate, $\tau>0$ ), the regulator uses an increasing and convex 
social damage function, $D(E)$; where $E=\sum_{i=1}^{n} e_{i}$ indicates aggregate emissions. We assume that subjects have to hold a permit to be legally able to emit a unit. The regulator issues a number of permits $S$ equal to $E^{*}$ and auctions off permits using an ascending clock auction.

A social planner minimizes total social costs concerning emissions and the number of firms. When the fixed investment cost is independent of the initial technology, and if not all firms are supposed to adopt in equilibrium the advanced technology, it is always optimal for at least those firms with the highest abatement costs to invest, i.e., there will be some index $j$ such that the firms $i=1, \ldots, j$ will invest.

Using $A M A C^{*}(E, j)$ to denote the optimal aggregate marginal abatement cost when the first $j$ firms have adopted the advanced abatement technology, the regulator will choose the optimal aggregate emission level $E^{*}$, satisfying:

$$
D^{\prime}\left(E^{*}\right)=A M A C^{*}\left(E^{*}, j\right)
$$

Assuming that a regulator uses taxes to control emissions, it will enforce the aggregate emission level $E^{*}$. Using $\tau$ to denote the tax level, firm $i$ with technology $k$ will choose an emission level $e_{i}(\tau, k)$ such that its marginal abatement cost equals the tax rate: $-c_{i}^{k}\left(e_{i}(\tau, k), k(i)\right)=\tau$.

Firms must report their emission levels to the regulator and pay taxes according to the reported emissions $r_{i}$. The regulator enforces compliance by auditing the firms with a homogeneous and exogenous probability $\pi$. If audited, the number of emitted units, $e_{i}$, will be compared with the emissions reported, $r_{i}$. A firm complies with the regulation if she reports the actual emissions $\left(r_{i}=e_{i}\right)$, while it does not comply with the regulation if she reports less emissions i.e., $\left(r_{i}<e_{i}\right)$. Thus, let $v_{i}=e_{i}-r_{i}$ define the violation level associated to underreporting the (real) emissions.

Assuming that a regulator uses permits to control emissions, it will issue a number of permits, $S=E^{*}$, to enforce the aggregate emission level $E^{*}$. Using $p$ to denote the price for permits, firm $i$ with technology $k$ will choose an emission level $e_{i}(p, k)$ such that its marginal abatement cost equals the permit price: $-c_{i}^{k}\left(e_{i}(p, k), k(i)\right)=p$.

To introduce the possibility of non-compliance, the firms have to decide how many units they emit and how many permits they buy. The regulator enforces compliance by auditing the firms with a homogeneous and exogenous inspection probability $\pi$. If audited, the number of emitted units, $e_{i}$, will be compared with the number of permits held $s_{i}$. A firm complies with the regulation if it discharges the number of permits it holds $\left(e_{i}=s_{i}\right)$, while it does not comply if firm's permit holding is below the real emission level $\left(s_{i}<e_{i}\right)$. Thus, let $v_{i}=e_{i}-s_{i}>0$ be the amount of violation. 
In case non-compliance is detected by the regulator, i.e., $v_{i}>0$, the corresponding firm is fined according to a fining function $F\left(v_{i}\right)$, increasing in the firm's violation level:

$$
F\left(v_{i}\right)=f_{1} v_{i}+f_{2} v_{i}^{2}
$$

A risk-neutral firm $i$ solves the following optimization problem (firm's compliance decision) in case of emission taxes:

$$
\begin{array}{ll}
\min _{c_{i}^{T}, c_{i}^{a}} & \left\{\begin{array}{l}
\min _{e_{i}, r_{i}} c_{i}^{T}\left(e_{i}\right)+\tau r_{i}+\pi F_{i}\left(v_{i}\right) ; \\
\min _{e_{i}, r_{i}} c_{i}^{a}\left(e_{i}\right)+\tau r_{i}+\pi F_{i}\left(v_{i}\right)+I
\end{array}\right\}, \\
\text { s.t. } & v_{i} \geq 0 .
\end{array}
$$

And in case of emission permits:

$$
\begin{array}{ll}
\min _{c_{i}^{T}, c_{i}^{a}} & \left\{\begin{array}{l}
\min _{e_{i}, r_{i}} c_{i}^{T}\left(e_{i}\right)+p s_{i}+\pi F_{i}\left(v_{i}\right) ; \\
\min _{e_{i}, r_{i}} c_{i}^{a}\left(e_{i}\right)+p s_{i}+\pi F_{i}\left(v_{i}\right)+I
\end{array}\right\}, \\
\text { s.t. } & v_{i} \geq 0 .
\end{array}
$$

After solving the Lagrangian problem, the optimal violation level given is by:

$$
\tau=p=\pi F^{\prime}\left(v^{*}\right)=D^{\prime}\left(E^{*}\right)
$$

Consequently, the hypotheses to be tested in this chapter for the emission taxes are:

Hypothesis 1: Allowing for firms' imperfect compliance does not alter the firms' technology adoption incentives and, as a corollary, the aggregate emission levels.

Hypothesis 2: The presence of imperfect compliance results only on tax evasion.

And for emission permits:

Hypothesis 3: The incentives to adopt an advanced abatement technology only depend on the firms' technological characteristics and the permit price, while they are independent of the monitoring strategy. If two alternative monitoring policies lead to the same equilibrium permit price, adoption incentives are the same.

Hypothesis 4: For a given supply of permits, the equilibrium permit price under imperfect compliance is smaller than that under perfect compliance. Therefore, adoption incentives under imperfect compliance are smaller than those under perfect compliance. 


\subsection{Experimental design}

The experiment was conducted in the Laboratori d'Economia Experimental (LEE) at the Universitat Jaume I using the z-Tree software (Fischbacher, 2007). Subjects were volunteer undergraduate students in Economics, Finance and Accounting and Business Administration. Earnings during the experiments were designated in Experimental Currency Units (ECUs) and converted into Euro at the end of the session.

\subsubsection{Parameters and treatments}

Our experimental design is close to that of Camacho-Cuena et al., 2012. We consider an industry consisting of 12 firms producing with one of five conventional technologies available: $T_{j}, j=1, \ldots, 5$ (see Table 3.1 for the initial distribution of technologies among firms); being each technology characterized by a default emissions level. The firms' technologies are represented by stepwise, downward sloping marginal abatement cost functions as depicted in Table 3.3. Note that technology $T_{1}$ (technology $T_{5}$ ) denotes the highest (lowest) maximum default emissions chosen in the absence of regulation. Firms obtain a default profit of 1200 ECU from their production activity and can adopt the advanced technology $a$ by investing $580 \mathrm{ECU},{ }^{1}$ which is the same for all firms. The adoption of advanced technology leads to lower default emissions and, therefore, lower marginal abatement cost (MAC) for the firm.

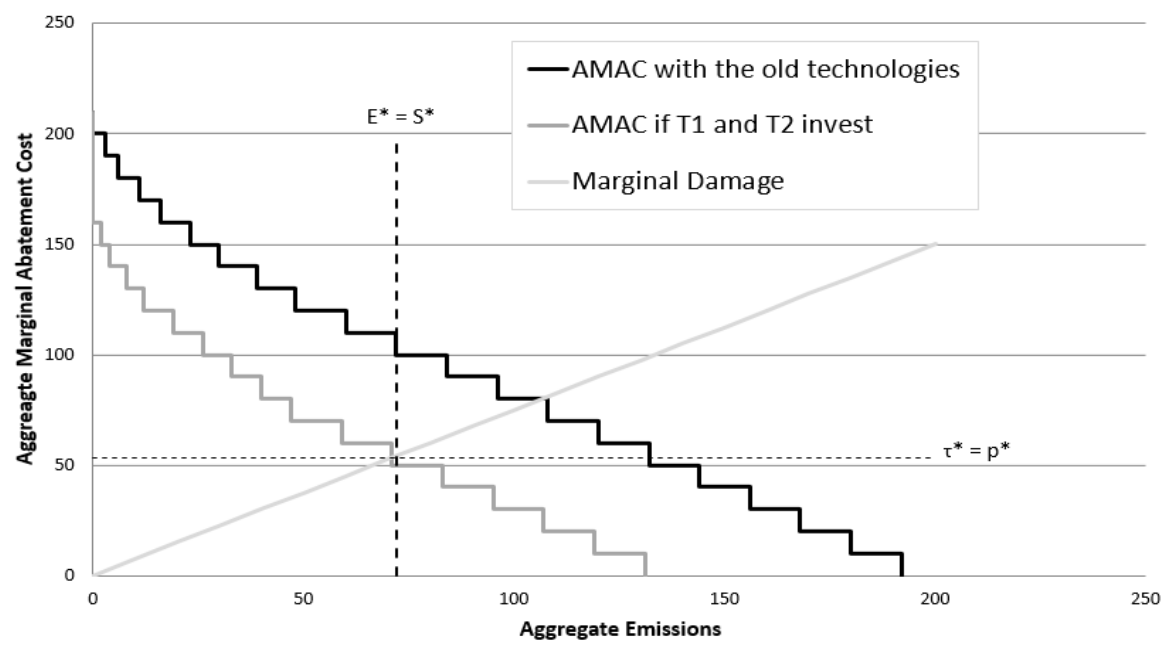

Figure 3.1 Socially optimal instrument level and tax

With these parameters, in equilibrium, only firms with technologies $T_{1}$ and $T_{2}$ (5 firms in total) have incentives to invest in the new technology. ${ }^{2}$ This investment

\footnotetext{
${ }^{1}$ For simplicity, we assume that adopting the new technology has the same cost for all firms regardless of the initial technology; however, we can easily relax this hypothesis as in Arguedas et al., 2010.

${ }^{2}$ Adopting the new technology costs to the firms 580 ECU and results in 7 emission units (see Table 3.3). A firm endowed with $T_{2}$ (18 emissions) prefers paying the adoption cost rather than the abatement cost that leads to these 7 emission units (18-7=11, abating 11 units costs 660 ECU). On the contrary, this changes as we move to cleaner technologies, regarding $T_{3}$ (16 emissions) she prefers abating (16-7=9, abating 9 units costs 450 ECU) rather than adopting the new technology.
} 
decision corresponds to optimal behavior based on expected profits, which are the same across firms sharing the same technology-as presented in the next section, and an optimal number of permits $S=72$ to be auctioned off from the perspective of the regulator. ${ }^{3}$ The resulting perfect-compliance equilibrium permit price (tax level) of the market is expected to be 53 ECU. ${ }^{4}$

\begin{tabular}{llllll}
\hline Firm type & $T_{1}$ & $T_{2}$ & $T_{3}$ & $T_{4}$ & $T_{5}$ \\
\hline Number of firms & 3 & 2 & 2 & 2 & 3 \\
\hline
\end{tabular}

Table 3.1 Distribution of technologies among firms: firm type (according to the initial technologies), number of firms per type

Table 3.2 shows the experimental treatments and parameters implemented. We conducted 2 (3) sessions of each of the 4 different treatments for both emission taxes and permits varying the inspection probability $(\pi)$ and the induced optimal violation level $\left(v_{i}=v^{*}\right)$ :

\begin{tabular}{ccccc}
\hline Treatment & $\pi$ & $v^{*}$ & $f_{1}$ & $f_{2}$ \\
\hline P35V0 & 0.35 & 0 & 152 & 2 \\
P35V2 & 0.35 & 2 & 144 & 2 \\
P70V0 & 0.70 & 0 & 76 & 1 \\
P70V2 & 0.70 & 2 & 72 & 1 \\
\hline
\end{tabular}

Table 3.2 Experimental treatments and parameters

Regarding inspection probability, in treatments P35V0 and P35V2 (in which $\pi=0.35$ ), firms are facing a low inspection probability, i.e., firms will be audited with a $0.35 \%$ probability; while in treatments P70V0 and P70V2 $(\pi=0.70)$ firms face a high inspection probability, i.e., firms will be inspected with a $70 \%$ probability.

Regarding the optimal violation level, in treatments P35V0 and P70V0, the optimal behavior concerning reported emissions results in perfect compliance (i.e. $\mathrm{v}^{*}=0$ ); while in treatments P35V2 and P70V2, the optimal violation level results in non-compliance, i.e., it is optimal for the firms to underreport emissions $\left(\mathrm{v}^{*}=2\right)$. We implement this by decreasing the fine through parameters $f_{1}$ and $f_{2}$, the linear and gravity components respectively, defining the fining function in equation (1). Under the assumption of expected profit maximization, expected fines are the same in all implemented treatments.

\footnotetext{
${ }^{3}$ The optimal emission level with a hypothetical damage function of $D(E)=\frac{E^{2}}{2.67}$ (as illustrated in Figure 3.1).

${ }^{4}$ Note that, given the optimal investment pattern, at any price below 53 ECU, there is excess demand for emission permits.
} 


\begin{tabular}{|c|c|c|c|c|c|c|}
\hline \multicolumn{6}{|c|}{ Emissions per technology type } & \multirow[t]{2}{*}{ MAC } \\
\hline$T_{1}$ & $T_{2}$ & $T_{3}$ & $T_{4}$ & $T_{5}$ & $a$ & \\
\hline 20 & 18 & 16 & 14 & 12 & 7 & 0 \\
\hline 19 & 17 & 15 & 13 & 11 & 6 & 10 \\
\hline 18 & 16 & 14 & 12 & 10 & 5 & 20 \\
\hline 17 & 15 & 13 & 11 & 9 & 4 & 30 \\
\hline 16 & 14 & 12 & 10 & 8 & 3 & 40 \\
\hline 15 & 13 & 11 & 9 & 7 & 2 & 50 \\
\hline 14 & 12 & 10 & 8 & 6 & 1 & 60 \\
\hline 13 & 11 & 9 & 7 & 5 & 0 & 70 \\
\hline 12 & 10 & 8 & 6 & 4 & & 80 \\
\hline 11 & 9 & 7 & 5 & 3 & & 90 \\
\hline 10 & 8 & 6 & 4 & 2 & & 100 \\
\hline 9 & 7 & 5 & 3 & 1 & & 110 \\
\hline 8 & 6 & 4 & 2 & 0 & & 120 \\
\hline 7 & 5 & 3 & 1 & & & 130 \\
\hline 6 & 4 & 2 & 0 & & & 140 \\
\hline 5 & 3 & 1 & & & & 150 \\
\hline 4 & 2 & 0 & & & & 160 \\
\hline 3 & 1 & & & & & 170 \\
\hline 2 & 0 & & & & & 180 \\
\hline 1 & & & & & & 190 \\
\hline 0 & & & & & & 200 \\
\hline
\end{tabular}

Table 3.3 Marginal Abatement Cost (MAC) per technology type. $T_{1}, \ldots, T_{5}$ denote the initial technologies, while $a$ denotes the advanced abatement technology

\subsection{Emission taxes}

\subsubsection{Experimental procedure}

A group of 12 subjects participated in each session, assuming the role of decisionmakers at firms operating in an industry subject to environmental regulation. ${ }^{5}$ Upon arrival at the laboratory, we randomly assigned subjects to one of the computers. We gave subjects the instructions and answered their questions before they played a trial period. ${ }^{6}$ In each session, subjects played 10 periods of a given treatment, and there was no time limit to make their decision. Each period consisted of the following three stages:

Stage 1: Technology decision Each subject is randomly assigned an initial technology $T_{1}, \ldots, T_{5}$, following the distribution displayed in Table 3.1, and are informed about the unit tax, inspection probability and marginal (and total) fines they will face in case non-compliance is detected. Subjects simultaneously decide whether to

\footnotetext{
${ }^{5}$ Each subject participated only in one session.

${ }^{6}$ This trial period was identical to the real periods, except that we did not take it into account for the final payoff.
} 
keep the initial technology or adopt the advanced technology $a$, investing 580 ECU.

Stage 2: Emissions decision Subjects decide on their real emission levels $\left(e_{i}\right)$ and the emission level they report to the regulator $\left(r_{i}\right)$. Firms should pay then a tax rate of $53 \mathrm{ECU}$ per emission unit reported to the regulator. The abatement level results in the difference between maximum and emitted (real) units.

Stage 3: Inspection and profit Once subjects have submitted their real and reported emissions, they are inspected with probability $\pi$, and if a positive violation level is detected $\left(v_{i}>0\right)$ they will pay the corresponding fine $F_{i}\left(v_{i}\right)$ (see equation $(1))$. Recall that the violation level $\left(v_{i}\right)$ is equal to the difference between real $\left(e_{i}\right)$ and reported $\left(r_{i}\right)$ emissions levels. Let's compute the profit of the firm $i$ in this period as: $\Pi_{i}^{t}= \begin{cases}1200-c_{i}^{T}\left(e_{i}\right)-53 r_{i}-F_{i}\left(v_{i}\right) & \text { if the firm does not invest in period } t, \\ 1200-c_{i}^{a}\left(e_{i}\right)-53 r_{i}-F_{i}\left(v_{i}\right)-580 & \text { if it invests in period } t\end{cases}$ where $c_{i}^{T}\left(e_{i}\right)$ and $c_{i}^{a}\left(e_{i}\right)$ are the abatement cost functions corresponding to the $j=1, \ldots 5$ conventional and new technologies, respectively. Note that in case of firms going uninspected or $v_{i}=0$, the fine term does not apply.

The subjects' final payoff is the accumulated profit obtained in two periods randomly chosen at the end of the session. Each session lasted approximately 90 minutes, and the average payoff was around $€ 17$.

\subsubsection{Results}

Arguedas et al., 2010 theoretical model predicts that under a system of exogenous pollution taxes with the possibility of underreporting, adoption decisions and emission levels would not change. The only consequence of imperfect compliance would be then tax evasion.

\section{Technology adoption}

Recall that, in equilibrium, it is optimal for those firms operating with technologies $T_{1}$ and $T_{2}$ (i.e., 5 out of 12 firms in the industry) to adopt the new technology $a$. On the contrary, the remaining firms using technologies $T_{3}$ thru $T_{5}$ have no incentives to invest and adopt the new technology.

Figure 3.2 shows the distribution of firms adopting the new technology as a function of the initial technology assigned. A general feature common to all implemented treatments is that most of the firms using initially technologies $T_{1}$ and $T_{2}$ adopt the new technology and this proportion decreases as we move to technologies $T_{3}, T_{4}$ and $T_{5}$, i.e., those with initially lower baseline emissions and lower marginal abatement 
costs.

We observe that inducing imperfect compliance reduces significantly the number of firms adopting the new technology only when the regulator applies a high inspection probability (P70V0 vs. P70V2), regardless of the initial technology. Instead, imperfect compliance brings the firms' behavior concerning the adoption of the new technology closer to the equilibrium if the regulator applies a low inspection probability. Indeed, relying on the Kolmogorov Smirnov $(\mathrm{K}-\mathrm{S})$ we obtain that for a low inspection probability, $\pi=0.35$, we cannot reject the null hypothesis that the two samples (P35V0 and P35V2) are drawn from the same distribution; however, for a high inspection probability, $\pi=0.70$, the null hypothesis of equal samples comparing P70V0 to P70V2 is rejected. Therefore, we confirm Hypothesis 1 for a low inspection probability, whereas we reject it if the regulator implements a high inspection probability.
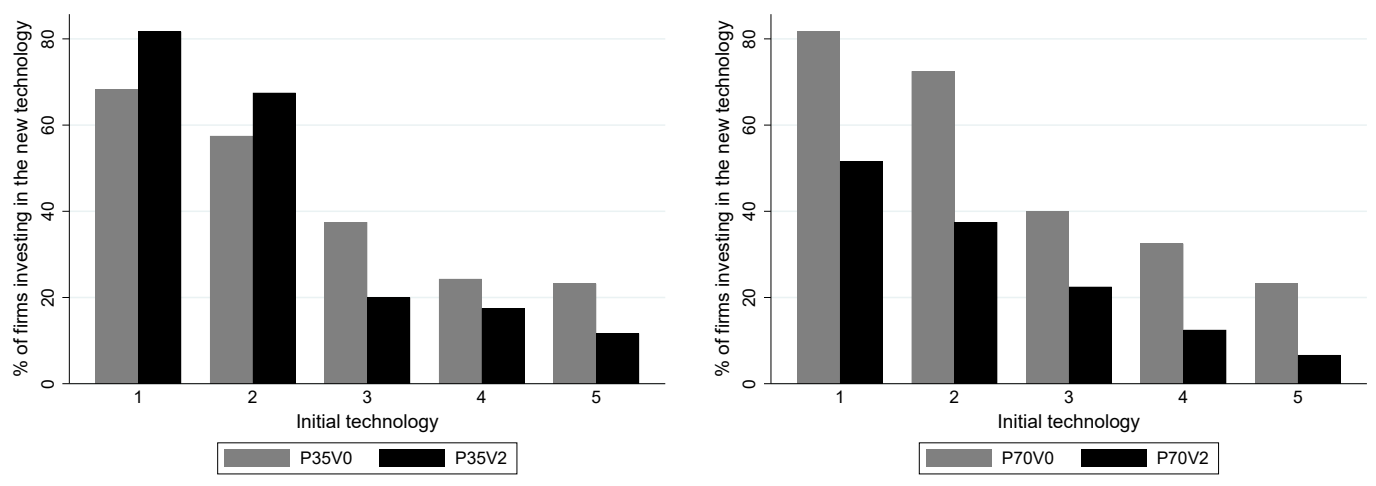

Figure 3.2 Percentage of firms investing in technology a per initial Technology $T_{1}, \ldots, T_{5}$

Result 8. Inducing imperfect compliance when the regulator implements a monitoring policy with a high inspection probability significantly reduces the firms adopting the new technology.

Turning now on the effect of the inspection probability on the firms' investment we observe a second asymmetry: under perfect compliance, $v^{*}=0$, increasing the inspection probability seems to increase the number of firms adopting the new technology (i.e., the adoption rate for P70V0 is greater than that for P35V0) although this difference is not statistically significant; while we observe the opposite effect when inducing imperfect compliance, $v^{*}=2$, since adoption rates in treatment P70V2 are significantly smaller than in treatment P35V2. Consequently, we conclude that increasing the inspection probability significantly reduces the number of firms adopting the new technology only under imperfect compliance. I.e.,

Result 9. Under imperfect compliance, increasing the inspection probability has a significant effect on the pattern of technology investments by reducing adoption rates.

Inducing imperfect compliance reduces firms' adoption in the new technology, the reason behind this result could be the trade-off between saving on investment cost 
and paying fines.

To properly explain the factors determining investment behavior in the various treatments, we estimated a pooled Probit model with robust standard errors clustered across sessions. As explanatory variables, we include dummies for the initial technologies assigned, the average fine in the previous period, and the period number. We analyze the influence of the initial technology on the probability of adoption.

\begin{tabular}{llccc}
\hline Treatment & P35V0 & P35V2 & P70V0 & P70V2 \\
\hline Technology $T_{2}$ & $-0.285^{* * *}$ & -0.474 & -0.315 & $-0.376^{* *}$ \\
& $(0.060)$ & $(0.389)$ & $(0.301)$ & $(0.185)$ \\
Technology $T_{3}$ & $-0.799^{* * *}$ & $-1.787^{* * *}$ & $-1.163^{* *}$ & $-0.828^{* * *}$ \\
& $(0.021)$ & $(0.344)$ & $(0.484)$ & $(0.011)$ \\
Technology $T_{4}$ & $-1.176^{* * *}$ & $-1.887^{* * *}$ & $-1.374^{*}$ & $-1.201^{* * *}$ \\
& $(0.304)$ & $(0.247)$ & $(0.731)$ & $(0.015)$ \\
Technology $T_{5}$ & $-1.219^{* * *}$ & $-2.141^{* * *}$ & $-1.648^{*}$ & $-1.575^{* * *}$ \\
& $(0.271)$ & $(0.774)$ & $(0.7852)$ & $(0.134)$ \\
Fine & -0.045 & 0.058 & -0.081 & 0.125 \\
& $(0.262)$ & $(0.130)$ & $(0.391)$ & $(0.101)$ \\
Period & $-0.019^{* * *}$ & $-0.067^{* *}$ & $-0.042^{* *}$ & $-0.080^{* * *}$ \\
& $(0.005)$ & $(0.028)$ & $(0.019)$ & $(0.022)$ \\
Cons & $0.589^{* * *}$ & $1.277^{* *}$ & $1.154^{*}$ & $0.405^{* * *}$ \\
& $(0.216)$ & $(0.516)$ & $(0.671)$ & $(0.058)$ \\
Pseudo - $R^{2}$ & 0.110 & 0.310 & 0.183 & 0.167 \\
Observations & 233 & 240 & 240 & 240 \\
\hline
\end{tabular}

Table 3.4 Pooled Probit estimation (with clustered standard errors across sessions) of investment per treatment using Technology $T_{1}$ as a baseline (std. err. are given in parentheses). The dependent variable: probability to adopt the new technology in period $t$ by firm $i .{ }^{* * *},{ }^{* *}$, and ${ }^{*}$ denote significance at the $1 \%, 5 \%$, and $10 \%$, respectively

Since firms assigned with highly polluting technologies gain more from adopting the new technology, we expect the firms' adoption probability to decay when initially being assigned with a less polluting technology. More specifically, we expect discrete jumps in adoption when moving across technologies (especially between $T_{2}$ and $T_{3}$ denoting the threshold or borderline between having incentives to adopt the new technology in equilibrium, and not). The results reported in Table 3.4 confirm our hypothesis for all implemented treatments. ${ }^{7}$

Regarding further results, we find that the fine is not an incentive to adopt the new technology.

\footnotetext{
${ }^{7}$ We use a t-test to compare the coefficients for every technology between perfect and imperfect compliance. We find that inducing imperfect compliance statistically decreases the probability to adopt the new technology when firms have initially been endowed with $T_{3}$ and $T_{5}$ only under a low inspection probability (P35V0 vs. P35V2).
} 


\section{Real emissions}

In this section, we study how emissions are affected by imperfect compliance. Figure 3.3 shows the average difference between individual real emissions and the optimal emissions $\left(e_{i}-e^{*}\right)$. Optimal emission $e^{*}$ is the units they should release given a tax rate of $\tau=53$. Given firms' observed behavior concerning the adoption of the new technology, we expect an increase in emissions under imperfect compliance, in particular, if the regulator implements a high inspection probability as monitoring policy. The figure shows that in treatment P70V0, the difference can be negative, i.e., some firms emit (report and/or abate) less (more) units than they should.
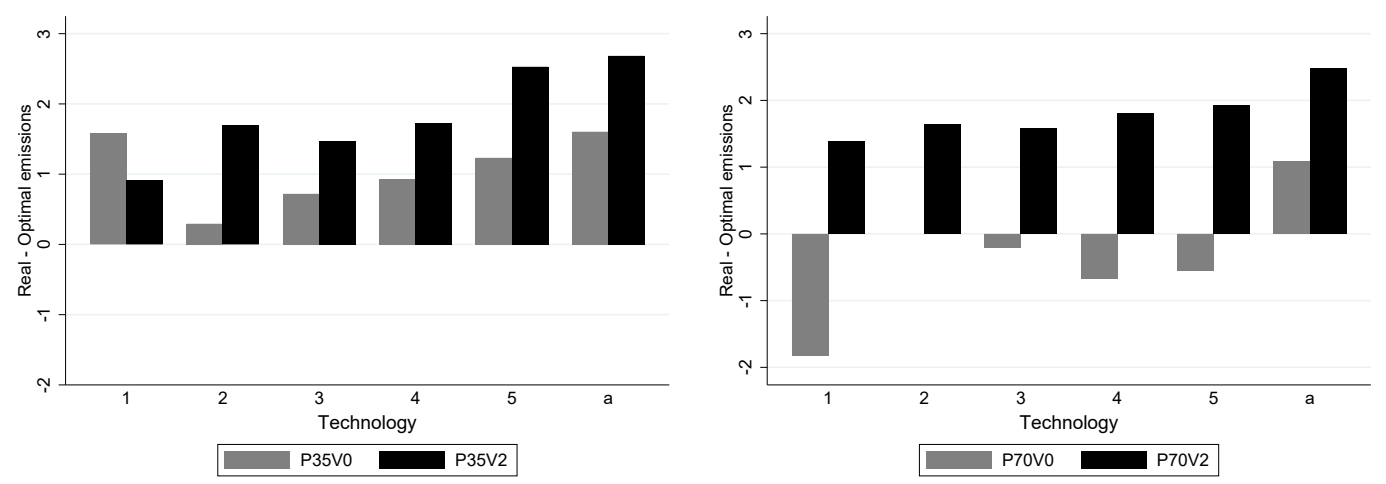

Figure 3.3 Average difference between individual real and optimal emissions $\left(e_{i}-e^{*}\right)$ per initial technology and treatment

The results clearly show that inducing imperfect compliance increases significantly firms' real emissions independently on the inspection probability implemented by the regulator. ${ }^{8}$ Using a K-S test, we can reject the null hypothesis that the two samples were drawn from the same distribution for the two inspection probabilities implemented (P35V0 and P35V2; P70V0 and P70V2).

Result 10. Inducing imperfect compliance significantly increases firms' emissions independently on the monitoring strategy implemented by the regulator.

Therefore, inducing imperfect compliance not only results in lower adoption rates, logically followed by higher emissions but, as we address in the next section, it is also coupled with widespread underreporting of emissions, i.e., higher violation levels. In Table 3.12 of Appendix 3.C, we show further results regarding the average real $\left(e_{i}\right)$ and reported $\left(r_{i}\right)$ individual and industry emissions per technology and treatment across periods and groups.

\footnotetext{
${ }^{8}$ See Table 3.12 in the Appendix for further detail. Using a Mann Whitney test, we can reject the null hypothesis that there is no difference between real emissions deviations from the optimum under perfect and imperfect compliance for the two inspection probabilities implemented.
} 


\section{Violation level and tax evasion}

Recall that subjects should decide on their real and reported emissions and pay emission taxes proportional to their reported emissions. When deciding the reported emissions subjects should consider that they will be inspected with probability $\pi$ paying the corresponding fine $F\left(v_{i}\right)$ if a positive violation level is discovered in the inspection (i.e. $v_{i}>0$, where $v_{i}=e_{i}-r_{i}$ ).

First, we want to study whether the behavior regarding violation level deviates from equilibrium, i.e., $v^{*}=0$ and $v^{*}=2$. For this purpose, using a one-sample Wilcoxon sign rank test comparing the violation level with the equilibrium violation level for each treatment, we can reject the null hypothesis that both distributions are the same (except in treatment P70V2 with firms using the new technology).

Consistent with previous results, Figure 3.4 shows that the average violation level deviations from optimal $\left(v_{i}-v^{*}\right)$ increases for all technologies as we move from $v^{*}=0$ to $v^{*}=2$ for the two inspection probabilities implemented. However, we also observe that when inducing perfect compliance violation levels are higher when a low inspection probability is applied (i.e., the violation level for P35V0 is higher than that for P70V0). On the contrary, under imperfect compliance, firms violate more when the regulator applies a high inspection probability (i.e., the violation level for P70V2 is higher than that for P35V2). Indeed, relying on the Kolmogorov Smirnov (K-S) we obtain that for induced perfect compliance, $v^{*}=0$, we reject the null hypothesis that the two samples (P35V0 and P70V0) are drawn from the same distribution. In the same line, when inducing imperfect compliance, $v^{*}=2$, the null hypothesis comparing P35V2 to P70V2 is rejected.
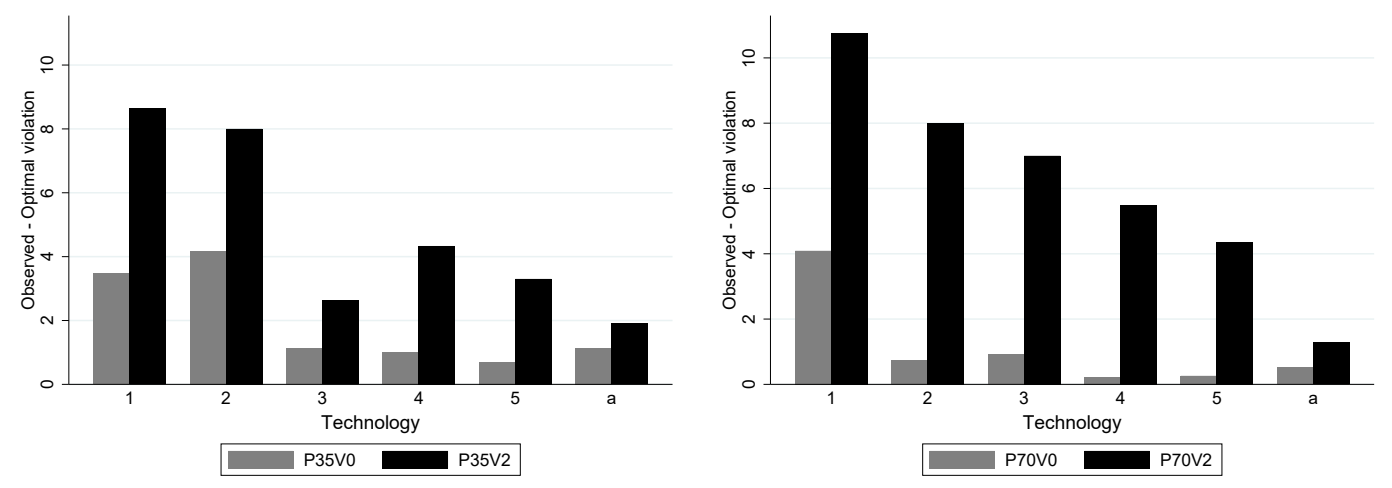

Figure 3.4 Average individual violation level deviations from optimal violation $\left(v_{i}-v^{*}\right)$ per initial technology and treatment

Assuming imperfect compliance with a given inspection probability results in uninspected violations, that is, firms evade taxes implying that the damage of these undetected emissions cannot be compensated in the form of fines either. Figure 3.5 shows the average individual and industry tax evasion, measured as $\sum_{i=1}^{12} \overline{u_{i}} \tau$, where 
$u_{i}$ are the uninspected violated emissions, per treatment and technology. ${ }^{9}$ Therefore, in line with the previous results on the violation level, we observe that inducing imperfect compliance increases tax evasion significantly. Moreover, we also observe an asymmetric effect, under perfect compliance a low inspection probability shows, on average, a higher violation level than a high inspection probability, while it is the other way around for imperfect compliance.

Result 11. Inducing imperfect compliance significantly increases tax evasion independently on the monitoring strategy implemented by the regulator.
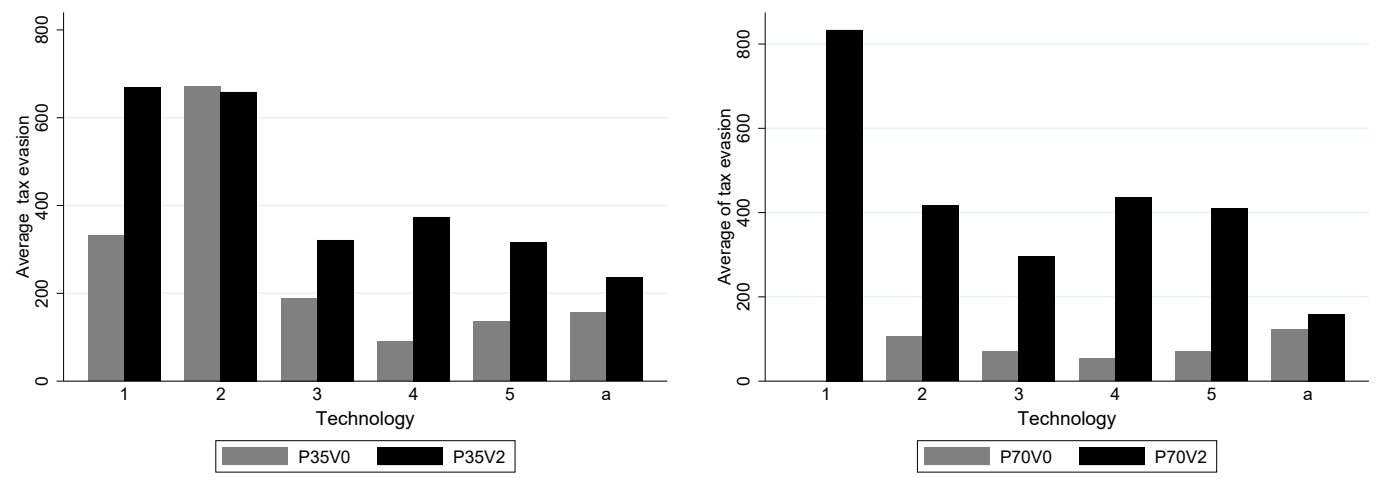

Figure 3.5 Average individual tax evasion per technology and treatment

Figure 3.6 shows the average individual fine per treatment and technology. ${ }^{10}$ As can be observed, fines are higher under perfect compliance for both inspection probabilities. Fines decrease as we move from a low to a high inspection probability and from perfect to imperfect compliance.
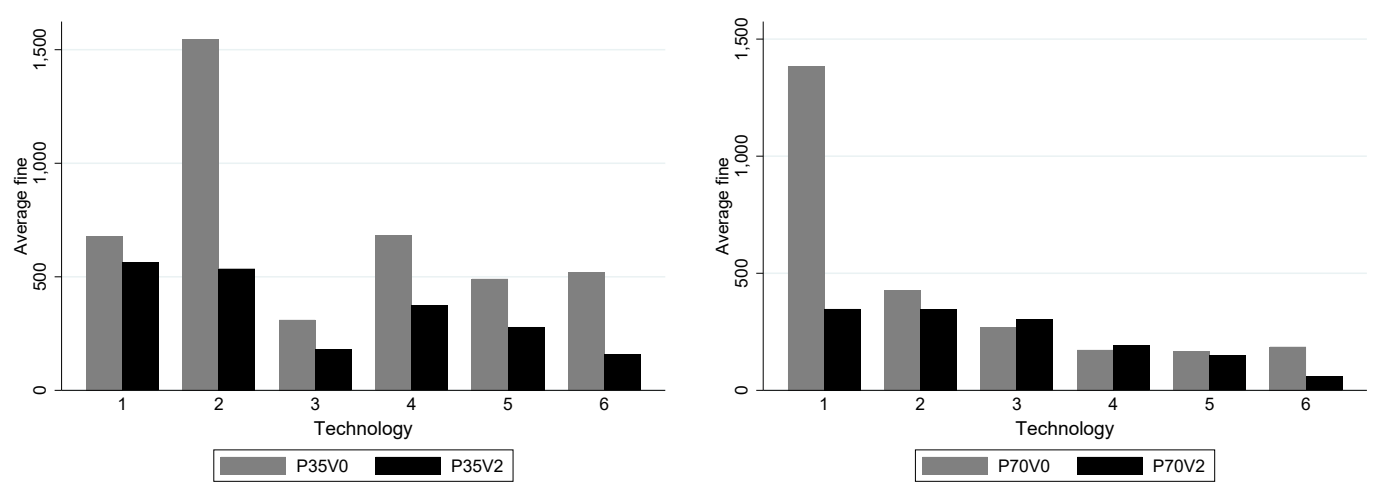

Figure 3.6 Average individual fine per technology and treatment

From a policy perspective, it is relevant that undetected violation must be compensated by fines on detected violations. From Figures 3.5 and 3.6, we see that for

\footnotetext{
${ }^{9}$ See Table 3.13 in the Appendix for further detail.

${ }^{10}$ See Table 3.14 in the Appendix for further detail.
} 
perfect compliance the fine exceeds the tax evasion (reinforced by the quadratic nature of the fine function vs. the linear nature of the tax evasion function).

In their survey Feld and Frey, 2007m show the ambiguous impact of deterrence on tax compliance. Most of the theoretical studies and some empirical evidence argue that the higher the penalties, the lower is tax evasion, and the higher is the monitoring probability, the lower is tax evasion. In other words, an increase in audit probability and an increase in tax penalty enhance tax compliance. However, Feld and Frey, 2002 found that a higher intensity of control increases tax evasion. In our study, the higher the penalties, the lower is indeed tax evasion; though, the higher the monitoring probability, the lower the tax evasion is only true under perfect compliance, but not under imperfect compliance.

In Tables 3.13 and 3.14 in Appendix 3.C, we show further results regarding the average individual and industry tax evasion and fine per treatment and technology, respectively.

\section{Efficiency comparisons}

A well-known efficiency measure, used by Camacho-Cuena et al., 2012, to test the performance of mechanisms in experimental economics is the ratio of the theoretical minimal social cost divided by the social cost induced by the observed behavior.

\begin{tabular}{ccccc}
\hline & P35V0 & P35V2 & P70V0 & P70V2 \\
\hline ER $R^{\text {Total }}$ & 0.90 & 0.85 & 0.77 & 0.92 \\
& $(0.26)$ & $(0.14)$ & $(0.12)$ & $(0.20)$ \\
\hline
\end{tabular}

Table 3.5 Mean (Std. Dev.) of the different efficiency ratios

We aim to study the total efficiency, estimated as the ratio of the lowest possible total abatement cost divided by the observed total abatement cost. For this purpose, we denote the total variable abatement cost as TVAC, i.e. $T V A C=\sum_{i=1}^{n} C^{i}\left(e_{i}, \kappa(i)\right)$, where $\kappa(i) \in\{k(i), a\}$ is the actual technology being used by firm $i$ after the adoption decision. Let $\kappa=(\kappa(1), \ldots, \kappa(n))$ be the technology profile after the investment stage. Further $\kappa^{o b s}=\left(\kappa^{o b s}(1), \ldots, \kappa^{o b s}(n)\right)$ is the observed technology profile while $\kappa^{*}=\left(\kappa^{\star}(1), \ldots, \kappa^{\star}(n)\right)$ is the efficient one. Additionally, we use $e^{o b s}=\left(e_{1}^{o b s}, \ldots, e_{n}^{o b s}\right)$ to indicate the observed emission-permit allocation, and $e^{\star}(\kappa)$ to indicate the optimal emission-permit allocation contingent on a given technology profile $\kappa$. Then $T V A C\left(e^{o b s}, \kappa^{o b s}\right)=\sum_{i=1}^{n} C^{i}\left(e_{i}^{o b s}, \kappa^{o b s}(i)\right)$ is the observed TVAC. $A=\left(A_{1}, \ldots, A_{n}\right)$ with $A_{i} \in\{0,1\}$ is the investment pattern in the advanced abatement technology, where $A_{i}=1$ if subject $i$ invests and $A_{i}=0$, otherwise. Further we write $A^{*}=\left(A_{1}^{*}, \ldots, A_{n}^{*}\right)$ for the optimal investment pattern, and $A^{o b s}=\left(A_{1}^{o b s}, \ldots, A_{n}^{o b s}\right)$ for the observed one. Clearly $A^{*}$ and $A^{o b s}$ induce the corresponding technology profiles $\kappa^{*}$ and $\kappa^{o b s}$. Finally, 
$F\left(v_{i}\right)$ is the fine contingent on the violation level, being $F\left(v_{i}^{*}\right)$ and $F\left(v_{i}^{o b s}\right)$ the fine corresponding to the optimal and observed violation levels.

$$
E R^{T o t a l}=\frac{T V A C\left(e^{*}\left(\kappa^{*}\right), \kappa^{*}\right)+I \Sigma_{i=1}^{n} A_{i}^{*}+\sum_{i=1}^{n} F\left(v_{i}^{*}\right)}{T V A C\left(e^{o b s}, \kappa^{o b s}\right)+I \sum_{i=1}^{n} A_{i}^{o b s}+\sum_{i=1}^{n} F\left(v_{i}^{o b s}\right)}
$$

Regarding the effect of imperfect compliance on efficiency, by using a Mann Whitney test, we observe a significant difference in overall performance between perfect and imperfect compliance when the regulator applies a high inspection probability (P70V0 vs. P70V2). While on the view of the inspection probability on efficiency, we observe a significant difference in overall performance between a low and a high inspection probability for both compliance scenarios (P35V0 vs. P70V0, and P35V2 vs. P70V2).

We summarize our findings as follows:

Result 12. Imperfect compliance leads to higher total efficiency when there is a high inspection probability.

Result 13. A low (high) inspection probability leads to higher efficiency under perfect (imperfect) compliance.

\subsection{Emission permits}

\subsubsection{Experimental procedure}

Concerning the experimental procedure, we conducted 3 sessions for each treatment. A group of 12 subjects participated in each session, mimicking firms operating in an industry subject to environmental regulation. ${ }^{11}$ Upon arrival at the laboratory, we randomly assigned subjects to one of the computer terminals. We distributed instructions to subjects and answered their questions before they participated in a trial period. ${ }^{12}$ In each session, subjects played 10 periods of a given treatment, and no time limit to submit their decision was introduced. Each period consisted of the following four stages:

Stage 1: Technology assignment and adoption decision Each subject is randomly assigned an initial technology $T_{1}, \ldots, T_{5}$, following the distribution displayed in Table 3.1. They are also informed about the number of auctioned permits, inspection probability and marginal (and total) fines they will face in case of non-compliance if audited. In this stage subjects simultaneously decide whether to keep the initial technology or to adopt the new technology a, paying the corresponding price of 580 ECU.

\footnotetext{
${ }^{11}$ Each subject participated only in one session.

${ }^{12}$ This trial period was identical to the real periods except that we did not take it into account for the final payoff.
} 
Stage 2: Permit auctioning Permits are allocated among firms using an ascending clock auction. In this process, the opening price is established at 5 ECU. Subjects then have three minutes to submit their permit demand at the current price. If aggregate permit demand exceeds the permit supply set by the regulator (72 permits), the price is increased by $10 \mathrm{ECU}$ (so that the next price is $15 \mathrm{ECU}$, then $25 \mathrm{ECU}$, and so on). The auction then proceeds until the quantity demanded by the firms is smaller or equal to the permit supply. If this is the case, the auction closes, and each subject is allocated the quantity demanded at this last price.

Stage 3: Real emissions Subjects decide on their real emission levels $\left(e_{i}\right)$. Recall that the violation level $v_{i}$ is equal to the difference between real emission levels $\left(e_{i}\right)$ and permits held $\left(s_{i}\right)$. The abatement level results in the difference between the maximum and real emissions.

Stage 4: Inspection and profit Subjects are inspected with probability $\pi$ paying the corresponding fine $\left(F\left(v_{i}\right)\right)$ if a positive violation level is discovered in the inspection $\left(v_{i}>0\right)$, that is, if their emissions exceed their permits holding. We compute the firm profit in this period as:

$\Pi_{i, t}= \begin{cases}1200-c_{i}^{T}\left(e_{i}\right)-p s_{i}-F_{i}\left(v_{i}\right) & \text { if the firm does not invest in period } t, \\ 1200-c_{i}^{a}\left(e_{i}\right)-p s_{i}-F_{i}\left(v_{i}\right)-580 & \text { if it invests in period } t,\end{cases}$

where $c_{i}^{T}\left(e_{i}\right)\left(c_{i}^{a}\left(e_{i}\right)\right)$ is the abatement cost function if the firm is using the conventional (new) technology, $p$ denotes the corresponding permit market price, while $s_{i}$ is the number of permits acquired by firm $i$ in the auction. Note that in case a firm is not inspected in that period or $v_{i}=0$ the fine does not apply.

The subjects' final payoff is the accumulated profit obtained in two periods randomly chosen at the end of the session. Each session lasts approximately 120 minutes, and the average payoff is around $€ 18$.

\section{Risk attitude}

At the beginning of the session, we run a test to elicit the subjects' risk attitudes. To this end, we used the low-payoff menu of paired lotteries (Holt and Laury, 2002), which ranks risk attitudes on a scale ranging from 1 (high degree of risk-loving) to 10 (high degree of risk-aversion). A measure of 5 indicates risk neutrality. Table 3.10 in the Appendix describes the menu. 


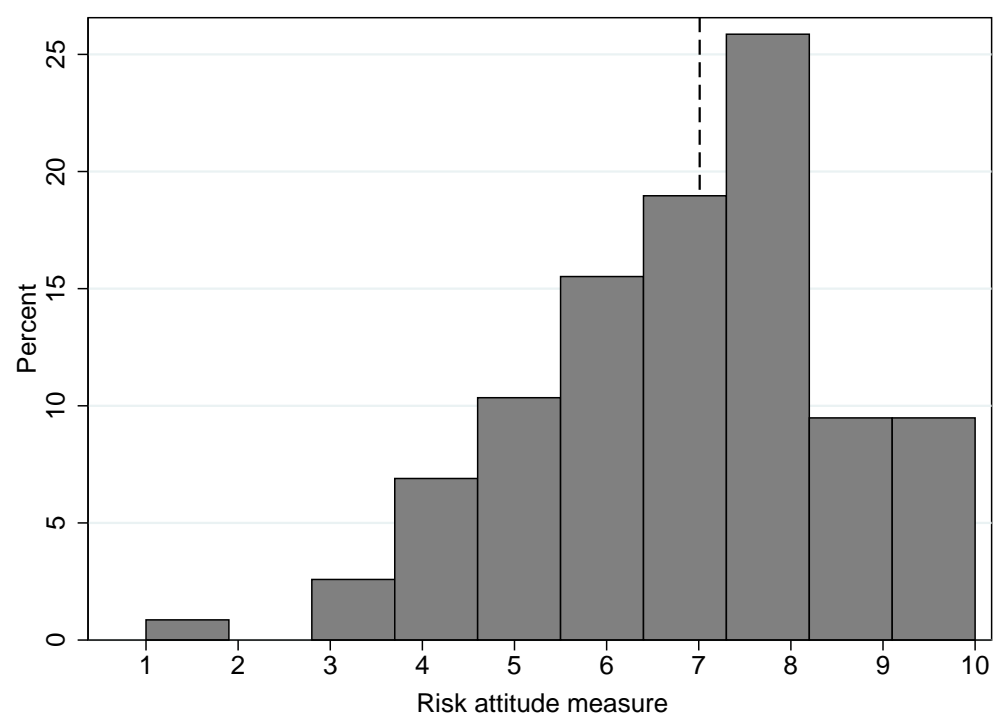

Figure 3.7 The distribution of the risk-attitude measures (average: 7.01; standard deviation: 1.85). Measure in the range 1-4 indicates risk-loving, a measure of 5 indicates risk neutrality, and measure in the range 6-10 indicates risk aversion

Figure 3.7 displays the distribution of the risk attitude measures of our sample. ${ }^{13}$ The figure shows that most subjects $(80 \%)$ are risk-averse; only $10 \%$ of the subjects are classified as risk neutral, which implies that they switched to the risky alternative after five consecutive choices. There are only a few subjects classified as risk-loving (10\% of the choices).

\section{New ecological paradigm scale}

Ecological attitudes have been measured using the revised 15-item NEP (New Ecological Paradigm) scale Dunlap et al., 2000. At the end of the session, participants were asked to rate the level of agreement for each statement on a 5-point Likert-like scale (Table 3.11 in the Appendix describes the questionnaire).

Figure 3.8 shows that the average NEP scale score is 48.75 on a range of $15-75$ where 15 is anti-ecological, and 75 is completely pro-ecological.

Subjects generally show positive attitudes towards the environment with $67 \%$ having mid-ecological attitudes, while $33 \%$ have anti-ecological attitudes; however, there are no pro-ecological attitudes.

\footnotetext{
${ }^{13}$ We had to drop 40 from 144 observations due to irrational behavior (multiple switching).
} 


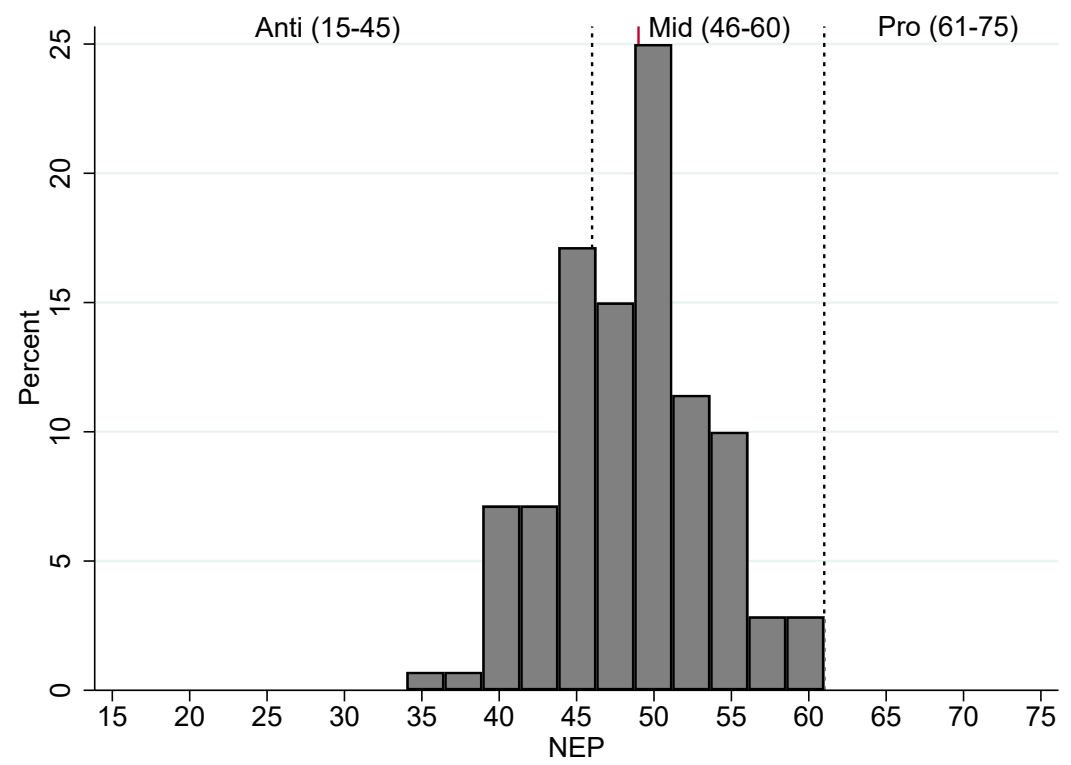

Figure 3.8 The distribution of the ecological-attitude measures (average: 48.75 ; standard deviation: 5.24). Measure in the range 15-45 indicates anti-ecological, a measure of 46-60 indicates mid-ecological, and measure in the range 61-75 indicates pro-ecological

\subsubsection{Results}

Arguedas et al., 2010 theoretical model predicts that the incentives to adopt the new technology only depend on the firms' technological characteristics and the permit price, while they are independent of the monitoring strategy. Moreover, for a given supply of permits, the equilibrium permit price under imperfect compliance is lower than that under perfect compliance. Therefore, adoption incentives under imperfect compliance are smaller than those under perfect compliance.

We are particularly interested to test whether there are significant differences in performance between inducing perfect and imperfect compliance, therefore, in this section, we will compare the results on technology adoption, emissions, violation level, permit price and permit holding if the regulator implements an enforcement policy where imperfect compliance is optimal for the firm.

\section{Technology adoption}

Recall that, in equilibrium, we expect 5 out of 12 firms in the industry to adopt the new technology $a$. In particular, given the parameters used in our experimental design, only those initially endowed with technologies $T_{1}$ and $T_{2}$ have incentives to adopt the new technology.

Figure 3.9 displays the distribution of firms investing in the new technology, depending on the assigned initial technology. 


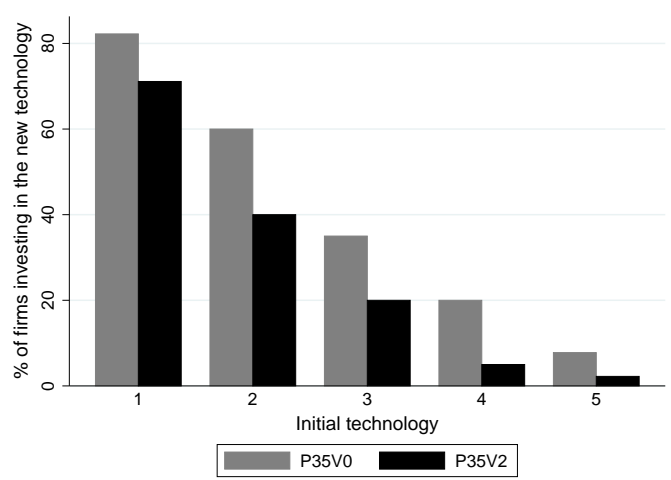

(a) Low inspection probability $(35 \%)$

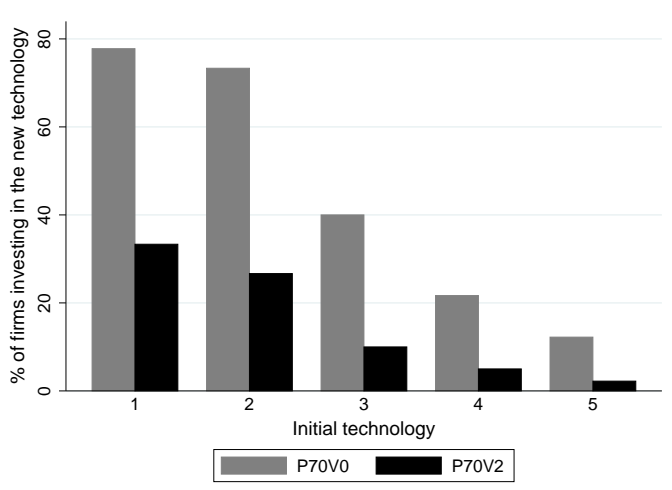

(b) High inspection probability $(70 \%)$

Figure 3.9 Percentage of firms investing in technology $a$ per initial Technology $k=$ $T_{1}, \ldots, T_{5}$ and monitoring strategy

A general feature common to all treatments is that most of the firms using initially technologies $T_{1}$ and $T_{2}$ adopt the new technology and this proportion decreases as we move to technologies $T_{3}, T_{4}$ and $T_{5}$, i.e., those with initially lower baseline emissions.

Note that our adoption rates under perfect compliance are very similar to those observed in Camacho-Cuena et al., 2012, while under imperfect compliance, they are lower.

We observe that inducing imperfect compliance reduces significantly the number of firms adopting the new technology regardless of the monitoring strategy (high and low inspection probability) and the initial technology. ${ }^{14}$

If a given compliance level is induced using a high inspection probability, the behavior of firms type $T_{1}$ and $T_{2}$ concerning investment does not differ significantly. This is not the case if a low inspection probability is implemented since the probability of adopting the new technology significantly reduces for firms $T_{2}$ when compared to those using technology $T_{1}$.

Turning now on the effect of the inspection probability on the firms' investment incentives we visually observe an asymmetry: under perfect compliance, $v^{*}=0$, we observe that more firms invest for a high inspection probability (i.e., the adoption rate for $\mathrm{P} 70 \mathrm{V0}$ is greater than that for $\mathrm{P} 35 \mathrm{~V} 0$, except for $T_{1}$ ), while under imperfect compliance, $v^{*}=2$, there are more firms investing when a low inspection probability is implemented, (i.e., adoption rates are reversed with that for P70V2 being smaller than that for P35V2). However, such difference is not statistically significant, since using a K-S test, we cannot reject the null hypothesis that the two samples were

\footnotetext{
${ }^{14}$ Using a Kolmogorov Smirnov test (K-S), we reject the null hypothesis that the two samples were drawn from the same distribution for both a low (P35V0 vs. P35V2) and a high (P70V0 vs. P70V2) inspection probability.
} 
drawn from the same distribution for the two monitoring strategies. Consequently, adoption incentives are independent of the monitoring strategy.

We can summarize our findings in the following results:

Result 14. Inducing imperfect compliance significantly reduces the firms' adoption of the new technology regardless of the monitoring strategy implemented by the regulator.

Result 15. The inspection probability does not affect the pattern of technology adoption.

To properly explain the factors determining investment behavior in the different treatments, we estimated a Probit model with robust standard errors clustered across sessions. We study the impact of the initial technology on the probability to invest. As explanatory variables, we include dummies for the initial technologies and the fine, the permit price in the previous period, the individual risk attitude measure between 1 and 10 (from risk-loving to risk-averse), the NEP measure between 15 and 75 (from anti-ecological to pro-ecological), and period number.

\begin{tabular}{lcccc}
\hline Treatment & $\mathrm{P} 35 \mathrm{~V} 0$ & $\mathrm{P} 35 \mathrm{~V} 2$ & $\mathrm{P} 70 \mathrm{~V} 0$ & $\mathrm{P} 70 \mathrm{~V} 2$ \\
\hline Technology $T_{2}$ & $-0.839^{* * *}$ & $-1.026^{* * *}$ & -0.061 & -0.216 \\
& $(0.155)$ & $(0.095)$ & $(0.125)$ & $(0.169)$ \\
Technology $T_{3}$ & $-1.529^{* * *}$ & $-1.666^{* * *}$ & $-1.615^{* * *}$ & $-0.985^{* * *}$ \\
& $(0.226)$ & $(0.241)$ & $(0.345)$ & $(0.225)$ \\
Technology $T_{4}$ & $-1.833^{* * *}$ & $-2.343^{* * *}$ & $-2.029^{* * *}$ & $-1.242^{* *}$ \\
& $(0.350)$ & $(0.348)$ & $(0.283)$ & $(0.589)$ \\
Technology $T_{5}$ & $-2.746^{* * *}$ & $-2.531^{* * *}$ & $-2.586^{* * *}$ & $-1.435^{* * *}$ \\
& $(0.309)$ & $(0.305)$ & $(0.114)$ & $(0.525)$ \\
Risk-attitude measure & -0.004 & -0.080 & $0.243^{* * *}$ & 0.053 \\
& $(0.135)$ & $(0.061)$ & $(0.027)$ & $(0.069)$ \\
Price t-1 & -0.001 & $0.007^{* * *}$ & -0.002 & 0.011 \\
& $(0.002)$ & $(0.003)$ & $(0.004)$ & $(0.015)$ \\
Fine t-1 & -0.182 & $0.168^{* * *}$ & $0.448^{* *}$ & 0.092 \\
& $(0.354)$ & $(0.036)$ & $(0.228)$ & $(0.276)$ \\
Ecological-attitude measure (NEP) & $0.026^{* * *}$ & 0.012 & $0.007^{*}$ & $0.047^{*}$ \\
Period & $(0.009)$ & $(0.027)$ & $(0.004)$ & $(0.025)$ \\
& -0.015 & -0.039 & -0.009 & $-0.095^{* * *}$ \\
Cons & $(0.032)$ & $(0.032)$ & $(0.035)$ & $(0.037)$ \\
& 0.155 & 0.511 & $-1.178^{* * *}$ & $-2.778^{* * *}$ \\
Pseudo - $R^{2}$ & $(0.637)$ & $(1.537)$ & $(0.455)$ & $(0.778)$ \\
\hline
\end{tabular}

Table 3.6 Pooled Probit estimation (with clustered standard errors across sessions) of investment per treatment using Technology $T_{1}$ as baseline (std. err. are given in parentheses). The dependent variable: new technology adoption in period $t$ by firm $i$. ***, $* *$, and $*$ denote significance at the $1 \%, 5 \%$, and $10 \%$, respectively

Since firms endowed with dirtier technologies gain more from adopting the new technology, we expect the firms' adoption probability to diminish when initially being 
endowed with a less polluting technology. More specifically, we expect discrete jumps in adoption when moving across technologies (particularly between $T_{2}$ and $T_{3}$ denoting the borderline between adoption and non-adoption in social optimum). The results reported in Table 3.6 confirm our hypothesis for all implemented treatments. ${ }^{15}$ These findings provide support for Hypothesis 1, which states that the incentives to adopt an advanced abatement technology only depend on the firms' technological characteristics, while they are independent of the monitoring strategy. However, those incentives seem to be only marginally dependent on the permit price for treatment P35V2.

Regarding further results, we find that risk attitude is relevant only if perfect compliance is induced using a high inspection probability (P70V0). In this case, risk aversion increases the probability to adopt the new technology. Given the price of emission permits in the previous period, we observe that it increases investment probability if imperfect compliance is induced with a low inspection probability (P35V2). Concerning the NEP, it increases investment probability if perfect compliance is induced with a low inspection probability (P35V0). Finally, getting a fine is not an incentive to adopt the new technology.

\section{Real emissions}

In this section, we study how emissions are affected by imperfect compliance. Figure 3.10 shows the average individual real emissions in relation to the optimal $\left(e_{i}-e^{*}\right)$. Optimal emission $e^{*}$ is the units they should release given the theoretical permit price (tax rate) of $p=\tau=53$. Given our results in the previous section, we expect an increase in emissions under imperfect compliance. The figure shows that in some treatments, the difference can be negative, i.e., some firms emit (buy more permits and/or abate) less (more) units than they should.

\footnotetext{
${ }^{15}$ We use a t-test to compare the coefficients for every technology between perfect and imperfect compliance. We find that inducing imperfect compliance statistically decreases the probability to adopt when firms have initially been endowed with $T_{4}$ under a low inspection probability (P35V0 vs. P35V2). While inducing imperfect compliance statistically increases the probability to adopt when firms have been assigned with $T_{3}$ and $T_{5}$ under a high inspection probability (P70V0 vs. P70V2).
} 


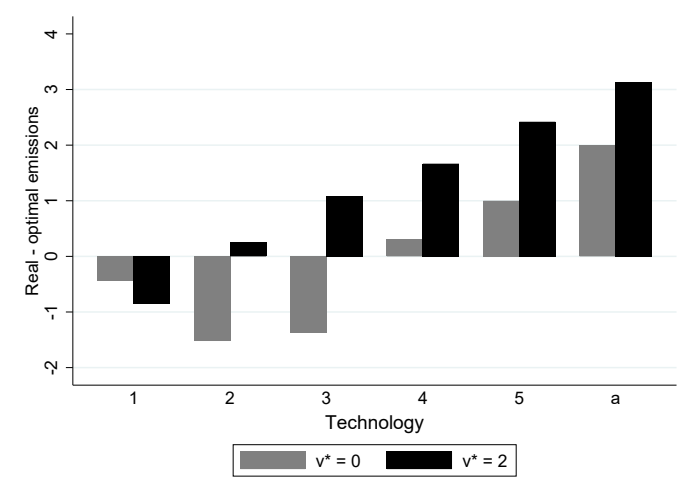

(a) Low inspection probability $(35 \%)$

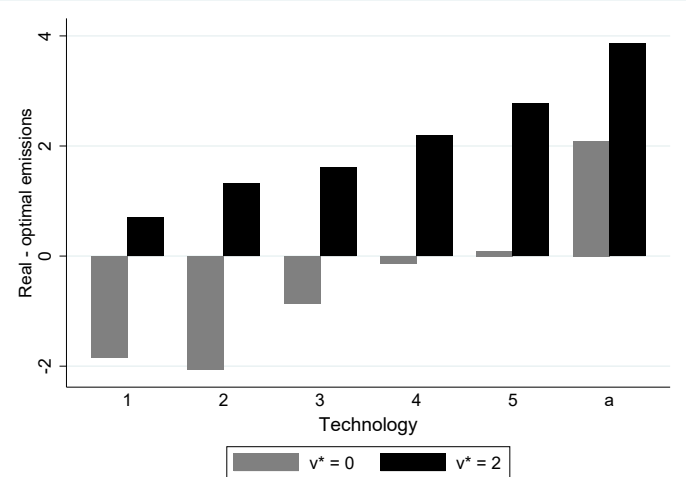

(b) High inspection probability (70\%)

Figure 3.10 Difference between average real and optimal emissions $\left(e_{i}-e^{*}\right)$ per technology and treatment

Contrary to Caffera and Chávez, 2016, the results displayed in Figure 3.10 show that inducing imperfect compliance increases firms' real emissions significantly independently on the inspection probabilities implemented by the regulator. ${ }^{16}$ Using a K-S test, we can reject the null hypothesis that the two samples are drawn from the same distribution for the two inspection probabilities (P35V0 vs. P35V2; P70V0 vs. P70V2).

Result 16. Inducing imperfect compliance significantly increases firms' emissions independently on the monitoring strategy implemented by the regulator.

\section{The permit auction}

In this section, we compare the different treatments focusing on permit prices and volumes. A relevant aspect is whether these prices and volumes are affected by the firms' decisions concerning the adoption of the new technology. Note that to evaluate the observed permit prices and volumes, we cannot use the theoretically optimal equilibrium price and volumes as benchmark, since that price results from the theoretically optimal investment pattern (if only firms of type $T_{1}$ and $T_{2}$ invest in the new technology, we expect that 72 permits are auctioned off at an equilibrium permit price equal to $53 \mathrm{ECU}$ - see Figure 3.1) and we have already seen that firms do not behave optimally concerning technology adoption. Therefore, we should calculate the theoretical equilibrium prices and volumes given the observed firms' investment pattern.

Table 3.7 shows the observed average prices and volumes in the first two columns and the efficient (expected) prices and volumes in the last two columns.

\footnotetext{
${ }^{16}$ Using a M-W test (Mann Whitney test), we can reject the null hypothesis that there is no difference between perfect and imperfect compliance for the two inspection probabilities implemented.
} 


\begin{tabular}{ccccc}
\hline Treatment & \multicolumn{2}{c}{ Observed } & \multicolumn{2}{c}{ Expected } \\
\hline & Price & Volume & Price & Volume \\
\hline P35V0 & 50.86 & 65.4 & 52.17 & 72 \\
& $(14.04)$ & $(5.97)$ & $(13.47)$ & $(-)$ \\
P35V2 & 47 & 63.87 & 49.87 & 72 \\
& $(10.14)$ & $(5.96)$ & $(11.49)$ & $(-)$ \\
P70V0 & 44.31 & 65.03 & 51.87 & 72 \\
& $(12.03)$ & $(5.96)$ & $(18.23)$ & $(-)$ \\
P70V2 & 29 & 59.2 & 65.17 & 72 \\
& $(6.64)$ & $(9.35)$ & $(13.64)$ & $(-)$ \\
\hline
\end{tabular}

Table 3.7 Mean observed and expected prices and volume of permits across sessions and periods within a given treatment (SD are given within parenthesis)

Regarding permit prices, in the P35V0 treatment, observed prices are close to expected prices; however, in the P70V0, P35V2, and P70V2 treatments, observed average prices are lower than the expected prices. As Hypothesis 2 predicted, the permit price under imperfect compliance is smaller than that under perfect compliance, contrary to Caffera and Chávez, 2016.

Figure 3.11 displays the evolution of the mean permit prices across all 10 periods and pooled across all 3 sessions.
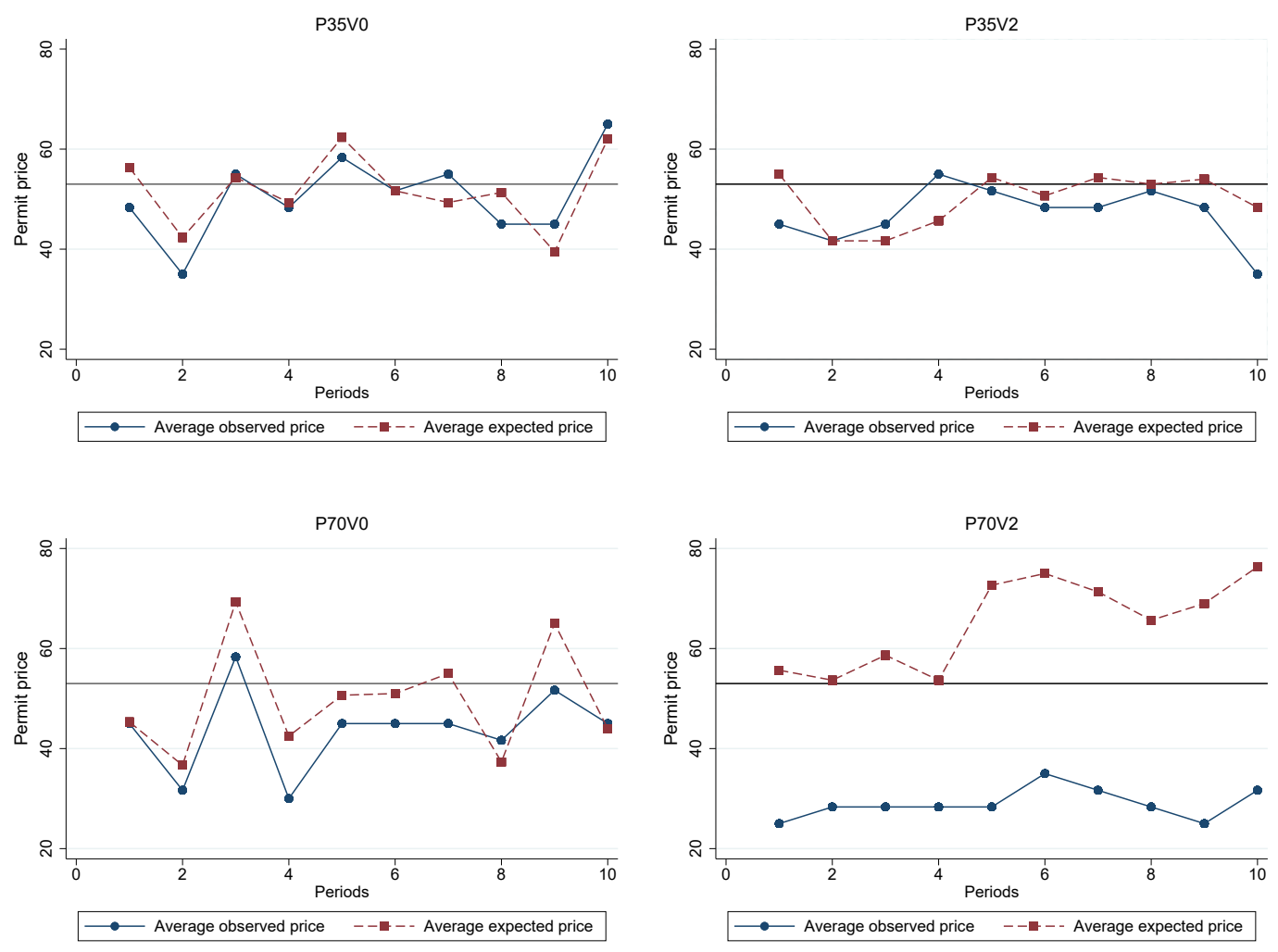

Figure 3.11 Average observed and expected price under the four different treatments i.e., median observed and expected auction price pooling all periods together 
Regarding permit holding, it is significantly lower than the number of permits issued by the regulator (on average) for all treatments (Wilcoxon signed-rank test p-value 0.000), i.e., there are spare permits in the auction. Moreover, under imperfect compliance permit holding is significantly lower than under perfect compliance for both monitoring strategies (Wilcoxon signed-rank test p-value 0.000).

Figure 3.12 displays the mean permit holding across all 10 periods and pooled across all 3 sessions.

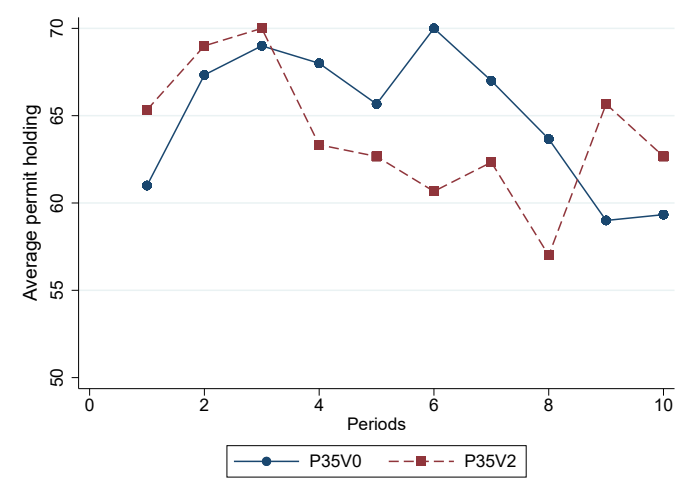

(a) Low inspection probability $(35 \%)$

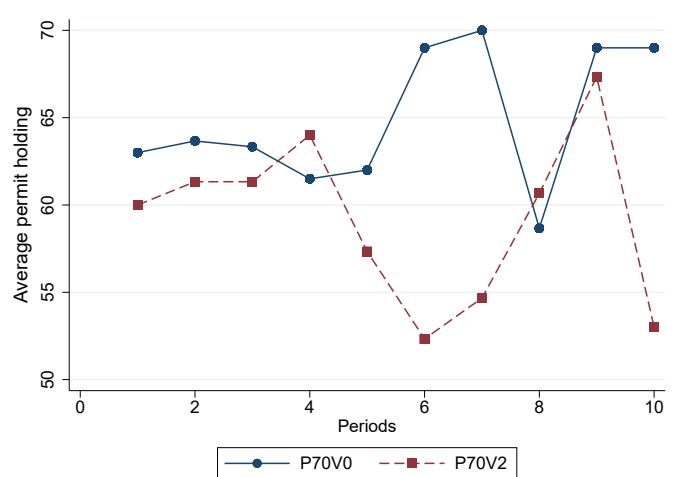

(b) High inspection probability $(70 \%)$

Figure 3.12 Average individual permits held $s$ per initial technology and treatment

We summarize our findings on the permit auction performance as follows:

\section{Result 17.}

(i) Observed permit prices are significantly lower than the expected prices in the treatments P35V2, ProV0, and ProV2.

(ii) Observed prices under imperfect compliance are significantly lower than under perfect compliance, independently of the inspection probability. This finding provides support for Hypothesis 2.

\section{Result 18.}

(i) Permit holding is significantly lower than the permits issued by the regulator.

(ii) Permit holding under imperfect compliance is significantly lower than under perfect compliance.

\section{Violation behavior}

Recall that subjects should decide on their real emissions and number of permits held. ${ }^{17}$ When deciding the number of permits held, subjects should consider that they will be inspected with probability $\pi$ paying the corresponding fine $F\left(v_{i}\right)$ if a positive

\footnotetext{
${ }^{17} \mathrm{~A}$ permit is needed to be legally able to emit one unit.
} 
violation level is discovered in the inspection $\left(v_{i}>0\right.$, where $\left.v_{i}=e_{i}-s_{i}\right)$.

First, we want to study whether the behavior regarding violation level deviates from equilibrium, i.e., $v^{*}=0$ and $v^{*}=2$. For this purpose, using a one-sample Wilcoxon sign rank test, we compare the observed with the equilibrium violation level for each treatment, we can reject the null hypothesis that both distributions are the same.

Consistent with previous results, Figure 3.13 shows that the average violation deviations from optimal $\left(v_{i}-v^{*}\right)$ increases as we move from $v^{*}=0$ to $v^{*}=2$ for both inspection probabilities (except for $T_{1}$ when the regulator applies a low inspection probability). Relying on the Kolmogorov Smirnov (K-S) we obtain that for induced perfect compliance, $v^{*}=0$, we reject the null hypothesis that the two samples (P35V0 and P70V0) are drawn from the same distribution; in the same line, when inducing imperfect compliance, $v^{*}=2$, the null hypothesis comparing P35V2 to P70V2 is rejected.

Therefore, inducing imperfect compliance not only results in lower adoption rates, logically followed by larger emissions, but it is also coupled with widespread emitting more than the permit holding; i.e., larger violation levels.

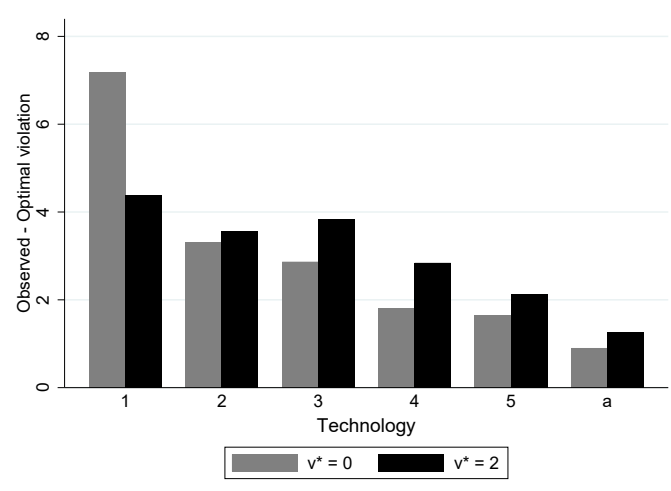

(a) Low inspection probability $(35 \%)$

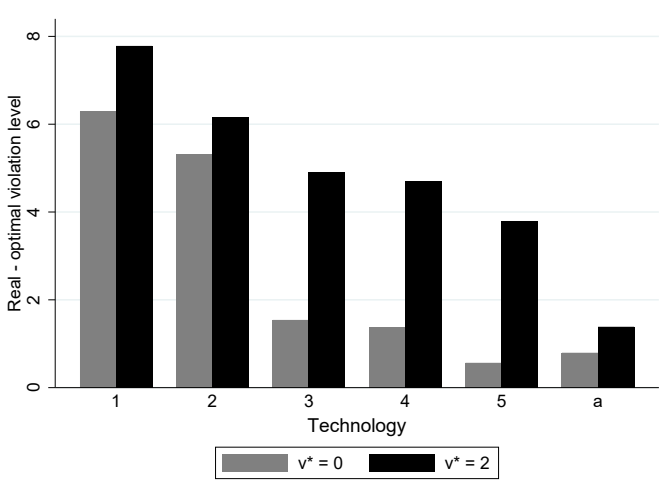

(b) High inspection probability $(70 \%)$

Figure 3.13 Average deviations from optimal violation level $\left(v_{i}-v^{*}\right)$ per technology and treatment

Figure 3.14 shows the average individual fine per treatment and technology. As can be observed, fines are larger under perfect compliance for both inspection probabilities. 


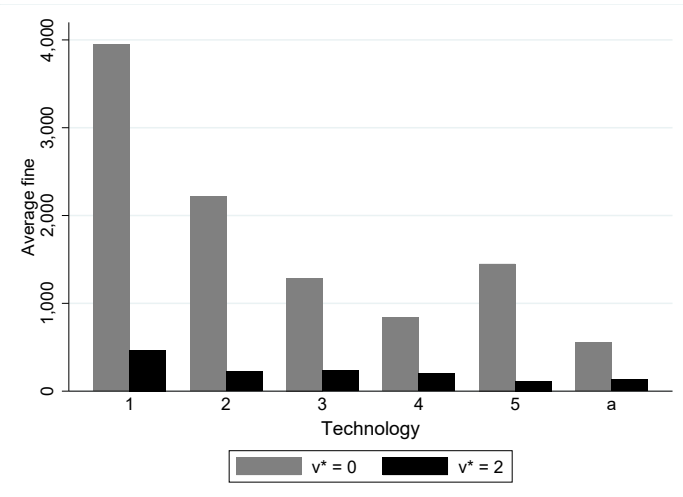

(a) Low inspection probability $(35 \%)$

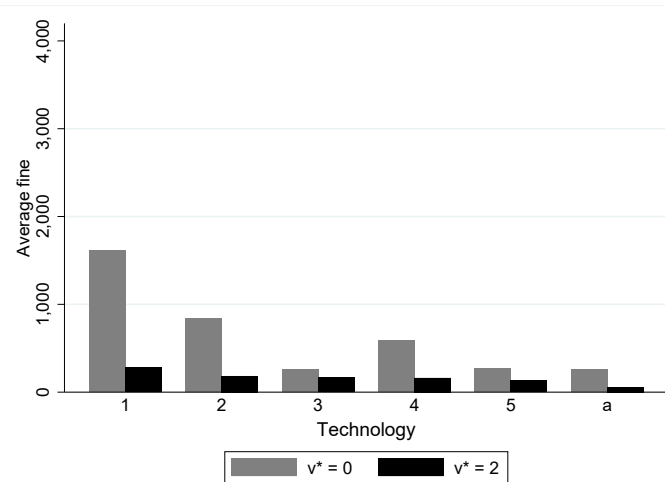

(b) High inspection probability (70\%)

Figure 3.14 Average individual fine per technology and treatment

\section{Efficiency comparisons}

In this section, we aim to compare the efficiency in the investment decisions and permit allocations through auction. A well-known efficiency measure, used by Camacho-Cuena et al., 2012, to test the performance of mechanisms in experimental economics is the ratio of the theoretical minimal social cost divided by the social cost induced by the observed behavior. In the mechanisms considered here, two sources for potential inefficiencies occur: suboptimal investment decisions and suboptimal permit allocations through auction.

\begin{tabular}{ccccc}
\hline & P35V0 & P35V2 & P70V0 & P70V2 \\
\hline ER Permit & 0.62 & 0.53 & 0.58 & 0.74 \\
& $(0.02)$ & $(0.01)$ & $(0.01)$ & $(0.01)$ \\
ER Invest & 0.95 & 1.29 & 0.94 & 1.35 \\
& $(0.004)$ & $(0.007)$ & $(0.003)$ & $(0.009)$ \\
ER Total & 0.75 & 0.98 & 0.76 & 1.10 \\
& $(0.009)$ & $(0.009)$ & $(0.006)$ & $(0.01)$ \\
\hline
\end{tabular}

Table 3.8 Mean (Std. Dev.) of the different efficiency ratios

\section{Efficiency of investment}

We study investment efficiency by looking at the total abatement cost (including investment) that will result if an efficient allocation results from permit auctioning. We define: $A=\left(A_{1}, \ldots, A_{n}\right)$ with $A_{i} \in\{0,1\}$ as the investment pattern, where $A_{i}=1$ if subject $i$ invests and $A_{i}=0$, otherwise. We denote as $A^{*}=\left(A_{i}^{*}, \ldots, A_{n}^{*}\right)$ for the optimal investment pattern, and as $A^{\text {obs }}=\left(A_{i}^{\text {obs }}, \ldots, A_{n}^{\text {obs }}\right)$ for the observed one. $A^{*}$ and $A^{\text {obs }}$ induce the corresponding technology profiles $\kappa^{*}$ and $\kappa^{o b s}$. Then we can define efficiency ratio of investment as the ratio between the lowest possible total abatement cost, including investment cost, and the observed total abatement cost, given that emissions are allocated efficiently. 


$$
E R^{\text {Invest }}=\frac{T V A C\left(e^{*}\left(\kappa^{*}\right), \kappa^{*}\right)+I \sum_{i=1}^{n} A_{i}^{*}}{T V A C\left(e^{*}\left(\kappa^{o b s}\right), \kappa^{o b s}\right)+I \sum_{i=1}^{n} A_{i}^{\text {obs }}}
$$

In the second row of Table 3.8, we see that the investment efficiency ratios are above $100 \%$ in the imperfect compliance treatments. This is because, under those treatments, only one firm was adopting the advanced abatement technology on average (compared to the 5 firms that should be adopting in equilibrium) making the numerator larger than the denominator. A pairwise application of a Mann Whitney test shows a significant difference in overall performance between perfect and imperfect compliance. We summarize our findings as follows:

Result 19. Imperfect compliance leads to higher investment efficiency when the regulator implements a low inspection probability.

\section{Efficiency in the permit auction}

We analyze now the efficiency of permit allocation. For this purpose, we denote the total variable abatement cost as $T V A C$, i.e. $T V A C=\sum_{i=1}^{n} C^{i}\left(e_{i}, \kappa(i)\right)$, where $\kappa(i) \in\{k(i), a\}$ is the actual technology used by firm $i$ after the investment decision. Let $\kappa=(\kappa(1), \ldots, \kappa(n))$ be the technology profile after the investment stage. Further $\kappa^{o b s}=\left(\kappa^{o b s}(1), \ldots, \kappa^{o b s}(n)\right)$ is the observed technology profile while $\kappa^{\star}=\left(\kappa^{\star}(1), \ldots, \kappa^{\star}(n)\right)$ is the efficient one. Additionally, we use $e^{o b s}=$ $\left(e_{1}^{o b s}, \ldots, e_{n}^{o b s}\right)$ to denote the observed emission-permit allocation, and $e^{\star}(\kappa)$ to denote the optimal emission-permit allocation contingent on a given technology profile $\kappa$. Then $T V A C\left(e^{o b s}, \kappa^{o b s}\right)=\Sigma_{i=1}^{n} C^{i}\left(e_{i}^{o b s}, \kappa^{o b s}(i)\right)$ is the observed TVAC, while $T V A C\left(e^{\star}\left(\kappa^{o b s}\right), \kappa^{o b s}\right)=$ $\sum_{i=1}^{n} C^{i}\left(e_{i}^{\star}\left(\kappa^{o b s}\right), \kappa^{o b s}(i)\right)$ is the theoretically minimal TVAC contingent on the observed investment profile $\kappa . F\left(v_{i}\right)$ is the fine contingent on the violation level, being $F\left(v_{i}^{*}\right)$ and $F\left(v_{i}^{o b s}\right)$ the fine corresponding to the optimal and observed violation levels.

Permit-market efficiency is now defined by the ratio of the expected TVAC contingent on the observed investment profile and optimal fine to the observed TVAC and fine, formally:

$$
E R^{\text {Permit }}=\frac{T V A C\left(e^{*}\left(\kappa^{o b s}\right), \kappa^{o b s}\right)+\sum_{i=1}^{n} F\left(v_{i}^{*}\right)}{T V A C\left(e^{o b s}, \kappa^{o b s}\right)+\sum_{i=1}^{n} F\left(v_{i}^{o b s}\right)}
$$

The first row of Table 3.8 displays the permit-auction efficiency-ratios resulting from our four treatments. A pairwise application of a Mann Whitney test (comparing average efficiency ratios at the session level for each pair of treatments, i.e., comparing between induced perfect and imperfect compliance for both inspection probabilities) shows a significant difference in overall performance between perfect and imperfect compliance. We summarize our results as follows:

Result 20. Imperfect compliance leads to higher permit-auction efficiency.

\section{Overall efficiency}


Finally we look at the total efficiency, measured as the ratio of the lowest possible total abatement cost divided by the observed total abatement cost. ${ }^{18}$

$$
E R^{\text {Total }}=\frac{T V A C\left(e^{*}\left(\kappa^{*}\right), \kappa^{*}\right)+I \Sigma_{i=1}^{n} A_{i}^{*}+\sum_{i=1}^{n} F\left(v_{i}^{*}\right)}{T V A C\left(e^{o b s}, \kappa^{o b s}\right)+I \sum_{i=1}^{n} A_{i}^{o b s}+\sum_{i=1}^{n} F\left(v_{i}^{o b s}\right)}
$$

The third row of Table 3.8 displays the results. We see that the overall efficiency ratios are above $100 \%$ in the $\mathrm{P} 70 \mathrm{~V} 2$ treatment. This is because under that treatment only one firm was adopting the advanced abatement technology on average (compared to the 5 firms that should be adopting in equilibrium), making again the numerator larger than the denominator. A pairwise application of a Mann Whitney test shows a significant difference in overall performance between perfect and imperfect compliance. We summarize our findings as follows:

Result 21. Imperfect compliance leads to higher total efficiency.

\section{Social cost}

In this subsection we use social cost as an alternative to measure efficiency. More specifically, we define social cost as the sum of total abatement cost and environmental damage. For this purpose, we denote the total variable abatement cost as $T A C$, i.e. $T A C=\Sigma_{i=1}^{n} C^{i}\left(e_{i}, \kappa(i)\right)$, where $\kappa(i) \in\{k(i), a\}$ is the actual technology used by firm $i$ after the investment decision. Let $\kappa=(\kappa(1), \ldots, \kappa(n))$ be the technology profile after the investment stage. And we denote the environmental damage as $\mathrm{D}(\mathrm{E})$, where $E=\sum_{i=1}^{n} e_{i}$ indicates aggregate emissions.

\begin{tabular}{ccccc}
\hline & P35V0 & P35V2 & P70V0 & P70V2 \\
\hline TAC & 165.40 & 106.03 & 171.98 & 99.11 \\
Damage & 2911.09 & 4872.22 & 2529.68 & 7041.31 \\
\hline Social Cost & 3076.49 & 4978.25 & 2701.66 & 7140.42 \\
\hline
\end{tabular}

Table 3.9 Mean (Std. Dev.) of the social cost

Result 22. Social cost under imperfect compliance is statistically higher than under perfect compliance regardless of the monitoring strategy implemented by the regulator.

\subsection{Conclusions}

An essential concern for policy-makers in designing effective policy instruments is the creation of incentives for firms to adopt advanced pollution technologies. This chapter investigates whether emission taxes and permits provide efficient incentives

\footnotetext{
${ }^{18}$ Note that the total efficiency cannot simply be written as the product of permit-market efficiency and investment efficiency, the reason being that $E-$ Ratio $^{\text {invest }}$ and $E-$ Ratio $^{\text {total }}$ contain the investment cost while $E-$ Ratio $^{\text {permit }}$ does not. To relate $E-$ Ratio $^{\text {permit }}$ and $E-$ Ratio $^{\text {invest }}$ by the factor $\frac{\sum_{i=1}^{n} A C_{i}\left(e_{i}^{o b s}, \kappa_{i}^{o b s}\right)}{\sum_{i=1}^{n} A C_{i}\left(e_{i}^{o b s}, \kappa_{i}^{o b s}\right)+\Sigma_{i=1}^{n} A_{i}^{o b s}+I} / \frac{\sum_{i=1}^{n} A C_{i}\left(e_{i}^{*}\left(\kappa^{o b s}\right), \kappa_{i}^{o b s}\right)}{\sum_{i=1}^{n} A C_{i}\left(e_{i}^{*}\left(\kappa^{o b s}\right), \kappa_{i}^{o b s}\right)+\Sigma_{i=1}^{n} A_{i}^{o b s}+I}$ the values of which, however, are of no further interest.
} 
for polluting firms to adopt cleaner technologies, using laboratory experiments.

Including imperfect compliance is one of the innovations of our experiment, which can bring in new comprehension into design characteristics of emission taxes and permit markets that promote dynamic efficiency. To evaluate the dynamic efficiency, we take the monitoring probability and induced violation behavior as the main treatment variables. Using as a theoretical benchmark Arguedas et al., 2010, we find that the firms' overall performance concerning investment is remarkably good; however, we observe some under-investment by firms with dirtier technologies and some overinvestment by firms with cleaner technologies (Gangadharan et al., 2013).

Regarding emission taxes, contrary to what Arguedas et al., 2010 predict, the results of our experiment suggest that firms may behave significantly different when confronted to an exogenous emission tax and an inspection probability that induces perfect compliance, as compared to the case in which firms are induced imperfect compliance. More specifically, inducing imperfect compliance reduces the number of firms adopting the new technology only if the regulator implements a monitoring policy with a high inspection probability. Therefore, we observe that inducing imperfect compliance increases emissions significantly concerning the induced perfect compliance benchmark, independently of the inspection probability implemented by the regulator. As a consequence, inducing violations significantly increases tax evasion regardless of the inspection probability, as predicted by the existing theory.

Regarding emission permits, the main result of our study is that inducing imperfect compliance reduces the number of firms adopting the new technology, regardless of the inspection probability; therefore, this significantly increases emissions and violation levels. Looking at the permit price, we find that permit prices are significantly lower than expected equilibrium prices. Further, as expected, investment in the abatement technology tends to put downward pressure on permit prices, as reflected by significantly lower price levels under imperfect compliance compared to the price levels under perfect compliance. These results hold for both low and high inspection probability. Permit holding is significantly lower under imperfect compliance relative to perfect compliance, and lower than the expected volume. This result is also as expected since the firms' marginal valuation of emissions (and abatement) drives the bidding for permits under auctioning. 


\section{Appendix}

\section{A Holt and Laury's (2002) menu of paired lottery}

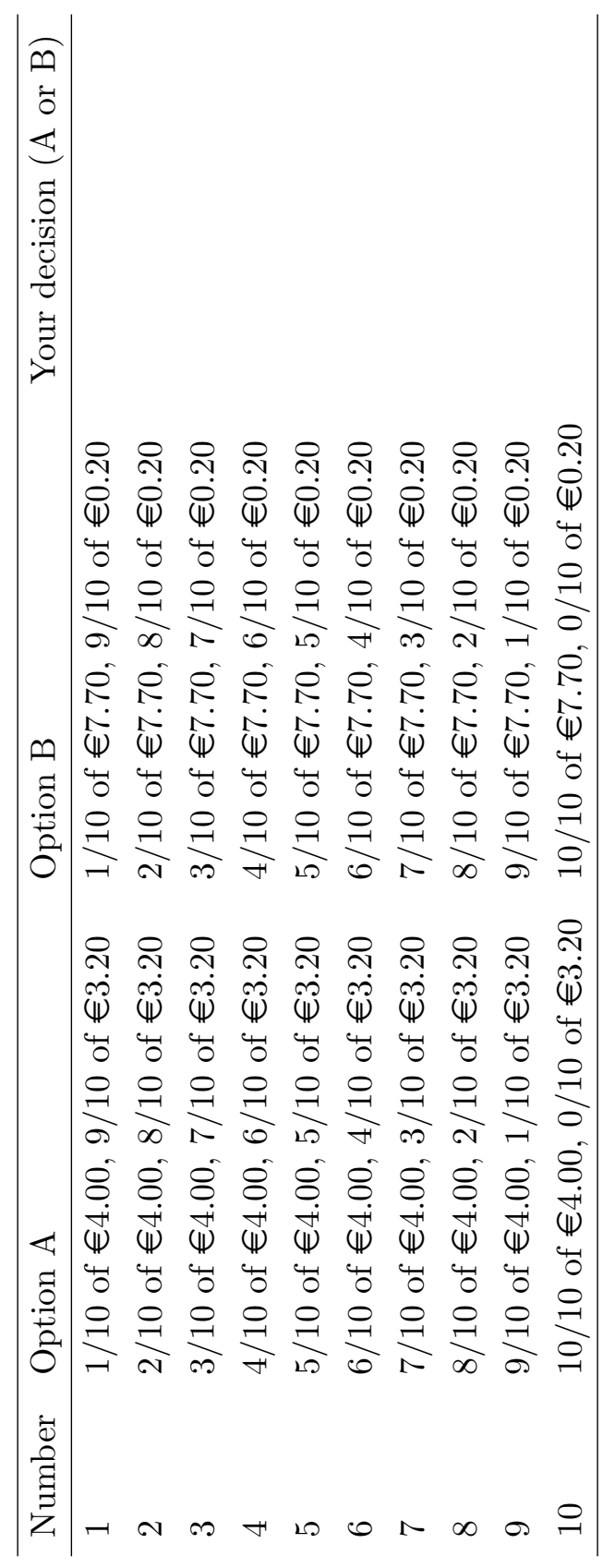

Table 3.10 Holt and Laury's (2002) menu of paired lottery 


\section{B New ecological paradigm}

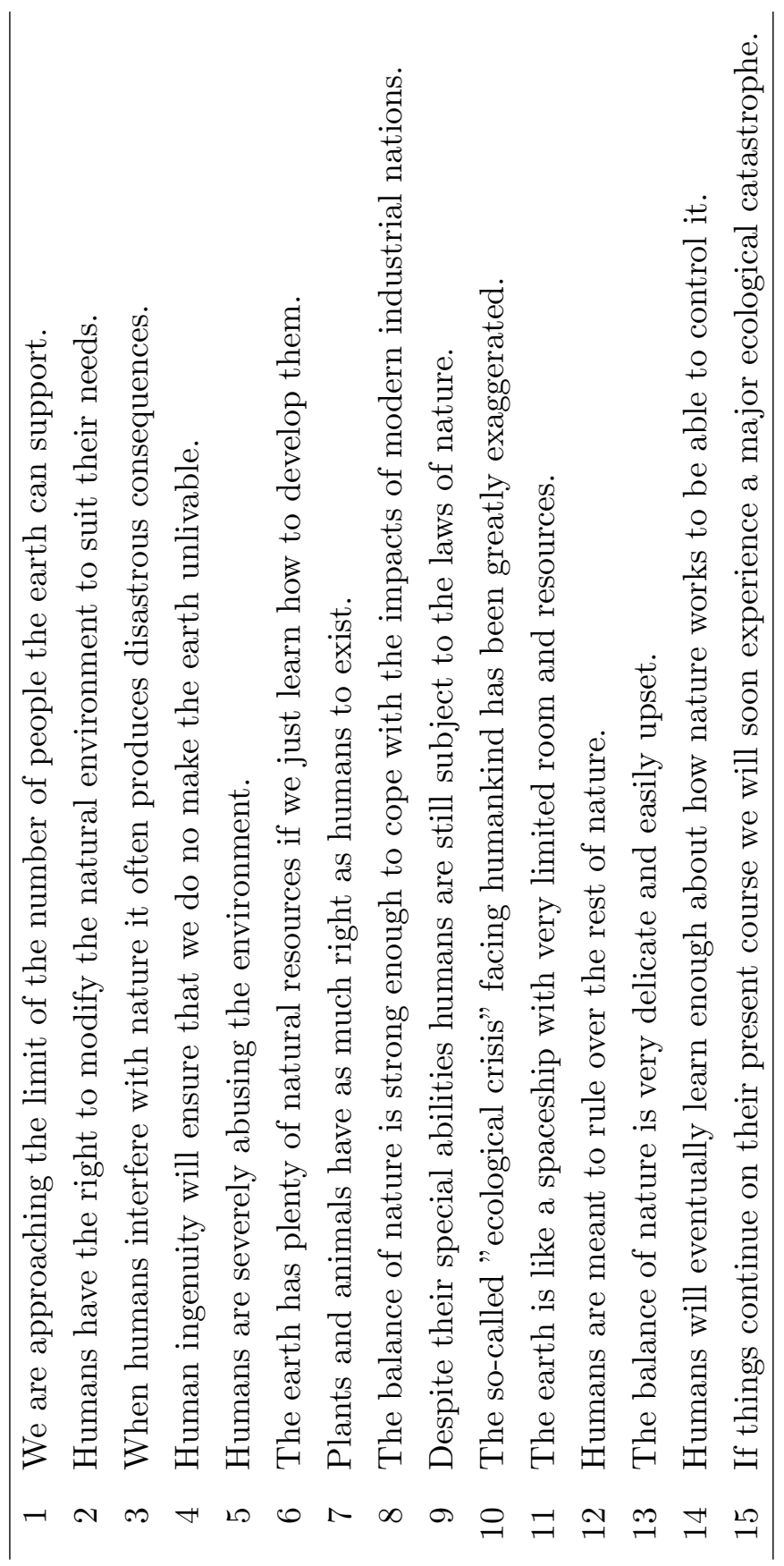

Table 3.11 The 15 Item Revised NEP Scale 


\section{C Additional results}

\begin{tabular}{cccccccccc}
\hline Treatment & \multicolumn{4}{c}{ P35V0 } & \multicolumn{2}{c}{ P35V2 } & \multicolumn{2}{c}{ P70V0 } & \multicolumn{2}{c}{ P70V2 } \\
\hline Emissions & $e_{\max }$ & $e_{i}$ & $r_{i}$ & $e_{i}$ & $r_{i}$ & $e_{i}$ & $r_{i}$ & $e_{i}$ & $r_{i}$ \\
\hline$T_{1}$ & 20 & 16.58 & 13.10 & 15.91 & 5.73 & 13.18 & 9.09 & 16.38 & 3.69 \\
$T_{2}$ & 18 & 13.29 & 9.12 & 14.69 & 5 & 13 & 12.27 & 14.64 & 4.84 \\
$T_{3}$ & 16 & 11.72 & 10.6 & 12.47 & 8.62 & 10.79 & 9.87 & 12.58 & 3.87 \\
$T_{4}$ & 14 & 9.93 & 8.10 & 10.73 & 4.79 & 8.33 & 8.11 & 10.8 & 3.54 \\
$T_{5}$ & 12 & 8.23 & 6.89 & 9.53 & 4.68 & 6.46 & 6.20 & 8.93 & 2.89 \\
$a$ & 7 & 3.60 & 2.46 & 4.68 & 1.34 & 3.08 & 2.57 & 4.48 & 1.78 \\
\hline Industry & & 8 & 6.22 & 8.68 & 3.92 & 6 & 5.36 & 9.98 & 3.12 \\
\hline
\end{tabular}

Table 3.12 Average real $\left(e_{i}\right)$ and reported $\left(r_{i}\right)$ individual and industry emissions per technology and treatment across periods and groups. $e_{\max }$ denotes the firm's default emissions if no abatement effort is made (See Table 3.3)

\begin{tabular}{ccccc}
\hline Treatment & P35V0 & P35V2 & P70V0 & P70V2 \\
\hline$T_{1}$ & 331.25 & 669.12 & 0 & 833.54 \\
$T_{2}$ & 671.33 & 658.71 & 106 & 416.43 \\
$T_{3}$ & 189.29 & 321.53 & 70.66 & 296.8 \\
$T_{4}$ & 90.86 & 373.94 & 53 & 435.36 \\
$T_{5}$ & 135.44 & 315.69 & 70.66 & 409.28 \\
$a$ & 156.79 & 236.88 & 123.77 & 159 \\
\hline Industry & 200.12 & 336.55 & 100.11 & 431.91 \\
\hline
\end{tabular}

Table 3.13 Average individual and industry tax evasion per treatment and technology

\begin{tabular}{ccccc}
\hline Treatment & P35V0 & P35V2 & P70V0 & P70V2 \\
\hline$T_{1}$ & 678.48 & 563.2 & 1384.35 & 347.64 \\
$T_{2}$ & 1546.72 & 535.6 & 426 & 346.07 \\
$T_{3}$ & 310.4 & 179.7 & 270.51 & 301.93 \\
$T_{4}$ & 681.6 & 374.04 & 172.73 & 191.33 \\
$T_{5}$ & 490.93 & 279.03 & 166.24 & 149.36 \\
$a$ & 519.51 & 157.3 & 186.06 & 58.97 \\
\hline Industry & 683.65 & 253.69 & 313.62 & 198.47 \\
\hline
\end{tabular}

Table 3.14 Average individual and industry fine per treatment and technology 


\begin{tabular}{|c|c|c|c|c|c|}
\hline Treatment & Group & Period & $E R^{\text {Investment }}$ & $E R^{\text {Permit }}$ & $E R^{\text {Total }}$ \\
\hline P35V0 & 1 & 1 & 0.8576642 & 1.207513 & 0.9920635 \\
\hline P35V0 & 1 & 2 & 0.8901515 & 0.875146 & 0.8488657 \\
\hline P35V0 & 1 & 3 & 0.8274648 & 0.6170119 & 0.6052333 \\
\hline P35V0 & 1 & 4 & 1 & 0.9085402 & 0.962878 \\
\hline P35V0 & 1 & 5 & 1 & 0.7458976 & 0.8845893 \\
\hline P35V0 & 1 & 6 & 1.1463410 & 0.26901 & 0.6385176 \\
\hline P35V0 & 1 & 7 & 0.9710744 & 0.6275525 & 0.7418398 \\
\hline P35V0 & 1 & 8 & 1 & 0.1835012 & 0.3698108 \\
\hline P35V0 & 1 & 9 & 0.8935362 & 0.1792436 & 0.4370142 \\
\hline P35V0 & 1 & 10 & 0.7164634 & 0.2160691 & 1.284434 \\
\hline P35V0 & 2 & 1 & 1 & 0.3684297 & 0.6036786 \\
\hline P35V0 & 2 & 2 & 0.9832636 & 0.3589948 & 0.7748615 \\
\hline P35V0 & 2 & 3 & 0.9710744 & 0.7949527 & 0.856102 \\
\hline P35V0 & 2 & 4 & 1 & 0.6217187 & 0.811016 \\
\hline P35V0 & 2 & 5 & 0.9215686 & 0.8887948 & 0.8513876 \\
\hline P35V0 & 2 & 6 & 0.9710744 & 0.6910926 & 0.7877447 \\
\hline P35V0 & 2 & 7 & 1 & 0.7842454 & 0.9046813 \\
\hline P35V0 & 2 & 8 & 1.004274 & 0.7058824 & 0.9073359 \\
\hline P35V0 & 2 & 10 & 0.9710744 & 0.4084808 & 0.5536446 \\
\hline P35V0 & 3 & 1 & 0.8935362 & 0.3072511 & 0.5900372 \\
\hline P35V0 & 3 & 3 & 0.9832636 & 0.3793467 & 0.7888553 \\
\hline P35V0 & 3 & 4 & 1 & 0.4831437 & 0.7093697 \\
\hline P35V0 & 3 & 5 & 0.8274648 & 0.7236389 & 0.674977 \\
\hline P35V0 & 3 & 6 & 1 & 0.6 & 0.7966102 \\
\hline P35V0 & 3 & 7 & 0.8935362 & 0.7317073 & 0.8245614 \\
\hline P35V0 & 3 & 8 & 0.9710744 & 0.3729797 & 0.5178264 \\
\hline P35V0 & 3 & 9 & 1.004274 & 0.4455666 & 0.7613555 \\
\hline P35V0 & 3 & 10 & 1.004274 & 0.2530791 & 0.5716649 \\
\hline P70V0 & 1 & 1 & 0.9710744 & 0.6137958 & 0.7314492 \\
\hline P70V0 & 1 & 2 & 1 & 0.6295027 & 0.8160572 \\
\hline P70V0 & 1 & 3 & 1 & 0.4938272 & 0.7181054 \\
\hline P70V0 & 1 & 4 & 1 & 0.3934426 & 0.6287625 \\
\hline P70V0 & 1 & 5 & 1.004274 & 0.6683003 & 0.8908939 \\
\hline P70V0 & 1 & 6 & 0.9710744 & 1.189465 & 1.058892 \\
\hline P70V0 & 1 & 7 & 1 & 0.6325555 & 0.8180172 \\
\hline P70V0 & 1 & 8 & 1.004274 & 0.6066121 & 0.8610897 \\
\hline P70V0 & 1 & 9 & 0.9215686 & 0.5790108 & 0.6230943 \\
\hline P70V0 & 1 & 10 & 1.004274 & 0.562377 & 0.8372226 \\
\hline P70V0 & 2 & 1 & 0.94 & 0.3271538 & 0.8187582 \\
\hline P70V0 & 2 & 2 & 0.9832636 & 0.2868297 & 0.7153512 \\
\hline
\end{tabular}




\begin{tabular}{|c|c|c|c|c|c|}
\hline P70V0 & 2 & 3 & 0.8576642 & 0.8848107 & 0.7778366 \\
\hline P70V0 & 2 & 5 & 1 & 0.6558333 & 0.8326542 \\
\hline P70V0 & 2 & 6 & 0.9710744 & 0.7370576 & 0.818958 \\
\hline P70V0 & 2 & 7 & 1.004274 & 0.7058824 & 0.9073359 \\
\hline P70V0 & 2 & 8 & 0.9832636 & 0.3687391 & 0.7816918 \\
\hline P70V0 & 2 & 9 & 0.7755775 & 0.8254041 & 0.6739511 \\
\hline P70V0 & 2 & 10 & 1.004274 & 0.3088008 & 0.6380668 \\
\hline P70V0 & 3 & 1 & 0.8901515 & 0.6989205 & 0.7761667 \\
\hline P70V0 & 3 & 2 & 0.8768657 & 0.2156592 & 0.5890757 \\
\hline P70V0 & 3 & 3 & 0.9215686 & 0.5399672 & 0.5902594 \\
\hline P70V0 & 3 & 4 & 0.8768657 & 0.6 & 0.8047945 \\
\hline P70V0 & 3 & 5 & 0.8671587 & 0.4547587 & 0.5567797 \\
\hline P70V0 & 3 & 6 & 0.8935362 & 0.5024284 & 0.7288629 \\
\hline P70V0 & 3 & 7 & 0.8274648 & 0.6163554 & 0.6047816 \\
\hline P70V0 & 3 & 8 & 0.8935362 & 0.6520322 & 0.7965562 \\
\hline P70V0 & 3 & 9 & 1 & 0.6798096 & 0.8471827 \\
\hline P70V0 & 3 & 10 & 0.8901515 & 0.5320721 & 0.6848317 \\
\hline P35V2 & 1 & 1 & 1.231292 & 0.466241 & 0.7943144 \\
\hline P35V2 & 1 & 2 & 1.350746 & 0.3825858 & 1.001043 \\
\hline P35V2 & 1 & 3 & 1.190789 & 0.7009768 & 1.072805 \\
\hline P35V2 & 1 & 4 & 1.471545 & 0.2108499 & 0.6785952 \\
\hline P35V2 & 1 & 5 & 1.231292 & 0.5838347 & 0.9129477 \\
\hline P35V2 & 1 & 6 & 1.231292 & 0.3753582 & 0.7131931 \\
\hline P35V2 & 1 & 7 & 1.222973 & 1.159429 & 1.325837 \\
\hline P35V2 & 1 & 8 & 1.350746 & 0.3115884 & 0.9742973 \\
\hline P35V2 & 1 & 9 & 1.110429 & 0.5163257 & 0.9663501 \\
\hline P35V2 & 1 & 10 & 1.222973 & 0.5117732 & 0.7422022 \\
\hline P35V2 & 2 & 1 & 1.533898 & 0.5639396 & 1.044046 \\
\hline P35V2 & 2 & 2 & 1.110429 & 0.6726695 & 1.013267 \\
\hline P35V2 & 2 & 3 & 1.110429 & 0.344734 & 0.8213834 \\
\hline P35V2 & 2 & 4 & 1.471545 & 0.6835669 & 1.218863 \\
\hline P35V2 & 2 & 5 & 1.471545 & 0.7444482 & 1.292338 \\
\hline P35V2 & 2 & 6 & 1.471545 & 0.5023514 & 1.063358 \\
\hline P35V2 & 2 & 7 & 1.190789 & 0.8624273 & 1.136364 \\
\hline P35V2 & 2 & 8 & 1.350746 & 0.3744302 & 0.9488806 \\
\hline P35V2 & 2 & 9 & 1.521008 & 0.7684838 & 1.153825 \\
\hline P35V2 & 2 & 10 & 1.198676 & 0.3763089 & 1.062315 \\
\hline P35V2 & 3 & 1 & 1.110429 & 0.3558282 & 0.8476821 \\
\hline P35V2 & 3 & 2 & 1.190789 & 0.6272672 & 1.023825 \\
\hline P35V2 & 3 & 3 & 1.350746 & 0.438862 & 1.054482 \\
\hline P35V2 & 3 & 4 & 1.198676 & 0.1777984 & 0.8894506 \\
\hline P35V2 & 3 & 5 & 1.471545 & 0.3253568 & 0.8915575 \\
\hline
\end{tabular}




\begin{tabular}{lccccc} 
P35V2 & 3 & 6 & 1.190789 & 0.4375 & 0.8368644 \\
P35V2 & 3 & 7 & 1.471545 & 0.3980637 & 0.9187188 \\
P35V2 & 3 & 8 & 1.167742 & 1.197414 & 1.343466 \\
P35V2 & 3 & 9 & 1.190789 & 0.5269112 & 0.9463446 \\
P35V2 & 3 & 10 & 1.350746 & 0.2422928 & 0.8435856 \\
\hline \hline P70V2 & 1 & 1 & 1.167742 & 0.6595995 & 0.8137137 \\
P70V2 & 1 & 2 & 1.946237 & 0.1294888 & 0.874312 \\
P70V2 & 1 & 3 & 1.533898 & 0.6512409 & 1.155104 \\
P70V2 & 1 & 4 & 1.471545 & 0.2514014 & 0.7184857 \\
P70V2 & 1 & 5 & 1.436508 & 0.8044502 & 1.140656 \\
P70V2 & 1 & 6 & 1.167742 & 0.9660502 & 1.121205 \\
P70V2 & 1 & 7 & 1.167742 & 0.9803367 & 1.136284 \\
P70V2 & 1 & 8 & 1.471545 & 0.5180864 & 1.096699 \\
P70V2 & 1 & 9 & 1.436508 & 1.039202 & 1.464471 \\
P70V2 & 1 & 10 & 1.436508 & 0.897954 & 1.250722 \\
\hline P70V2 & 2 & 1 & 1.110429 & 0.4875605 & 0.9380643 \\
P70V2 & 2 & 2 & 1.222973 & 0.101318 & 1.2210 \\
P70V2 & 2 & 3 & 1.222973 & 0.745555 & 0.9944751 \\
P70V2 & 2 & 4 & 1.533898 & 0.6784604 & 1.185977 \\
P70V2 & 2 & 5 & 1.222973 & 0.989054 & 1.198852 \\
P70V2 & 2 & 6 & 1.167742 & 0.9114224 & 1.0692 \\
P70V2 & 2 & 7 & 1.533898 & 0.6015546 & 1.089816 \\
P70V2 & 2 & 8 & 1.521008 & 0.8806918 & 1.340641 \\
P70V2 & 2 & 9 & 1.190789 & 0.6566308 & 1.027187 \\
P70V2 & 2 & 10 & 1.167742 & 1.027168 & 1.178447 \\
\hline P70V2 & 3 & 1 & 1.231292 & 0.5968586 & 0.9394841 \\
P70V2 & 3 & 2 & 1.231292 & 0.6864599 & 1.004358 \\
P70V2 & 3 & 3 & 1.350746 & 0.4571786 & 1.06855 \\
P70V2 & 3 & 4 & 1.190789 & 0.6273526 & 0.9964231 \\
P70V2 & 3 & 5 & 1.222973 & 0.6746657 & 0.9291145 \\
P70V2 & 3 & 6 & 1.521008 & 0.8606416 & 1.316225 \\
P70V2 & 3 & 7 & 1.167742 & 0.7082993 & 0.86167 \\
P70V2 & 3 & 8 & 1.521008 & 0.8399968 & 1.276095 \\
P70V2 & 3 & 9 & 1.521008 & 1.159885 & 1.653333 \\
\hline & 3 & 10 & 1.521008 & 0.6861017 & 1.088952 \\
\hline
\end{tabular}

Table 3.15 Efficiency ratios per group and period for the four treatments in the case of permits. 


\section{D Experimental instructions}

We handed out and read aloud the instructions to the participants at the beginning of the experiment.

\section{Emission taxes P35V0 treatment}

Welcome. Next, you will participate in an economic experiment. During the experiment, your earnings will be measured in ECU that will be converted into Euros at the end of the experiment, using an exchange rate of $€ 1.25$ for every 100 accumulated ECU, plus a show-up fee of $€ 3$. The corresponding amount in Euros will be paid in cash at the end of the experiment.

At the beginning of the experiment, each of you will be assigned a number. From now on, you and the rest of the participants will be identified by that number. No type of communication is allowed between the participants in the experiment during the session. Any participant who does not comply will be expelled without payment.

\section{Economic environment and rules of the experiment:}

Consider an industry composed of 12 firms. Imagine that you run one of those firms. Each firm produces a product with a certain technology. As a result of your productive activity, you get a profit of 1200 ECU each period. However, the productive activity of firms generates emissions to the environment.

In this industry, firms use different technologies to control emissions. Each of the participants will be randomly assigned a particular technology. In total, there are 5 different technologies available. The difference between technologies is in the maximum level of emissions per unit of product, and as a consequence, in the cost of reducing emissions (see table 1). All firms can invest in a new technology that is expensive but generates fewer emissions.

The regulator uses a tax system to control emissions; this means that you must pay a tax for each unit of emissions reported by your firm. Since the regulator does not know your real emissions (only those that you report), he will verify with a probability of $35 \%$ if your reported emissions are the real ones. In case the reported emissions are below the real ones, the regulator will impose a fine.

The experiment lasts 10 periods. At the beginning of each period, both the amount of the tax per unit of emissions and the technology assigned to each of the firms will be announced. Then both you and the other participants must decide simultaneously and independently according to the following sequence: 
- 1st sub-period: You must decide if you want to invest and use the new technology or continue using the conventional technology. If you choose to adopt the new technology you must pay a cost of 580 ECU.

- 2nd sub-period: You have to decide on:

- Your level of emissions, or what is the same, decide how many units you want to reduce your emissions on the maximums imposed by your technology (the conventional or the new one in case you have adopted it). Do not forget that your cost of reducing emissions depends on the number of reduced units (see table 1).

- The emissions you report to the regulator. You must pay a tax based on the emissions you report to the regulator. Therefore, the reported emissions must be less than or equal to the actual emissions.

The regulator inspects your firm with a $35 \%$ probability to verify the difference between the real and reported emissions, applying, where appropriate, the corresponding fine (see table 2).

As a result of this sequence, the accumulated profit for your firm at the end of each period is:

\section{0-investment cost (if applicable) - total cost of emission reduction - tax - fine (if applicable)}

Example 1: Suppose a tax of 60 ECU per reported unit of emissions. You use TC1 technology and decide not to invest in the new technology. Also, you decide to issue 14 units, that is, to reduce 6 units, and also, you decide to report the 14 units, so in case of inspection, you will not be fined. Your profit in this period will be:

$$
\begin{gathered}
1200 \text { (initial profit) } \\
-210 \text { (total cost of emission reduction in } 6 \text { units) } \\
-60 \times 14=840 \text { (tax payment) }
\end{gathered}
$$$$
\text { TOTAL: } 150 \text { ECU }
$$

Example 2: Suppose a tax of 60 ECU per reported unit of emissions. You use TC1 technology and choose not to invest in the new technology. Also, you decide to issue 14 units, that is, reduce 6 units, but decide to report only 11 units. Note that, in case of inspection, you will be fined 91 ECU for the 3 unreported units. Your profit in this period depends on whether or not you are inspected. So, your profit is the following:

- If you are inspected (with a probability of $35 \%$ ): 
1200 (initial profit)

- 210 (total cost of emission reduction in 6 units)

- $60 \times 11=660$ (tax payment)

- 91 (fine)

TOTAL: 239 ECU

- If you are not inspected (with a $65 \%$ chance):

1200 (initial profit)

- 210 (total cost of emission reduction in 6 units)

$-60 \times 11=660$ (tax payment)

TOTAL: 330 ECU

Example 3: Suppose a tax of 60 ECU per reported unit of emissions. You decide to invest in the new technology and issue 1 unit, that is, reduce 6 units (note that if you have invested in the new technology, your maximum emission is 7 units). In addition, you decide to report said unit, so in case of inspection, you will not be fined. Your profit in this period will be:

$$
\begin{gathered}
1200 \text { (initial profit) } \\
-580 \text { (cost of investment in technology) } \\
\frac{-60 \times 1=60 \text { (tax payment) }}{\text { TOTAL: } 350 \text { ECU }}
\end{gathered}
$$

Example 4: Suppose a tax of 60 ECU per reported unit of emissions. You decide to invest in the new technology and issue 1 unit (that is, reduce 6 units since your maximum emissions in the case you have invested are 7 units), but you decide to report 0 units. Note that, in case of inspection, you will be fined 25 ECU for the unreported unit. Your profit in this period depends on whether or not you are inspected. So, your profit is the following:

- If you are inspected (with a probability of $35 \%$ ):

1200 (initial profit)

- 580 (cost of investment in technology)

- 210 (total cost of emission reduction in 6 units)

- $60 \times 0=0$ (tax payment)

- 25 (fine) 
- If you are not inspected (with a $65 \%$ chance):

$$
\begin{gathered}
1200 \text { (initial profit) } \\
-580 \text { (cost of investment in technology) } \\
-210 \text { (total cost of emission reduction in } 6 \text { units) } \\
-60 \times 0=0 \text { (tax payment) }
\end{gathered}
$$$$
\text { TOTAL: } 410 \text { ECU }
$$

Your payment at the end of the experiment will be the profit obtained in two of the periods chosen at random at the end of the session. Therefore, it is in your own interest that you correctly understand the experiment.

Before starting the experiment, you will participate in a trial period to familiarize yourself with it. If you have any questions, do not hesitate to raise your hand and ask the person in charge.

Thanks for your participation. 
Table 1. Technologies

\begin{tabular}{|c|c|c|c|c|c|c|c|c|}
\hline \multicolumn{6}{|c|}{ YOUR EMISSIONS } & \multicolumn{3}{|c|}{ ABATE EMISSIONS } \\
\hline TC1 & TC2 & TC3 & TC4 & TC5 & New Tech & $\begin{array}{l}\text { MARGINAL } \\
\text { Cost }\end{array}$ & $\begin{array}{c}\text { TOTAL } \\
\text { Cost }\end{array}$ & $\begin{array}{l}\text { ABATED } \\
\text { Units }\end{array}$ \\
\hline 20 & 18 & 16 & 14 & 12 & 7 & ---- & 0 & 0 \\
\hline 19 & 17 & 15 & 13 & 11 & 6 & 10 & 10 & 1 \\
\hline 18 & 16 & 14 & 12 & 10 & 5 & 20 & 30 & 2 \\
\hline 17 & 15 & 13 & 11 & 9 & 4 & 30 & 60 & 3 \\
\hline 16 & 14 & 12 & 10 & 8 & 3 & 40 & 100 & 4 \\
\hline 15 & 13 & 11 & 9 & 7 & 2 & 50 & 150 & 5 \\
\hline 14 & 12 & 10 & 8 & 6 & 1 & 60 & 210 & 6 \\
\hline 13 & 11 & 9 & 7 & 5 & 0 & 70 & 280 & 7 \\
\hline 12 & 10 & 8 & 6 & 4 & & 80 & 360 & 8 \\
\hline 11 & 9 & 7 & 5 & 3 & & 90 & 450 & 9 \\
\hline 10 & 8 & 6 & 4 & 2 & & 100 & 550 & 10 \\
\hline 9 & 7 & 5 & 3 & 1 & & 110 & 660 & 11 \\
\hline 8 & 6 & 4 & 2 & 0 & & 120 & 780 & 12 \\
\hline 7 & 5 & 3 & 1 & & & 130 & 910 & 13 \\
\hline 6 & 4 & 2 & 0 & & & 140 & 1050 & 14 \\
\hline 5 & 3 & 1 & & & & 150 & 1200 & 15 \\
\hline 4 & 2 & 0 & & & & 160 & 1360 & 16 \\
\hline 3 & 1 & & & & & 170 & 1530 & 17 \\
\hline 2 & 0 & & & & & 180 & 1710 & 18 \\
\hline 1 & & & & & & 190 & 1900 & 19 \\
\hline 0 & & & & & & 200 & 2100 & 20 \\
\hline
\end{tabular}

EXPLANATION: Given any technology, TOTAL COST refers to the cost of reducing emissions in a certain number of units. For example, if you want to reduce your emissions by 4 units from your maximum emissions, this will cost you $10+20$ $+30+40=100$ ECU. Note, however, that the cost of reducing each of the units is not the same, the more units you want to reduce, the greater the cost of reducing each additional unit. This cost is called MARGINAL COST. For example, if you want to reduce your emissions from 4 to 5 units, this will cost you 50 additional ECU. Therefore, the total cost of reducing your emissions by 5 units is $10+20+30+40+$ $\mathbf{5 0}=150 \mathrm{ECU}$ 
Table 2. Your unreported emissions

\begin{tabular}{|c|c|c|}
\hline \multirow{2}{*}{$\begin{array}{c}\text { Your unreported } \\
\text { emissions (real } \\
\text { emissions - reported } \\
\text { emissions) } \\
\end{array}$} & \multicolumn{2}{|c|}{ Inspection Prob. $=\mathbf{3 5} \%$} \\
\hline & $\begin{array}{l}\text { MARGINAL } \\
\text { Fine }\end{array}$ & $\begin{array}{c}\text { TOTAL } \\
\text { Fine }\end{array}$ \\
\hline 0 & 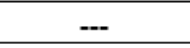 & 0 \\
\hline 1 & 205 & 205 \\
\hline 2 & 210 & 415 \\
\hline 3 & 216 & 631 \\
\hline 4 & 221 & 852 \\
\hline 5 & 226 & 1078 \\
\hline 6 & 231 & 1309 \\
\hline 7 & 236 & 1545 \\
\hline 8 & 242 & 1787 \\
\hline 9 & 247 & 2034 \\
\hline 10 & 252 & 2286 \\
\hline 11 & 257 & 2543 \\
\hline 12 & 262 & 2805 \\
\hline 13 & 268 & 3073 \\
\hline 14 & 273 & 3346 \\
\hline 15 & 278 & 3624 \\
\hline 16 & 283 & 3907 \\
\hline 17 & 288 & 4195 \\
\hline 18 & 294 & 4489 \\
\hline 19 & 299 & 4788 \\
\hline 20 & 304 & 5092 \\
\hline
\end{tabular}

EXPLANATION: TOTAL fine refers to the cost of not reporting a certain number of emissions. For example, if you do not report 5 units of which you have chosen to issue and you are inspected, this will cost you $25+30+36+41+46=178$ ECU. The cost of the fine for not reporting an additional unit (the 6 unit) is 51 additional ECU. This is called MARGINAL FINE. Therefore, the total cost of not reporting 6 units and being inspected is $25+30+36+41+46+51=\mathbf{2 2 9}$ ECU. 


\section{Emission permits P70V0 treatment}

Welcome. Next, you will participate in an economic experiment. During the experiment, your earnings will be measured in ECU that will be converted into Euros at the end of the experiment, using an exchange rate of $€ 1.25$ for every 100 accumulated ECU. The corresponding amount in Euros will be paid in cash at the end of the experiment.

At the beginning of the experiment, each of you will be assigned a number. From now on, you and the rest of the participants will be identified by that number. No type of communication is allowed between the participants in the experiment during the session. Any participant who does not comply will be expelled without payment.

\section{Economic environment and rules of the experiment:}

Consider an industry composed of 12 firms. Imagine that you run one of those firms. Each firm produces a product with a certain technology. As a result of your productive activity, you get a revenue of 1200 ECU each period. However, the firms' production activity generates emissions to the environment.

In this industry, firms use different technologies to control emissions. Each of the participants will be randomly assigned a particular technology. In total, there are 5 different technologies available. The difference between one technology and another is in the maximum level of emissions per unit of product, and as a consequence, in the cost of reducing emissions (see table 1). All firms are allowed to invest in a new technology that is expensive but generates fewer emissions.

The regulator uses a system of permits to control emissions. The objective of the regulator is that the total emissions of the industry do not exceed 72 units. For this, at the beginning of each period the regulator auctions 72 emission permits. The permit system works in the following way: you must have a permit for each emission unit of your firm.

The government will issue a series of permits with a duration of 1 period, which means that you can only use the permits for that period. The price of the permits will be determined by an auction in which you can buy permits from the regulator.

The experiment has a duration of $\mathbf{1 0}$ periods. At the beginning of each period, the technology assigned and the number of permits will be announced. Then, you and the rest of the participants must decide simultaneously and independently according to the following sequence:

- 1st sub-period: You must decide if you want to invest and use the new technology or continue using the conventional technology. If you choose to adopt the new technology, you must pay a cost of 580 ECU. 
- 2nd sub-period: The permit market opens. An auction will determine the permit prices (its operation will be explained below).

- 3rd sub-period: You have to decide on your level of emissions considering the permits hold. I.e., indirectly, you decide how many units you want to reduce your emissions on the maximums imposed by your technology (the conventional or the new one in case you have adopted it). Do not forget that your cost of reducing emissions depends on the number of reduced units (see table 1).

The regulator inspects your firm with a probability of $70 \%$ to verify the difference between the real emissions and the permits held, applying, where appropriate, the corresponding fine (see table 2).

As a result of this sequence, the accumulated profit for your firm at the end of each period is:

\section{0-investment cost (if applicable) - total cost of emission reduction - auction cost (number*price of permits) - fine (if applicable)}

\section{AUCTION OF EMISSION PERMITS:}

The regulator issues 72 permits each period.

Each auction will have the following phases:

- The price of permits starts at 5 ECU.

- You and the other participants enter the number of permits you are willing to buy at that price. Keep in mind that you will not be able to buy more permits than your maximum level of emissions.

- The total demand for permits will be calculated (total number of permits required by all firms).

- If the total demand for permits is equal to or less than 72, the auction ends, and you will obtain the number of permits you had requested at that price.

- If the total demand for permits is greater than 72 , the permit price will increase by 10 ECU, and a new period of auctions will begin.

Here are some examples:

Example 1: Suppose that you use TC1 technology and decide not to invest in the new technology. The auction stops at the price of 55 ECU per permit, and you have bought 14 permits at that price. You decide to reduce 6 units, so in case of inspection, you will not be fined. Your profit in this period will be: 


\section{0 (initial profit) \\ - $770(55 * 14$ auction cost) \\ - 210 (total cost of emission reduction in 6 units)}

\section{TOTAL: 220 ECU}

Example 2: Suppose that you use TC1 technology and decide not to invest in the new technology. The auction stops at the price of 55 ECU per permit, and you have bought 11 permits at that price. You decide to reduce 6 units, so you are emitting 3 units. Note that, in case of inspection, you will be fined 91 ECU for the 3 units you emit over the number of permits you hold. Your profit in this period depends on whether or not you are inspected. So, your profit is the following:

- If you are inspected (with a probability of $70 \%$ ):

$$
\begin{gathered}
1200 \text { (initial profit) } \\
-605\left(55^{*} 11 \text { auction cost }\right)
\end{gathered}
$$

- 210 (total cost of emission reduction in 6 units)

- 91 (fine)

\section{TOTAL: 294 ECU}

- If you are not inspected (with a $65 \%$ chance):

$$
\begin{gathered}
1200 \text { (initial profit) } \\
\frac{-210 \text { (total cost of emission reduction in } 6 \text { units })}{\text { TOTAL: } 385 \text { ECU }}
\end{gathered}
$$

Example 3: SSuppose that you are assigned TC1 technology and you decide to invest in the new technology. The auction stops at 65 ECU per permit, and you have bought 1 permit at that price. You decide to reduce 6 units (note that if you have invested in the new technology, your maximum emission is 7 units), so in case of inspection, you will not be fined. Your profit in this period will be:

$$
\begin{gathered}
1200 \text { (initial profit) } \\
-580 \text { (cost of investment in technology) } \\
-65\left(65^{*} 1 \text { auction cost) - } 210 \text { (total cost of emission reduction in } 6\right. \text { units) }
\end{gathered}
$$

\section{TOTAL: 345 ECU}

Example 4: Suppose that TC1 technology is assigned to you, but you choose to invest in the new technology. You do not buy any permits in the auction, and you decide to issue 1 unit (that is, reduce 6 units since your maximum emissions in 
the case you have invested are 7 units). Note that, in case of inspection, you will be fined $25 \mathrm{ECU}$ for the unit you issue not covered by permits. Your profit in this period depends on whether or not you are inspected. So, your profit is the following:

- If you are inspected (with a probability of $70 \%$ ):

$$
\begin{gathered}
1200 \text { (initial profit) } \\
-580 \text { (cost of investment in technology) } \\
-210 \text { (total cost of emission reduction in } 6 \text { units) } \\
-25 \text { (fine) }
\end{gathered}
$$$$
\text { TOTAL: } 385 \text { ECU }
$$

- If you are not inspected (with a $65 \%$ chance):

$$
\begin{gathered}
1200 \text { (initial profit) } \\
-580 \text { (cost of investment in technology) } \\
-210 \text { (total cost of emission reduction in } 6 \text { units) }
\end{gathered}
$$

\section{TOTAL: 410 ECU}

Your payment at the end of the experiment will be the profit obtained in two of the periods chosen at random at the end of the session. Therefore, it is in your interest that you correctly understand the experiment.

Before starting the experiment, you will participate in a trial period to get familiar with it. If you have any questions, do not hesitate to raise your hand and ask the person in charge.

Thanks for your participation. 
Table 1. Technologies

\begin{tabular}{|c|c|c|c|c|c|c|c|c|}
\hline \multicolumn{6}{|c|}{ YOUR EMISSIONS } & \multicolumn{3}{|c|}{ ABATE EMISSIONS } \\
\hline TC1 & TC2 & TC3 & TC4 & TC5 & New Tech & $\begin{array}{l}\text { MARGINAL } \\
\text { Cost }\end{array}$ & $\begin{array}{l}\text { TOTAL } \\
\text { Cost }\end{array}$ & $\begin{array}{l}\text { ABATED } \\
\text { Units }\end{array}$ \\
\hline 20 & 18 & 16 & 14 & 12 & 7 & ---- & 0 & 0 \\
\hline 19 & 17 & 15 & 13 & 11 & 6 & 10 & 10 & 1 \\
\hline 18 & 16 & 14 & 12 & 10 & 5 & 20 & 30 & 2 \\
\hline 17 & 15 & 13 & 11 & 9 & 4 & 30 & 60 & 3 \\
\hline 16 & 14 & 12 & 10 & 8 & 3 & 40 & 100 & 4 \\
\hline 15 & 13 & 11 & 9 & 7 & 2 & 50 & 150 & 5 \\
\hline 14 & 12 & 10 & 8 & 6 & 1 & 60 & 210 & 6 \\
\hline 13 & 11 & 9 & 7 & 5 & 0 & 70 & 280 & 7 \\
\hline 12 & 10 & 8 & 6 & 4 & & 80 & 360 & 8 \\
\hline 11 & 9 & 7 & 5 & 3 & & 90 & 450 & 9 \\
\hline 10 & 8 & 6 & 4 & 2 & & 100 & 550 & 10 \\
\hline 9 & 7 & 5 & 3 & 1 & & 110 & 660 & 11 \\
\hline 8 & 6 & 4 & 2 & 0 & & 120 & 780 & 12 \\
\hline 7 & 5 & 3 & 1 & & & 130 & 910 & 13 \\
\hline 6 & 4 & 2 & 0 & & & 140 & 1050 & 14 \\
\hline 5 & 3 & 1 & & & & 150 & 1200 & 15 \\
\hline 4 & 2 & 0 & & & & 160 & 1360 & 16 \\
\hline 3 & 1 & & & & & 170 & 1530 & 17 \\
\hline 2 & 0 & & & & & 180 & 1710 & 18 \\
\hline 1 & & & & & & 190 & 1900 & 19 \\
\hline 0 & & & & & & 200 & 2100 & 20 \\
\hline
\end{tabular}

EXPLANATION: Given any technology, TOTAL COST refers to the cost of reducing emissions in a certain number of units. For example, if you want to reduce your emissions by 4 units from your maximum emissions, this will cost you $10+20$ $+30+40=100$ ECU. Note, however, that the cost of reducing each of the units is not the same, the more units you want to reduce, the greater the cost of reducing each additional unit. This cost is called MARGINAL COST. For example, if you want to reduce your emissions from 4 to 5 units, this will cost you 50 additional ECU. Therefore, the total cost of reducing your emissions by 5 units is $10+20+30+40+$ $\mathbf{5 0}=150$ ECU. 
Table 2. Your emissions non covered by permits

\begin{tabular}{|c|c|c|}
\hline \multirow{2}{*}{$\begin{array}{c}\text { Your uncovered } \\
\text { emissions (real } \\
\text { emissions - permits } \\
\text { held) }\end{array}$} & \multicolumn{2}{|c|}{ Inspection Prob. $=70 \%$} \\
\hline & $\begin{array}{l}\text { MARGINAL } \\
\text { Fine }\end{array}$ & $\begin{array}{c}\text { TOTAL } \\
\text { Fine }\end{array}$ \\
\hline 0 & -- & 0 \\
\hline 1 & 103 & 103 \\
\hline 2 & 105 & 208 \\
\hline 3 & 108 & 316 \\
\hline 4 & 110 & 426 \\
\hline 5 & 113 & 539 \\
\hline 6 & 116 & 655 \\
\hline 7 & 118 & 773 \\
\hline 8 & 121 & 894 \\
\hline 9 & 123 & 1017 \\
\hline 10 & 126 & 1143 \\
\hline 11 & 129 & 1272 \\
\hline 12 & 131 & 1403 \\
\hline 13 & 134 & 1537 \\
\hline 14 & 136 & 1673 \\
\hline 15 & 139 & 1812 \\
\hline 16 & 142 & 1954 \\
\hline 17 & 144 & 2098 \\
\hline 18 & 147 & 2245 \\
\hline 19 & 149 & 2394 \\
\hline 20 & 152 & 2546 \\
\hline
\end{tabular}

EXPLANATION: TOTAL fine refers to the cost of issuing a certain number of emissions not covered by permits. 


\section{D.1 Fines in the V2 treatments}

\begin{tabular}{|c|c|c|}
\hline \multirow{2}{*}{$\begin{array}{c}\text { Your unreported } \\
\text { emissions (real } \\
\text { emissions - reported } \\
\text { emissions) } \\
\end{array}$} & \multicolumn{2}{|c|}{ Inspection Prob. $=35 \%$} \\
\hline & $\begin{array}{c}\text { MARGINAL } \\
\text { Fine }\end{array}$ & $\begin{array}{c}\text { TOTAL } \\
\text { Fine }\end{array}$ \\
\hline 0 & --- & 0 \\
\hline 1 & 25 & 25 \\
\hline 2 & 30 & 55 \\
\hline 3 & 36 & 91 \\
\hline 4 & 41 & 132 \\
\hline 5 & 46 & 178 \\
\hline 6 & 51 & 229 \\
\hline 7 & 56 & 285 \\
\hline 8 & 62 & 347 \\
\hline 9 & 67 & 414 \\
\hline 10 & 72 & 486 \\
\hline 11 & 77 & 563 \\
\hline 12 & 82 & 645 \\
\hline 13 & 88 & 733 \\
\hline 14 & 93 & 826 \\
\hline 15 & 98 & 924 \\
\hline 16 & 103 & 1027 \\
\hline 17 & 108 & 1135 \\
\hline 18 & 114 & 1249 \\
\hline 19 & 119 & 1368 \\
\hline 20 & 124 & 1492 \\
\hline
\end{tabular}

Figure 3.15 Fines for P35V2.

\begin{tabular}{|c|c|c|}
\hline \multirow{2}{*}{$\begin{array}{l}\text { Your unreported } \\
\text { emissions (real } \\
\text { emissions - reported } \\
\text { emissions) }\end{array}$} & \multicolumn{2}{|c|}{ Inspection Prob. $=70 \%$} \\
\hline & $\begin{array}{c}\text { MARGINAL } \\
\text { Fine }\end{array}$ & $\begin{array}{c}\text { TOTAL } \\
\text { Fine }\end{array}$ \\
\hline 0 & -- & 0 \\
\hline 1 & 13 & 13 \\
\hline 2 & 15 & 28 \\
\hline 3 & 18 & 46 \\
\hline 4 & 20 & 66 \\
\hline 5 & 23 & 89 \\
\hline 6 & 26 & 115 \\
\hline 7 & 28 & 143 \\
\hline 8 & 31 & 174 \\
\hline 9 & 33 & 207 \\
\hline 10 & 36 & 243 \\
\hline 11 & 39 & 282 \\
\hline 12 & 41 & 323 \\
\hline 13 & 44 & 367 \\
\hline 14 & 46 & 413 \\
\hline 15 & 49 & 462 \\
\hline 16 & 52 & 514 \\
\hline 17 & 54 & 568 \\
\hline 18 & 57 & 625 \\
\hline 19 & 59 & 684 \\
\hline 20 & 62 & 746 \\
\hline
\end{tabular}

Figure 3.16 Fines for P70V2. 


\section{E Screenshots}

\section{Tax treatments}

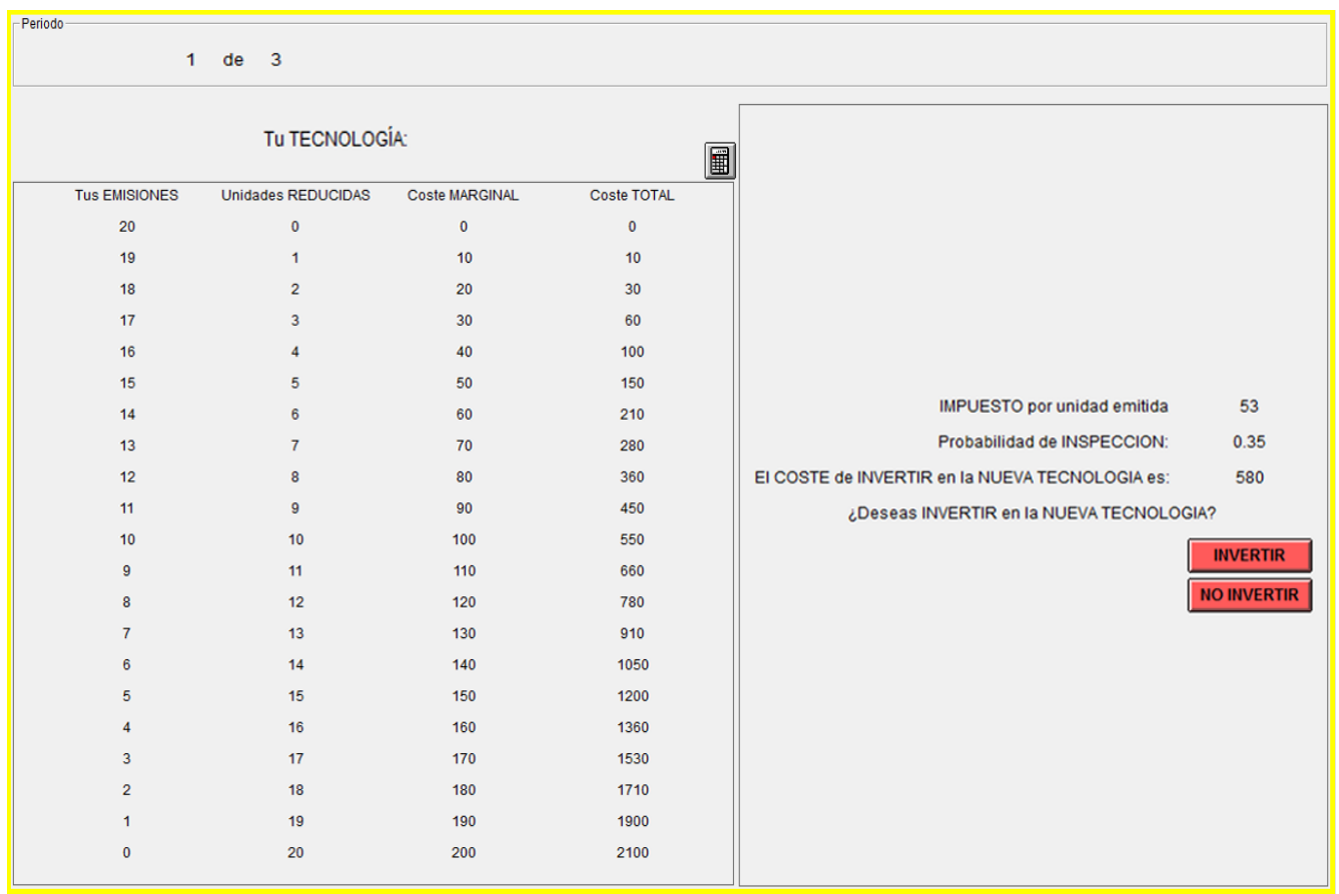

Figure 3.17 Screenshot of Stage 1. The left-hand side of the screen displays the current technology, while the right-hand side indicates the tax rate, the inspection probability, and the cost of investment. On the right-hand side, the subject indicates whether he/she wishes to invest in the new technology or no

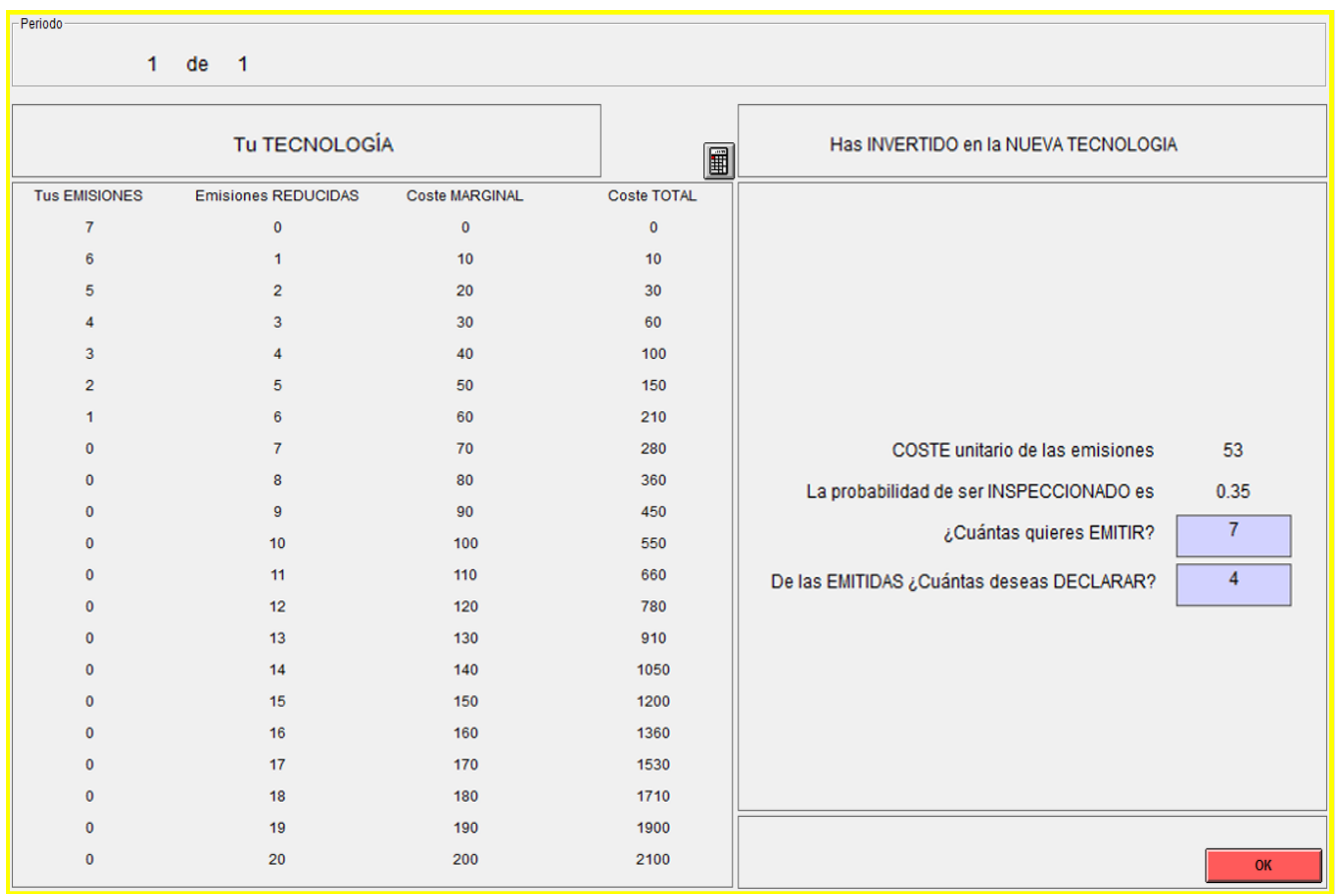

Figure 3.18 Screenshot of Stage 2. The left-hand side of the screen displays the current technology. On the right-hand side, the subject indicates how many units he/she wants to emit, and from those how many he/she wants to report 


\section{Permit treatments}

\begin{tabular}{|c|c|c|c|c|c|}
\hline \multicolumn{6}{|l|}{ Prenosos- } \\
\hline \multicolumn{4}{|c|}{1 de 1} & \multicolumn{2}{|c|}{ Tiempo restante [sek]: 33} \\
\hline \multicolumn{2}{|c|}{ TU TECNOLOGIA: } & \multicolumn{2}{|c|}{ 㘣 } & & \\
\hline TUS EMISIONES & Emisiones REDUCIDAS & Coste MARGINAL & Coste TOTAL & & \\
\hline 20 & 0 & 0 & 0 & & \\
\hline 19 & 1 & 10 & 10 & & \\
\hline 18 & 2 & 20 & 30 & & \\
\hline 17 & 3 & 30 & 60 & & \\
\hline 16 & 4 & 40 & 100 & & \\
\hline 15 & 5 & 50 & 150 & Número de permisos emitidos por el regulador & 72 \\
\hline 14 & 6 & 60 & 210 & La probabilidad de INSPECCIÓN es: & 0.35 \\
\hline 13 & 7 & 70 & 280 & EI COSTE de INVERTIR E I I NUEVA TECNOLOGIAA ES: & 580 \\
\hline $\begin{array}{l}12 \\
11\end{array}$ & $\begin{array}{l}8 \\
9\end{array}$ & $\begin{array}{l}80 \\
90\end{array}$ & $\begin{array}{l}360 \\
450\end{array}$ & Deseas INVERTIR en Ia NUEVA TECNOLOC & \\
\hline 10 & 10 & 100 & 550 & & IIIVERTIR \\
\hline 9 & 11 & 110 & 660 & & \\
\hline 8 & 12 & 120 & 780 & & NO INVERTIR \\
\hline 7 & 13 & 130 & 910 & & \\
\hline 6 & 14 & 140 & 1050 & & \\
\hline 5 & 15 & 150 & 1200 & & \\
\hline 4 & 16 & 160 & 1360 & & \\
\hline 3 & 17 & 170 & 1530 & & \\
\hline 2 & 18 & 180 & 1710 & & \\
\hline 1 & 19 & 190 & 1900 & & \\
\hline 0 & 20 & 200 & 2100 & & \\
\hline
\end{tabular}

Figure 3.19 Screenshot of Stage 1. The left-hand side of the screen displays the current technology, while the right-hand side indicates the number of permits being issued, the inspection probability and the cost of investment. On the right-hand side, the subject indicates whether he/she wishes to invest in the new technology or not

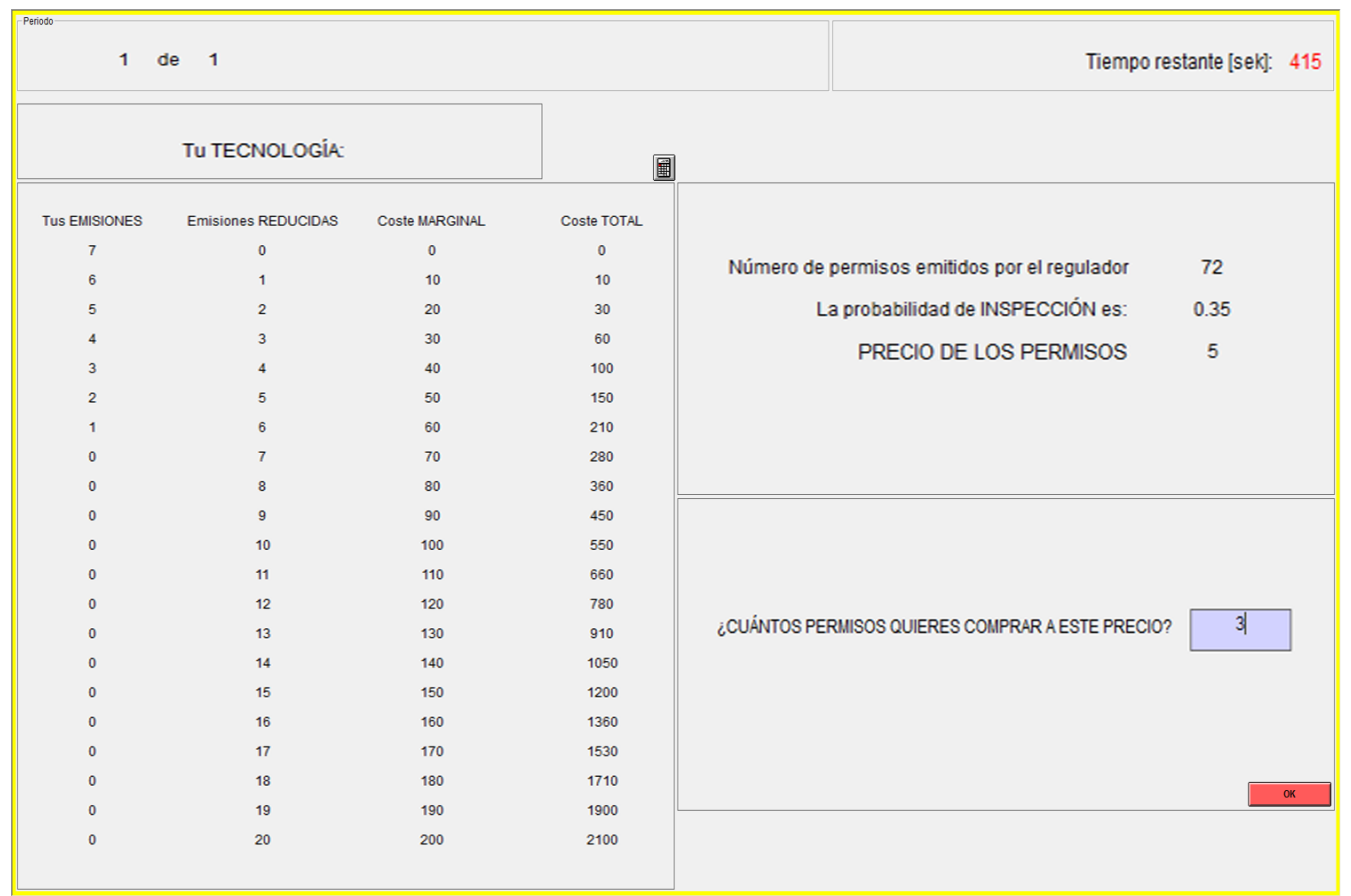

Figure 3.20 Screenshot of Stage 2. The left-hand side of the screen displays the current technology. On the right-hand side, the subject indicates how many permits he/she wants to buy at that price 


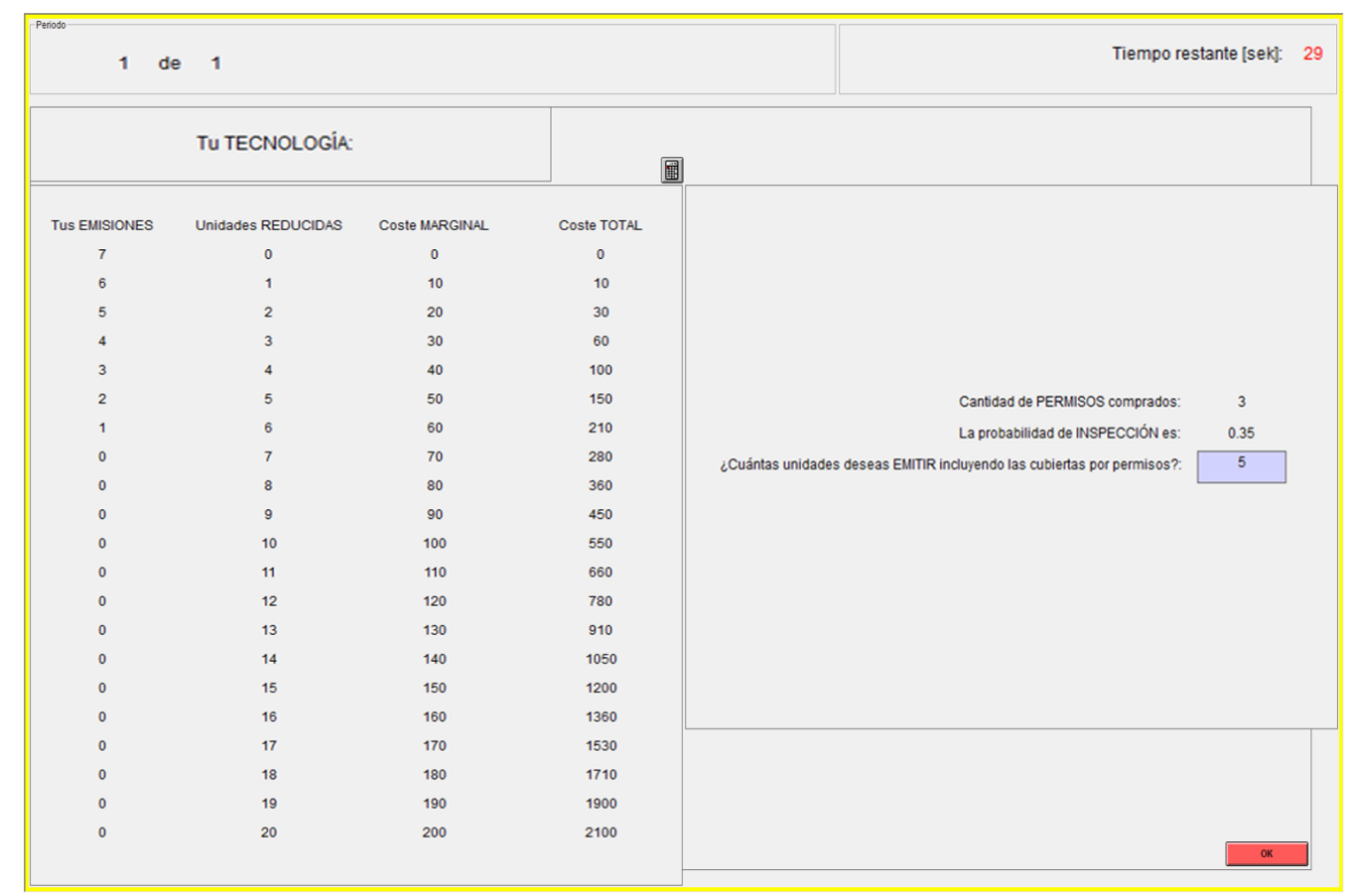

Figure 3.21 Screenshot of Stage 3. The left-hand side of the screen displays the current technology. On the right-hand side, the subject indicates how many permits he/she purchased at the final price, and how many units he/she is willing to release including those covered by permits 


\section{General conclusions and future perspectives}

In the late years, researchers have discussed the efficiency of different policy instruments without reaching a consensus. This thesis aims to investigate whether market-based pollution control instruments are powerful and efficient tools for curbing pollution. More specifically, we attempt to study whether emission taxes and tradable permits provide incentives for pollutive firms to adopt advanced abatement technologies using laboratory experiments. We design an experiment that is characterized by (i) an industry with small asymmetric polluting firms, and (ii) adopting the new technology has the same cost for all firms.

In the first chapter, using a simple duopoly model, we study how the industrial policy implemented by governments might be affected by international oligopolistic trade. There is only one firm in the home industry, the foreign industry is imperfectly competitive, and firms compete à la Cournot. We show that the domestic government has an incentive to set emission taxes, as long as the asymmetry between the markets remains sufficiently low. Conversely, in the case of significant market asymmetries between home and foreign countries, our results confirm the optimality for governments to abandon their environmental policy to improve their industrial competitiveness. Our model shows that an industrial policy based on emission taxes is less effective than one based on production subsidies as an instrument for improving industrial competitiveness in the home country.

In the first experiment, we investigate whether emission taxes and permits provide efficient incentives for polluting firms to adopt cleaner technologies under perfect compliance. Considering timing is one of the innovations of our experiment, we study the effects of setting the optimal policy level before or after the firms' investment decision. The key result of our study is that timing has (no) significant effect on the pattern of technology adoption when firms are initially endowed with a dirtier (cleaner) technology. In other words, timing has a significant effect on the investment decision of those firms endowed with technology $T_{3}$, that is, the first with no incentives to adopt the new technology in equilibrium. We find that observed tax rates are significantly higher than the expected ones in the ex-ante treatment. As well as, observed emissions are lower than the expected ones in the two treatments, and they are significantly higher in the ex-ante treatment. Looking at the permit price, we find that in ex-ante treatment prices are significantly lower than in the ex-post treatment. In terms of market liquidity, our results show that permit holding depends on timing since in the ex-ante treatment firms hold more permits compared to the ex-post treatment; moreover, 
observed permit holding is significantly lower than the expected one in both treatments.

In the second experiment, we want to go a step forward and assume imperfect compliance. In particular, we investigate the effect of different inspection probabilities and different induced optimal violation levels (perfect vs. imperfect compliance) on the firms' behavior concerning the adoption of advanced abatement technologies. Regarding emission taxes, inducing imperfect compliance reduces the number of firms adopting the new technology only if the regulator implements a monitoring policy with a high inspection probability. As a consequence, inducing violations significantly increases tax evasion regardless of the inspection probability, as predicted by the existing theory. In the case of permits, permit prices under imperfect compliance are smaller than that under perfect compliance. As a consequence, adoption incentives under imperfect compliance are smaller, regardless of the inspection probability.

These results are particularly interesting for scholars and policymakers engaged in understanding the incentives and causes of inefficiencies in the adoption of advanced abatement technologies, and yield a significant contribution to the previous literature which only considers perfect compliance; i.e., we include variations in the compliance behavior of firms and the timing of the policy.

The current thesis, despite its virtues, also suffers some limitations. Here we propose some ways for further research. First, in Chapter 1 we could apply both policies at the same time through a feed-in tariff. Second, the method employed to analyze the efficiency in Chapter 2 was based on the traditional efficiency analysis for perfect compliance. In general, it is necessary additional research on more advanced techniques to measure the incorporation of imperfect compliance. We could also relax the assumption that adopting the new technology has the same cost for all firms regardless of the initial technology; i.e., we can assume different adoption costs depending on the endowed initial technology. Finally, we have observed that there are always spare permits in an ascending clock auction, therefore, becoming a possible reason for inefficiency in the permit market. Perhaps we should look for another type of auctions in which all permits are sold out. 


\section{Bibliography}

Arguedas, Carmen (2008). "To comply or not to comply? Pollution standard setting under costly monitoring and sanctioning". In: Environmental and Resource Economics 41.2, pp. 155-168.

Arguedas, Carmen, Eva Camacho, and José Luis Zofío (2010). "Environmental policy instruments: Technology adoption incentives with imperfect compliance". In: Environmental and Resource Economics 47.2, pp. 261-274.

Asano, Takao and Noriaki Matsushima (2014). "Environmental regulation and technology transfers". In: Canadian Journal of Economics/Revue canadienne d'économique 47.3, pp. 889-904.

Baksi, Soham and Amrita Ray Chaudhuri (2009). "On trade liberalization and transboundary pollution". In: Economics Bulletin 29.4, pp. 2605-2612.

Barrett, Scott (1994). "Strategic environmental policy and international trade". In: Journal of public Economics 54.3, pp. 325-338.

Ben-David, Shaul et al. (1999). "Heterogeneity, irreversible production choices, and efficiency in emission permit markets". In: Journal of Environmental Economics and Management 38.2, pp. 176-194.

Botelho, Anabela, Eduarda Fernandes, and Lígia Costa Pinto (2011). "An experimental analysis of grandfathering versus dynamic auctioning in the EU ETS". In: Experiments on Energy, the Environment, and Sustainability. Emerald Group Publishing Limited, pp. 37-76.

Brander, James A and Barbara J Spencer (1985). "Export subsidies and international market share rivalry". In: Journal of international Economics 18.1-2, pp. 83-100.

Burguet, Roberto and Jaume Sempere (2003). "Trade liberalization, environmental policy, and welfare". In: Journal of Environmental Economics and Management 46.1 , pp. $25-37$. 
Caffera, Marcelo and Carlos Chávez (2016). "The Regulatory Choice of Noncompliance in the Lab: Effect on Quantities, Prices, and Implications for the Design of a CostEffective Policy". In: The BE Journal of Economic Analysis $\&$ Policy 16.2, pp. 727753.

Caffera, Marcelo and Carlos A Chávez (2011). "The cost-effective choice of policy instruments to cap aggregate emissions with costly enforcement". In: Environmental and Resource Economics 50.4, pp. 531-557.

Camacho, Eva et al. (2009). "Comercio de derechos de emisión, adopción de tecnología y heterogeneidad de industria: un enfoque experimental". In: Cuadernos Económicos de ICE 77 .

Camacho-Cuena, Eva, Till Requate, and Israel Waichman (2012). "Investment incentives under emission trading: An experimental study". In: Environmental and Resource Economics 53.2, pp. 229-249.

Cason, Timothy N and Frans P de Vries (2018). "Dynamic Efficiency in Experimental Emissions Trading Markets with Investment Uncertainty". In: Environmental and Resource Economics, pp. 1-31.

Chen, Daniel L, Martin Schonger, and Chris Wickens (2016). "oTree-An open-source platform for laboratory, online, and field experiments". In: Journal of Behavioral and Experimental Finance 9, pp. 88-97.

Cochard, François, Marc Willinger, and Anastasios Xepapadeas (2005). "Efficiency of nonpoint source pollution instruments: an experimental study". In: Environmental and Resource Economics 30.4, pp. 393-422.

Conrad, Klaus (1993). "Taxes and subsidies for pollution-intensive industries as trade policy". In: Journal of environmental economics and management 25.2, pp. 121135 .

Copeland, Brian R and M Scott Taylor (2004). "Trade, growth, and the environment". In: Journal of Economic literature 42.1, pp. 7-71.

Coria, Jessica (2009). "Taxes, permits, and the diffusion of a new technology". In: Resource and Energy Economics 31.4, pp. 249-271.

Coria, Jessica and Xiao-Bing Zhang (2015). "State-dependent enforcement to foster the adoption of new technologies". In: Environmental and Resource Economics 62.2, pp. 359-381. 
Dixit, Avinash (1984). "International trade policy for oligopolistic industries". In: The Economic Journal 94, pp. 1-16.

Dunlap, Riley E et al. (2000). "New trends in measuring environmental attitudes: measuring endorsement of the new ecological paradigm: a revised NEP scale". In: Journal of social issues 56.3 , pp. 425-442.

Duval, Yann and Stephen F Hamilton (2002). "Strategic environmental policy and international trade in asymmetric oligopoly markets". In: International Tax and Public Finance 9.3, pp. 259-271.

Eaton, Jonathan and Gene M Grossman (1986). "Optimal trade and industrial policy under oligopoly". In: The Quarterly Journal of Economics 101.2, pp. 383-406.

Ekins, Paul (1999). "European environmental taxes and charges: recent experience, issues and trends". In: Ecological economics 31.1, pp. 39-62.

Feld, Lars P and Bruno S Frey (2002). "The tax authority and the taxpayer: An exploratory analysis". In:

- (2007). "Tax compliance as the result of a psychological tax contract: The role of incentives and responsive regulation". In: Law $\&$ Policy 29.1, pp. 102-120.

Fischbacher, Urs (2007). "z-Tree: Zurich toolbox for ready-made economic experiments". In: Experimental economics 10.2, pp. 171-178.

Fischer, Carolyn (2016). "Environmental protection for sale: strategic green industrial policy and climate finance". In: Environmental and Resource Economics, pp. 1-23.

Frondel, Manuel, Rainer Kambeck, and Christoph M Schmidt (2007). "Hard coal subsidies: A never-ending story?" In: Energy Policy 35.7, pp. 3807-3814.

Gangadharan, Lata, Rachel Croson, Alex Farrell, et al. (2013). "Investment decisions and emissions reductions: results from experiments in emissions trading". In: Handbook on experimental economics and the environment. Edward Elgar Publishing Ltd, Cheltenham, pp. 233-264.

Holt, Charles A and Susan K Laury (2002). "Risk aversion and incentive effects". In: American economic review 92.5, pp. 1644-1655.

Jewell, Jessica et al. (2018). "Limited emission reductions from fuel subsidy removal except in energy-exporting regions". In: Nature 554.7691, p. 229. 
Kennedy, Peter W (1994). "Equilibrium pollution taxes in open economies with imperfect competition". In: Journal of environmental economics and management 27.1, pp. 49-63.

Kneese, Allen V and Charles L Schultze (1975). "Pollution, prices, and public policy: a study sponsored jointly by Resources for the Future, inc. and the Brookings Institution". In:

Krugman, Paul (1984). "Import protection as export promotion: International competition in the presence of oligopoly and economies of scale". In: Monopolistic competition and international trade, pp. 180-93.

Lai, Yu-Bong and Chia-Hsien Hu (2008). "Trade agreements, domestic environmental regulation, and transboundary pollution". In: Resource and Energy Economics 30.2 , pp. 209-228.

Montero, Juan-Pablo (2002). "Permits, standards, and technology innovation". In: Journal of Environmental Economics and management 44.1, pp. 23-44.

Muller, R Andrew and Stuart Mestelman (1998). "What have we learned from emissions trading experiments?" In: Managerial and decision economics, pp. 225-238.

Newell, Richard G and Robert N Stavins (2003). "Cost heterogeneity and the potential savings from market-based policies". In: Journal of Regulatory Economics 23.1, pp. $43-59$.

Nichols, Albert L (1984). "Targeting economic incentives for environmental protection". In:

Plott, Charles R (1983). "Externalities and corrective policies in experimental markets". In: The Economic Journal 93.369, pp. 106-127.

Porter, Michael E and Claas Van der Linde (1995). "Toward a new conception of the environment-competitiveness relationship". In: The journal of economic perspectives 9.4 , pp. 97-118.

Poyago-Theotoky, JA (2010). "Corrigendum to "The organization of R\&D and environmental policy" [J. Econ. Behav. Org. 62 (2007) 63-75]". In: Journal of Economic Behavior \& Organization 76.2, p. 449.

Poyago-Theotoky, Joanna A (2007). "The organization of R\&D and environmental policy". In: Journal of Economic Behavior \& Organization 62.1, pp. 63-75. 
Requate, Till (2005a). "Dynamic incentives by environmental policy instruments-a survey". In: Ecological economics 54.2-3, pp. 175-195.

- (2005b). "Timing and commitment of environmental policy, adoption of new technology, and repercussions on R\&D". In: Environmental and resource Economics 31.2, pp. 175-199.

- (2006). "Environmental policy under imperfect competition". In: The international yearbook of environmental and resource economics 2007, pp. 120-207.

Requate, Till and Wolfram Unold (2001). "On the incentives created by policy instruments to adopt advanced abatement technology if firms are asymmetric". In: Journal of Institutional and Theoretical Economics JITE 157.4, pp. 536-554.

Simpson, R David (1995). "Optimal pollution taxation in a Cournot duopoly". In: Environmental and Resource Economics 6.4, pp. 359-369.

Spencer, Barbara J and James A Brander (1983). "International R\&D rivalry and industrial strategy". In: The Review of Economic Studies 50.4, pp. 707-722.

Stranlund, John K (2007). "The regulatory choice of noncompliance in emissions trading programs". In: Environmental and Resource Economics 38.1, pp. 99-117.

- (2015). "The Economics of Enforcing Emissions Markets: A Review of the Literature". In:

Taschini, Luca, Marc Chesney, and Mei Wang (2014). "Experimental comparison between markets on dynamic permit trading and investment in irreversible abatement with and without non-regulated companies". In: Journal of Regulatory Economics 46.1 , pp. 23-50.

Ulph, Alistair (1996). "Environmental policy and international trade when governments and producers act strategically". In: Journal of environmental economics and management 30.3, pp. 265-281.

Villegas-Palacio, Clara and Jessica Coria (2010). "On the interaction between imperfect compliance and technology adoption: taxes versus tradable emissions permits". In: Journal of Regulatory Economics 38.3, pp. 274-291. 